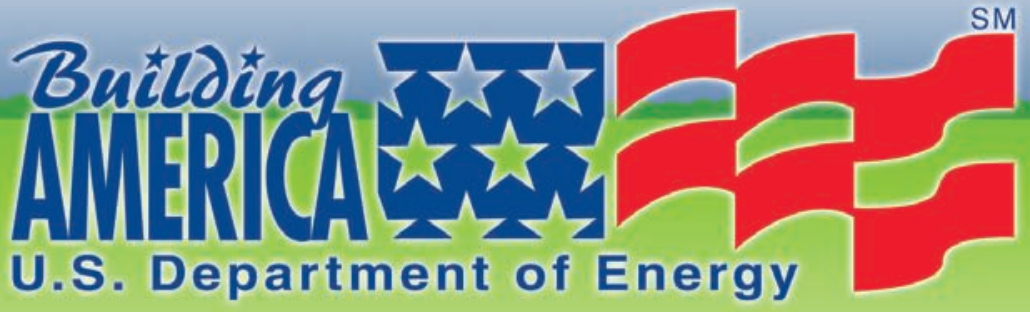

Research that Works

Research Toward Zero Energy Homes

December 2006 • NREL/SR-550-39744

\title{
Building America Residential System Research Results: Achieving 30\% Whole House Energy Savings in Mixed-Humid Climates
} January 2006-December 2006

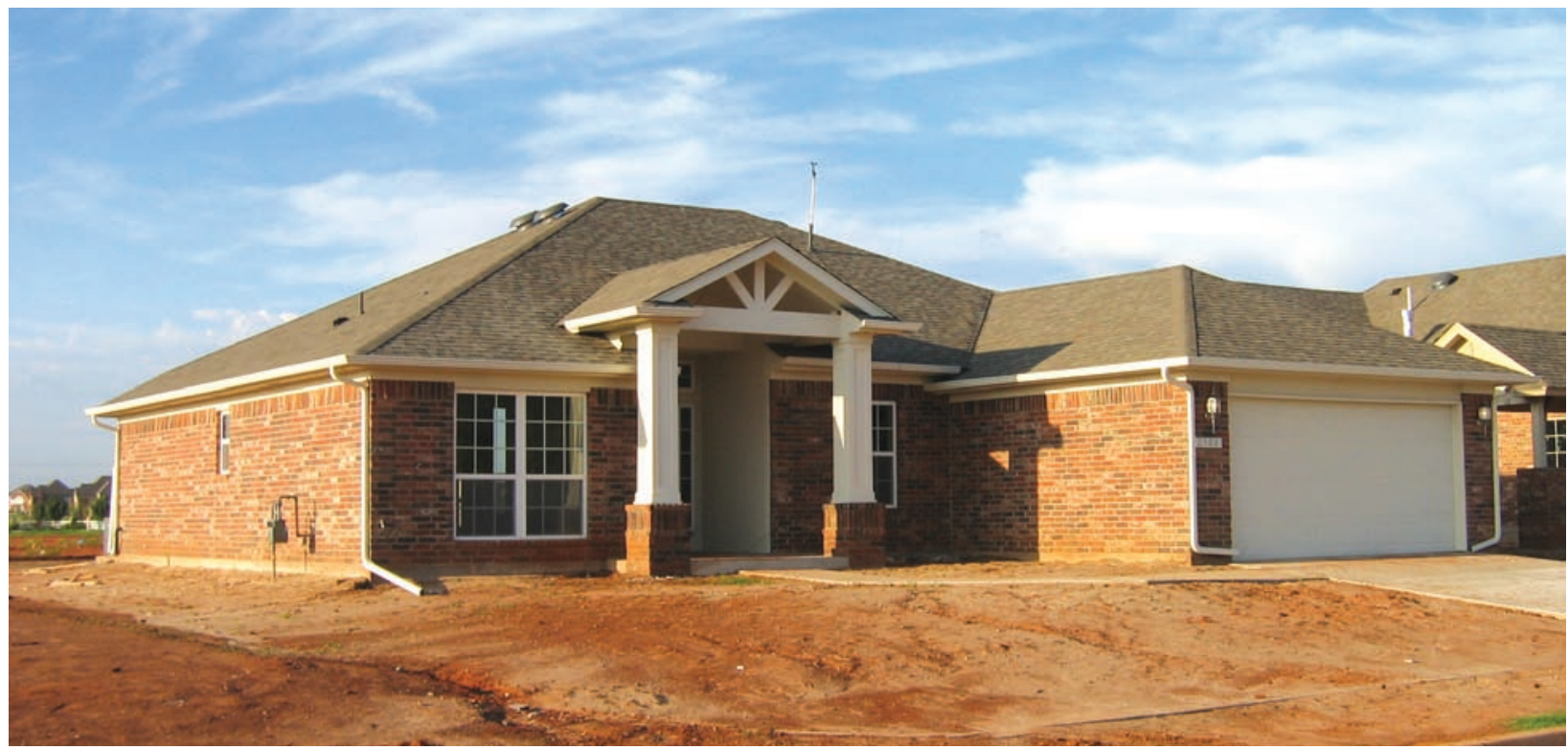

Building America Industrialized Housing Partnership (BAlHP) Cocoa, Florida

Building Industry Research Alliance (BIRA) Stockton, California

Building Science Consortium (BSC) Westford, Massachusetts

Consortium for Advanced Residential Buildings (CARB) Norwalk, Connecticut
Davis Energy Group (DEG)

Davis, California

IBACOS

Pittsburgh, Pennsylvania

National Association of Home Builders Research Center (NAHBRC)

Upper Marlboro, Maryland

National Renewable Energy Laboratory (NREL)

Golden, Colorado 


\section{Building America Residential System Research Results: Achieving 30\% Whole House Energy Savings in Mixed-Humid Climates}

Subcontract Report NREL/SR-550-39744

December 2006

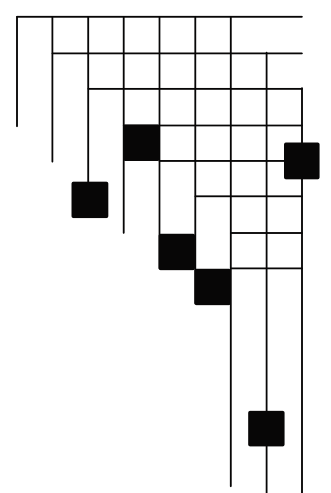

Building Science Consortium (BSC)

Westford, Massachusetts

Consortium for Advanced Residential Buildings (CARB)

Norwalk, Connecticut

Davis Energy Group (DEG)

Davis, California

IBACOS

Pittsburgh, Pennsylvania

National Association of Home Builders Research Center (NAHBRC) Upper Marlboro, Maryland

National Renewable Energy Laboratory (NREL)

Golden, Colorado

NREL Technical Monitors: R. Anderson, R. Hendron, M.

Eastment, and A. Jalalzadeh-Azar

Prepared under Subcontract Nos. KAAX-3-32443-10, KAAX-3-33411-10,

KAAX-3-33412-10, KAAX-3-33410-10

National Renewable Energy Laboratory

1617 Cole Boulevard, Golden, Colorado 80401-3393

303-275-3000 • www.nrel.gov

Operated for the U.S. Department of Energy

Office of Energy Efficiency and Renewable Energy

by Midwest Research Institute $\bullet$ Battelle

Contract No. DE-AC36-99-G010337 


\section{NOTICE}

This report was prepared as an account of work sponsored by an agency of the United States government. Neither the United States government nor any agency thereof, nor any of their employees, makes any warranty, express or implied, or assumes any legal liability or responsibility for the accuracy, completeness, or usefulness of any information, apparatus, product, or process disclosed, or represents that its use would not infringe privately owned rights. Reference herein to any specific commercial product, process, or service by trade name, trademark, manufacturer, or otherwise does not necessarily constitute or imply its endorsement, recommendation, or favoring by the United States government or any agency thereof. The views and opinions of authors expressed herein do not necessarily state or reflect those of the United States government or any agency thereof.

Available electronically at http://www.osti.gov/bridge

Available for a processing fee to U.S. Department of Energy and its contractors, in paper, from:

U.S. Department of Energy

Office of Scientific and Technical Information

P.O. Box 62

Oak Ridge, TN 37831-0062

phone: 865.576 .8401

fax: 865.576 .5728

email: mailto:reports@adonis.osti.gov

Available for sale to the public, in paper, from:

U.S. Department of Commerce

National Technical Information Service

5285 Port Royal Road

Springfield, VA 22161

phone: 800.553 .6847

fax: 703.605.6900

email: orders@ntis.fedworld.gov

online ordering: http://www.ntis.gov/ordering.htm 


\section{Table of Contents: $30 \%$ Mixed Humid}

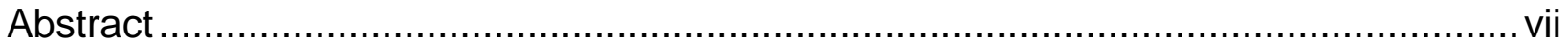

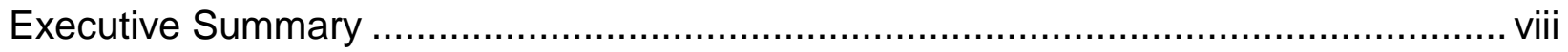

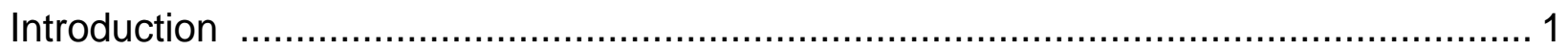

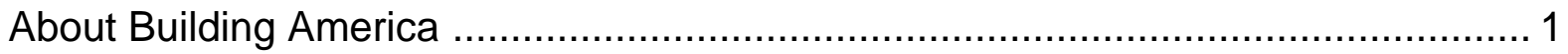

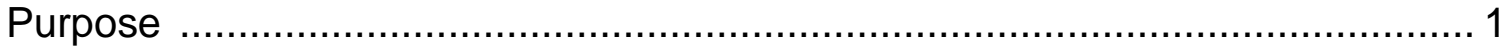

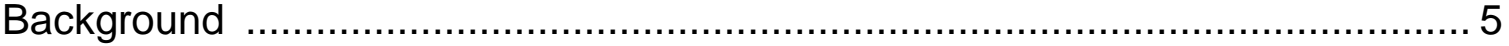

Electronic Reporting of System Research Results ...................................... 9

Identification of Component Development Needs ........................................... 9

Documentation and Resource Development ................................................. 9

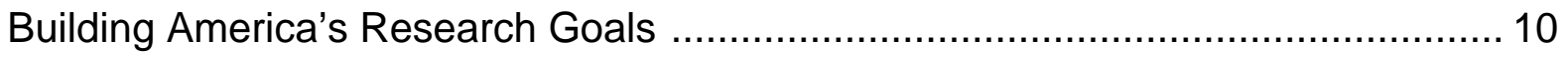

30\% Whole-House Energy Savings ...................................................... 11

System Approach to Least-Cost Energy Savings …......................................... 14

Integrated Design Process ...................................................................... 14

Analysis and Design Optimization ......................................................... 14

Building America Research Benchmark .................................................... 15

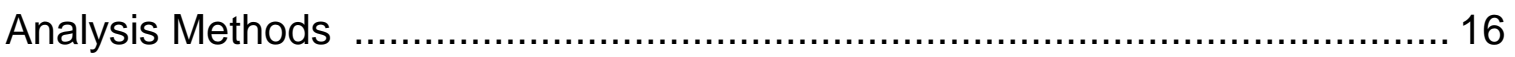

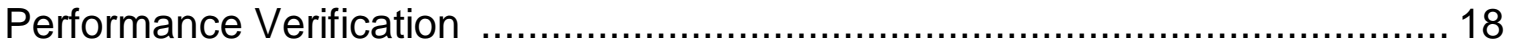

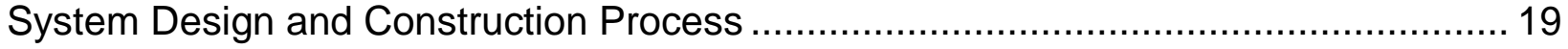

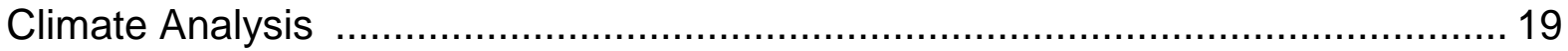

Key Climate Elements that Affect Building Design ...................................... 19

Design Strategy Modification for Variances within a Climate Region ............... 22

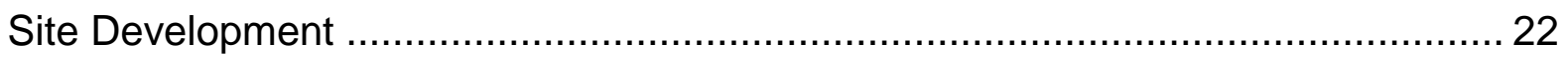

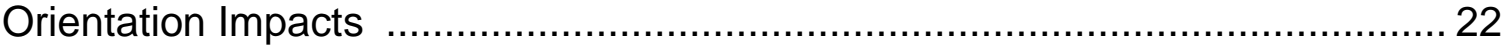

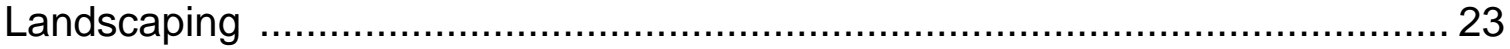

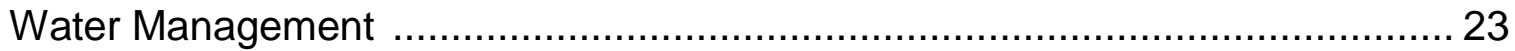

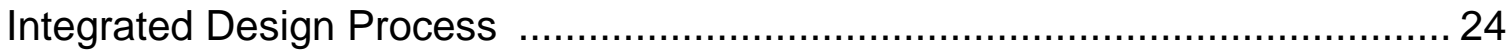

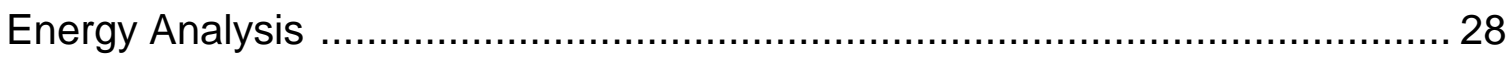

Passive Design Strategies for Minimizing Cooling and Optimizing Heating ...... 30

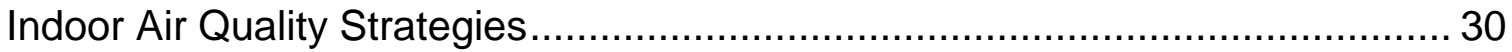

Heating and Cooling Equipment and Distribution Strategies ........................... 36 


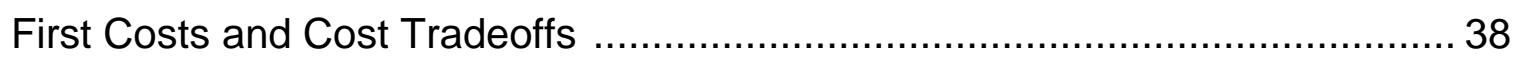

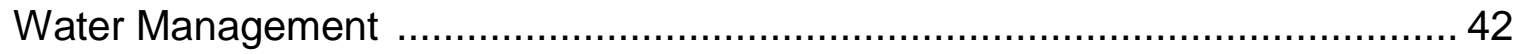

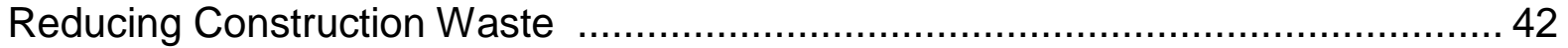

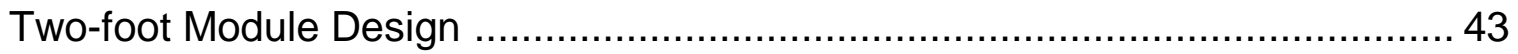

Value Engineered or "Advanced" Framing ...................................................... 44

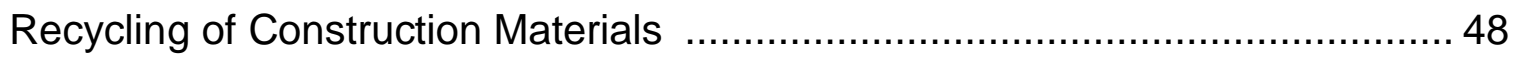

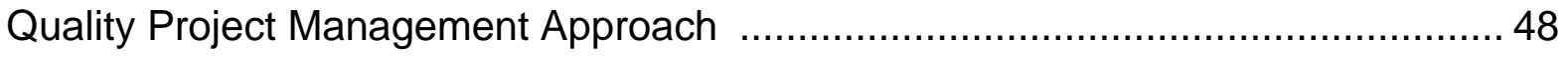

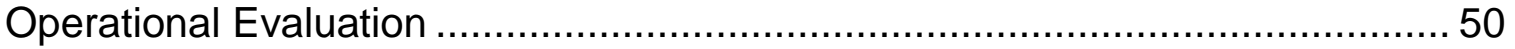

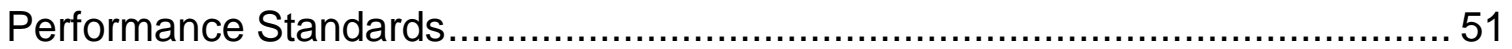

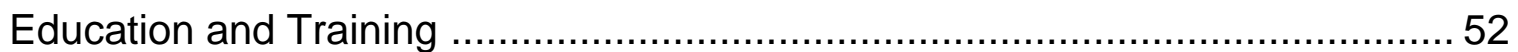

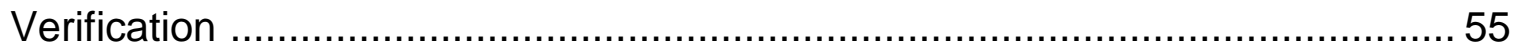

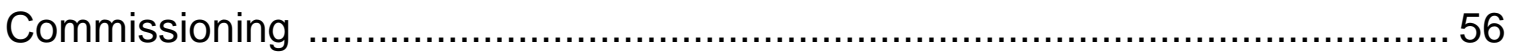

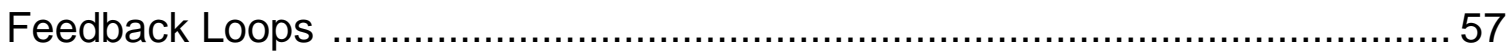

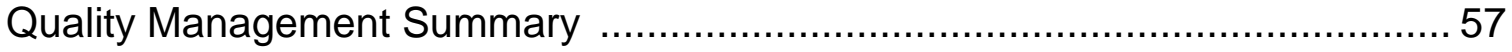

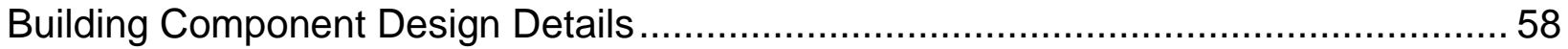

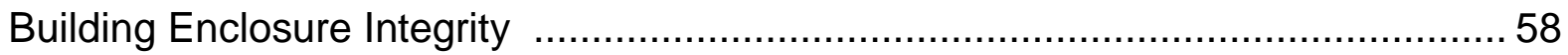

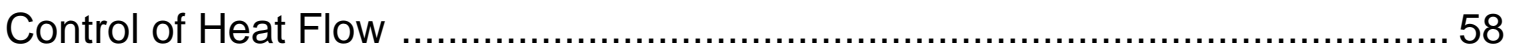

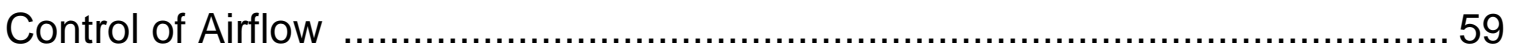

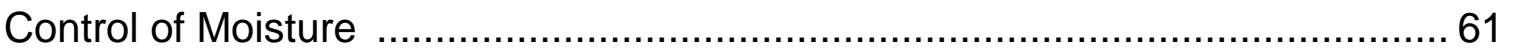

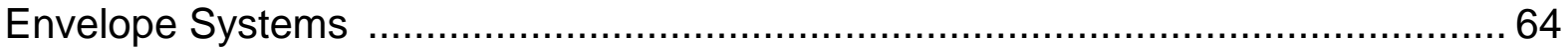

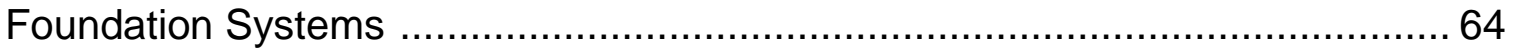

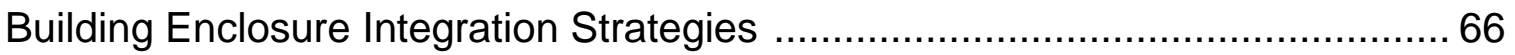

Space Conditioning and Ventilation Systems …............................................... 73

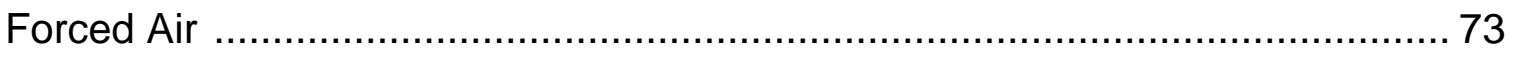

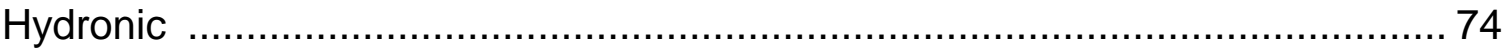

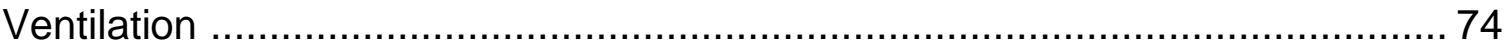

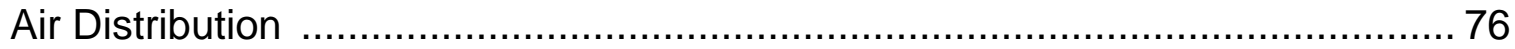

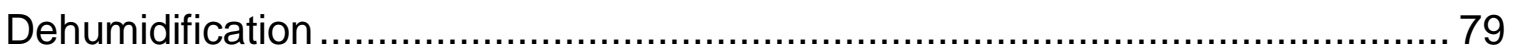

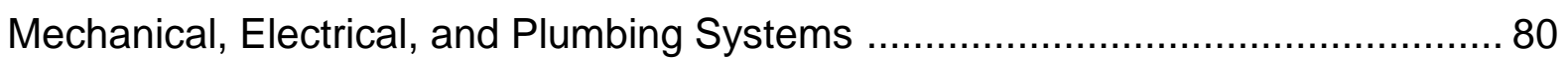

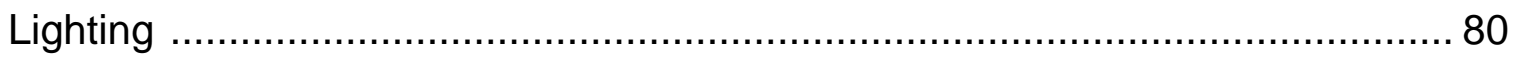

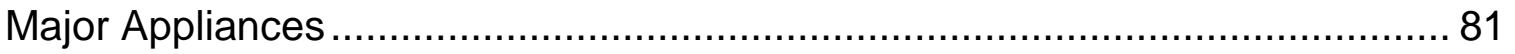

Water Heating and Distribution Systems …….......................................... 81 
Combination Systems - Space and Water Heating ..................................... 85

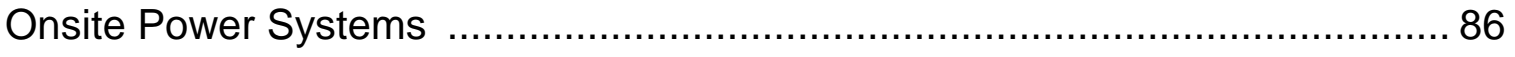

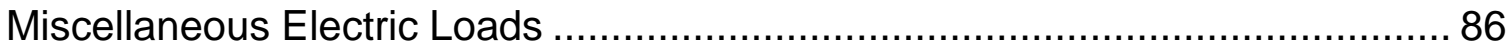

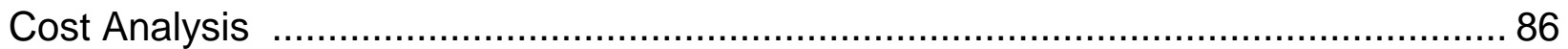

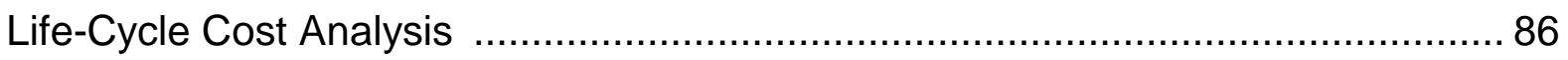

Building Characteristics Considered in this Study ....................................... 86

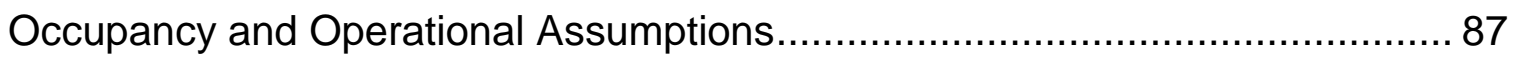

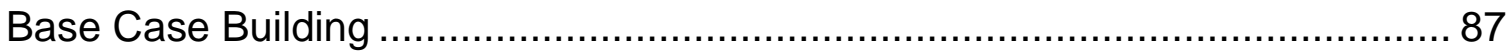

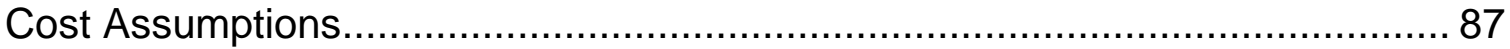

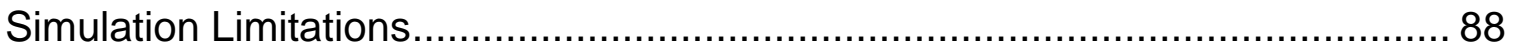

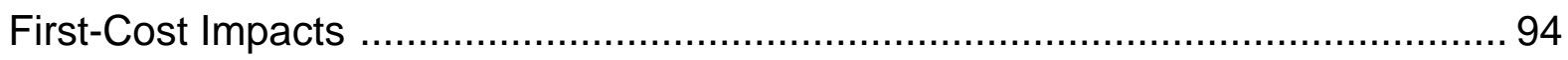

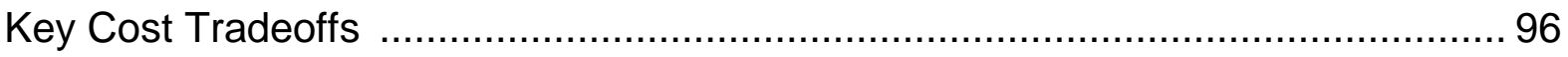

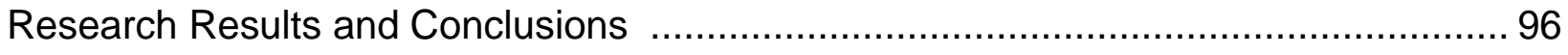

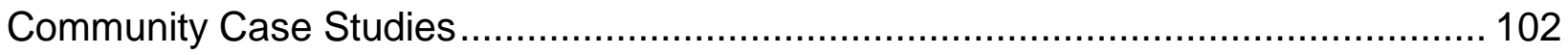

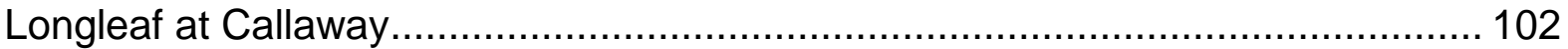

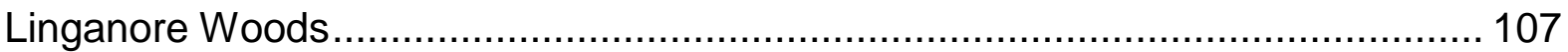

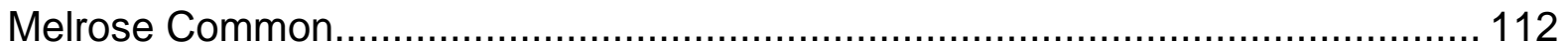

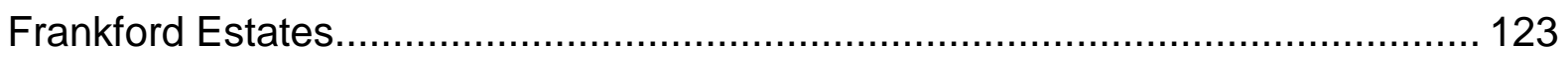

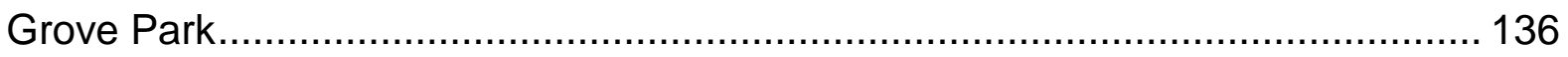

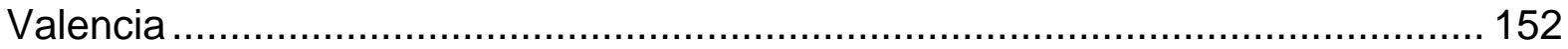

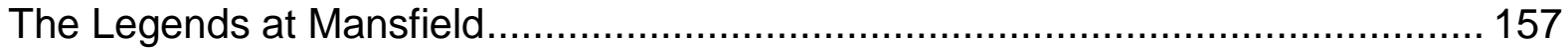

Appendix A: Passive Solar Design Considerations .............................................. 167

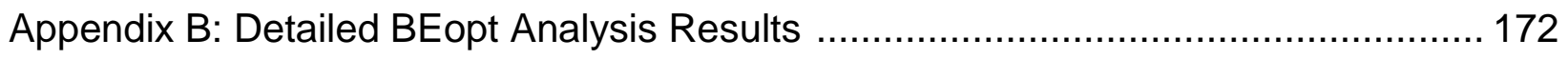

Appendix C. List of Key Trade-based Certifications .............................................. 178

Appendix D: National Housing Quality Rating Table ............................................ 183

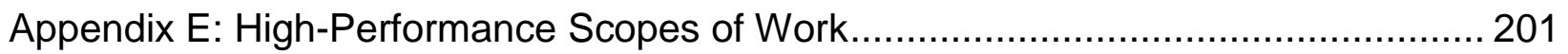

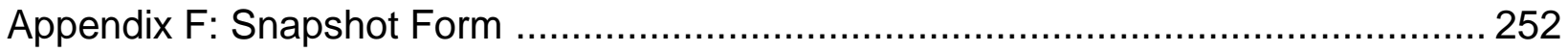

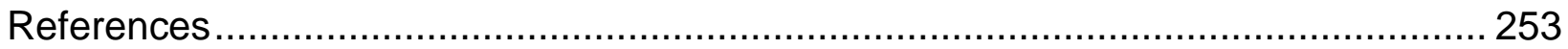




\section{Definitions}

ACCA

$\mathrm{ACH}$

ACT2

AFUE

$\mathrm{AHU}$

ALA

ASHRAE

BECT

BEopt

BESTEST

BII

BPI

BPM

CAD

CDCU

CEC

CFL

CFM

CRI

CT

DHW

DOE

DOE2

ECM

EDHA

EEBA

EEM

EER

EF
Air Conditioning Contractors of America

air changes per hour

Advanced Customer Technology Test for Maximum Energy Efficiency

Annual Fuel Utilization Efficiency

air-handler unit

American Lung Association

American Society of Heating

Building Energy Code Training

Software for identifying optimal building design

A benchmark for building energy simulation: Building Energy Simulation Test and Diagnostic Method

Building Industry Institute

Building Performance Institute

brushless permanent magnet

computer-aided design

Community Development Corporation of Utah

California Energy Commission

compact fluorescent lamps

cubic feet per minute

color-rendering index

color temperature

domestic hot water

U.S. Department of Energy

Building energy analysis program that can predict the energy use and cost for all types of buildings

electronically commutated motor

Eastern Dakota Housing Alliance

Energy and Environmental Building Association

Energy-efficient mortgages

Energy Efficiency Rating

energy factor 


$\begin{array}{ll}\text { EFL } & \text { Environments for Living }{ }^{\circledR} \\ \text { EGUSA } & \begin{array}{l}\text { Energy-Gauge USA software (FSEC's residential front-end user } \\ \text { interface for DOE2.1E simulation tool) }\end{array} \\ \text { EPA } & \text { U.S. Environmental Protection Agency } \\ \text { EPS } & \text { expanded polystyrene } \\ \text { ERV } & \text { Energy recovery ventilation } \\ \text { FAU } & \text { forced air unit } \\ \text { FF } & \text { framing factor } \\ \text { FFA } & \text { finished floor area } \\ \text { FG } & \text { fiberglass } \\ \text { GenOpt } & \text { generic optimization program } \\ \text { HVAC } & \text { heating, ventilation, and air conditioning } \\ \text { HERS } & \text { Home Energy Rating System developed by RESNET } \\ \text { HPL } & \text { high-performance lighting } \\ \text { HRV } & \text { heat recovery ventilators } \\ \text { HSPF } & \text { Heating Seasonal Performance Factor } \\ \text { HUD } & \text { U.S. Department of Housing and Urban Development } \\ \text { IAQ } & \text { Indoor air quality } \\ \text { IDEC } & \text { Indirect-Direct Evaporative Cooler } \\ \text { IDP } & \text { Integrated Design Process } \\ \text { IECC } & \text { International Energy Conservation Code } \\ \text { IEQ } & \text { Indoor Environmental Quality } \\ \text { IOSEU } & \text { incremental overall source energy use } \\ \text { Mcf } & \text { million cubic feet } \\ \text { MEC } & \text { Model Energy Code } \\ \text { MEF } & \text { modified energy factor } \\ \text { MERV } & \text { Minimum Efficiency Reporting Value } \\ \text { NAECA } & \text { National Appliance Energy Conservation Act } \\ \text { NAHB } & \text { National Association of Home Builders } \\ \text { NASEO } & \text { National Association of State Energy Officials } \\ \text { NATE } & \text { North American Technician Excellence } \\ \text { NHQ } & \text { Nating Quality } \\ \text { NZEH } & \end{array}$


OA

OASys

OC

OSB

PA

PATH

PEX

PSC

PV

R-Value

R.A.P.

RESNET

$\mathrm{RH}$

SA

SEER

SHGC

SHW

SLA

SIP

TAB

TMY2

TOU

UL

U-Value

UA

VOC

WUFI

XPS

ZEH

ZNE outdoor air

an indirect/direct evaporative cooler

on center

oriented strand board

Pascal

Partnership for Advancing Technology in Housing

cross-linked Polyethylene tubing

permanent split-capacitor motors

photovoltaics

A measure of thermal resistance used to describe thermal insulation materials in buildings

return-air pathway

Residential Energy Service Network

relative humidity

supply air

seasonal energy efficiency ratio

solar heat gain coefficient

solar hot water

specific leakage area

Structural insulated panels

testing, adjusting, and balancing

Typical Meteorological Year weather data

time of use

Underwriter's Laboratory

The thermal transmittance of a material, incorporating the thermal conductance of the structure along with heat transfer resulting from convection and radiation.

heat loss coefficient

volatile organic compounds

Modeling program for simulating heat and moisture transfer extruded polystyrene

zero energy home

zero net energy 


\begin{abstract}
The Building America program conducts the system research required to reduce risks associated with the design and construction of homes that use an average of $30 \%$ to $90 \%$ less total energy for all residential energy uses than the Building America Research Benchmark, including research on homes that will use zero net energy on an annual basis.

To measure the program's progress, annual research milestones have been established for five major climate regions in the United States (Table A). The systems research activities required to reach each milestone take from 3 to 5 years to complete and include research in individual test houses, studies in pre-production prototypes, and research studies with lead builders that provide early examples that the specified energy savings level can be successfully achieved on a production basis. As additional homes are completed at each performance level, future studies will be conducted to confirm the average energy savings of large numbers of homes and the impacts of improved housing quality on builder warranty and callback costs.

Two criteria are used to evaluate progress toward annual Building America research goals:

- At a minimum, system energy savings must be achievable at a neutral annual energy-related cost relative to the Building America Research Benchmark.

- System solutions must be "production-ready" and meet minimum constructability, reliability, durability, and availability requirements to be implemented successfully by lead builders.

This report summarizes research results for the 30\% energy savings level and demonstrates that lead builders can successfully provide 30\% homes in the Mixed-Humid climate region on a costneutral basis. These research results represent the early starting point for the construction of increased numbers of high-performance homes. The broad diffusion of $30 \%$ homes in the MixedHumid climate region will depend upon a number of other factors in addition to the research results presented in this report, including the level of technical support provided by federal, state, and local deployment programs, the consumer cost of energy, and the development of policy incentives that support implementation of whole-house residential energy efficiency strategies.
\end{abstract}

Table A. Near-Term Energy Savings Goals for Five Major Climate Regions in the United States

\begin{tabular}{cccccc}
\hline \hline $\begin{array}{c}\text { Target } \\
\text { Energy } \\
\text { Savings }\end{array}$ & Marine & Hot Humid & $\begin{array}{c}\text { Hot-Dry I } \\
\text { Mixed-Dry }\end{array}$ & $\begin{array}{c}\text { Mixed } \\
\text { Humid }\end{array}$ & Cold \\
\hline $30 \%$ & 2006 & 2007 & 2005 & 2006 & 2005 \\
$40 \%$ & 2008 & 2010 & 2007 & 2008 & 2009 \\
$50 \%$ & 2011 & 2015 & 2012 & 2013 & 2014 \\
\hline
\end{tabular}




\section{Executive Summary}

\section{Background}

Through the use of systems engineering and operations research, the Building America (BA) program has shown that homes that save $30 \%$ whole-house source energy in Mixed-Humid climates can be built by production builders, providing a home with lower annual energy-related costs while improving comfort, reliability, durability, and indoor air quality. A series of seven case studies are presented in this report, documenting some of the important cost and performance trade-offs that were made by BA builder partners in order to achieve the $30 \%$ energy-savings target in a production context. The key features of the approaches demonstrated in each of these examples can be adapted as needed to provide homes that achieve at least $30 \%$ whole-house energy savings in a cost-neutral manner.

Building America uses a team-based systems-research approach to identify cost and performance trade-offs that improve whole-building performance and value while minimizing increases in overall building cost when applied on a production basis. This systems research approach is applied to the development of advanced energy-efficient residential buildings using systemperformance studies in test houses, pre-production houses, and community-scale developments. Research includes analysis of system performance and cost tradeoffs as they relate to wholebuilding energy performance and cost optimization, including interactions between advanced enclosure designs, mechanical and electrical systems, lighting systems, space-conditioning systems, hot water systems, appliances, miscellaneous electric loads, energy control systems, and onsite power generation systems. Research results are documented in technical research reports that serve as references for students, educators, building scientists, architects, designers, and engineers.

The overall objective of Building America is to develop integrated energy efficiency and onsite/renewable power solutions that can be successfully used on a production basis to reduce whole-house energy use in new homes by an average of $50 \%$ by 2015 and an average of $90 \%$ by 2020, relative to the Building America Research Benchmark, including homes that are capable of achieving zero net energy (ZNE) use on an annual basis. Building America's energy-saving goals form the core of the research effort and have been staged to complete an additional $10 \%$ of incremental savings every 3 to 5 years. To ensure meeting the near-term targets along the path to Zero Energy Homes (ZEH), Building America has specified interim performance targets for each climate region, as shown in Table ES-1. The climate regions defined by Building America can be seen in Figure ES-1. Technical performance requirements to meet these targets are driven by regional differences in building energy loads and construction techniques. The purpose of this report is to provide an overview of three years of Building America systems research that led to the development of production-scale homes that can be built cost-effectively and can reduce whole-house energy use by $30 \%$ relative to the Benchmark in the Mixed-Humid climate region. 
Table ES-1. Building America Performance Targets by Climate Region

\begin{tabular}{cccccc}
\hline \hline $\begin{array}{c}\text { Target Energy } \\
\text { Savings }\end{array}$ & Marine & Hot Humid & $\begin{array}{c}\text { Hot-Dry I } \\
\text { Mixed Dry }\end{array}$ & $\begin{array}{c}\text { Mixed } \\
\text { Humid }\end{array}$ & Cold \\
\hline \hline $30 \%$ & 2006 & 2007 & 2005 & 2006 & 2005 \\
$40 \%$ & 2008 & 2010 & 2007 & 2008 & 2009 \\
$50 \%$ & 2011 & 2015 & 2012 & 2013 & 2014 \\
\hline
\end{tabular}

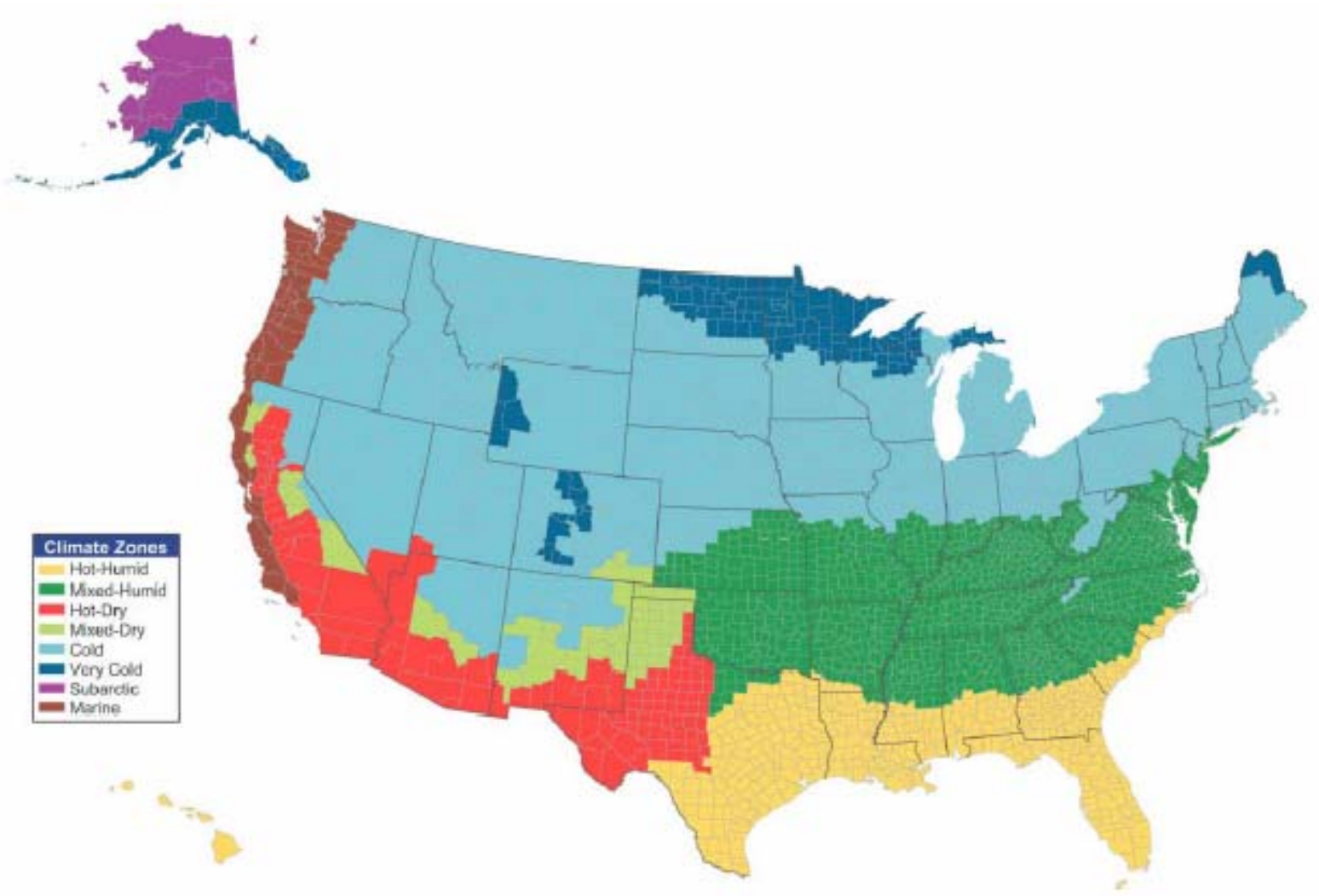

Figure ES-1. Building America climate regions 
To ensure a well-defined reference for evaluation of energy savings and progress toward multiyear goals, a detailed research Benchmark definition has been developed for use by all participants in Building America research projects. The Benchmark is generally consistent with the 1999 Home Energy Rating System (HERS) Reference Home, with additions that allow the evaluation of all home energy uses. The Building America Research Benchmark is a fixed reference point that is used to track progress towards multi-year goals and represents typical standard practice in the mid-1990s, when DOE initiated the Building America program. A standard reporting format for research results has also been developed to facilitate comparisons of performance between different research projects.

\section{Design Strategies}

This report is not intended to be an exhaustive design guide. Rather, the intent is to document key results and performance criteria based on several years of Building America research on cost effective strategies to reduce whole-house energy use by $30 \%$ compared to the Research Benchmark in Mixed-Humid climates and provide case studies documenting that the criteria for the Building America 30\% performance goals in the Mixed-Humid climate have been reached.

Rainfall in the Mixed-Humid climate region can range from moderate to extreme. In coastal areas, the rainwater control measures should follow the Marine climate design, while the enclosure design could be less conservative in the interior sections of the climate region.

To achieve the $30 \%$ level of energy savings, it is not necessary to orient homes in any particular direction. It is also not necessary to undertake any special passive solar-design strategies, though it should be recognized that proper orientation of the building and implementation of passive solar strategies can be a low- or no-cost method to significantly improve the energy performance of a house.

An Integrated Design Process (IDP) ensures that all the key players and design consultants, including the architect, planner, mechanical engineer, landscape architect, energy consultant and the site engineer, work together starting with the conceptual design stage, even though the role of each may be limited for a particular design stage. The IDP is a key aspect in achieving the systems-design approach. By utilizing an IDP, builders are better able to incorporate the 30\% improvement level strategies with less disruption of their normal construction process and to do so cost effectively. Creating specific high-performance goals early in the design process will also allow the design and construction team and their external vendors to have a clear understanding of the intent and performance metrics associated with the design.

A key component of high-performance system design and any high-performance construction process is quality project management. In the context of Building America high-performance homes, quality management is an ongoing effort to systematically and comprehensively improve customer-focused satisfaction with emphasis on methods and processes that yield an optimal combination of energy efficiency, comfort, durability, indoor air quality, and moisture management. This definition recognizes quality management as an integral part of achieving $30 \%$ whole-house energy savings, and encompasses homebuyer expectations of performance with energy efficiency as just one of several performance attributes that any home should provide.

In high-performance home building, quality is only achieved with performance standards for design AND materials (specifications) AND installation (scopes). Building America takes this 
premise one step further by stating that many performance standards must be climate-specific, indeed even lot-specific, when local terrain and environments bring with them additional challenges such as extreme slopes, expansive soils, coastal high winds, and flooding. Training is also an essential element of quality in the Building America program. Ongoing efforts within the industry are necessary to develop, deploy, and continually update training programs to disseminate accurate information. Also important are verification tools for both performance and quality, including performance testing and inspection checklists. In general, for production builders, Building America has recommended a testing strategy similar to the EPA ENERGY STAR strategy of 1-in-7 random testing after a period of $100 \%$ testing to verify that key performance metrics are met on a consistent basis. Commissioning is also critical for ensuring that the house developed through the whole-building design process is successfully constructed and operates as intended. Detailed check lists are included in Appendix E identifying key construction details that are critical to the success of high-performance homes.

In general, Building America houses at the 30\% energy savings level in the Mixed-Humid climate region include increased levels of thermal insulation, higher-performance windows, significant air sealing, a strategy that eliminates the possibility of introducing the by-products of combustion into the house, a mechanical ventilation system, a properly sized and engineered space-conditioning system, higher efficiency space-conditioning and water-heating appliances, and may also include improvements in the efficiency of the appliances and lighting. The extent to which any of these strategies must be implemented varies by the specific micro-climate within the Mixed-Humid climate region, and the level of energy performance the builder is seeking to achieve.

In order to function as an environmental separator, the elements, components, assemblies, and sub-systems that comprise a house must control the flows of heat, air, rainwater, groundwater, and water vapor. It is important that walls be designed with (I) an insulation approach that prevents condensing temperatures from occurring inside the wall, (II) an adequate drainage plane to allow rain driven by wind through the exterior cladding to quickly drain out of the wall, and (III) the right flashing system to ensure that there are no local moisture entry points as a result of wall penetrations like windows. Once moisture sources are controlled, then (IV) an appropriate vapor-control strategy should be chosen so that excessive vapor transport is reduced, but walls have the opportunity to dry if the become wetted.

Exterior walls in Building America Homes at the 30\% performance level in Mixed-Humid climates are usually wood-frame construction with 2x6 framing and cavities insulated with fiberglass batts, spray-applied cellulose, or low-density spray-applied foams. The 2x4 framing with insulating sheathing may also be acceptable in parts of the Mixed-Humid climate region with fewer heating degree days. In general, insulating sheathing is not necessary to meet the 30\% savings goal if 2x6 wall construction is used. However, insulating sheathing of sufficient thickness and a perm rating of 1 or higher moves the condensation temperature out of the framing and allows for the use of vapor-diffusion retarders with a permeability of slightly greater than 1 perm, thereby enhancing the inward drying capability of the assembly and reducing the likelihood of moisture problems. An interior vapor-diffusion retarder with permeability less than 1 perm is recommended if insulating sheathing is not used. Fenestration with a maximum U-value of 0.35 and with a SHGC value of 0.4 or lower is recommended. An interior air barrier is necessary and is most cost-effectively obtained using interior gypsum sheathing combined with framing elements, such as draft-stopping and fire-stopping 
components. Installing both interior and exterior air-barrier systems can address the weaknesses of each. The air leakage target should be less than 0.25 CFM50 $\left(\mathrm{ft}^{3} / \mathrm{min}\right.$ at $\left.50 \mathrm{~Pa}\right)$ per square foot of thermal envelope area. The approach to rainwater control is to shed water by layering wall materials in such a way that water is directed downward and outward from the building. This principle applies not only to walls, but to assemblies such as roofs and foundations, as well as to the components that can be found in walls, roofs, and foundations, such as windows, doors, and skylights.

When using slab-on-grade construction in Mixed-Humid climates, it is recommended that the concrete slab be thermally isolated from the ground and outdoor air. Passive sub-slab ventilation is recommended to reduce atmospheric air pressure soil gas drivers. Crawlspaces may be conditioned by insulating the crawlspace walls and supplying conditioned air either via a dedicated duct or via transfer air from the house with a continuously operating exhaust fan in the crawlspace. Alternatively, crawlspaces may be vented and insulated above the crawlspace if the ducts are located elsewhere. The recommended approach for basements includes insulating and conditioning the basement. Interior rigid-foam insulation is the insulation system of choice for both basement and crawlspace walls because it is not water sensitive.

As long as there is no ductwork planned for the attic space, the optimum approach to roof insulation involves blowing insulation on the top surface of ceiling gypsum board. When possible, raised heel roof trusses should be used so that at least six in. of ceiling insulation is maintained completely to the top plates of the exterior wall framing. If there is ductwork in the attic space, an unvented, airtight, cathedralized roof construction is recommended to create a conditioned attic space for the ductwork. In this way, the mechanical equipment and ductwork are located in conditioned space, reducing the energy losses associated with locating the mechanical equipment in a vented attic.

To accomplish the target of 30\% whole-house energy savings in the Mixed-Humid climate region, a sealed-combustion condensing furnace is recommended. Sealed-combustion furnaces use outdoor air for combustion and can be easily located within the conditioned space. This was the approach taken for several of the case studies provided. In regions where natural gas is not available, a high efficiency electric heat pump is recommended.

Air conditioners in Mixed-Humid climates should have SEER ratings of 13 or greater, which reflects federal minimum efficiency. However, it should be noted that there is a wide range of cooling requirements in the Mixed-Humid climate region, and the SEER rating should be evaluated based on annual hours of operation. In general, the greater the cooling need, the higher the SEER rating should be. Designers also need to check the mean coincident wet-bulb temperature at outdoor design conditions and select equipment based on this. This strategy helps to prevent oversizing of the equipment. All space heating and cooling systems should be sized according to the procedures described in ACCA Manuals $\mathrm{J}$ and S.

Ductwork should be located within the thermal envelope of the house. Methods for locating the duct system within the conditioned space include the use of open-web floor trusses, dropped ceilings and soffits, interior chase walls with duct risers (exterior walls should not be used as chase walls), modified roof trusses, or an unvented or "cathedralized" attic. In some climate regions the ducts may be buried in attic insulation, but in the Mixed-Humid climate this is not a recommended practice without careful consideration for the possibility of condensation on the ducts. The "best" method for locating ducts in conditioned space depends upon the house plan, 
the type of foundation, and the builder's preferences. Central hard-ducted returns are recommended with passive-return air paths such as jump ducts or transfer grilles from bedrooms. If ducts cannot be brought within conditioned space, supply ducts should be insulated to R-8 minimum and return ducts to R-4 minimum. Ducts should be sealed with UL181 mastic for metal and flex duct connections, and UL181 foil tape for ductboard to ductboard connections. Duct leakage to the outside should be less than 5\% of air handler flow at a pressure of $25 \mathrm{~Pa}$.

Furnaces or air handlers with "variable-speed” brushless permanent magnet (BPM) DC motors are recommended. These motors are more efficient at lower speeds than the more common permanent split-capacitor (PSC) type motors. Efficiency at lower speed operation is increasingly important for systems that feature multiple gas firing stages, enhanced dehumidification capability during cooling, air cleaning equipment, or integrated ventilation.

Providing good indoor air quality (IAQ) at the 30\% improvement level is important to maintain occupant health and comfort and may minimize the possibility of high humidity levels and associated mold growth. Because $30 \%$ houses will have higher levels of insulation (which affects enclosure hygrothermal characteristics) and because they will be reasonably air tight (which will affect internal moisture gain and removal), good IAQ requires a more proactive approach. There are several approaches to good IAQ, including control of pollutant-generating sources, removal of the contaminants from the indoor air by ventilation, and air filtration or cleaning. A wholehouse mechanical ventilation system is recommended, such as a balanced system using a heatrecovery ventilator, an exhaust-only system rated for continuous duty, or a supply-only system integrated with the central air-handling unit.

For high-performance, low sensible heat gain homes, there may be a need for supplemental dehumidification during the mild swing seasons and at night. Because low sensible heat gain reduces the demand for cooling while a latent load still exists, the addition of supplemental dehumidification to a high-performance house enables efficient temperature control without suffering from high, uncontrolled indoor humidity. In the Mixed-Humid climate region, the need for supplemental dehumidification can be more dependent on the homeowner's habits with the thermostat and internal moisture generation. Lowering the thermostat cooling set point tends to lower the humidity via the cooling system, whereas elevating the cooling set point tends to increase the humidity.

High efficiency $(\mathrm{EF}=0.62)$ tank-type gas water heaters offer the best value for domestic water heating with relatively steady, continuous-use patterns at the $30 \%$ performance level. . If electricity is the energy source for water heating, additional improvements to other areas of the house will likely be needed to achieve the 30\% savings levels, because there is very little room for improvement in electric water-heating efficiency compared to the possible efficiency gains using gas-fired technologies. Primarily because of their cost, tankless gas and solar water heating systems are not cost effective at the $30 \%$ improvement level.

Simple screw-in CFL substitution is a viable strategy at the $30 \%$ level; however, there are questions as to the persistence of energy savings because the homeowner is free to replace the CFL with a traditional incandescent light bulb. A High-Performance Lighting (HPL) approach using a full complement of hard-wired, dedicated compact and linear fluorescent fixtures does not appear to be cost effective relative to other energy saving options for a house at the 30\% improvement level. 
At the present time, the best practice recommendation for the 30\% improvement house is to use ENERGY STAR-rated appliances. Within the ENERGY STAR-rated offerings, there are differences in performance levels, but these are probably not of significance at the $30 \%$ improvement level.

At the $30 \%$ energy savings level, it is not required to address the miscellaneous electric load (MEL) category.

On-site power systems, such as photovoltaic systems and fuel cells, are very costly and are not cost effective as a strategy to achieve the 30\% energy-savings level.

All of these systems must be properly designed and applied to realize both energy-related and non-energy performance benefits associated with occupant health, safety, comfort and long-term building durability and efficiency.

One of the key challenges in developing best practice recommendations is to develop an approach that quickly focuses on combinations of measures that represent the least-cost solutions for a given level of energy savings. To address this challenge, NREL has developed an iterative trade-off analysis method, which identifies packages of energy efficiency measures that provide energy savings at minimal cost, including the utility cost and the cost for energy improvements financed as part of a 30-year mortgage.

Using this method of analysis for one- and two-story homes in Atlanta helps to identify the trends that result in a home that saves 30\%-39\% whole-house energy relative to the Benchmark. For a house with $30 \%$ energy savings, these trends are improved exterior-wall construction, crawlspace wall insulation, high-performance glazing, air-sealing measures to reduce infiltration, and ducts in conditioned space. For a house at the upper end of the energy savings range ( 39\%), features such as tankless gas water heaters, condensing furnaces, ENERGY STAR appliances, and elevated levels of compact fluorescent lighting are commonly added. The results indicate that the main drivers for energy and cost savings in Atlanta are heating-load reduction strategies (high levels of insulation) coupled with high efficiency space and water heating equipment. Of course other considerations, such as durability, comfort, aesthetics, and health, are also important, but cannot be easily addressed in an automated optimization program.

A total of seven case studies demonstrating recommended energy-saving strategies with energy savings ranging from $30 \%$ to $43 \%$ and project sizes ranging from 24 homes to 210 homes are included in this report, demonstrating that energy savings of $30 \%$ relative to the Building America Research Benchmark can be successfully achieved in the Mixed Humid climate. 
Table ES-2. Summary of Source Energy Savings by End-use for the Mixed-Humid Climate Case Studies

\begin{tabular}{|c|c|c|c|c|c|c|c|}
\hline \multirow[b]{2}{*}{ End Use } & \multicolumn{7}{|c|}{ Percent Source Energy Savings } \\
\hline & $\begin{array}{l}\text { Longleaf, } \\
\text { Pine } \\
\text { Mountain, } \\
\text { Georgia }\end{array}$ & $\begin{array}{c}\text { Habitat, } \\
\text { Montgomery } \\
\text { County, } \\
\text { Maryland }\end{array}$ & $\begin{array}{c}\text { Melrose } \\
\text { Commons, } \\
\text { Bronx, New } \\
\text { York }\end{array}$ & $\begin{array}{l}\text { Frankford } \\
\text { Estates, } \\
\text { Baltimore, } \\
\text { Maryland }\end{array}$ & $\begin{array}{c}\text { Outlook } \\
\text { Grove Park, } \\
\text { Cartersville, } \\
\text { Georgia }\end{array}$ & $\begin{array}{l}\text { Ideal Homes, } \\
\text { Oklahoma } \\
\text { City, } \\
\text { Oklahoma }\end{array}$ & $\begin{array}{l}\text { Legends at } \\
\text { Mansfield, } \\
\text { Columbus, } \\
\text { New Jersey }\end{array}$ \\
\hline Space Heating & $39 \%$ & $75 \%$ & $50 \%$ & $51 \%$ & $52 \%$ & $38 \%$ & $53 \%$ \\
\hline Space Cooling & $57 \%$ & $56 \%$ & $2 \%$ & $49 \%$ & $72 \%$ & $59 \%$ & $45 \%$ \\
\hline DHW & $28 \%$ & $1 \%$ & $30 \%$ & $35 \%$ & $13 \%$ & $10 \%$ & $55 \%$ \\
\hline Lighting & $-4 \%$ & $67 \%$ & $66 \%$ & $52 \%$ & $-8 \%$ & $70 \%$ & $68 \%$ \\
\hline $\begin{array}{c}\text { Appliances + } \\
\text { MEL }\end{array}$ & $5 \%$ & $4 \%$ & $9 \%$ & $2 \%$ & $3 \%$ & $9 \%$ & $5 \%$ \\
\hline $\begin{array}{c}\text { Total Energy } \\
\text { Use }\end{array}$ & $30 \%$ & $34 \%$ & $30 \%$ & $36 \%$ & $32 \%$ & $36 \%$ & $43 \%$ \\
\hline $\begin{array}{c}\text { Number of } \\
\text { Homes }\end{array}$ & 30 & 24 & 210 & 78 & 73 & 73 & 39 \\
\hline
\end{tabular}





\section{Building America Residential System Research Results: Achieving 30\% Whole House Energy Savings in Mixed-Humid Climates}

\section{Introduction}

\section{About Building America}

\section{Purpose}

The Building America Program develops innovative systems-engineering approaches to advanced housing that will enable the housing industry in the United States to deliver energyefficient, affordable, and environmentally sensitive housing while maintaining profitability and competitiveness of homebuilders and product suppliers in domestic markets. For innovative building energy technologies to be viable candidates over conventional approaches, it must be demonstrated that they can cost-effectively increase overall product value and quality while significantly reducing energy use and use of raw materials when used in community-scale developments. To make this determination, an extensive, industry-driven, team-based, systemengineering research program is necessary to develop, test, and design advanced building energy systems for all major climate regions of the United States in conjunction with material suppliers, equipment manufacturers, developers, builders, designers, and state and local stakeholders.

Building America research results are the result of a team-based systems-research approach, including use of systems-research techniques ${ }^{1}$ and cost and performance trade-offs that improve whole-building performance and value while minimizing increases in overall building cost. Figure 1 shows the Building America system-research approach in its most basic form. Building America is an analysis-focused research program that specifically targets technical barriers that limit residential system energy performance. Building America applies systems research approaches to the development of advanced energy-efficient residential buildings using systemperformance studies in test houses, pre-production houses, and community-scale developments. Research includes analysis of system performance and cost tradeoffs as they relate to wholebuilding energy performance and cost optimization, including interactions between advanced envelope designs, mechanical and electrical systems, lighting systems, space-conditioning systems, hot water systems, appliances, miscellaneous electric loads, energy control systems, and onsite power generation systems. Use of a systems approach creates process innovations that improve efficiency and flexibility of housing production and increase control over component interactions that improve house efficiency and performance.

Use of a systems approach also accelerates adoption of new technologies by increasing integration between the design and construction process, increasing system performance, increasing system cost effectiveness, and increasing system reliability and durability. Community-scale evaluation of advanced system concepts in partnership with builders, contractors, and state and local governments provides opportunities for early adopters and

\footnotetext{
${ }^{1}$ Systems Research is research focused on understanding cost, performance, and reliability interactions between different system components.
} 


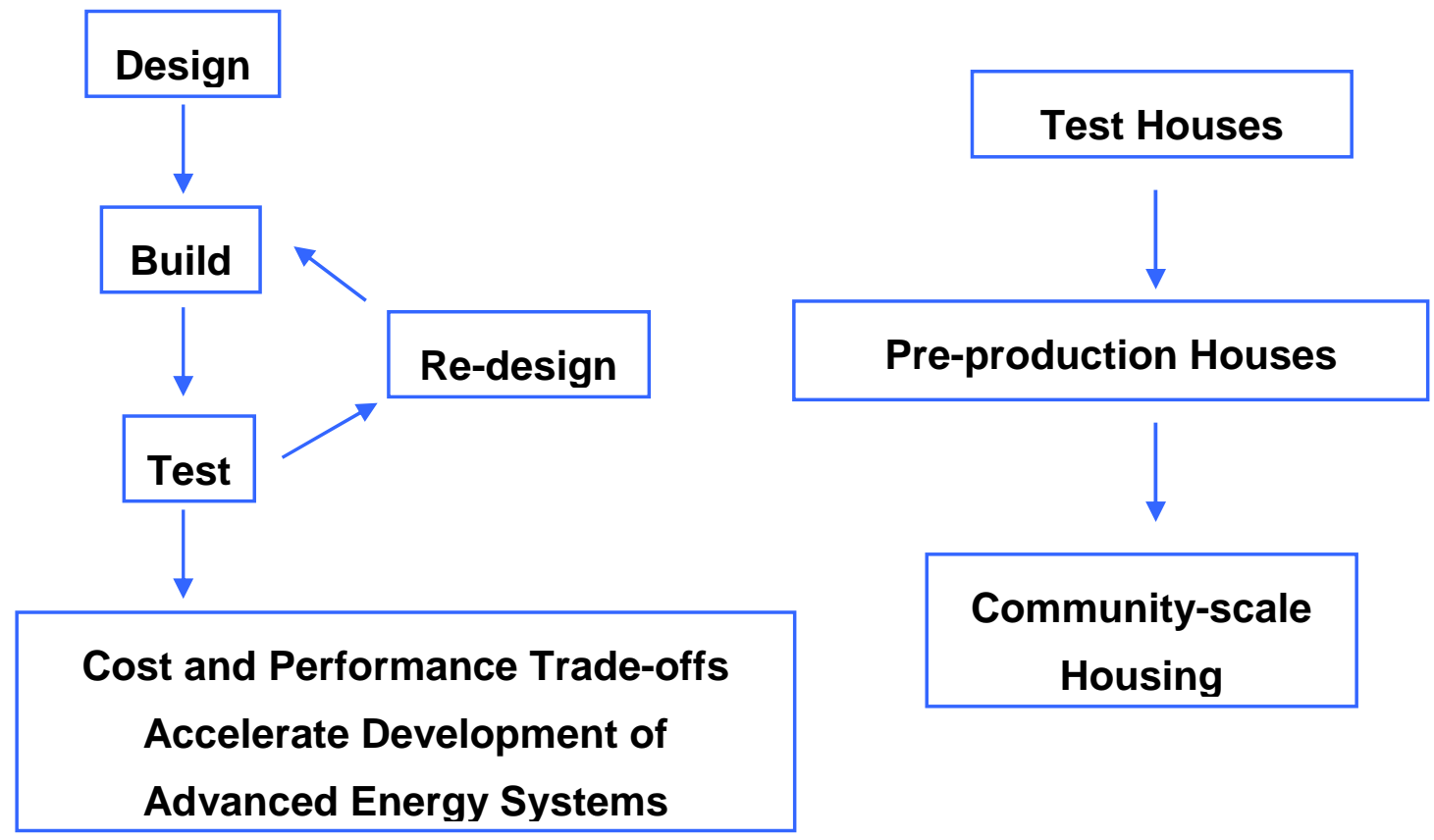

Figure 1. Overview of Building America's systems-engineering approach with. The development of production-ready results covering the range from test houses to community-scale housing takes from $\mathbf{3}$ to 5 years.

industry leaders to directly contribute to key results from the research program. A systems approach for development of advanced residential buildings is defined to be any approach that utilizes comprehensive examination and analysis of overall design, delivery, business practices, and construction processes, including financing, and that performs cost and performance tradeoffs between individual building components and construction steps that produce a net improvement in overall building value and performance. A systems approach requires integrated participation and team building among all interested parties in the building process including developers, architects, designers, engineers, builders, equipment manufacturers, material suppliers, community planners, mortgage lenders, state and local governments, utilities, and others.

The final products of each Building America research project include performance measurements and cost/performance evaluations in test houses, pre-production homes, and community-scale developments. These measurements and evaluations lead to development of innovative system concepts that can be applied on a production basis by the industry partners and stakeholders involved in the program. The range of innovative system concepts considered in projects include onsite power systems, innovative envelope systems, advanced mechanical and lighting systems, advanced space-conditioning systems, efficient water-heating systems, 
renewable energy systems, efficient appliances, energy-control systems, and design and construction strategies. Performance results from the evaluation of these systems are presented to a broad residential building science audience via development of technical papers, the Building America Web site, and presentations at major building-industry conferences.

Subject to available resources, Building America industry teams continuously evolve and expand their membership so that the number of buildings and systems influenced by the program continues to show growth over time.

The overall objective of the Building America research program is to develop integrated energy efficiency and onsite/renewable power solutions that can be successfully used on a production basis to reduce whole-house energy use in new homes by an average of $50 \%$ by 2015 and $90 \%$ (which also includes onsite/renewable power solutions) by 2020, relative to the Building America Research Benchmark (Hendron 2005), ${ }^{2}$ including homes that are capable of achieving zero net energy (ZNE) use on an annual basis.

The key system research questions addressed by Building America research teams include the following:

- Evaluation of overall system cost tradeoffs relative to current systems. What are the system's incremental costs and how will the system affect overall building costs?

- Evaluation of overall system benefits relative to current systems. What overall value is delivered by the system to builders? To contractors? To consumers? (Examples of system benefits include utility bill savings, contribution to whole-house energy-savings goals, increased durability, reduced warranty and callback costs, increased comfort, reduced construction waste, increased labor productivity, increased water efficiency, increased safety and health, reduced peak loads)

- Evaluation of the expected market impact of new residential energy systems. What fraction of the residential housing market will be directly affected by research results? What are barriers to broad market use? What research can be done to reduce barriers to broad use?

- Evaluation of the constructability of new residential energy systems. What are barriers and risks associated with the use of new systems? Can results be implemented on a production basis? What additional research is required to develop a clear description of whole-house system-performance requirements and key system-design details that minimize barriers and risks and maximize benefits?

- Evaluation of the potential community-scale benefits of advanced residential energy systems. What additional benefits will result when systems are implemented on a community scale?

Taken together, these research questions frame the overall difficulty of resolving the risks associated with use of advanced energy systems, help to define the systems research required to integrate new systems seamlessly into a production construction process, and emphasize the importance of documenting the performance benefits of advanced systems.

Construction of new homes requires the combined efforts of a large number of suppliers and contractors whose efforts are coordinated by a large number of builders. Because of the high cost

\footnotetext{
${ }^{2}$ Hereafter in this report referred to as the Benchmark.
} 
of failure, the residential construction industry is highly risk-intolerant and first-cost sensitive. Development of new systems and corresponding changes in design and the relatively low level of R\&D investment further complicate construction practices by the housing industry.

Figure 2 compares $R \& D$ expenditures for various residential markets. The key market barriers to development of advanced residential energy systems are the large number of market players, the relatively low level of investment in $R \& D$ relative to other sectors of the economy, and strict requirements for market acceptance based on achievement of low incremental costs and high reliability.

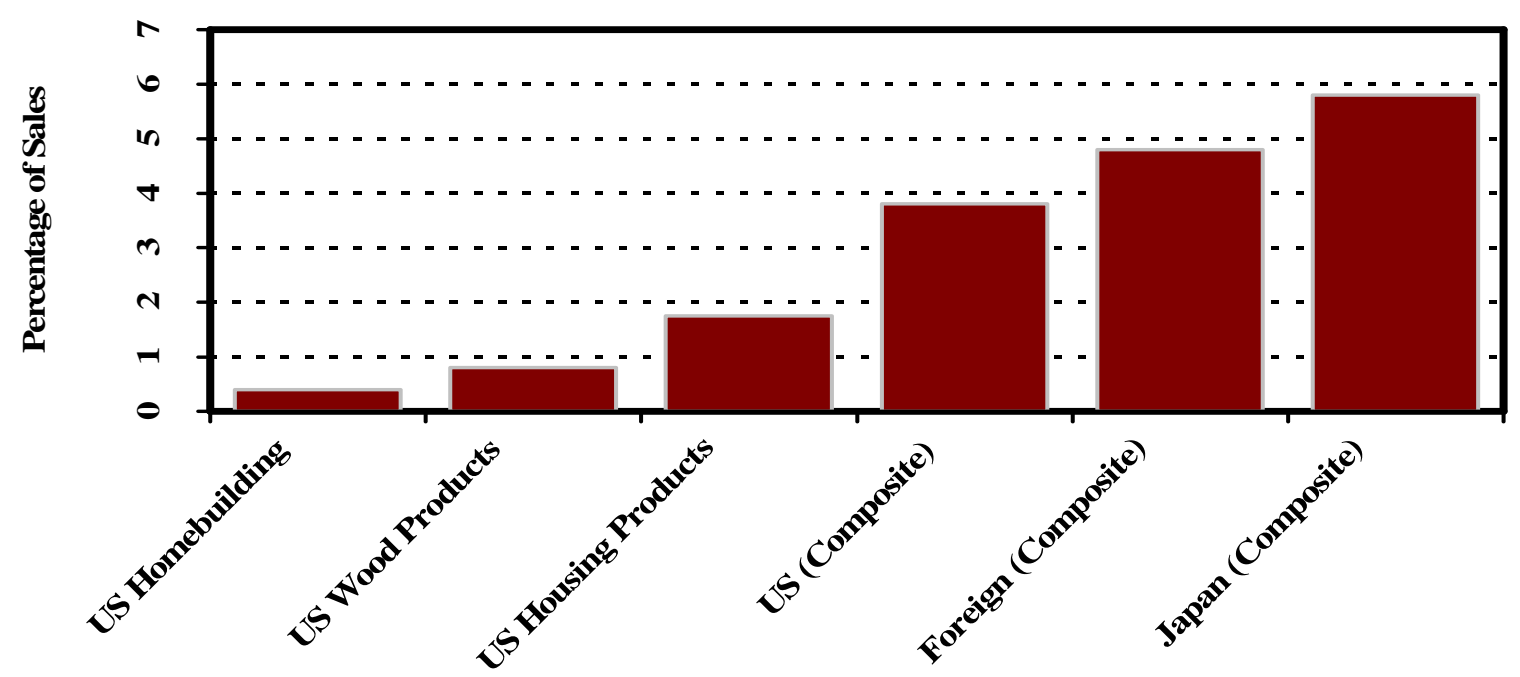

Figure 2. Research and development expenditures ${ }^{3}$

The key technical barriers to the development of advanced residential energy systems are the large number of technical performance requirements that must be met before a new system can be implemented on a production basis. These technical performance requirements are driven by regional differences in building energy loads and construction techniques. Systems that work well in cold climates may not be applicable in hot climates. Systems that work well in hot-dry climates may not function well in hot-humid climates.

A recent study by the RAND Corporation (2003) for HUD’s Partnership for Advancing Technology in Housing (PATH), entitled Building Better Homes: Government Strategies for Promoting Innovation in Housing, concludes that

... the housing industry is large and complex, involving many public and private entities. The interests, roles, and capacities of each participant and the relationships they share have shaped the housing industry into what it is today... Instead of trying to identify barriers and asking the industry to change itself (or asking the government to change it), this study seeks to identify options

\footnotetext{
${ }^{3}$ The United States homebuilding industry invests $0.25 \%$ of sales in research compared to $\$ 3.8 \%$ for all market sectors (Business Week R\&D Scoreboard, June 28, 1993).
} 
to accelerate innovation within the housing industry as it exists today. It begins by critically examining the concept of innovation and how it might be better understood within the context of the housing industry. What results is a departure from the linear model of innovation that assumes logical and unidirectional movement from research to development, demonstration, and deployment to one that recognizes much greater interactive dynamics in the innovation process. Research in this model is a base for knowledge, which contributes to invention, development, demonstration, and deployment. Moreover, all these activities or stages in the innovation process are affected by market forces.

Because of the strong interaction between technical and market barriers, a linear research approach that begins with basic R\&D and ends with technology deployment is not likely to be successful when applied to residential systems. A market-driven, system-based research approach can provide valuable benefits to builders, consumers, and utilities while simultaneously resolving market and technical barriers to innovation.

Pulte Homes Southwest Division has used technical assistance from the U.S. Department of Energy's (DOE) Building America program to create what one residential expert calls "the best production house in the world," which won the 2001 National Association of Home Builders' Energy Value Housing Award. In Tucson, Phoenix, and Las Vegas, Pulte Homes has worked with the DOE to redesign the energy features of its basic models. Using advanced insulation techniques, highly efficient equipment and windows, and right-sized heating and cooling systems, the homes look the same, but perform so well that they use half the energy for heating and cooling at virtually no increase in construction costs. The whole-building/systems engineering approach used in the Building America program allows builders to add more insulation and more efficient windows while reducing the size of the heating and cooling equipment. The trade-off means no added cost to the builder, better value for the buyer, reduced electric load for the utility and improved affordability.

\section{Background}

Building America was started in 1995 to conduct the systems research required to develop residential energy efficiency solutions that achieve 30\%-100\% savings when used on a production basis by builders of new homes. The long-term 2020 research goal for the program is to develop cost-effective system designs that can result in Net Zero Energy Homes (NZEH). ${ }^{4}$ In the past 10 years, Building America has made significant progress on the path to NZEH, including the completion of more than 32,000 homes.

Building America research participants have developed an in-depth systems research process by combining operations research ${ }^{5}$ and systems engineering. ${ }^{6}$ The first step of the systems-research

\footnotetext{
${ }^{4}$ A net zero energy house is a house that produces as much energy as it uses on an annual basis through integration of energy efficiency solutions and onsite power systems.

${ }^{5}$ Operations Research is research aimed at understanding the how a builder can integrate Systems Engineering to maximize building performance, based on the builder's organizational structure and business processes.

${ }^{6}$ Systems Engineering is engineering based on knowledge from systems research aimed at maximizing the performance and durability of a system, subject to operating constraints.
} 
process is to use operations research techniques to identify the technology pathways that will achieve the target energy savings in each region for the lowest potential installed cost. From these results, the optimal efficiency targets can be identified and technologies can be developed that will meet the energy-savings needs cost effectively in all climate regions. The second step in the systems research is to implement the optimal technology pathways through systems engineering in homes. The systems-engineering step will identify challenges and barriers unanticipated by the optimization. The combination of operations research and systems engineering ensures that the solutions created meet the energy savings and cost goals and can be used on a production basis. Figure 3 shows a more detailed look at the Building America systems research approach (Table 1$)$.

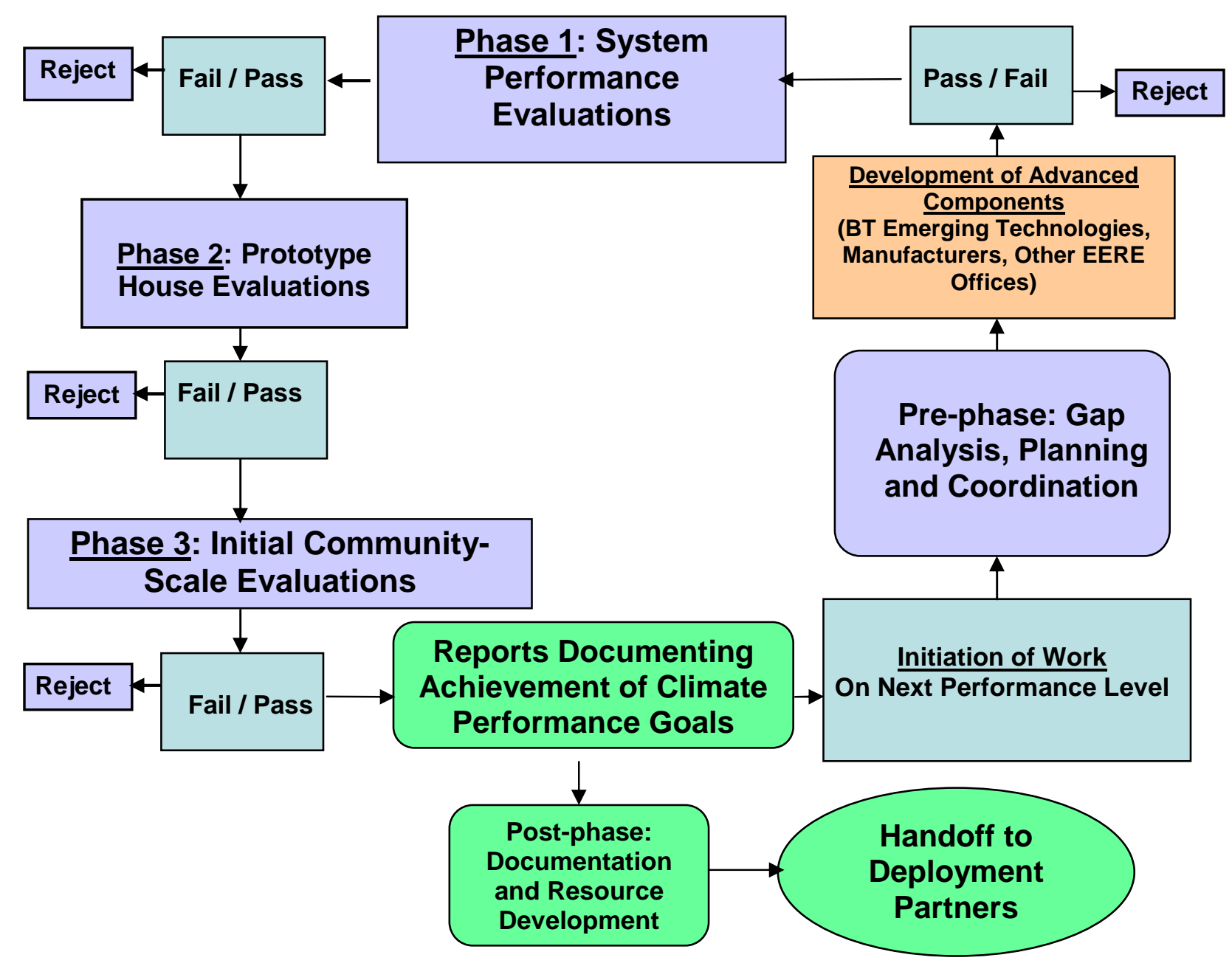

Figure 3. A more detailed look at the Building America system research strategy 
Table 1. Building America Background

Start date

Target market(s)

Accomplishments to date

Current activities

Future directions

Projected end date(s)
1995

New, single-family residential buildings

1. Developing the Benchmark Definition

2. Developing protocols for validating whole-house energy performance

3. Completion of integrated cost-effective, wholebuilding strategies to enable new, single-family residential buildings to use $30 \%$ less total energy than the Benchmark in the Hot-Dry/Mixed-Dry and Cold climate regions.

4. Documenting research and publishing Houses That Work, Builder Guides, and Best Practices

5. Significant annual increases in the number of ENERGY STAR $®$ homes

Developing integrated cost-effective, whole-building strategies to enable new, single-family residential buildings to use 30\% less total energy than the Building America Benchmark in the Marine and Mixed-Humid climate regions.

Continuing to develop the strategies for new, singlefamily residential buildings to use 40\%-100\% less energy than the Benchmark in the Marine, Hot-Humid, Hot-Dry/Mixed-Dry, Mixed-Humid, and Cold climate regions 2020 
The systems research is applied in three phases for each climate region. During the three phases, which are conducted in parallel to allow feedback between phases, Building America acts as a national residential energy systems test bed where homes with different system options are designed, built, and tested at three levels of system integration, including research houses, production prototype houses, and evaluations in community-scale housing to validate the reliability, cost effectiveness, and marketability of the energy systems when integrated in production housing. After completion of the community evaluations, a low level of technical support may be provided as needed to ensure successful implementation of system research results at each performance level targeted by the program. A detailed summary of the three phases of the system research process is captured in Table 2.

Table 2. Residential Integration Systems Research Approach

\begin{abstract}
Phase 1 - System Evaluations
In Phase 1, the Building America Consortia design, construct, and test subsystems for whole-house designs in research houses to evaluate how components perform. The focus of Phase 1 is to evaluate and field-test prototype subsystems to determine the most reliable and cost-effective solution for a given performance level and climate.
\end{abstract}

\title{
Phase 2 - Prototype Houses
}

In Phase 2, the successful Phase 1 subsystems are designed and constructed by production builders working with the Building America Consortia to evaluate the ability to implement the systems on a production basis. The focus of Phase 2 research is to move the research prototype house and building practices to the point that they are production-ready and capable of being integrated with production construction techniques practiced by today's builders.

\section{Phase 3 - Initial Community-Scale Evaluations}

In Phase 3, the Building America Consortia provide technical support to builder partners to advance from the production prototypes to evaluation of production houses in a subdivision. The results are documented in a case-study report. Several of these reports are distilled into a final research report that describes the system design and construction practices needed to achieve a particular level of energy savings within each climate region targeted by the program.

The three system-engineering stages overlap one another to allow issues to be quickly resolved as they are identified. The three system-research stages currently take about 3 to 4 years, but for more advanced energy efficiency levels at and above $40 \%$ whole-house savings, the systemsresearch process is expected to take additional iterations of whole-house testing before implementation in production ready homes. At the 50\% whole-house level and above, the system research stages are expected to take 4 to 5 years to complete. 


\section{Electronic Reporting of System Research Results}

Final research results from the program are reported electronically via the Building America Website (www.buildingamerica.gov). Research results include project data, research reports, case studies, research highlights, and background information on the research program and its participants. The website also includes a document database and reference materials on the performance analysis and measurement procedures.

\section{Identification of Component Development Needs}

The three-phase systems-engineering approach (Table 2) requires identification of future system needs to allow the lead time required to develop and evaluate options to meet those needs. Before initiation of Phase 1 studies in research houses, components must be developed and evaluated to determine their potential to fill gaps between the performance of current systems and future whole-house performance goals. The component research requires significant lead time in some cases and focuses on communication of system-integration needs and requirements to component developers. Building America's role is to provide inputs to component developers that help to identify residential system integration needs, requirements, and gaps based on annual residential cost/performance studies using analysis methods such as BEopt. ${ }^{7}$ Components must be developed for Phase 1 and have to meet minimum requirements for energy performance, reliability, and cost effectiveness before they are included as part of the residential integration activities in Phases 2 and 3.

\section{Documentation and Resource Development}

At the completion of Phase 3, the research results are documented in technical research reports that serve as references for students, educators, building scientists, architects, designers, and engineers. For the research results to be successfully transferred to additional important participants in the housing industry, they must be translated into a format appropriate for dissemination to developers, builders, contractors, homeowners, realtors, insurance companies, and mortgage providers.

This post-Phase-3 activity of the DOE fosters movement of the research and building techniques of the Building America Program to the market and establishes voluntary collaborations with housing and financial industries to make the nation's houses more energy-efficient and affordable. This final stage of the process focuses on documentation of best practices and development and evaluation of resources to hand-off DOE building-research findings to private and public sector implementation programs. This work supports activities that improve the energy efficiency of public and privately owned single-family housing. The program coordinates presentations at technical conferences on peer-reviewed, validated, research results and facilitates validation, field-testing, and evaluation of the post-Phase-3 documentation.

The Building America resource development effort creates a variety of documents and other materials from the Phase-3 research reports that are designed for builders, building scientists, contractors, manufacturers, homeowners, realtors, educators, insurance companies, and mortgage providers. For example, best practice manuals summarize best-practice recommendations in

\footnotetext{
${ }^{7}$ BEopt stands for "Building Energy Optimization Analysis Method,” as defined in Anderson et al. 2004.
} 
illustrated text that are targeted to a specific audience to make them easily assimilated and that synthesize research findings into energy-efficient processes for the building industry. To facilitate construction of affordable homes designed for non-profit organizations and small builders, Building America has made floor plans and section details available through its website. Other resources developed or supported by BA research include case studies, technical publications, software tools, and the Builder’s Guides for various climate regions.

\section{Building America's Research Goals}

Building America's energy-saving goals form the core of the research effort and have been staged to complete an additional 10\% of incremental savings every 3 to 5 years (Table 3 ).

To ensure meeting the interim targets along the path to Zero Energy Homes (ZEH), Building America has also specified the interim performance targets for each climate region (Table 4).

Table 3. Building America Research Goals ${ }^{8}$

\begin{tabular}{lcccccc}
\hline \multirow{2}{*}{ Characteristics } & Units & \multicolumn{5}{c}{ Year } \\
\cline { 3 - 7 } & & $\mathbf{2 0 0 7}$ & $\mathbf{2 0 1 0}$ & $\mathbf{2 0 1 5}$ & $\mathbf{2 0 1 8}$ & $\mathbf{2 0 2 0}$ \\
\hline \hline Average Source Energy Savings & $\%$ & 30 & 40 & 50 & 70 & 90 \\
Cost & $\$$ & Zero or Positive Net Cash Flow & \\
\hline
\end{tabular}

Table 4. Building America Performance Targets by Climate Region

\begin{tabular}{cccccc}
\hline \hline $\begin{array}{c}\text { Target } \\
\text { (Energy Savings) }\end{array}$ & Marine & Hot Humid & $\begin{array}{c}\text { Hot-Dry I } \\
\text { Mixed Dry }\end{array}$ & $\begin{array}{c}\text { Mixed } \\
\text { Humid }\end{array}$ & Cold \\
\hline $30 \%$ & 2006 & 2007 & 2005 & 2006 & 2005 \\
$40 \%$ & 2008 & 2010 & 2007 & 2008 & 2009 \\
$50 \%$ & 2011 & 2015 & 2012 & 2013 & 2014 \\
\hline
\end{tabular}

\footnotetext{
${ }^{8}$ Year of completion of annual performance targets in six climate regions. Energy savings are measured relative to Benchmark. The targets in Table 4 are updated on an annual basis dependent on technical progress and funding.

${ }^{9}$ Life cycle cost (Hendron 2005).
} 
In addition to energy savings, Building America has additional system-performance goals that are critical to the success of the systems research process. These include the following:

- Accelerating the development and implementation of advanced-energy systems in new and existing residential construction through application of systems-engineering research projects by cross-cutting industry teams

- Reducing residential building construction site waste, increasing the use of recycled materials, reducing construction cycle time, increasing system durability and reliability, and reducing warranty and call-back costs

- Developing innovative technologies and strategies that enable the housing industry in the United States to deliver environmentally sensitive, quality housing on a community-scale while maintaining profitability and competitiveness of homebuilders and product suppliers

- Increasing housing value and affordability for homeowners in the United States.

30\% Whole-House Energy Savings

Building America's current research activities target 30\% total energy savings in new singlefamily homes in six of the eight climate regions defined by Building America as shown in Figure 4, including Marine, Hot-Humid, Hot-Dry, Mixed-Dry, Mixed-Humid, and Cold. The Hot-Dry and Mixed-Dry climates have been combined into a single climate target for Building America planning purposes because of the similarities of the solutions for the two climates. Residential buildings include a limited number of different end uses with many similarities in a particular climate region. Therefore, a climate region approach is appropriate because residential system solutions can be easily replicated on a regional basis.

Because of limited resources, Building America is not targeting the Very Cold and Subarctic climate regions because of limited resources and the lack of residential growth as a percentage of annual United States housing starts in those regions. 


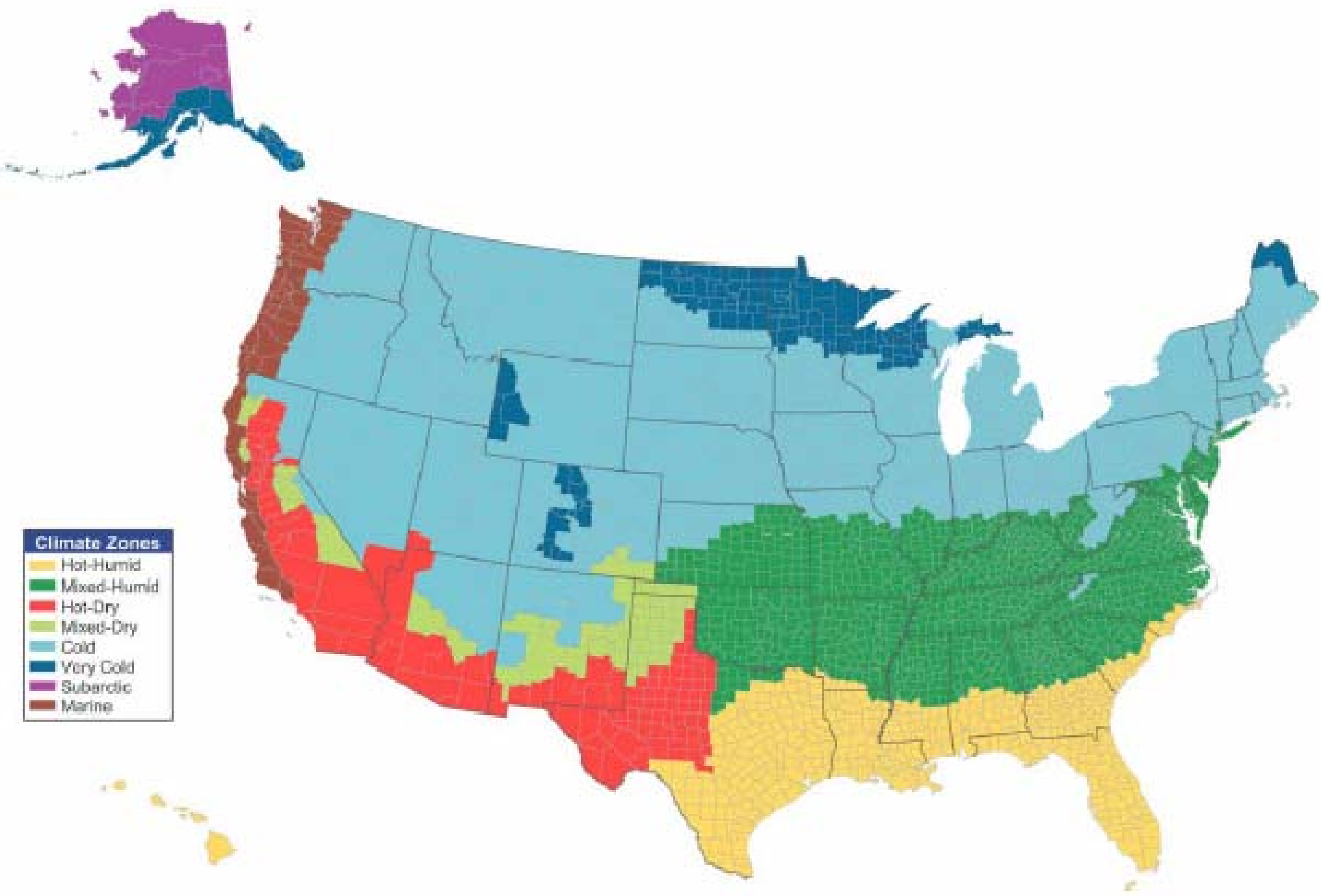

Figure 4. Building America climate regions 


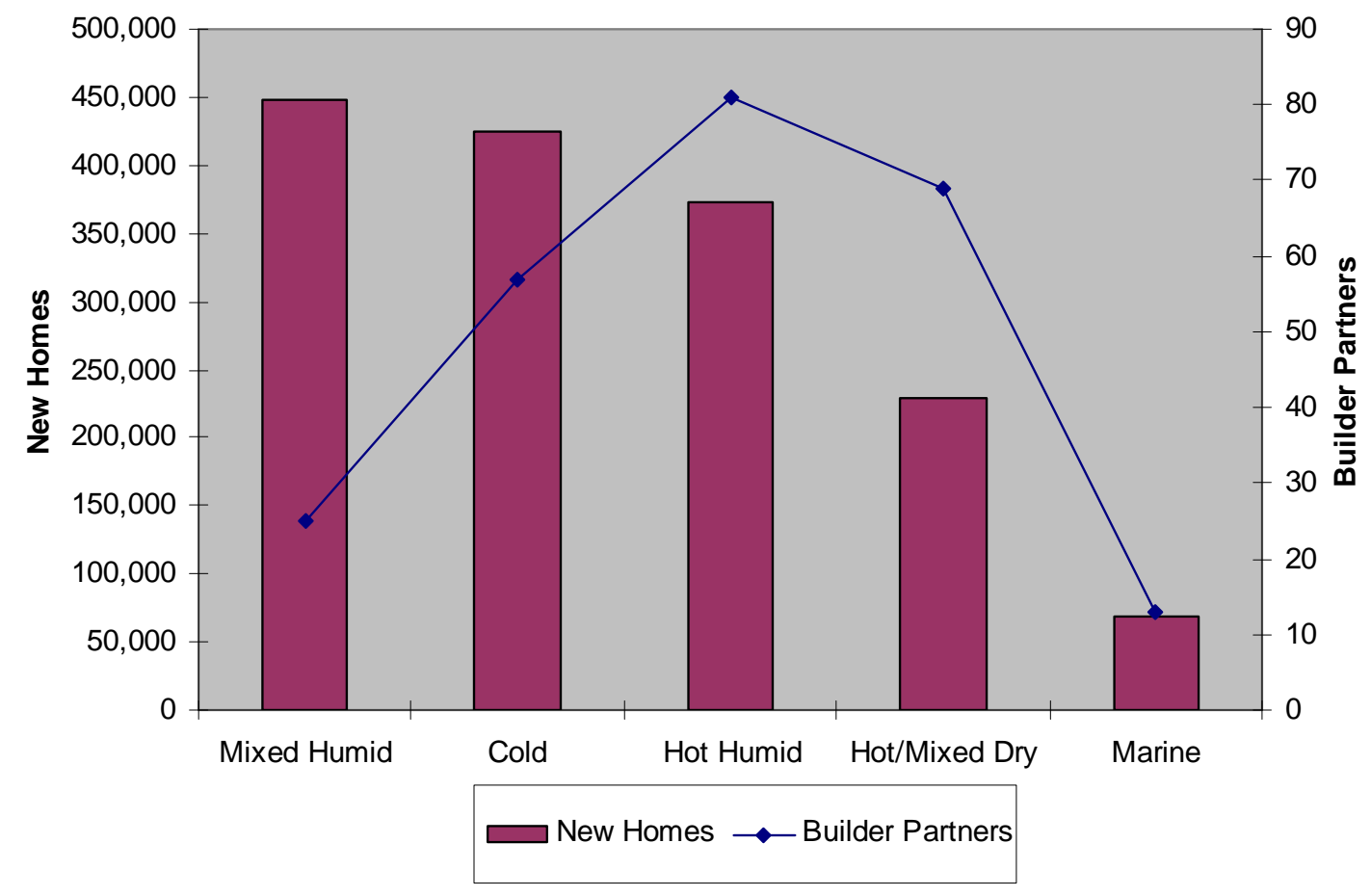

Figure 5. New homes ${ }^{10}$ and builder partners ${ }^{11}$ by climate region

From 2003 to 2005, Building America has developed solutions to use 30\% less total source energy than the Benchmark for the Mixed-Humid and Marine climate regions. These climate regions present opportunities for research because of the number of new homes being built and the relationships established with builder partners. The number of new homes and builder partners for each climate region can be seen in Figure 5. Building America will focus on developing 30\% solutions for the Hot-Humid region and $40 \%$ solutions for the Hot and Mixed Dry regions in 2007.

Through 2025, Building America will continue to develop the strategies for new, single-family residential buildings to use $30 \%-100 \%$ less total source energy in the Marine, Hot-Humid, Hotdry/Mixed-Dry, Mixed-Humid, and Cold climate regions over the full range of house sizes, styles, and price points.

\footnotetext{
${ }^{10}$ July 1, 2002, to July 1, 2003. U.S. Census Bureau Housing Unit Estimates (HU-EST2003-04), “Annual Estimates of Housing Units for Counties: April 1, 2000, to July 1, 2003,” Last revised September 2, 2004.

11 "House Counts by Climate Zone (detailed)", U.S. Department of Energy, Building America House Performance Database, January 5, 2005.
} 
The purpose of this report is to provide an overview of 3 years of Building America system research in the Mixed-Humid climate region that led to the development of homes that save $30 \%$ relative to the Benchmark. ${ }^{12}$ Based on the research results and case studies included in this report, the Building America industry teams have demonstrated that $30 \%$ homes can be reliably designed and constructed by production builders in Mixed-Humid climates. The actual rate of adoption of the research results contained in this report will depend upon a number of factors, including residential energy costs and national, state, and local incentives for the use of energyefficient construction techniques.

\section{System Approach to Least-Cost Energy Savings}

\section{Integrated Design Process}

Building America's team-based systems-research approach, including use of systems-engineering and operations research techniques, provides opportunities for cost and performance trade-offs that improve whole-building performance and value, while minimizing increases in overall building cost. Systems engineering is conducted at multiple scales, including individual test houses, pre-production houses, and community-scale developments. Systems research includes analysis of system performance and cost tradeoffs as they relate to whole-building energy performance and cost optimization, including interactions between advanced enclosure designs, mechanical and electrical systems, lighting systems, space-conditioning systems, hot water systems, major appliances, miscellaneous electric loads, energy control systems, renewable energy systems, and onsite power generation systems. Accordingly, the best practice recommendations in this report have been demonstrated to cost-effectively increase overall product value and quality compared to conventional approaches, while significantly reducing energy use and use of raw materials when used on a production basis.

The final products of each research project include performance measurements and cost/performance evaluations in prototype houses, pre-production homes, and community-scale developments, and climate-based system research design/technology packages, including system performance specifications. These measurements, evaluations, and system-performance packages are the basis of the recommendations provided in this report.

\section{Analysis and Design Optimization}

The research path to future residential energy savings extends from a base case (e.g., a currentpractice building, a code-compliant building, or some other reference building) to a ZNE building with $100 \%$ energy savings. To ensure a well-defined reference for evaluation of energy savings and progress toward multi-year goals, a detailed Benchmark (Hendron 2005) building definition has been developed for use by all participants in Building America research projects. A standard reporting format for research results has also been developed to facilitate comparisons of performance between different research projects.

The Benchmark is generally consistent with the 1999 Home Energy Rating System (HERS)

\footnotetext{
${ }^{12}$ The Research Benchmark provides a detailed description of all residential energy uses and serves as the reference point for the energy savings goals in Building America research project. More information about the Benchmark can be found on the Building America website: www.eere.energy.gov/buildings/building_america/pa_resources.html.
} 
Reference Home, as defined by the National Association of State Energy Officials/Residential Energy Services Network (NASEO/RESNET), with additions that allow the evaluation of all home energy uses. The Benchmark represents typical standard practice in the mid-1990s, when DOE initiated the Building America program. Additional documentation to support the use of the Benchmark, including spreadsheets with detailed hourly energy usage and load profiles, can be found on the Building America Web site. ${ }^{13}$ As Building America teams develop innovative new technologies and systems approaches that move the program toward its research goals, the Benchmark will be re-evaluated and refined periodically to ensure that energy savings from these features are accurately credited. Many other valid techniques and definitions have been developed by other organizations, and they can be very useful to builders for specialized applications. For example, the HERS rating procedure must be followed to obtain an ENERGY $\mathrm{STAR}^{\circledR}$ rating for building energy efficiency. Also, it might be necessary to determine whether or not a Prototype meets the International Energy Conservation Code (IECC 2003, 2004) or Model Energy Code (MEC 1995), which could apply if adopted by the state or local government.

\section{Building America Research Benchmark}

The Benchmark was developed to track and manage progress toward the Building America multi-year whole-building energy savings goals for new construction, using a fixed reference point. To provide a context for the potential impacts of research projects on local and regional markets at a given point in time, energy usage is also compared with current Regional Standard Practice and Builder Standard Practice. Standard occupant profiles for use in conjunction with these reference houses have also been developed based on review of the available literature; the intent is to represent typical occupant behavior. Additional analysis and end-use monitoring (Norton et al 2003) are required to evaluate energy savings for specific occupants whose individual behavior could vary from the average profiles defined in the Benchmark. In general, relative savings for an individual user are expected to be approximately the same as those for an average user.

Energy savings can be defined in terms of site energy (used at the building site) or source energy (sometimes called primary energy). For electricity purchased from a utility, site energy can be converted to source energy to account for power plant generation efficiency and electrical transmission and distribution losses. The source-to-site energy ratio for electricity typically has a value of about 3 , depending on the mix of electrical generation types (coal-fired, natural gas combined cycle, nuclear, hydropower, etc.). For the purpose of Building America analysis, national average site-to-source multipliers of 3.16 for electricity, 1.02 for natural gas, and 1.00 for all other fuels are used. From the view of all stakeholders in the building process, site and source energy are both important. Source energy has been chosen as the basis for tracking progress toward the Building America energy-saving targets and is also used as the basis of the cost/performance tradeoffs analyzed in this report. Site energy savings are also calculated as part of ongoing research projects and included in project evaluations because of their importance in determining specific utility bill savings. Additional important reference buildings whose definitions will vary over the timespan of the Building America Program include State and Local Code, regional standard practice, and specific builder standard practice.

\footnotetext{
${ }^{13}$ www.eere.energy.gov/buildings/building_america/pa_resources.html.
} 


\section{Analysis Methods}

A key issue in any building energy analysis is which tool or program to choose to estimate energy consumption. An hourly simulation is often necessary to fully evaluate the timedependent energy impacts of advanced systems used in Building America houses. Thermal mass, solar heat gain, and wind-induced air infiltration are examples of time-dependent effects that can be accurately modeled only by using a model that calculates heat transfer and temperature in short time intervals. In addition, an hourly simulation program is also necessary to accurately estimate peak energy loads. Because of the large number of users, public availability, and level of technical support, DOE-2 is the most commonly used hourly simulation engine for systems analysis studies performed under the Building America program.

EnergyGauge $^{14}$ is a frequently used interface for DOE-2, tailored specifically to residential buildings. EnergyGauge can also automatically calculate HERS scores and evaluate compliance with the IECC performance path. Teams are encouraged to use other simulation tools when appropriate for specialized building simulation analysis, provided the tool has met the requirements of BESTEST (Judkoff and Neymark 1995) in accordance with the software certification sections of the RESNET/HERS Guidelines (RESNET 2002).

Building energy simulations are often used for trial-and-error evaluation of "what-if" options in building design (i.e., a limited search for an optimal solution). In some cases, a more extensive set of options is evaluated and a more methodical approach is used. For example, in the Pacific Gas and Electric ACT2 project (Davis Energy Group 1993), energy-efficiency measures were evaluated using DOE2 simulations in a sequential-analysis method that explicitly accounted for interactions. With today's computer power, the bottleneck is no longer simulation run time, but rather the human time to handle input/output. Computerized option analysis has the potential to automate the input/output, evaluate many options, and perform enough simulations to explicitly account for the effects of interactions among combinations of options. However, the number of simulations still needs to be kept reasonable, by using an efficient search technique rather than attempting exhaustive enumeration of all combinations of options.

Even with simulations that run in a few seconds, run time for an exhaustive study of all possible combinations is prohibitive for the millions of combinations that can result from options in the ten or more categories needed to accurately describe a residential building. Several computer programs that automate building energy optimization have been recently developed. For example, EnergyGauge-Pro ${ }^{15}$ uses successive, incremental optimization (similar to the ACT2 approach) with calculations based on the "energy code multiplier method" for Florida. GenOpt ${ }^{16}$ is a generic optimization program for use with various building energy simulation programs and user-selectable optimization methods.

To evaluate the cost required to reach a specific energy target, energy and cost results can be plotted in terms of annual costs (the sum of utility bills and mortgage payments for energy options) versus percent energy savings (Figure 6). The optimal least-cost path can then be

\footnotetext{
${ }^{14}$ This is available for purchase from the Florida Solar Energy Center (http://energygauge.com/).

${ }^{15}$ Florida Solar Energy Center. EnergyGauge Pro. Cocoa, FL: Florida Solar Energy Center (energygauge.com/FlaRes/features/pro.htm).

${ }^{16}$ Wetter, M. “GenOpt ${ }^{\circledR}$, "Generic Optimization Program,” Seventh International IBPSA Conference, Rio de Janeiro, Brazil. (www.ibpsa.org/proceedings/BS2001/BS01_0601_608.pdf).
} 
determined by connecting the points for building designs that achieve various levels of energy savings at minimal cost (i.e., that establish the lower bound of results from all possible building designs). Alternatively, net present value or other economic figures of merit could be chosen. Inclusion of even a modest number of possible options for major system choices can lead to a very large number of possible building designs. One of the key challenges in developing a practical analysis method is to develop an approach that quickly focuses on the combinations that are nearest to the least-cost limit. To address these challenges, NREL is currently developing the BEopt Analysis Method.

Points of particular interest on the least-cost path are shown in Figure 6 and can be described as follows: from the Benchmark at point 1 , energy use is reduced by employing building efficiency options (e.g., improvements in space-conditioning systems, hot water systems, lighting systems, thermal distribution systems, etc.) A minimum annual cost optimum occurs at point 2. Additional building efficiency options are employed until the marginal cost of saving energy for these options equals the cost of producing power onsite at point 3. In this study, residential PV systems are used as the system option for onsite power. As research on distributed energy systems continues, it is anticipated that other onsite power technologies will also become available for residential-scale projects. From point 3 on, the building design does not change and energy savings are solely a result of adding additional onsite power capacity, until ZNE is achieved at point 4.

The horizontal dashed line in Figure 6 defines solutions that provide energy savings at an annual cost that is less than or equal to the utility cost for the reference house when energy improvements are financed as part of a 30-year mortgage. All solutions in a vertical region below the neutral-cost line are essentially equivalent from an energy-savings perspective. The specific design package chosen by a builder to achieve a specific energy-savings level will depend on a number of factors, including material and equipment cost and availability, and overall homeowner preferences.

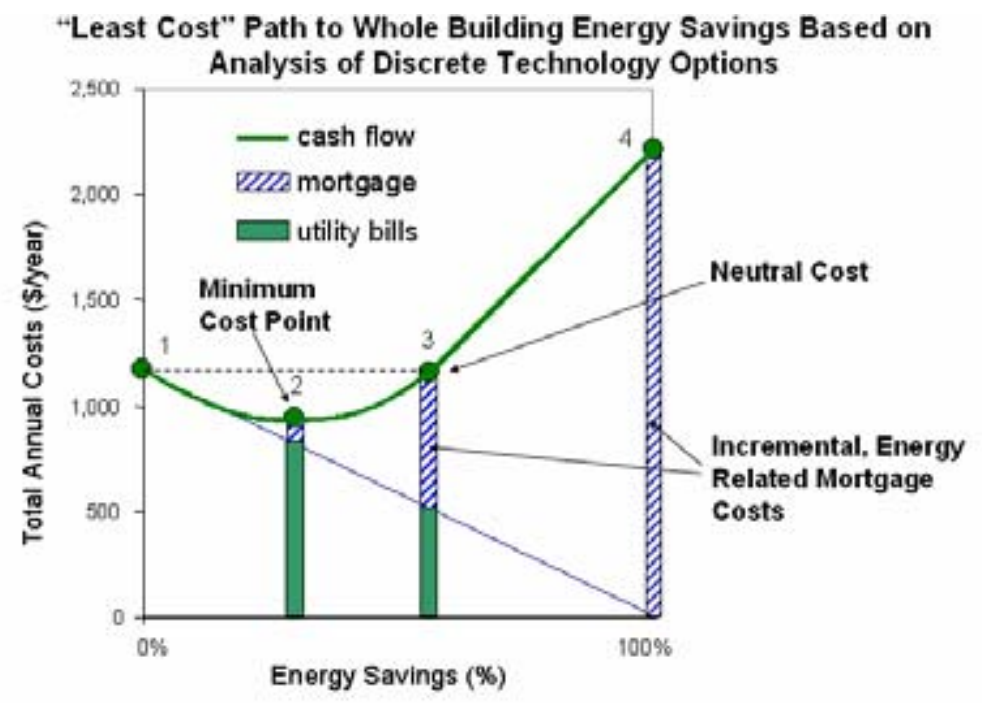

Figure 6. Least-cost curve calculated using the BEopt analysis method 


\section{Performance Verification}

Modeling provides the generalized energy calculations necessary to compare a prototype house to the Benchmark. Because weather, occupant behavior, and miscellaneous electric loads can dramatically affect actual energy use, it is essential that simulations be used to separate the objective performance of a prototype house from the effects of these uncontrolled variables. Modeling also allows the evaluation of "what-if" scenarios, where alternative design features are compared to those of the as-built prototype house.

However, short-term field evaluations of actual prototype building systems provide information that modeling alone cannot. Field testing increases confidence in building models by improving simulation accuracy in areas that are difficult to know without direct measurements, such as duct and envelope air leakage, solar collector efficiency for solar hot water (SHW), and even the whole-building heat loss coefficient (UA). Common measurement techniques include tracer-gas tests, blower-door and duct-blaster tests, infrared imaging, current-voltage traces for photovoltaic systems (PV), and co-heating tests. Other tests are often developed based on the specific design features and uncertain performance characteristics of the house.

The intent of short-term testing is to characterize the performance of unoccupied building and systems under controlled conditions, not under the idiosyncratic control of random occupants. Short-term tests may be repeated seasonally to characterize performance changes from winter to summer. These tests can also help identify equipment installation issues, operational problems, or malfunctions at an early stage before the occupants are inconvenienced.

HERS raters are a valuable resource in the process of energy-efficient construction with builders. Many Building America teams have successfully partnered with local HERS raters to provide initial testing, construction monitoring, and performance-verification testing services during the construction of test homes. The relationship between the builder and rater may continue after the test home, with the rater providing services, including ongoing performance verification and, in some cases, design and engineering services, depending on the rater's skill set.

Long-term field measurements provide valuable insights into the actual performance of the home under realistic conditions, including interactions between occupants and technology. Ultimately, it is essential for Building America to demonstrate that houses can meet the target levels of energy efficiency in reality and not just on paper. However, individual long-term tests under occupied conditions must always be put in the context of the specific occupants. Number of occupants, thermostat settings, operation of windows and interior shades, hot water and appliance-use patterns, and lifestyle are all important drivers of energy consumption. The recommended approach is, therefore, to compare measurements with simulated energy use based on actual occupant behavior and weather conditions and to make adjustments to the simulation based on the results of this comparison if justified. A more accurate energy savings analysis can then be performed based on actual instead of theoretical building system performance characteristics.

Long-term monitoring activities are still ongoing for the houses designed to meet the $30 \%$ savings target discussed in this report. The results will be reported in future technical publications, and the lessons learned will be used to inform future projects at the same or higher energy-savings target. Building America is committed to long-term energy savings, health and comfort, durability, and reliability of its system design recommendations at each performance 
level, and we will continue to track the performance of our prototype houses for several years to come.

\section{System Design and Construction Process}

\section{Climate Analysis}

\section{Key Climate Elements that Affect Building Design}

Houses should be designed and constructed in a manner that is suited to their environment, both exterior and interior. Rain, temperature, humidity and the interior climate are examples of environmental loads that act on houses.

The recommendations in this research report are applicable to houses constructed in MixedHumid climate regions.

A Mixed-Humid climate is defined as:

- A region that receives more than 20 inches $(50 \mathrm{~cm})$ of annual precipitation

- Has 5,400 heating degree days or fewer $\left(65^{\circ} \mathrm{F}\right.$ basis)

- Where the average monthly outdoor temperature drops below $45^{\circ} \mathrm{F}\left(7^{\circ} \mathrm{C}\right)$ during the winter months.

The following maps show the approximate outline of areas of the Untied States that are defined by the above characteristics, as well as the other climate regions. While the boundary lines have been chosen based on the above characteristics, note that being on or near a boundary line between climates generally indicates that the principles of either adjoining climate region will cover the majority of circumstances under normal siting conditions. 


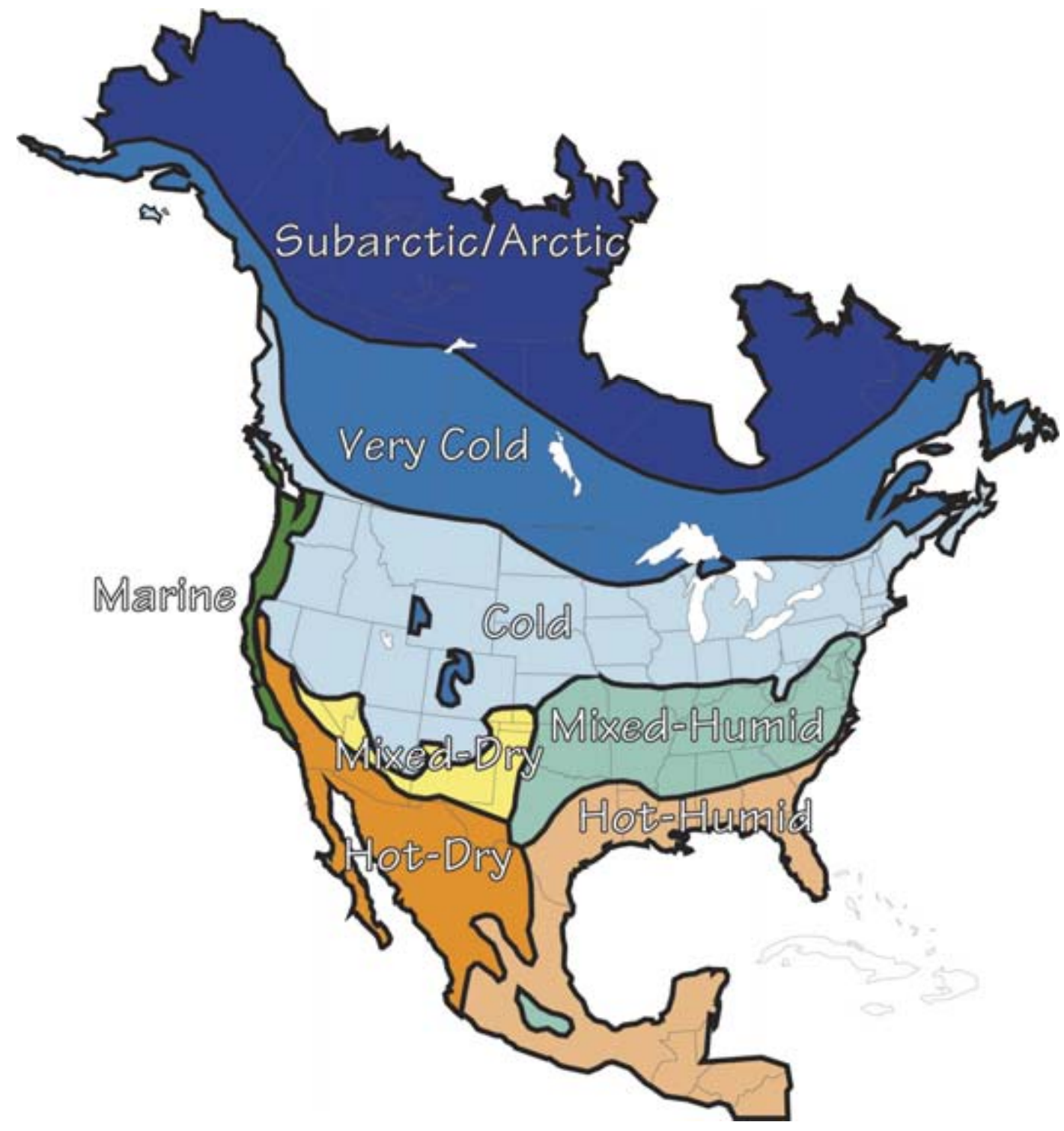

Figure 7. Climate Region map

The Mixed-Humid climate region is illustrated in Figure 7. The Mixed-Humid climate region covers a narrower range of temperatures, and therefore insulating levels would be more similar across the region. The IECC requirements for the different degree day zones give an idea of the range of insulation levels necessary, even though they are code minimums. With the goal of $30 \%$ savings homes, the insulation levels should be increased to minimize energy consumption.

Rain exposure zones are illustrated in Figure 8. The rainfall variation in the Mixed-Humid climate region runs the gamut from moderate to extreme. On the coastal areas of the climate region, the enclosure design should follow elements of the Marine climate best practices, while the interior sections of the climate region could be less conservative. 


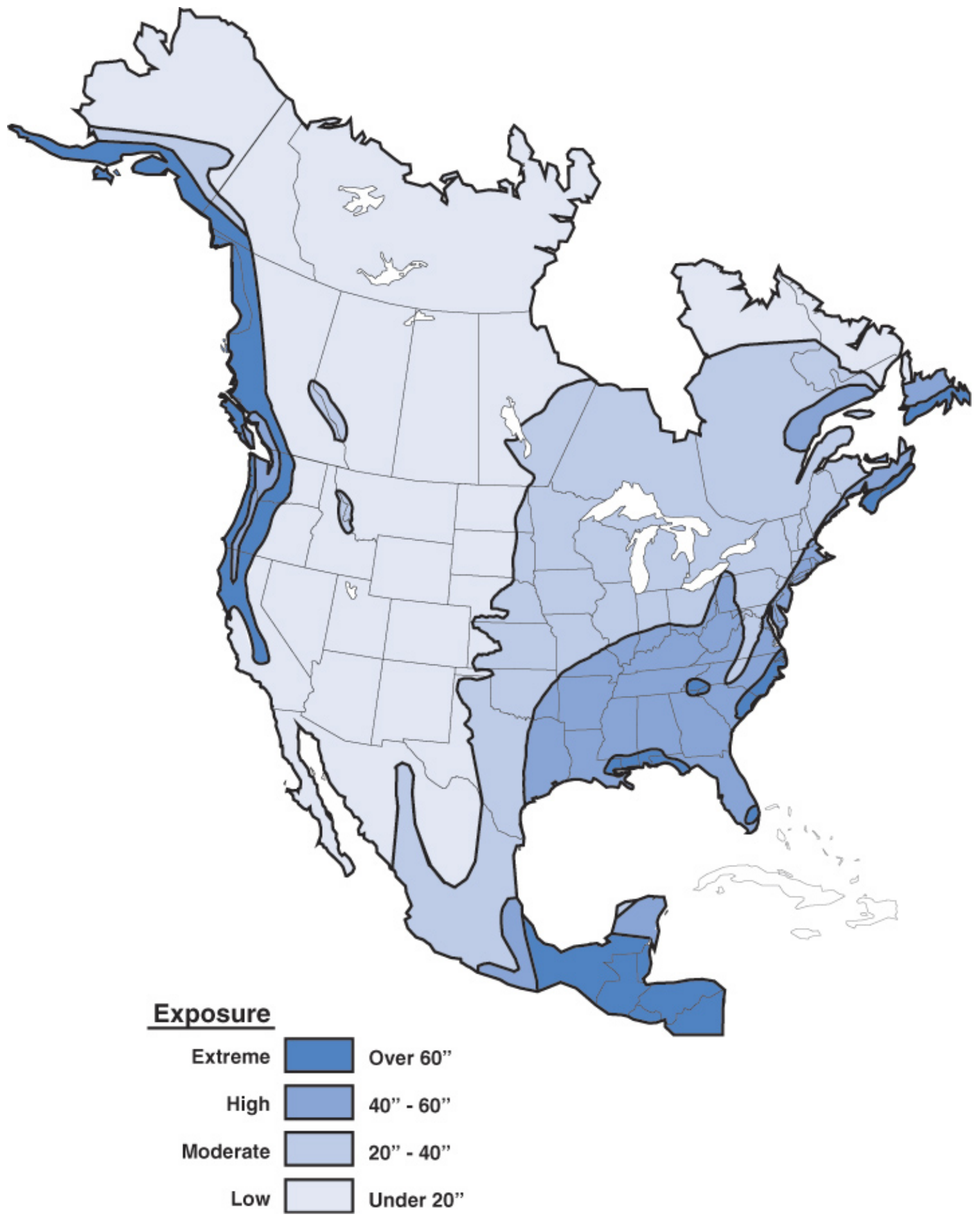

Figure 8. Rainfall total map 
Individual locations within the broad general regions and zones described above can vary significantly. For a specific location designers and builders must consider local weather records, local experience, and the micro-climate around a building. Elevation, incident solar radiation, nearby water and wetlands, vegetation, and undergrowth can all affect the micro-climate.

\section{Design Strategy Modification for Variances within a Climate Region}

In general, the approach to rain control (Figure 8) is far more dependent on individual location within this climate region, than the approach to energy efficiency. For example, levels of thermal insulation do not vary significantly across the Mixed-Humid climate region; however, approaches to rain control do. With high rain exposure, the use of a vented rain screen is recommended, whereas with lower rain exposure, a drainage plane / drainage space would be sufficient.

\section{Site Development}

\section{Orientation Impacts}

To achieve the $30 \%$ level of energy savings, it is not necessary to orient homes in any particular direction. In many instances, the builder does not have any influence over lot orientation, and the house will face the street as laid out by the developer. The predominant window placement will typically be to the street and the back of the house. However, if it is possible to consider orientation at the site development level of the homebuilding process, one virtually no-cost option for improving energy performance is to subdivide for solar orientation. Alternately, on larger lots that do not have to "respect the street," site planning can be undertaken to optimize the orientation of the house for passive solar benefit. An example of land planning and lot layout to allow for passive solar orientation is shown in Figure 9. For more information about the benefits of solar orientation in passive solar design see Appendix A: Passive Solar Design

Considerations.
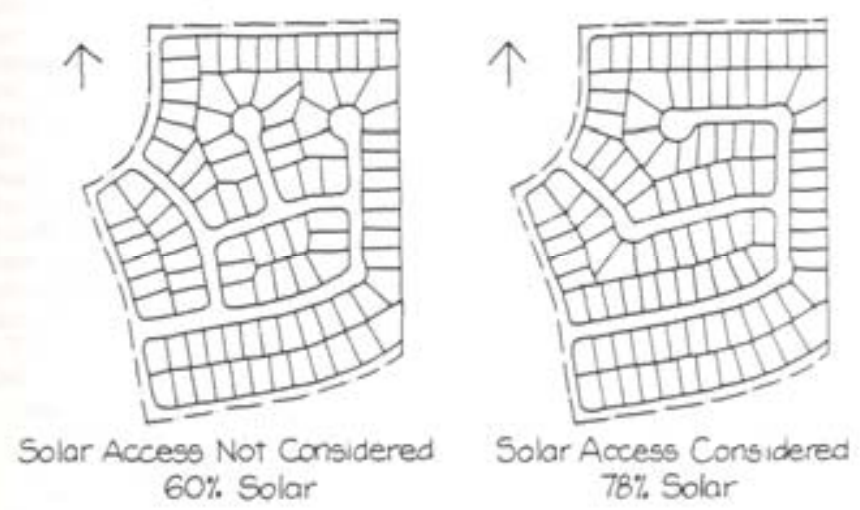

Figure 9. Subdivision site plan for solar orientation ${ }^{17}$

\footnotetext{
${ }^{17}$ Shelley Dean and Fuller, Energy Principles in Architectural Design Architects California Energy Commission 1981.
} 


\section{Landscaping}

While not a required strategy for achieving 30\% whole-house savings, evaluating the vegetation on a lot and retaining trees that provide beneficial shading can be a low- or no-cost way to improve energy performance, predominantly by providing shade in the cooling season and helping to buffer or direct beneficial prevailing winds. Shade trees block summer sunlight before it strikes windows, walls, and roofs, dissipating absorbed heat to the air where it can be carried away by the breeze. It is most effective when located next to windows, walls, and air conditioners, and when located on the side of the home receiving the most solar exposure in summer. Shade to the southwest and west is especially important for blocking peak solar gain in the summer in late afternoon. Trees more than 35 feet from the structure are probably too far away for shade. Trees to the north of a house in a Mixed-Humid climate region can help block cold north winds, reducing one driving force for air infiltration. Trees, shrubs, and vines not only block sunlight, but also can cool the nearby air beneath the canopy or behind the plant by as much as $15^{\circ} \mathrm{F}$ because of natural evaporation from the plant's leaves.

\section{Water Management}

In natural settings, most precipitation infiltrates into the ground, while a small portion runs off on the surface and into receiving waters. This surface runoff water is classified as storm-water run off. As areas are constructed and urbanized, surface permeability is reduced, resulting in increased storm water run-off volumes that are transported via urban infrastructure (e.g., gutters, pipes and sewers) to receiving waters. These storm water volumes contain sediment and other contaminants that have negative impact on water quality, navigation, and recreation. Furthermore, conveyance and treatment of storm water volumes require significant municipal infrastructure and maintenance.

Reduction and treatment of run-off volumes decrease or eliminate contaminants that pollute receiving water bodies. Minimizing the need for storm water infrastructure also reduces construction impacts and the overall ecological footprint of the building. Finally, infiltration of storm water on site can recharge local aquifers, mimicking the natural water cycle.

Storm-water management strategies that prevent or reduce the pollution of water include the following:

- Reduce impervious surface: The most effective method to minimize storm water run-off volume is to reduce the amount of impervious area. By reducing impervious area, stormwater infrastructure can be minimized or deleted from the project. To minimize the impervious surface and to encourage the natural process of evaporation and infiltration, consider such methods as designing a smaller building footprint; clustering or concentrating developments to reduce the amount of paved surfaces such as roads, parking lots and sidewalks; and paving with pervious materials, such as asphalt or poured concrete with incorporated air spaces or concrete unit-paving systems with large voids that allow grass or other vegetation to grow between the voids.

- Storm-water harvesting: Capture storm water from impervious areas to reuse within the building. Storm-water harvesting from roofs and hardscapes can be used for non-potable uses, such as sewage conveyance, fire suppression, and industrial applications. 
- Storm-water Volume. For storm-water volumes that must be conveyed from the site to a receiving water body, design treatment practices to match the needs of the location and the specific drainage area. Design storm-water facilities to remove contaminants and release the volumes to local water bodies. Utilize biologically based and innovative storm-water management features for pollutant load reduction, such as constructed wetlands, storm-water filtering systems, bioswales, bioretention basins, and vegetated filter strips.

- Buffer Vegetation. Use vegetated buffers around parking lots to remove runoff pollutants, such as oil and grit.

- Water Treatment. Specify and install water-quality structures for pretreatment of runoff from surface parking areas. Do not disturb existing wetlands or riparian buffers when constructing ponds at the lowest elevations of a site.

- Structure Design. Design storm-water runoff to flow into vegetated swales rather than into structured pipes for conveyance to water-quality ponds. Swales provide filtration for storm water volumes and require less maintenance than constructed storm-water features.

\section{Integrated Design Process}

Typically a house goes through the following design process:

- Conceptual Design Development. Planning Stage where the price range, square footage, number of stories, lot sizes, general features, and styles are determined.

- Preliminary Design Development. Develop floor plan sketches, number of bedrooms, major options, basic circulation, and function locations, as well as some elevation concepts.

- Design Development. Preliminary structural, mechanical, electrical, plumbing, and Compliance.

- Construction Documents Development. Final working drawings ready for bidding, submittal. Back-checking and coordination by consultants.

\section{- Construction and Commissioning.}

An Integrated Design Process (IDP) ensures that all the key players and design consultants, including the architect, planner, mechanical engineer, landscape architect, energy consultant and the site engineer, work together starting with the conceptual design stage, even though the role of each may be limited for a particular design stage. The IDP is a key aspect in achieving the systems-design approach.

An IDP approach may seem to be an expensive approach, but in the long run the overall costs and advantages significantly outweigh the traditional approach. For example, the mechanical engineer may be involved in the project much later and be asked to design the mechanical system with the already defined constraints of attic/plenum space - resulting in an inefficient HVAC distribution system.

By developing better IDP, builders can incorporate 30\% improvement level strategies more effectively with less disruption of their normal construction process and do so more cost effectively. While use of IDP at 30\% improvement level for builders is quite desirable, it will be even more important at higher energy performance levels of $40 \%, 50 \%$, and $70 \%$ energy savings. 
Approaches to an IDP will vary with different builders, as their relationships with design professionals, suppliers, and the trades are often different. For example, a builder with an inhouse architectural staff, that prepares all new house designs, may have a different level of control and continuity of design as compared to a builder that works with an independent architectural firm. Approaches to the IDP are evolving in Building America's programs, and a single, clearly defined process has not been established.

An example of this is the HVAC system. HVAC designers need to provide input as early as possible in the design process, giving feedback to the architect regarding architectural features and structural designs that cause comfort issues and are difficult or impossible to overcome with typical HVAC practices. They also need to make sure the architect allows adequate space to run ducts. Many architects have had to re-design plans enough times as a result of HVAC issues that they know fairly well how to accommodate HVAC items. Still many problems commonly arise that could be avoided through earlier input and better coordination.

To continue with our example, Table 5 shows the main trades and consultants who are affected by the HVAC system. The first column lists the item or issue and each subsequent column how each trade is affected by it.

As shown from the matrix, all trades are intertwined in the design and building process. This matrix could be easily applied to the builder, electrician, plumber, etc. As homes become more efficient, it will be critical that all involved in the system will need to coordinate their efforts to ensure quality control and to employ quality assurance tools and processes through the IDP.

One model of the information flows and actions associated with an integrated design process are shown in Figure 10. Some of the key activities of the integrated design process is setting a performance standard, identifying and integrating all systems in the house from the predesign stage through construction documentation, and having feedback loops in the design process from key participants in organization and trade base.

\section{Setting Performance Standards}

To implement an IDP process, the team needs to have a set of standards to which the building will be expected to achieve. The first step in setting a performance standard is to understand the customer base and what level of performance they are receptive to. Targeted customer and market-area surveys help to give as clear a picture as possible of the factors that motivate home sales in general and home purchasing patterns for the target market. This data is used to direct the design of new products and respond to market pressures. The ability to survey, synthesize, and extract meaning from customers and the market can provide a significant advantage to builders, in that they have a better understanding of market and can apply this knowledge to fulfill unmet needs. If the market is indicating a need for greater energy efficiency, durability, improved indoor air quality, or comfort, then the adoption of Building America performance packages may be appropriate as the standard.

Similarly, the builder must determine what level of quality and performance their housing will achieve. This may have to do with energy efficiency, moisture performance, comfort, increased durability, and reduced risk. All of these issues are typically addressed by following the recommendations included in this report. 
Table 5. Matrix of Trades

\begin{tabular}{|c|c|c|c|c|c|c|c|}
\hline Item & Architect & $\begin{array}{l}\text { Builder/Framer } \\
\text { IStructural } \\
\text { Engineer }\end{array}$ & $\begin{array}{l}\text { HVAC } \\
\text { Installer }\end{array}$ & $\begin{array}{l}\text { Energy } \\
\text { Consultant }\end{array}$ & Electrical & Plumber & $\begin{array}{l}\text { Drywall } \\
\text { or } \\
\text { insulation }\end{array}$ \\
\hline $\begin{array}{l}\text { FAU } \\
\text { location }\end{array}$ & $\begin{array}{l}\text { Roof pitch } \\
\text { furnace } \\
\text { closets, } \\
\text { clearance in } \\
\text { parage }\end{array}$ & $\begin{array}{l}\text { Truss design, } \\
\text { platform, } \\
\text { clearance, } \\
\text { closets, bollards, } \\
\text { atfic orogss } \\
\text { froming }\end{array}$ & $\begin{array}{l}\text { Type of FAY } \\
\text { fuptlow, } \\
\text { hocizontaly, } \\
\text { clearance, } \\
\text { timing of } \\
\text { instalfetion }\end{array}$ & $\begin{array}{l}\text { Modeling } \\
\text { correct } \\
\text { location of } \\
\text { ducts for } \\
\text { ompuputer } \\
\text { model }\end{array}$ & $\begin{array}{l}\text { Power, } \\
\text { service light, } \\
\text { control } \\
\text { wiring. etc. }\end{array}$ & $\begin{array}{l}\text { Condensate } \\
\text { lines, gas: } \\
\text { piping }\end{array}$ & $\begin{array}{l}\text { Insulation } \\
\text { under } \\
\text { platform } \\
\text { may be } \\
\text { different }\end{array}$ \\
\hline $\begin{array}{l}\text { Equipment } \\
\text { size, load } \\
\text { calculations }\end{array}$ & $\begin{array}{l}\text { Clearances, } \\
\text { \# of systems. } \\
\text { bulding } \\
\text { feratures }\end{array}$ & $\begin{array}{l}\text { Structural impacts } \\
\text { (weight) }\end{array}$ & $\begin{array}{l}\text { Materials, } \\
\text { labor, costs }\end{array}$ & $\begin{array}{l}\text { Energy } \\
\text { features } \\
\text { impact sizing }\end{array}$ & $\begin{array}{l}\text { Electrical } \\
\text { loads }\end{array}$ & & \\
\hline $\begin{array}{l}\text { Supply } \\
\text { register } \\
\text { locations }\end{array}$ & $\begin{array}{l}\text { Avesthetcs, } \\
\text { clearances }\end{array}$ & $\begin{array}{l}\text { Register boot } \\
\text { support }\end{array}$ & $\begin{array}{l}\text { Materials. } \\
\text { labor }\end{array}$ & & & & $\begin{array}{l}\text { Sealing } \\
\text { around } \\
\text { registers }\end{array}$ \\
\hline $\begin{array}{l}\text { Return grille } \\
\text { locations }\end{array}$ & $\begin{array}{l}\text { Avesthebcs, } \\
\text { noise issues }\end{array}$ & Framend openings & $\begin{array}{l}\text { Materials, } \\
\text { labor }\end{array}$ & & & & $\begin{array}{l}\text { Sealing } \\
\text { arcuund } \\
\text { grilies }\end{array}$ \\
\hline $\begin{array}{l}\text { Condenser } \\
\text { locations } \\
\text { and line set }\end{array}$ & $\begin{array}{l}\text { Avesthetics, } \\
\text { nouse issues }\end{array}$ & $\begin{array}{l}\text { Clearance, } \\
\text { accessibaity to } \\
\text { yard (set-back } \\
\text { issues). } 2 \text { xb̆ wolls, } \\
\text { chases }\end{array}$ & $\begin{array}{l}\text { Materials, } \\
\text { labor, } \\
\text { serviceability }\end{array}$ & & $\begin{array}{l}\text { Power, } \\
\text { service } \\
\text { disconnect }\end{array}$ & & \\
\hline Attic access & Ansthetict & $\begin{array}{l}\text { Framed opening. } \\
\text { anus5 issues }\end{array}$ & $\begin{array}{l}\text { Access,s, } \\
\text { serviceability }\end{array}$ & & & & \\
\hline $\begin{array}{l}\text { Routing } \mathrm{B} \text {. } \\
\text { vent }\end{array}$ & $\begin{array}{l}\text { Chases, } \\
\text { clearances, } \\
\text { eesthetics. } \\
\text { (con roof) }\end{array}$ & $\begin{array}{l}\text { Framed chases, } \\
\text { roof cap }\end{array}$ & $\begin{array}{l}\text { Materiels, } \\
\text { labor, } \\
\text { instaliation }\end{array}$ & & & $\begin{array}{l}\text { No contlicts } \\
\text { with vent }\end{array}$ & \\
\hline $\begin{array}{l}\text { Chases, } \\
\text { soffits, and } \\
\text { drops }\end{array}$ & $\begin{array}{l}\text { Avesthetics, } \\
\text { feasibility }\end{array}$ & $\begin{array}{l}\text { Framing, } \\
\text { clearances for } \\
\text { ducts, conflicts }\end{array}$ & $\begin{array}{l}\text { Materials, } \\
\text { labor, } \\
\text { instalfetion }\end{array}$ & & & $\begin{array}{l}\text { No contlicts } \\
\text { with ducts }\end{array}$ & \\
\hline $\begin{array}{l}\text { Thermostat } \\
\text { location }\end{array}$ & Avesthetics & & $\begin{array}{l}\text { Materials, } \\
\text { labor, } \\
\text { instaliation }\end{array}$ & & Wiring & & $\begin{array}{l}\text { Seal hole } \\
\text { for wires }\end{array}$ \\
\hline $\begin{array}{l}\text { Equipment } \\
\text { efficiency }\end{array}$ & & & Materials & $\begin{array}{l}\text { Efficiency } \\
\text { determined } \\
\text { by ennergy } \\
\text { consultant }\end{array}$ & & & \\
\hline $\begin{array}{l}\text { Combustion } \\
\text { air }\end{array}$ & $\begin{array}{l}\text { Allic wetil } \\
\text { calcs, routing } \\
\text { for CA ducts }\end{array}$ & 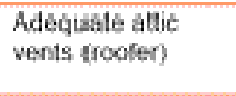 & Ducting, if any & & & & \\
\hline
\end{tabular}




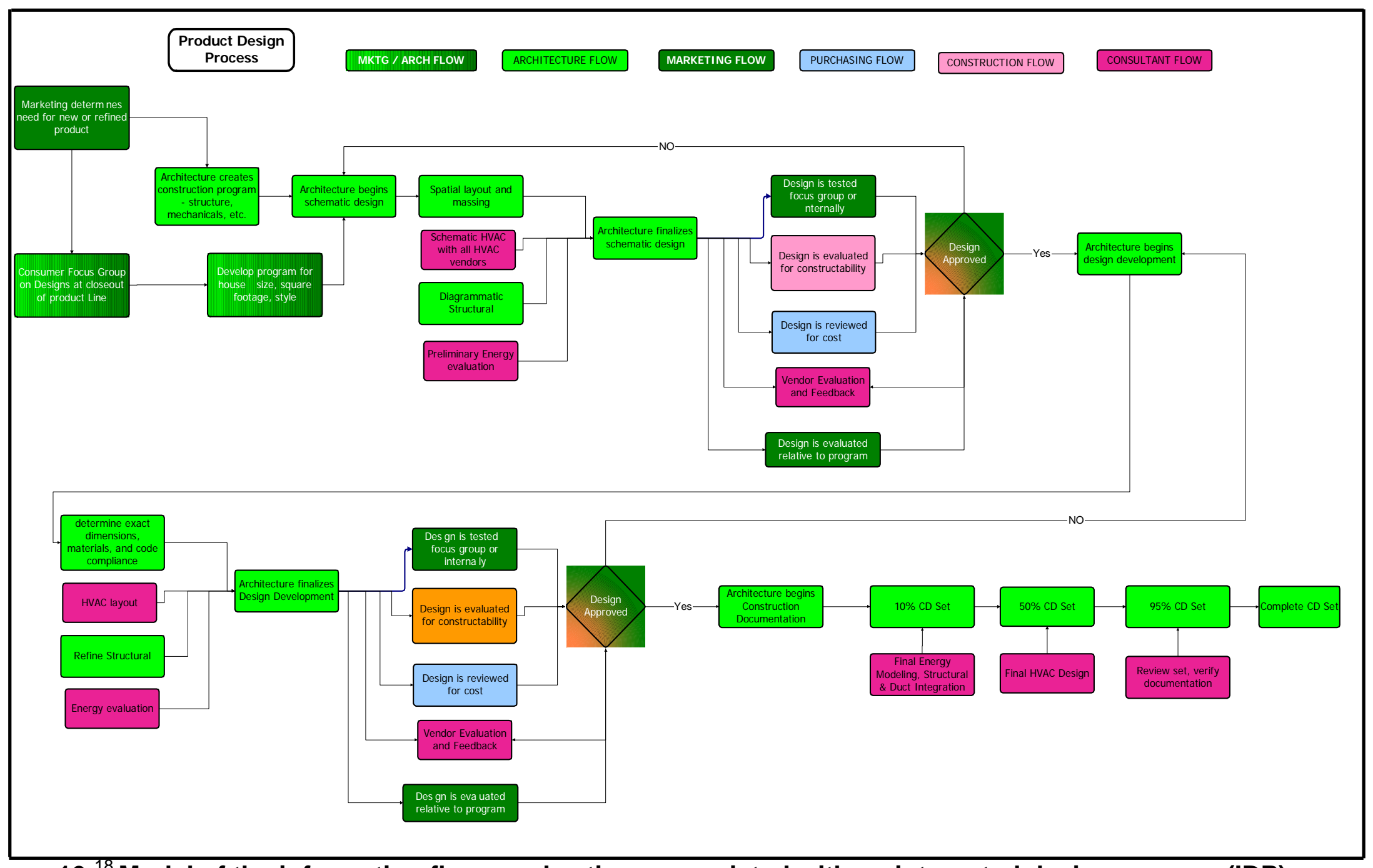

Figure $10 .{ }^{18}$ Model of the information flows and actions associated with an integrated design process (IDP)

\footnotetext{
${ }^{18}$ IBACOS, Inc. KAAX-3-33410-06 B.2, Community Scale Process Research Results. Pittsburgh: IBACOS. November 2004.
} 


\section{Set Goals Early in the Design Stage}

By creating specific high-performance goals early in the design process, the design and construction team and their external vendors all have a clear understanding of the intent and performance metrics associated with a product line. As designs are being developed, all systems and strategies are considered, and feedback is solicited. This allows for early identification of potential conflicts or opportunities for alternate solutions before designs are finalized.

The goal setting also demonstrates to vendors that the builder has committed to a level of performance, and all parties will need to play their role in seeing that it is achieved. A recognized best practice found by many of the Building America teams is a commitment to vendors to participate in long-term relationships, as opposed to simply forming relationships based on the lowest bid. This allows for mutual trust and respect to be built and the opportunity to improve and innovate is increased.

\section{Gain Team-Based Feedback during Design}

When asked about the most important design issue in its success in achieving higher performance levels, one participating builder identified framing as the area that they spend the most time on. The location of every stud, floor truss, and roof truss must be specifically located and coordinated with all other trades in order to make installation of other systems go smoothly and efficiently. This has been true throughout the Building America program. Builders may want to consider use of advanced CAD and panelization programs for generating a specific set of architectural and framing plans for each house type. It is important to work with the framing and HVAC contractors to identify conflicts and develop solutions before houses go into production.

A best practice by some builders participating in the Building America Program is to create a single system design that would be approved, installed, and warranted by any installing contractor. This can apply for many systems in the house, including but not limited to framing, electrical, plumbing, and HVAC. For example this level of up-front design with the HVAC system helps control consistency and allows for better performance through proper sizing and design. It is important to have proper load calculations, equipment selection, and duct layouts with documentation that is somewhat transparent, so that HVAC vendors can evaluate system design options and agree upon a final solution. At this point, design changes can also be made to floor plan and framing layouts that can facilitate duct installation. While there is never a perfect solution for all parties, this level of discussion between the vendors, design, and construction greatly enhances the opportunity to "get it right." This process can be applied for virtually any system in the house.

\section{Energy Analysis}

From a purely energy perspective, the section of this report entitled System Approach to Least-Cost Energy Savings describes the process involved with optimizing Building America Houses. It must be noted that energy cannot be evaluated in a vacuum, and other issues have to be considered in the design process. In order for higher levels of efficiency to be accepted by builders and consumers, other key attributes of the house must be addressed. The systemsdesign approach is a process by which all the various subsystems in the house are evaluated and their interrelationships are understood, planned, and optimized. All of these systems must 
be designed and applied to realize both energy-related and non-energy performance benefits associated with occupant health, safety, comfort and long-term building durability and efficiency. To only achieve energy efficiency without meeting these other criteria could cause consumer dissatisfaction and ultimately rejection of higher levels of energy efficiency, because the occupant's other expectations of a new house are not being met.

In a general sense, Building America houses include increased levels of thermal insulation, higher-performance windows, significant air sealing, a strategy that eliminates the possibility of introducing the by-products of combustion into the house, a mechanical ventilation system, a properly sized and engineered space-conditioning system, higher efficiency spaceconditioning and water-heating appliances, and may also include improvements in the efficiency of the appliances and lighting. The extent to which any of these strategies must be implemented varies by climate region and the level of energy performance the builder seeks to achieve. A systems-design approach helps assure that the energy-related aspects of the project are being satisfied in conjunction with the non-energy benefits and is done in a way that optimizes the synergies of the various systems in the house.

An important part of getting to the 30\% energy savings, or any other level of energy savings, is to be able to evaluate alternative combinations of energy features before homes are built. Energy-simulation software, also referred to as computer or simulation modeling tools, are used to estimate energy performance of buildings quickly and inexpensively long before anything is purchased or constructed. Builders can access the costs of the various combinations of energy features to determine the most cost effective way of achieving the desired energy savings level early in the design process.

Very often, energy savings of homes only refers to savings of heating and cooling energy, or heating, cooling, and water heating. It is important to note that in the $30 \%$ savings level referenced throughout this report and throughout the Building America Program, references are made to whole-house energy savings, including all the energy used in the home for heating, cooling, water heating, and all the appliances and miscellaneous electrical loads, often referred to as plug loads.

The other challenge in energy analyses is to be able to compare energy studies done from one person to another, in fact from company to company, across the country. For this purpose, the Building America program has developed a Benchmark, so that assumptions made in conducting energy analyses across the country can be standardized, enabling results to be fairly and reasonably compared.

The Benchmark guidelines are used to define a base-case house for determining levels of energy savings in conducting energy analyses. The Benchmark is generally consistent with mid-1990s standard practice, as reflected in the Home Energy Rating System (HERS) Technical Guidelines (RESNET 2002), with additional definitions that allow the analyst to evaluate all residential end-uses, an extension of the traditional HERS rating approach that focuses on space conditioning and water heating. A series of user profiles, intended to represent the behavior of a "standard" set of occupants, was created for use in conjunction with the Benchmark. 
Energy simulations are conducted using software such as Energy Gauge, Energy 10, DOE 2.2, TRNSYS and Micropas, to predict the yearly energy consumption in homes. ${ }^{19}$ Energy simulations are run for both the Benchmark, as well as the designed home. The design home consists of enhanced energy-efficient features and systems. The detailed energy-simulation results are used to compute the energy savings of the designed home compared to the Benchmark base case.

\section{Passive Design Strategies for Minimizing Cooling and Optimizing Heating}

To achieve a 30\% whole-house energy savings, it is not necessary to undertake any specific passive solar-design strategies. It should be recognized that proper orientation of the building and implementation of passive solar strategies can be a low or no-cost method to significantly improve the energy performance of a house.

Strategies for passive solar design are discussed in Appendix A. When considering passive solar design, one must evaluate the available solar resource. Monthly and annual solar resource maps are available from a variety of sources, including http://rredc.nrel.gov/solar/old_data/nsrdb/redbook/atlas/ (accessed 08-08-2006).

\section{Indoor Air Quality Strategies}

The Environmental Protection Agency ranks poor indoor air quality among the top five environmental risks to public health. Levels of air pollution inside the home can be 2 to 5 times higher (and occasionally 100 times higher) than outdoor levels. If too little outdoor air enters a home, pollutants can accumulate to levels that can pose health and comfort problems. Unless they are built with special mechanical means of ventilation, homes that are designed and constructed to minimize the amount of outdoor air entering the home may have a higher pollutant levels.

Providing good indoor air quality (IAQ) at the 30\% improvement level is important to maintain customer health and comfort and may minimize the possibility of high humidity levels and associated mold growth. Because 30\% houses will have higher levels of insulation (which affects envelope hygrothermal characteristics) and because they will be reasonably air tight (which will affect internal moisture gain and removal), good IAQ requires a more proactive approach. Good IAQ requires control of indoor moisture, $\mathrm{CO}_{2}, \mathrm{CO}, \mathrm{NO}_{2}, \mathrm{SO}_{2}$, ozone, particulates, dust-mite droppings, odors, and other hazardous airborne contaminants. There are several approaches to good IAQ: (1) control the generating source, (2) remove the contaminant from the indoor air by ventilation or air filtration; and/or (3) physical cleaning (vacuuming, dusting, etc.)

\section{Source Control}

Source control is the most positive approach in 30\% improved homes. A number of means of source control have been employed:

- Control entry of water and condensation. Control of moisture to remove one of the key support elements for mold growth. This is a broad subject and includes application of all of the following principles:

\footnotetext{
${ }^{19} \mathrm{DOE}$ 's list of energy simulation software can be found at www.eere.energy.gov/buildings/tools_directory/subjects_sub.cfm/pagename_menu=whole_building_analysis
} 
o Proper flashing details for windows, doors, wall/roof junctions, penetrations of all sorts (pipes, ducts, skylights, etc.), attachments (such as porches and decks), offsets and projections (such as bay windows) to control the entry of bulk water.

o Control of envelope condensation potential through appropriate insulation and vapor permeability of layers. Appropriate designs must be applied for all components of the building envelope, including walls, roof, and foundations. The section of this report entitled Envelope Systems discusses climate-specific assemblies. In addition, a builder may utilize other regionally specific guidelines, such as the Builders Guides (Lstiburek 2004). At a more detailed level, static analysis techniques or dynamic models such as WUFI $^{20}$ can be used. It should be noted that currently WUFI analysis will handle many wall and roof configurations, but it is not capable of foundation analysis. While ongoing research projects are adding to our knowledge of the hygrothermal performances of different forms of foundation insulation, following the practices outlined in the section of this report entitled Envelope Systems should result in good moisture performance.

o One wood-frame wall construction detail that has proven quite effective for condensation control is to use an exterior insulating sheathing in addition to the traditional cavity insulation. During the heating season, this helps to raise the temperature of the interior surface of the sheathing (the first condensing surface) above the indoor air dew point. During periods of hot, humid weather, it acts as a vapor retarder and helps prevent moisture from entering the wall, which reduces the potential for condensation on the backside of the interior gypsum board in air-conditioned homes. For specific design considerations of this wall assembly, see further detail in the section of this report entitled Building Enclosure Integration Strategies, Walls Section.

o Foundation waterproofing, damp-proofing, and capillary moisture control are important moisture-management actions taken at the 30\% improvement level. Failure to properly control moisture in crawlspace and full-basement constructions can result in high relative humidity in these spaces, which can lead to mold and mildew growth. Recommendations include the following:

- $\quad$ Exterior foundation waterproofing/damp-proofing with a drainage layer and footing drain, to intercept and drain off exterior water. The drainage layer is often an impervious plastic mat, fiberglass, or foam insulation board, or uniformly graded gravel. The insulation board offers the advantage of combining exterior foundation insulation (the most beneficial location for foundation insulation) with a good drainage material.

- $\quad$ After a large rainfall or after water has been applied for irrigating grass or plantings near the house, moisture can accumulate below and next to a footing. Moisture movement, by capillary action, can occur from this location through to the concrete footing and, from there, the moisture can be transferred into the slab or concrete or block foundation wall. Water stains on the perimeter of the slab or at the interior of the foundation wall can result and are not only

${ }^{20}$ WUFI 2D, Version 2.1. Simulation of heat and moisture transfer. September 2000. 
unsightly, but they also offer an environment for mold growth to occur. This moisture pathway may be controlled by forming a continuous capillary break between the ground and the concrete foundation system. With monolithic slabon-grade construction, polyethylene sheeting should be placed under the entire slab and footing up to grade. With footings poured independent of slabs or with foundation walls, a bituminous damp-proof coating, masonry capillary-break paint, or a layer of poly can be used to isolate the footing from the remainder of the assembly.

- Air-seal the building envelope. Air-leakage control is another key method of reducing IAQ pollution sources. Air leaking in from the outdoors may carry outdoor air pollutants (including vehicle exhaust and plant pollens) into the house, but outdoor air is typically (though not always) considered a fresh air source. What outdoor air does bring, in hot humid weather, is moisture that can condense on internal building components that may then support mold growth. In winter, air leakage outward through the building envelope can bring relatively moist indoor air into contact with cold surfaces. Building envelope air sealing (in addition to reducing energy consumption) is valuable to reduce moist-air migration that could lead to mold growth under both summer or winter conditions and reduce occupant exposure to outdoor pollutants.

Sealing against air leakage is primarily for thermal reasons, but when coupled with appropriate mechanical ventilation, this procedure also assists in providing good IAQ for the occupant. Extensive air sealing is one of the primary 30\% improvement strategies. It includes a range of recommendations to builders, including the following:

o Develop a continuous air barrier with interior gypsum board on walls and ceilings, giving attention to sealing at edges and joints, around penetrations and electrical boxes (including ceiling recessed downlights). Particularly important is to get sheathing continuity behind bathtubs and showers, at fireplaces, soffits, stairways, and at the band joist.

o Develop an air barrier with exterior sheathing using taped and caulked joints.

o Use foam seal (non-expansive) around window and doorframes.

o Construct well-sealed attic access hatches.

o Take particular care to seal all contact surfaces between attached garages and the occupied house. This must include sealing at all penetrations and the provision of gasketed, self-closing doors between garage and house.

- Seal forced-air distribution systems. Leaky duct systems contribute to poor IAQ in several ways. Leaky ducts can cause pressure imbalances, which can draw air from the outdoors, building cavities, or attached garage spaces. In addition, pressure imbalances can move moisture laden air into building cavities where the water vapor can condense, causing a habitat for mold and mildew. Specific strategies and techniques associated with the proper design and construction of air distribution systems can be found elsewhere in this report. 
- Control of radon and other soil gasses. The principal method of controlling the entry of these gases into a house is through the use of under-slab ventilation. House pressurization can be effective for this purpose as well, but is difficult to implement and control with current HVAC technologies. Under-slab ventilation typically takes the form of modest depth of uniformly graded crushed stone (i.e., with good void spaces) 4 in. to 8 in. deep, in which is embedded an array of perforated plastic drainpipe and covered with a poly air/vapor barrier. The piping is linked by a header, to which is connected a vertical vent pipe leading up through the house and out at the roof. This system is often installed as a precaution even when no evidence of radon has been shown, as it is far easier to do this than to come back later and retrofit an under-slab venting system. Usually, the vent goes through the roof and functions as a passive vent. It is designed, however, for the subsequent installation of an exhaust fan should the need for a more positive ventilating action be demonstrated. An electrical outlet for a possible future fan installation is located in the attic or basement adjacent to the vent pipe. Further information on sub-slab ventilation systems can be found in the EPA's Model Standards And Techniques For Control of Radon in New Residential Buildings ${ }^{21}$

- Combustion Safety. To avoid the possibility of the introduction of the by-products of combustion being brought into the house, several components associated with combustion safety must be addressed in the 30\% improved house. Because these houses are generally quite air tight, natural-draft appliances are not recommended. The basic recommendations are as follows:

o Furnaces. Use sealed-combustion units or draft-induced units with dedicated make-up air that do not allow combustion by-products into the house itself.

o Tank or Tankless Domestic Hot Water (DHW) Heaters. Use sealed-combustion, direct-vent, or power-vented types that do not allow combustion by-products into the house.

o Fireplaces. If fireplaces are installed (gas-fired or solid-fuel-burning) are installed, use units that directly vent the by-products of combustion to the outdoors, are equipped with tight-fitting glass doors, and preferably use outside air for combustion.

o Gas Appliances. Eliminate unvented gas appliances, except cooking appliance, which should be vented to the outdoors by a ducted-range hood.

- Finishes. Finishes such as paints, sealers, adhesives, fabrics, and surface-covering roll goods (i.e., vinyl wall coverings) are all potential sources of indoor air pollutants, including various volatile organic compounds (VOCs). Most of the liquid-applied materials dissipate potential pollutants rather rapidly as they dry. Leaving windows open as they are applied and dry removes the high initial concentrations. After this initial "dryout" period, a properly designed ventilation system will continue to bring in fresh air and remove further off-gassing of pollutants. Thus, for any but highly sensitive occupants, the selection of special, low-VOC, materials and finishes is not seen as necessary to achieve the $30 \%$ whole-house energy-savings level. Should a homeowner have IAQ sensitivity

\footnotetext{
${ }^{21}$ Environmental Protection Agency. Model Standards and Techniques for Control of Radon in New Residential Buildings. Environmental Protection Agency Website. www.epa.gov/radon/pubs/newconst.html.
} 
needs, then the application of the American Lung Association (ALA) Health House Specifications $^{22}$ or specifications to meet the EPA's Indoor Air Package ${ }^{23}$ would be appropriate.

- Relative Humidity Control. The control of indoor relative humidity (RH) is another key strategy to maintain good IAQ. It is recommended that internal RH be maintained below $60 \%$ during periods with high dew points to minimize the potential for condensation and growth of mold and mildew. Ventilation strategies play a key role in maintaining these ranges and are discussed more fully in the ventilation section of this report. However, a variety of ventilation forms, including heat-recovery ventilators (HRVs) or energy recovery ventilation (ERVs), may reduce excess humidity through increased air exchange in the winter and ERVs, dehumidifying ventilators, dedicated dehumidifiers, and advanced HVAC control systems are used to control excess humidity in the summer. The importance of winter or summer humidity control, of course, varies with climate region.

\section{Pollutant Removal and/or Dilution}

Ventilation and air cleaning are the principle methods of airborne pollutant removal or dilution. Ventilation system design and strategies are treated more fully in another section of this report, but key features relative to good IAQ in 30\% improvement houses will be noted here.

- Whole-house mechanical ventilation is recommended. Any of a number of system configurations can meet this requirement and include the following:

o Passive inlet direct to the return-air duct with appropriate dampers and controls. In northern parts of the Mixed-Humid climate region, total volume of air through the passive inlet may need to be limited to keep return air temperatures above manufacturers' lower limits. The balance of ventilation air can be introduced using low sone, energy efficient exhaust fans rated for continuous operation.

o Dedicated supply fans designed for continuous operation are appropriate in the southern part of the Mixed-Humid climate region.

o Dedicated exhaust fans designed for continuous operation are appropriate in the northern part of the Mixed-Humid climate region. It is recommended that some form of whole house air mixing be used with this strategy to ensure appropriate distribution of ventilation air throughout the house.

o HRVs or ERVs

o Dedicated central dehumidifier with ventilation.

- Whole-house ventilation air should be distributed to all the primary occupied spaces in the house, particularly bedroom and living areas either through direct distribution or by mixing or air to maintain uniform conditions within the home. This is typically accomplished by ducting ventilation air into the heating/cooling duct system. For this

\footnotetext{
${ }^{22}$ American Lung Association. Builder Guidelines. American Lung Association ${ }^{\circledR}$ (ALA) Health House ${ }^{\circledR}$. www.healthhouse.org/build/Guidelines.asp October 1, 2004.

${ }^{23}$ Environmental Protection Agency. Indoor Air Package label. Environmental Protection Agency Website. www.energystar.gov/index.cfm?c=bldrs_lenders_raters.nh_iap.
} 
distribution to be continually effective, however, the HVAC system must be periodically cycled, even in periods when no heating or cooling is required. Dedicated ventilation distribution ductwork is occasionally used, particularly if no forced-air system exists, but it is a more costly option. Fresh-air intakes should be provided with nominal filtration to prevent the entry of insects and large particulates.

- For good IAQ, the HVAC return air stream should be filtered with a 4-in. standard filter or a new Minimum Efficiency Reporting Values (MERV) ${ }^{24}$ of 6 or 8 normal-thickness filters. Ventilation air should also pass through this filter, if possible. Filters should be easily accessible for cleaning or replacement and the filter slot should be designed so that there is no air bypass around the filter when the HVAC system is operating.

- It is important to provide local exhaust fans for bathrooms, range hoods in the kitchen, and exhaust fans in other areas where pollutants may be generated (utility, hobby rooms, etc.). All of these fans must be ducted to outdoors via the most direct path.

- Ventilation technology has developed significantly in recent years, but a few areas remain problematic:

o It is difficult to find low-airflow ventilation units, particularly HRVs and ERVs.

o Design of distribution systems is a challenge. Using HVAC ductwork requires cycling the central fan, which increases the electric consumption. Dedicated ventilation ductwork is quite small and must be well designed to function properly. The ventilation air from a dedicated ventilation fan (i.e., ERV, HRV) may not be fully distributed to all rooms when only the ventilation airflow is being moved through the larger ducts of the central space-conditioning system.

o Builders do not like the additional cost of installing a ventilation system and often have a difficult time explaining why it is needed to the consumer.

o Ventilation controls are often difficult to integrate with the HVAC system because the products are not usually designed for integration. A newer generation of integrated ventilation and space-conditioning controls are beginning to be introduced by major manufacturers, and it is anticipated that this trend will continue in the future with more options becoming available to builders.

- Ventilation should be accomplished in the most energy-efficient manner, balancing fan energy consumption with the cost of conditioning the ventilation air.

\section{Physical Cleaning}

Builders have very little control over occupant behavior and, as such, there are limited strategies a builder can incorporate in this area. One primary opportunity is in the installation of a whole-house vacuum system that exhausts to the outdoor, which limits the reintroduction of dust in the house. Another is the inclusion of a discussion of maintaining good indoor air quality in an owner's manual for the house, including cleaning practices as they relate to indoor air quality.

\footnotetext{
${ }^{24}$ See www.filters-for-home.com/merv.htm for MERV definitions.
} 


\section{Heating and Cooling Equipment and Distribution Strategies}

For the 30\% improvement house and all new home construction, it is highly recommended that the heating and cooling system be designed according to industry standard methodologies, most notably ACCA Manual J (ACCA 2003), S (ACCA 1995a), D (ACCA 1995b), and T (ACCA 1993). With the use of low-SHGC glass, it is practical to design each house model of a builder's line for the worst orientation without significant penalty in other orientation. The use of low-SHGC glazing reduces the solar component of the cooling load and helps to level the cooling load and minimize variations resulting from orientation. Whenever practical, the design should be specific to an individual house and its orientation. System implications based on variations with orientation are a result of the different solar loads and, for system design purposes, do not affect heating loads. The impact is primarily on the cooling system design as a result of solar load through windows.

\section{Heating and Cooling Equipment}

The preference is for a single heating/cooling unit to serve the entire house, frequently utilizing a zoning system with multiple fan speeds and variable output. This is an efficient approach and allows the closest tailoring of unit size to peak and part-load conditions. In some cases, especially homes of more than $2,500 \mathrm{ft}^{2}$, two or more units may be needed to meet the load or to serve distinct zones in the house. With the better thermal envelope of the $30 \%$ improved house, a single HVAC unit may often be feasible where two were used before. A single HVAC unit with zoning dampers and controls is also better able to adapt to major load differences. It is strongly recommended that the air-handler unit be located within the conditioned space of the house. When located in unconditioned space, as in vented attic or garage locations, the units are exposed to full winter and summer temperature conditions and experience major thermal losses, because HVAC units are poorly insulated and have significant air leakage.

More detailed discussion of heating and cooling equipment selections are given in the section of this report entitled Space Conditioning and Ventilation. In the 30\% improvement house, when natural gas or propane is chosen for heating, the recommendation is to use a sealedcombustion furnace or draft-induced unit with dedicated make-up air so that the combustion process is atmospherically decoupled from the house itself and located in conditioned space, for efficiency and combustion safety reasons.

In the Mixed-Humid climate region, a high-efficiency electric heat pump may also be an effective choice for heating, although, because of the source energy conversion, a Heating Season Performance Factor (HSPF) of approximately 9.7 is necessary to match the source energy efficiency of a 92\% AFUE furnace. In the most southern edge of the Mixed-Humid climate (Atlanta or Dallas for instance), if the thermal envelope of the house has been significantly improved, the heating load may be dramatically reduced. However, the cost effectiveness of a gas furnace and all the associated piping and utility infrastructure costs need to be weighed against the potential increase in source energy consumption associated with using a heat pump with a HSPF lower than 9.7.

It should also be noted that there is a wide range of cooling requirements in the Mixed-Humid climate region, and the SEER rating should be evaluated based on annual hours of operation. In general, the greater the cooling need, the higher the SEER rating should be. From a design 
standpoint, if the architecture of the home incorporates passive strategies for cooling-load reduction (such as shaded south-, west-, and east-facing glass, minimized unshaded westfacing glass, or a design that incorporates low-SHGC glazing and a small number of windows) cooling system run hours can be reduced, smaller capacity equipment will be appropriate, and SEER ratings as low as 13 may give reasonable performance. In this climate region, designers should also recognize that because of the relatively high humidity levels and moderate temperatures for much of the year, supplemental dehumidification may be necessary. Designers also need to check the mean coincident wet-bulb temperature at outdoor design conditions and select equipment based on this. This strategy helps to prevent oversizing of the equipment. Builders may also want to consider air conditioning equipment with variable speed fans and control strategies that enable higher levels of latent removal at low speeds, however this is only effective when cooling is also needed.

\section{Air Distribution Systems}

To achieve a 30\% whole-house energy reduction, a number of requirements apply to design of the duct system:

- Design should be in accordance with ACCA Manual D.

- Ductwork should be located within the thermal envelope of the house; in some climate regions they may be buried in attic insulation, but in the Mixed-Humid climate region this is not a recommended practice without careful consideration for the possibility of condensation on the ducts.

- Ducts should not be located in exterior walls.

- Ducts must be air-sealed using UL 181-approved mastic or equivalent for the particular duct type

- "Panning” between joists and the use of stud cavities for supply or return air is not recommended.

- Ducts may be of galvanized sheet metal, duct board, or flex duct.

- There must be continuity of the vapor barrier on insulated ducts not running inside conditioned spaces.

Sometimes duct systems need to run in unconditioned spaces. For a discussion of the treatment of these ducts, see the section entitled Space Conditioning and Ventilation Systems.

To accommodate heating and cooling units and duct systems within the thermal envelope of the house, a number of techniques may be employed. This typically affects the architectural design of the house and should be considered at the early schematic phase of design. Keeping ducts inside the conditioned space may also involve framing systems that allow ducts to be run through it, such as an open-web floor-truss system. Alternately, dropped soffits, tray ceilings, and lower ceiling heights in "service" function rooms like baths, hallways, and closets can accommodate ducts inside the envelope. Strategies include the following:

- Locate ducts within an insulated, non-vented, conditioned crawl space or basement

- Locate within an insulated "cathedralized” attic

- Locate in open-web floor trusses 
- Develop chase walls to accommodate duct risers

- Design closets inside the conditioned space for locating the air handler in houses using slab-on-grade construction.

More specific discussion of many of these recommendations is found in the Section entitled Space Conditioning and Ventilation Systems.

Where a boiler or water heater is used for hydronic space heating, a radiant floor or baseboard convection distribution system is necessary. These are particularly suited to mixed-humidclimate applications where there may not be a need for air conditioning and the associated duct-distribution system. If a radiant floor system is selected in a slab-on-grade installation, it is required that the slab be insulated from the ground and at the slab edge with at least R-10 (2-in.) of rigid insulation. Slab edges need to be insulated because they are exposed to cold exterior conditions. If a boiler or water heater serves a fan coil and ducted system, all recommendations for ducts noted above apply. Hydronic systems are described in more detail in the section of this report entitled Space Conditioning and Ventilation Systems.

\section{First Costs and Cost Tradeoffs}

Useful and representative costs information for 30\% improvements has not been easy to determine. In many cases, these are pilot homes and are the first of this level of energy performance that have been done by a builder. Thus, the energy-use-reduction construction strategies are new to the builder and costs do not represent a mature purchasing structure or experienced installation practices. Furthermore, there are often compensating or beneficial attributes of the improvement strategies that are not realized until multiple houses are built. An example is the ease of air sealing that is inherent with spray-foam insulation systems that replace tedious hand-caulk and foam-gun sealing done by laborers. Until a builder experiences the change, it is usually not valued.

Some of the common cost tradeoffs that builders in the Building America program have used include the following:

- Reduced costs associated with advanced framing

- Reduced costs associated with downsizing space-conditioning equipment and simplifying air-distribution systems

- Increased costs for higher performance windows and insulation and air-sealing packages, that enable the reduction in HVAC system size

- Substituting insulating sheathing for structural-panel sheathing increases wall-insulation levels at low or no incremental cost

- Increased cost of installing mechanical ventilation

- More usable floor space in slab-on-grade construction through the use of tankless water heaters instead of tank type water.

Builders who commit to evolving their organizations to the consistent production of quality high-performance homes face a transition period. Figure 11 illustrates how the organization will typically change through phases and the corresponding change in first costs. 


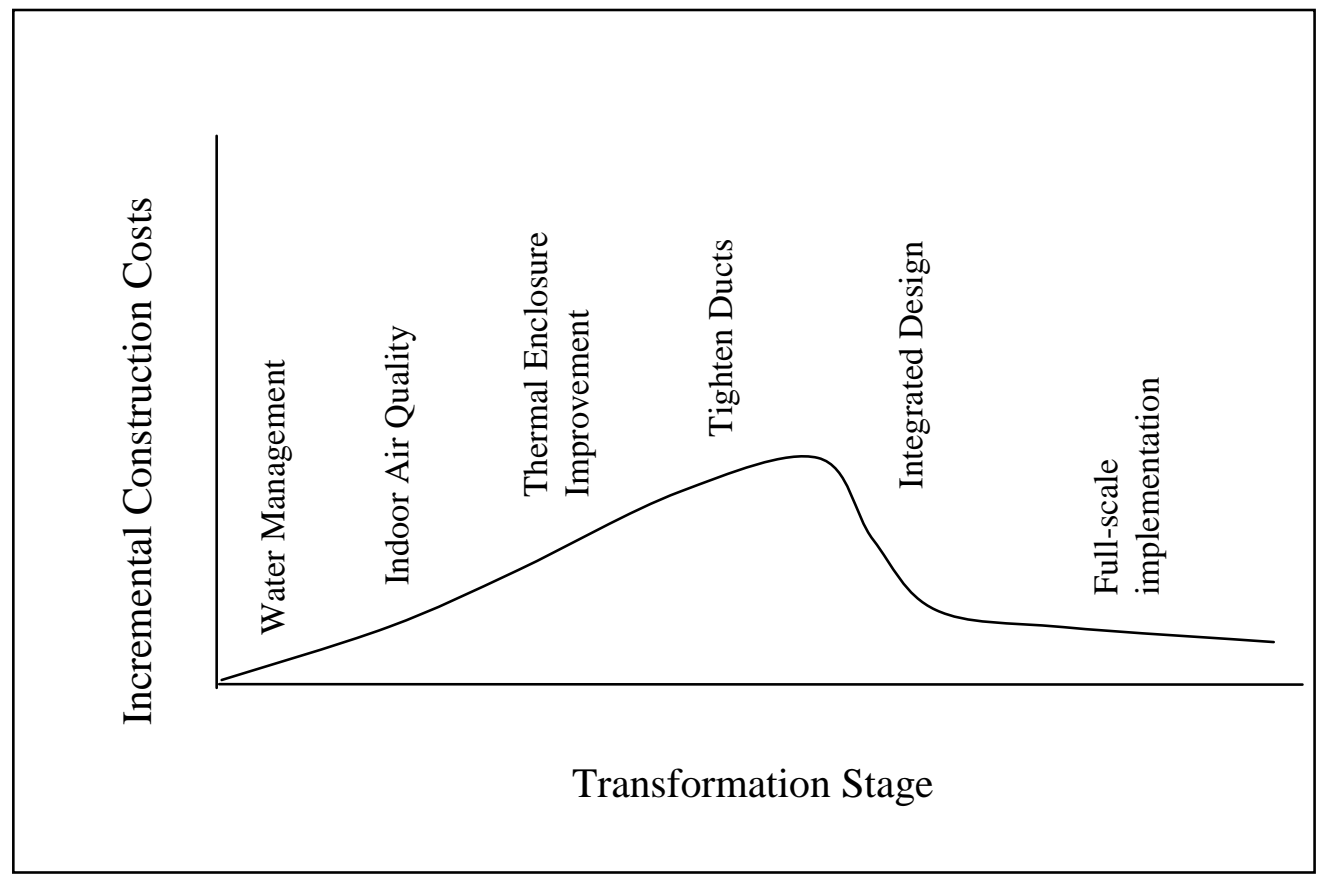

\section{Figure 11. Incremental Cost versus Transformation Stage curve}

The transition strategy outlined here provides a logical progression to higher-performance housing, but builders need to be prepared to make an investment in other costs associated with implementing a high-performance package, including staff and vendor training, product redesign, collateral development, and testing. Each of these issues will be discussed and suggestions made as to best practices in order to minimize costs.

If the steps taken to transform a company are followed, a builder will have a transitional period where higher costs will be incurred. It is only at the last step, where integrated designs are developed, that a builder can realize immediate construction cost savings. If the total operational costs of running a homebuilding business are considered, potential cost savings should begin to accrue from the first step.

The improvements to the indoor air quality, thermal enclosure, and duct sealing will all require additional expense. It is, therefore, important to successfully integrate these strategies as quickly as possible. This is where relationships with vendors are critical. Builders must be willing to support the trades during the transition; however, trades must take some level of responsibility for adapting and developing cost-effective solutions for delivering improved performance cost effectively. Examples of this include rethinking duct installations to allow for prefabrication and sealing of major components or panelization of structural systems to speed erection, cut cycle time, and reduce costs. In addition, vendors must have continuingeducation costs built into their overhead structure.

It should be noted that this curve is diagrammatic by nature and will vary from builder to builder and by region. For example, if a builder has already addressed water management, then there is no expected incremental cost associated with this practice. Also note that the tail end of the curve still shows some increase in costs. This represents the most conservative scenario, where a builder has already optimized many aspects of their houses (i.e., integrated 
advanced framing or does not significantly oversize HVAC equipment). For the consumer, this added cost is offset by reduction in utility bills and, as discussed in the section of this report entitled Systems Approach to Least Cost Energy Savings, should prove to be net cost neutral or even put the consumer at a net positive monthly cash flow.

To achieve the goals of a high-performance home transformation, builders and vendors must embark on a training program that engages all levels of the companies. Training must be provided for different levels of employees within the company and for the different departments within the company.

The integrated design process comes with some inherent additional costs, especially if the builder takes responsibility for HVAC system design, as opposed to having the vendors do a "design build" system. The advantages of the builder doing the design are that a greater level of consistency can be achieved, and documentation exists for site supervisors to readily check work. It does involve additional costs, either through contracting with outside designers or by training and utilizing internal resources to cover systems integration, including HVAC, framing integration, and detailing. In addition, the cost of re-bidding work involves time and expense on the part of the builder's purchasing department, the trades, and their suppliers. For this reason, it is best that as a builder transitions to a high-performance approach, they do it as part of their ongoing product-redesign process, where many of these activities are already budgeted for. Unfortunately, this can lead to a disparity in the builder' marketing approach because some product may meet the new standards and others may not during the transition period. Builders must evaluate the volume they are building, the number of plan types, the current redesign cycle, and the uniformity of marketing message they wish to project when doing this cost-benefit analysis.

During the transformation, builders will need to be measuring how well they are doing compared to the performance goals they set. This measuring requires undertaking some level of performance testing. Typically, this performance testing will be $100 \%$ during the initial steps in order to gain insight into the effectiveness of various practices and techniques being used in the field. As vendors become adept at achieving performance targets, some builders have chosen to decrease testing activities, while others have chosen to maintain $100 \%$ testing as a quality-control measure. In either case, performance testing is a cost that needs to be budgeted for.

Some cost data have been developed from recent Building America 30\% improvement level projects. The extent of improvement work varies considerably depending on the thermal performance quality of a builder's basic model. These costs are also generally not representative of mature costs and, in some instances, are reduced because materials have been donated by manufacturers.

Table 6 is one example of the incremental costs associated with achieving 39\% energy savings in houses for one community in Sacramento, California. The case study for this project, Premier Gardens, can be found in the report for the 30\% Hot-Dry/Mixed-Dry climate region (Baechler et al. 2005).

The cost of the energy efficiency improvements less the cost of the photovoltaic system is $\$ 3,355$, and the monthly and annual utility savings are $\$ 38$ and $\$ 453$, respectively. The simple payback for these homes will be 7.41 years, or more than $\$ 34$ per month in positive cash flow if the homes are financed with 30 -year mortgages at $7 \%$ interest. 
Table 6. Illustrative Incremental Costs of a 39\% Energy-Saving House in Sacramento, California

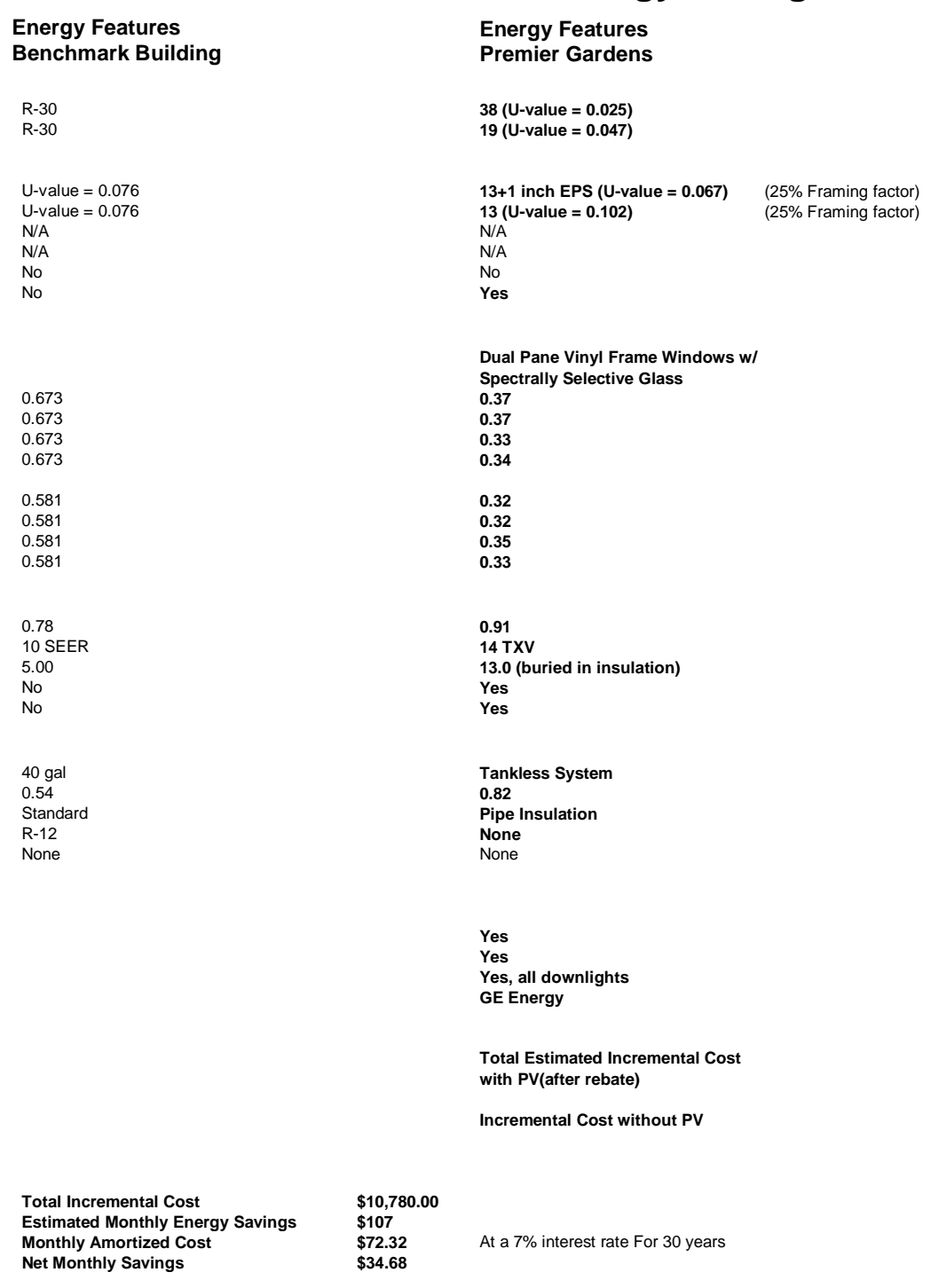




\section{Water Management}

Many warranty issues are associated with water intrusion; therefore, a solid water-management plan can reduce future costs, limiting the reserves builders need to put aside for future claims. Analysis of past history of water damage issues, both short-term and long-term, can help quantify the per-house costs associated with the "status quo" versus an improved watermanagement strategy. This issue is more fully discussed in the section entitled Building Component Design Details.

\section{Reducing Construction Waste}

Research conducted by the National Association of Home Builders (NAHB) and the NAHB Research Center shows that $87.7 \%$ of the 1.7 million homes built in the United States in 1999 were stick-framed, that a "typical” home consumes just over 13,100 board feet of framing lumber (about three-quarters of an acre of forest) and that the wood scrap pile for the construction of this "typical” home is approximately 2 tons.

A combination of factors has worked to increase the consumption of wood in home building:

1. Single-family detached units. Realizing the American dream of owning one's own home uses more wood per household than multi-family housing. According to NAHB, single-family detached units went from about $71 \%$ of overall housing starts to nearly 80\% just between 1978 and 2001.

2. Home size. In the last 40 years, the median new home size in the United States has increased from 1,365 square feet to well over 2,000 square feet, this despite the fact that household size has actually decreased by $20 \%$.

3. Complexity. Not many of today's homes are simple in form. Jogs, dormers, vaulted ceilings, convoluted roof lines, and elaborate staircases abound.

4. Safety standards. We require more of our structures today, particularly in regions with seismic and wind considerations. Re-engineering for these loads has resulted in some increase in wood use requirements, but has also spawned site practices that simply "throw more wood" at the problem.

5. Lumber versus labor. Just as the relative value of materials versus labor seems to have reversed (today, materials are "cheap" - it's the labor that is “dear”), the typical skills set of both designers and framers has diminished, leading to waste at the front and tail ends of wood construction.

6. The nature and structure of the industry. Home building is like no other production process in the 21st century. Nearly all of the 1.7 million homes built each year are sitebuilt, making home building one of the most fragmented of United States industries. It is journeymen framers - not architects, engineers or even general contractors-who control what and how much wood goes where on the job site. And most training occurs informally, by word-of-mouth, during production. 


\section{Two-Foot Module Design}

Starting with foundation layout, the house footprint should be based on 2-ft increments, often with significant savings in both framing members and sheathing and always with a lot less waste. Sheet goods come in $4 \mathrm{ft}$ by $8 \mathrm{ft}$ dimensions. Layouts should be based on the fundamental unit dimensions of the materials used. Work by the NAHB Research Center found that the wood savings are dependent on the starting dimension. The use of a 2-ft grid is illustrated in Figure 12 for a simple rectangular floor plan.

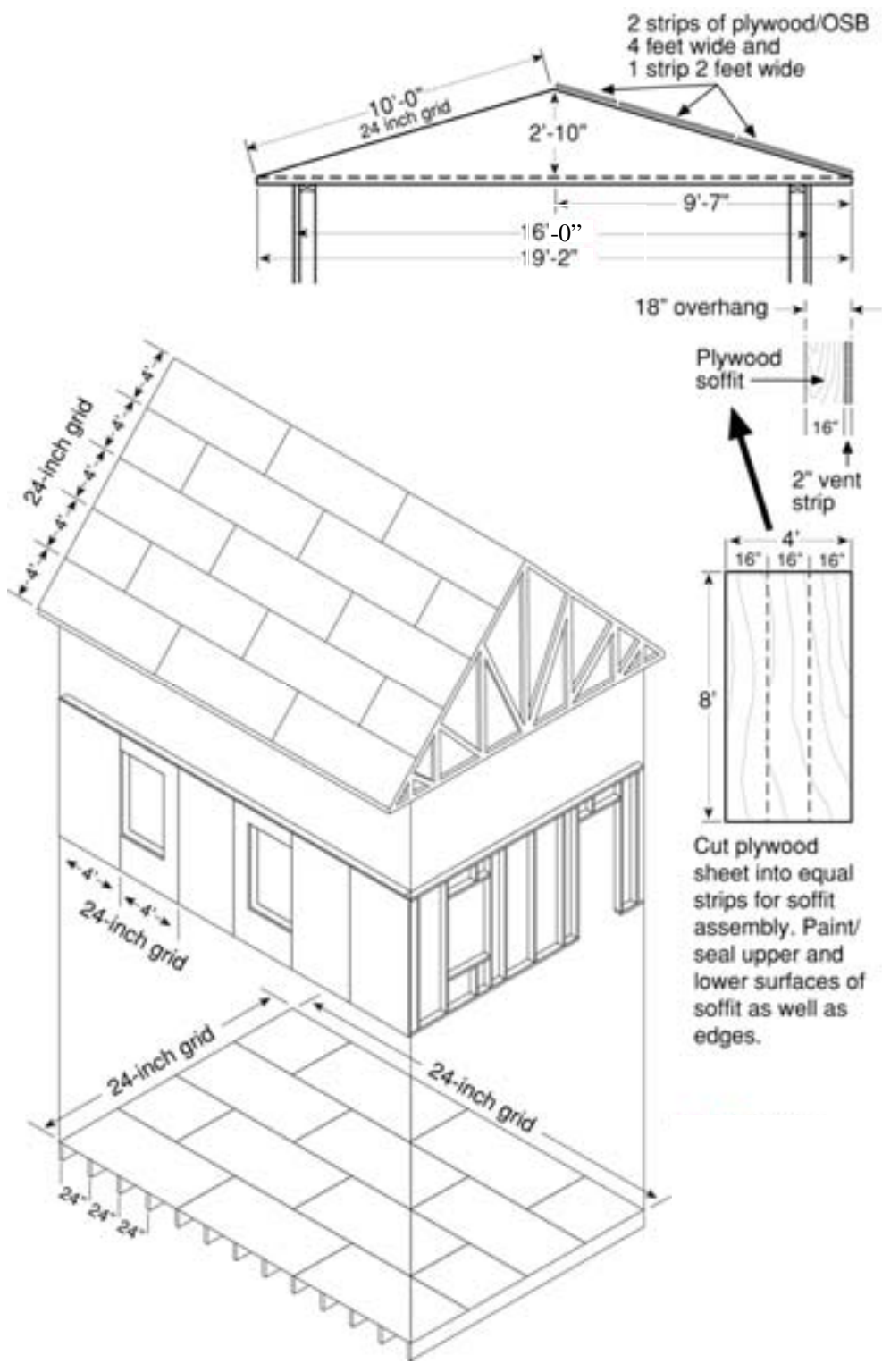

Figure 12. Two-foot modular approach to framing (drawing courtesy of BSC) 
It is most important that 2-ft increments be maintained for the exterior dimensions to the extent possible, including exterior sheathing, ceiling, and foundation perimeters. As a result, the drywall dimensions will necessarily be slightly less than the 2-ft increments, and the spacing of certain studs and floor joists at edges and corners will be less than 24 in. A more complete discussion of the 2-foot modular design approach can be found in the Building Science Corporation (BSC) report entitled "Using Wood Efficiently: From Optimizing Design to Minimizing the Dumpster.” (Baczek et al 2002).

\section{Value Engineered or "Advanced" Framing}

There are a number of substantial advantages to optimized framing: it saves time and money up front, it improves homebuyer satisfaction, it saves money and energy over the long term, and it improves builder image.

More than 7,000 homes built by Building Science Consortium production builders have used advanced framing. The resultant savings in waste are the products of "systems-thinking" and a breakdown of age-old myths about how wood framing works.

The following sections are descriptions of the major optimized framing techniques, with appropriate references from the International Residential Code ${ }^{\circledR}$, cited in brackets.

- Frame 24 in. on center. The prevailing practice among California builders is to frame walls, floors, and often roofs at 16-in. centers. However, 24-in. centers are structurally adequate for most residential applications. Even when the stud size must be increased from $2 \times 4$ to $2 \times 6$, changing spacing from 16 to 24 in. can reduce framing lumber needs significantly. [Table R602.3(5).] See Figure 12 for an example.

- Align framing members and use a single top plate. Double top plates are used principally to distribute loads from framing members that are not aligned above studs and joists. By aligning framing members vertically throughout the structure, the second plate can be eliminated. Plate sections are cleated together using flat plate connectors. For multistory homes that are framed with $2 x 4$ s, this may increase the stud size on lower floors to $2 x 6$; however, there is still typically a net decrease in lumber used. This "stack-framing" approach is illustrated in Figure 13. [Section R602.3.2. A single top plate is listed as an acceptable option for in-line framing and with properly tied joints.]

- Size headers for actual loading conditions. Headers are often oversized for the structural work that they do. Doubled-up 2x6 (or 4x6) headers end up in non-load-bearing walls. Doubled-up 2x12 (or 4x12) headers end up in all load-bearing walls, regardless of specific loading conditions. "Load-tuned" headers should be in the vocabulary and practice of all engineers, architects, builders and framers. [Section R602.7.2. This section states that nonbearing walls do not need structural headers.]

- Ladder-block exterior wall intersections. Where interior partitions intersect exterior walls, three-stud "partition post” or stud-block-stud configurations are typically inserted. Except where expressly engineered, these are unnecessary. Partitions can be nailed either directly to a single exterior wall stud or to flat blocks inserted between studs. This technique is called "ladder blocking” or "ladder framing." This also creates room for more insulation. 
- Use two-stud instead of three-stud corners. Exterior wall corners are typically framed with three studs. The third stud generally only provides a nailing edge for interior gypsum board and can be eliminated. Drywall clips, a 1x nailer strip or a recycled plastic nailing strip can be used instead. Using drywall clips also reduces opportunities for drywall cracking and nail popping, frequent causes of builder callbacks. Alternative designs for two-stud corners are illustrated in Figure 14. [Figure R602.3(2) shows let-in 1x4 bracing in place of sheathing and has a note at the bottom of the page for two-stud corners and drywall clips. The figure also shows “optimized” cripples (on spacing pattern, with no sill support cripples at the jack studs).]

- Eliminate redundant floor joists. Double floor joists are often installed unnecessarily below non-load-bearing partitions. Nailing directly to the subfloor provides adequate attachment and support. Partitions parallel to overhead floor or roof framing can be attached to 2x3 or 2x4 flat blocking.

- Use 2x3s for partitions. Interior, non-load-bearing partition walls can be framed with 2x3s at 24 in. on-center or 2x4 "flat studs" at 16 in. on-center [Section R602.5]. 


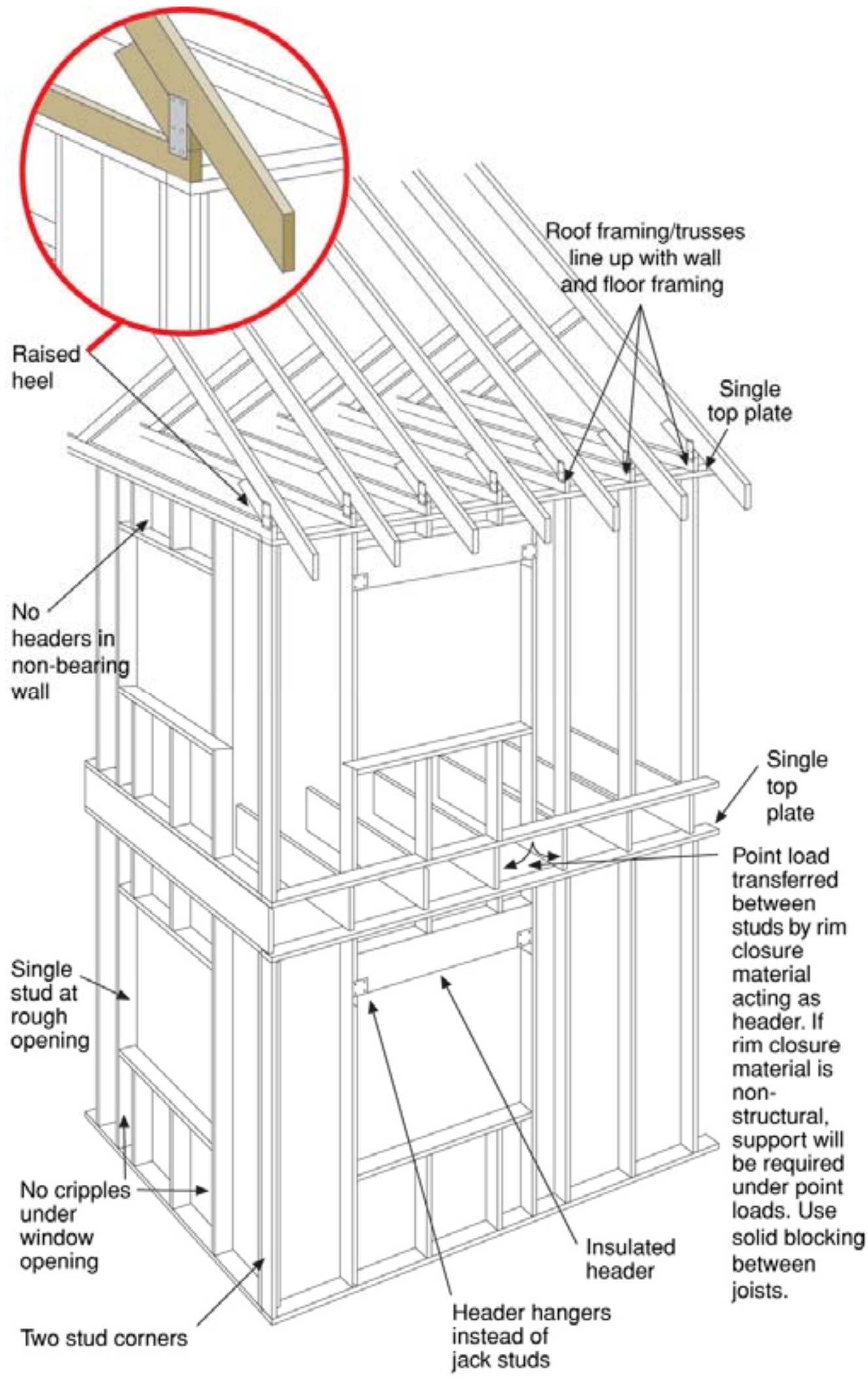

Figure 13. Stack-framing approach (drawing courtesy of BSC) 


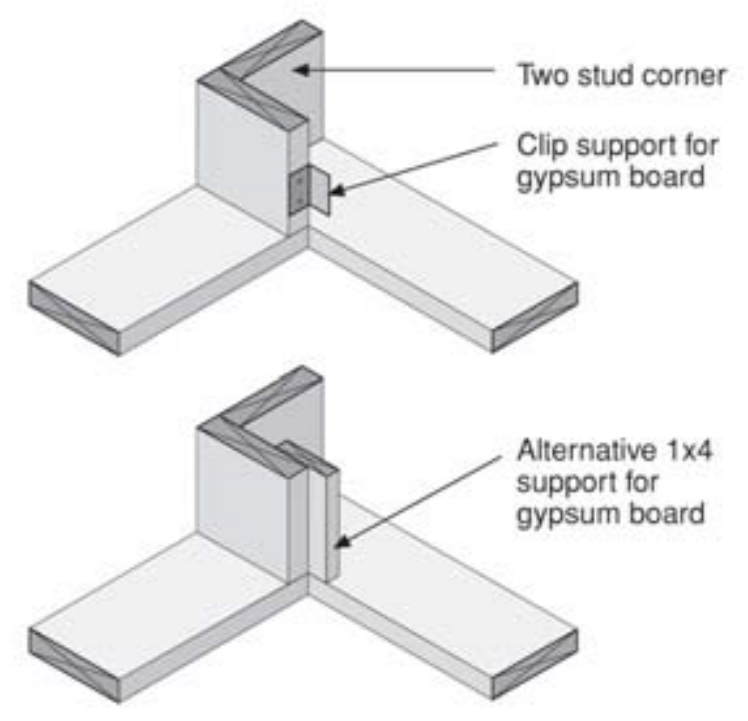

Figure 14. Two-stud corner framing (drawing courtesy of BSC).

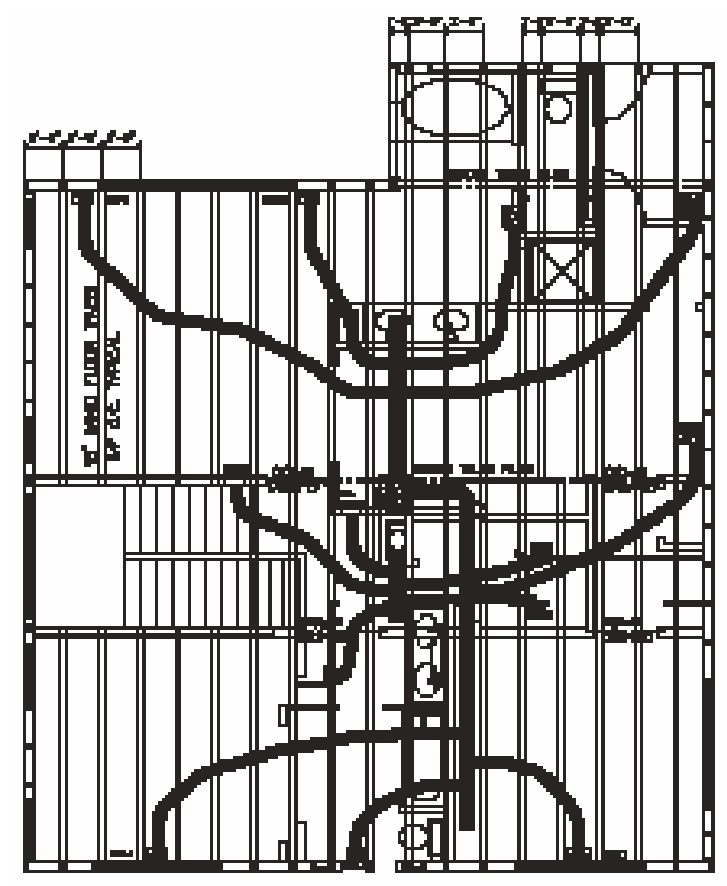

Figure 15. Integrated framing plan

A framing plan (Figure 15) can do more than just lay out floor joists. There are opportunities to value engineer the floor system and obtain a proper joist count, to ensure all plumbing is coordinated with the floor framing, to ensure all HVAC is coordinated with the floor framing, and to ensure that the "stack framing" concept is followed on the job site. Most importantly, all these issues are resolved on paper prior to casting the foundation. 


\section{Recycling of Construction Materials}

No matter how efficient our use of wood there will be some waste-off-cuts from both solidsawn lumber and sheathing. Even for the most efficiently framed buildings, wood waste will be one of the largest components of the new construction waste stream.

- Reduced wood purchase and disposal costs. Actual field counts for a production builder in California have found a $40 \%$ reduction in the cost of a wall-framing package after implementing optimized framing methods: a purchase savings for the builder of more than $\$ 1,100$ on each house. Another builder in Maryland reduces total wood waste disposal by $15 \%$ using efficient framing. Note that neither of these examples takes into account the labor savings from handling less wood and wood waste.

- Reduced environmental impact. The annual toll for residential construction in the United States is 2 billion board feet of framing lumber and nearly 2.5 million tons of wood waste. That translates into 1.1 million acres of clear-cut forest and 30-yard dumpsters lined up endto-end from Phoenix to Chicago! Clearly, builders can achieve and claim significantly reduced global and local environmental impact with optimized framing.

- On-site grinding. If you can grind your waste into wood chips it makes a great soil erosion control mat at job site entrances or bermed at the base of silt fences.

\section{Quality Project Management Approach}

A key component of high-performance system design and any high-performance construction process is quality project management. Quality management is a well-traveled term, but its definition can be elusive. In terms of Building America high-performance homes, the following definition is useful:

Quality management is an ongoing effort to systematically and comprehensively improve customer-focused satisfaction with emphasis on methods and processes that yield an optimal combination of energy efficiency, comfort, durability, indoor air quality, and moisture management.

This definition recognizes quality management as an integral part of achieving $30 \%$ whole-house energy savings. It emphasizes that improvements in energy efficiency must be accompanied by commensurate improvements or at least maintenance of other key performance attributes of the home to reflect a true systems-thinking approach. This definition also reflects the built-in costeffectiveness of high-performance quality management as a risk-reduction strategy (comfort, durability, indoor air quality, and moisture management) for the builder. And finally, the definition encompasses homebuyer expectations of performance - with energy efficiency as just one of several performance attributes that any home should provide.

This definition also establishes the inherent relationship between quality and high performance. It is essentially this: while a quality home need not necessarily be a high-performance home, any high-performance home MUST be a quality home. For any Building America high-performance home builder to truly incorporate a systems approach, he or she must also incorporate a quality management approach.

In order to successfully build high-performance houses in today's marketplace, builders must be willing to make some fundamental changes in their operations. It is evident that those builders 
who have already embarked down the path of operational excellence have the best ability to succeed in a competitive market. Once a builder has the operational systems in place to efficiently manage all aspects of the design and construction process, then they must look at how those operations need to be modified in order to adopt a high-performance approach, which includes the following considerations:

- Operational Evaluation

- Performance-Based Standards

- Training/Education

- Verification

- Feedback.

Operationally, builders should be prepared to go through the following steps (listed in order of importance) to achieve Building America levels of performance and quality, which are also discussed in the section on First Costs and Cost Tradeoffs:

- $\quad$ Address water management

- Address indoor air quality

- Improve thermal enclosure, including air sealing

- Tighten duct systems

- Implement integrated design of structure and mechanical systems, bringing ducts inside thermal enclosure, right sizing equipment, and applying advanced framing practices.

The quality-management approach is an essential element of the Building America approach to homebuilding because it is the main vehicle for moving from science and concepts of high performance to implementation. The package of tools within the Building America quality management approach includes the following:

- Operational Evaluation (Modified $\mathrm{NHQ}^{25}$ )

o Paper Review

o Key Player Interviews

- Performance-Based Standards

o Design

o Specifications

o Scopes

- Training/Education

o For builders

o For individual trades

\footnotetext{
${ }^{25}$ The NHQ (National Housing Quality) is the NAHB Research Center’s National Housing Quality Program, discussed in detail later in this report. Building America team leader, IBACOS, modified the NHQ system to include criteria specific to housing performance.
} 


\section{o Certifications}

- Verification Tools

o Performance Testing

o Inspections (Checklists)

- Feedback Loops.

Although this package has not been developed from a single source or as a comprehensive system, it certainly could be used as a comprehensive quality project-management approach. Each of these is discussed in detail below.

\section{Operational Evaluation}

Modified from the (National Association of Home Builders) NAHB Research Center's National Housing Quality® program, the Building America operational evaluation is a two-step process to help builders evaluate their own operations. The first is a paper review of all the documentation a builder has that is associated with its operations and the actual housing being built. The second is an interview with key individuals in the company. A reasonable list of the builders' primary source information for the first part of this evaluation includes the following:

- Annual operating plan. This includes company mission, vision, organizational values, and goals for each department; strategic objectives; and reporting and other operational guidelines. The annual operating plan supports the long-range strategic plan by documenting specific actions and goals that will help the company achieve the strategic plan.

- Long-range strategic plan. This includes the direction the company is headed, what types of barriers might exist, and how these barriers might be overcome. This document is a roadmap, which is made more specific in each year's annual operating plan.

- Process maps. These include any diagrammatic or written representation of the workflows operationally within the company.

- Design documentation. This category includes construction drawings, scopes of work, written specifications, contracts, field guides, etc., that communicate the work to be done by the builder and sub-contractors.

- Operational tools. These include any sort of departmental tools used to facilitate business processes. For example, construction schedules or other field tools used by site supervisors to assist in the day-to-day management of construction or template letters and reports to assist in the standardization of company processes.

- Training programs. This includes any internally developed or externally developed program for continuing education of staff within the builders operations. The intent here is not to specifically review the content of all training programs, but to evaluate the general attitude, approach, depth, and breadth of training activities in the builder's organization.

- Human resource manual. This includes company policy, safety programs, benefits, and items documenting company culture. 
- Marketing materials. This includes any type of material used to communicate the builder's message about their product to consumers.

- Survey mechanisms and results. These include any surveys done by the company or outside consultants, which can be for employees, customers, or vendors or can collect regional or local information on competitive information, such as sales prices or volume of construction.

A reasonable list of key builder staff to interview as part of the second step in an operational evaluation includes the following:

- Operations

- Marketing

- Sales

- Purchasing

- Construction

- Customer Service

- Human Resources

- Land Development.

This two-step process gives a comprehensive understanding of the builder's current operations. This evaluation process could be adopted internally by a builder or externally through the use of a consultant in order to identify what areas may need to be addressed if the builder is considering transforming their product line to achieve Building America high-performance home technology packages. The process is comprehensive, but not overly detailed. Appendix D contains the latest version of the modified NHQ two-step process as developed by IBACOS.

\section{Performance Standards}

Quality is often compared to the three-legged stool (the stool is of little use without all three legs). In high-performance home building, quality is only achieved with performance standards for design AND materials (specifications) AND installation (scopes). Building America takes this premise one step further by stating that many performance standards must be climatespecific; indeed even lot-specific when local terrain and environments bring with them additional challenges, such as extreme slopes, expansive soils, coastal high winds and flooding, etc.

\section{Design and Design Review}

An effective means of assuring these goals are implemented during the planning stages of a project is through a design review of the project, this can be a key instrument in making sure the whole energy system is incorporated in the design. It is highly unlikely that a home will be designed singularly around the HVAC system, or window orientation, or its ability to resist heat. For this purpose, value engineering techniques must be employed to ensure that all the systems in the home cannot only be designed to perform at optimum levels, but also be coordinated with those involved with actual construction of the project to make sure that the homes are built practically and as intended when designed on paper. 
Each of the Building America teams has conducted dozens of detailed design reviews, resulting in resources such as the Building America Houses That Work climate-specific Best Practices, the Houses That Work building profiles, the Noisette Home Performance Standards, the draft Risk Assessment Protocol, etc. The common ground among these design standards is that they respond to climate-specific protection of the energy efficiency, the comfort, the indoor air quality, the durability, and the moisture management of each high-performance home. Thus, they make up the first leg of the "quality stool"-high-performance design.

Another critical aspect of higher performing houses is the engineering of the mechanical system. In order to assure energy efficiency, comfort, and consistency of installation, some builders are using a third-party engineering firm to develop a single HVAC system design for a house plan, which is then implemented by one or more HVAC installation contractors. Alternately, a design build contractor may do the design, but if other companies are installing systems, they must follow the design-build contractor's design. This approach helps ensure quality design and allows for more consistent commissioning of systems.

\section{Specifications}

Specifiers, and subsequently purchasers, rarely take into account the overall performance of the home and its systems when making crucial material/component/subsystem choices. Standard specifications often don't take into account individual component performance variations, much less the impact of single-component choices on assemblies or systems. Various Building America projects have addressed this issue. High-performance specifications were developed for the EcoVillage Townhome project in Cleveland, Ohio. ${ }^{26}$ Such specifications could be modified and applied to other high-performance home projects.

\section{Scopes of Work}

Even with careful design and the right materials, quality can fall short of intended performance without the right installation. Production builders generally rely upon their scopes of work to achieve the installation required. But, as a rule, these scopes do not reflect systems thinking or climate-specific building science. More than one Building America team leader has developed project-specific mock-ups (for walls and window installation; for example BSC at EcoVillage, IBACOS at Summerset at Frick Park) or detailed installation procedures that could be used by high-performance builders in their scopes. BIRA, in conjunction with the ComfortWise program, has developed and posted high-performance specifications for several key trades, including HVAC and insulation. A sample set of supplemental high-performance scopes of work that build on the system put forth in the NAHB BuilderBooks, The Scopes of Work Program (Hass Davenport 2000) in key areas impacting Building America construction practices is included in Appendix E.

\section{Education and Training}

Training is needed throughout the Building America program. Ongoing efforts within the industry will be necessary to develop, deploy, and continually update training programs to disseminate information from the Building America program if widespread implementation is to

\footnotetext{
${ }^{26}$ Building Science Corporation. 2002. EcoVillage Sample Spec Language. www.buildingscience.com/buildingamerica/casestudies/ecovillage/ecovillage.pdf
} 
take place. While Building America has not been specifically charged with the development and deployment of training programs, this section discusses some of the opportunities, activities, and issues involved with training at the residential construction industry level.

\section{Builders}

The starting point for quality management approaches has typically been builder training. These programs have included pre-construction training meetings and site training of trade contractors. Each Building America team has conducted such trainings, and their work in the context of Building America has led to any number of building-science-based training programs in the industry:

- The Energy \& Environmental Building Association's Houses That Work Training Program. This public-private training partnership has trained hundreds of builders all across the country in the principles of climate-based high-performance building science. Several of the Building America teams have certified Houses That Work trainers. Although not explicitly portrayed as such, the Houses That Work trainings have many of the elements of quality management as listed above.

- The Environments for Living ${ }^{\circledR 27}$ (EFL) Diamond Class Training. Long-time Building America partner, Masco Contractor Services, has developed a new 3-day builder training program, a program that focuses on the principles of building science and their application in production homebuilding.

- Colorado Built Green ${ }^{\circledR} 2005$ training. The new three-tier version of this program has criteria based specifically on the Building America program and best practices, as well as Tier II and III training patterned after Houses That Work.

- Build IQ ${ }^{\circledR}$ Best Practices. An online training company, Build IQ, has been incorporating best practices from the Building America program for inclusion in their free and for-fee coursework. Build IQ delivers online training to top 100 homebuilders throughout the United States.

- National Housing Quality ${ }^{\circledR}$ Consulting and training services for builders and their trade partners on the fundamentals of documenting management processes and implementing customer-focused quality assurance systems.

- First Time Quality \& Safety for Home Builders®. This service provides training, templates, and tools to help builders partner with trade contractors to deliver defect-free homes. First Time Quality \& Safety emphasizes “build it right the first time” at every stage of the construction process. Problems are prevented so production runs faster, safer, and more efficiently.

- BECT (Building Energy Code Training). Since 1995, BECT has helped the building industry keep up with changes in energy codes. The Building Industry Institute (BII) and their subcontractor, ConSol, under contract to the California Energy Commission (CEC) began a training program for large production builders in California and Nevada. The

\footnotetext{
${ }^{27}$ Environments for Living is a building-science-based, high-performance home-building program of Masco Contractor Services. The program was developed approximately 5 years ago in a public-private partnership with Building America.
} 
program has improved compliance with energy standards by improving builders' understanding and implementation of the energy codes.

The BECT program has trained more than 3,000 contractors and subcontractors in the California and Nevada area since its beginnings in the mid-1990s. Through the BECT program, California is able to train builders in the following:

o Current codes and issues

o Upcoming code changes

o Construction techniques that improve quality of construction

o Common enforcement issues.

California's energy code has long been at the forefront of implementing energy-efficient standards in home building. The energy code's goal in the beginning was to increase energy efficiency of a home being built in California every three years by approximately $5 \%$. But since the energy crisis, the percentage has been increased to 12\% in 2001 and 15\% in 2005. Having an infrastructure in place like the BECT program has greatly facilitated this dramatic change to the building industry.

\section{Training - Trade Contractors}

Each Building America team has conducted trade contractor training on climate-specific building science and systems approach. Targeted trades have included framing, insulation, and HVAC. The EFL program conducts trade contractor building science training for framing and insulation contractors and is developing an HVAC training module. The BETC program in California also provides training to subcontractors.

\section{Builder and Trade Certifications}

The Building America program has led at least one of its builders to develop its own certification related to high performance. Artistic Homes of Albuquerque, New Mexico, certifies its entire sales staff under a high-performance training program. The program is called the High Performance Homes Sales Specialist.

A variety of specialized third-part certification programs for companies / firms are available on quality systems and technical services. These certifications are provided by such as groups as the North American Technician Excellence (NATE), Building Performance Institute (BPI), and the NAHB Research Center (National Housing Quality Certified $\left.{ }^{\circledR}\right)$. These programs require recurring review to maintain certification status.

Feedback from builders who have participated in the Building America program reveals that one of the most difficult aspects of sustaining the delivery of high-performance housing is the continuous need for trade training and re-emphasizing the performance targets each trade must meet. This, in part, can be attributed to the high turnover in the building industry. Certification programs can help provide incentives to maintain the discipline of management that is an essential ingredient in a viable and effective quality assurance system. These quality assurance management systems are resulting in transformations for individual companies and with time the influence will be seen industry-wide. A list of key trade-based certifications associated with delivery of high-performance housing can be found in Appendix C. 


\section{Verification}

Verification tools for both performance and quality include performance testing and inspection checklists. Clearly the first choice is almost always a quantitative test, such as any of the following:

- Using a blower door for measuring air tightness

- Using a calibrated fan system for measuring for duct tightness

- Using a flow hood for measuring supply and return airflows at registers and grilles

- Using a manometer for room-to-room pressurization

- Using a digital thermometer to measure room-to-room temperature variation

- Using a low-e detector to verify glazing properties.

The beauty of these tests is that quantitative metrics can be established that summarize the quality of design, materials, and installation for one or more performance attributes. Most performance tests for the residential building industry deal with energy efficiency directly and then may be indirectly reflective of other performance attributes, such as indoor air quality and comfort. But quantitative tests for other performance attributes, such as moisture management and durability, are generally not available, at least not in a cost-effective application. For verification of these performance attributes, a detailed inspection checklist and visual inspections act as a proxy determination of both quality and performance.

An important consideration in any quality management approach is the cost of verification. The primary determinants of at least the initial costs are the number of homes tested-ranging from one initial model home to $100 \%$ testing of every home built - and what entity does the testingeither in-house testing, third-party testing, or some combination of the two. In general, for production builders, Building America has recommended a testing strategy similar to the EPA ENERGY STAR strategy of 1-in-7 random testing after a period of $100 \%$ testing to verify that key performance metrics are met on a consistent basis. But more than one Building America production builder has determined that either the pace at which they build or their reputation for quality (or both) makes 100\% in-house testing and random 1-in-7 third-party testing the most cost-effective strategy in the long run, based on looking at the total costs and total benefits of a much more rigorous quality protocol. The Building America Best Practices Guides (Baechler et al. 2005) produced by Pacific Northwest National Laboratory (PNNL) contain recommendations for testing protocols for each climate. In addition, a "SNAPSHOT" performance testing protocol and report process has been documented by Building Science Corporation and is included as Appendix F.

Each Building America team has made up prescriptive checklists to handle non-quantitative performance assessment, particularly for performance attributes such as durability and moisture management. While it is difficult to address all of the variables that lead to customization of these lists — climate, lot, aspect, surrounding local features, building type, etc. - these checklists can be referenced as examples of how quality management of high-performance attributes are assessed and verified for builders seeking to achieve the Building America "standard."

One of the difficulties that builders face with non-quantitative metrics and verification are the 
questions, "How do I know when enough is enough? When is our practice a best practice, substandard, or overkill?” Builders must use their local conditions and past product history (in terms of callbacks, legal claims, 1- and 2-year warranty trends) to intelligently manage durability and moisture. Proxy, qualitative tools can be applied-such as infra-red imaging of assemblies, water testing, and moisture meter readings but these approaches have not been documented as part of the Building America body of research.

\section{Commissioning}

Building commissioning is a systematic process of ensuring that a building performs in accordance with the design intent, contract documents, and the owner's operational needs. Because of the sophistication of building designs and the complexity of building systems constructed today, commissioning is necessary, but not automatically included as part of the typical design and construction process. Commissioning is critical for ensuring that the design developed through the whole-building design process is successfully constructed and operated.

Building commissioning includes the following:

- Systematically evaluating all pieces of equipment to ensure that they are working according to specifications. This includes measuring temperatures and flow rates from all HVAC devices and calibrating all sensors to a known standard.

- Reviewing the sequence of operations to verify that the controls are providing the correct interaction between equipment.

In particular, building commissioning includes these activities:

- Engaging a commissioning authority and team

- Documentation

- Verification procedures, functional performance tests, and validation

- Training.

Building commissioning is not one of these:

- Construction observation (punch list)

- $\quad$ Start-up

- Testing, adjusting, and balancing (TAB)

- Final punch-out.

These activities are individual steps in the systematic process of commissioning, but by themselves these activities cannot meet the goals of building commissioning.

Commissioning HVAC systems is even more important in energy-efficient buildings, because equipment is less likely to be oversized and must, therefore, run as intended to maintain comfort. Also, HVAC equipment in better-performing buildings may require advanced control strategies. Commissioning goes beyond the traditional HVAC elements. More and more buildings rely on parts of the envelope to ensure comfort. 
Commissioning includes evaluating the building elements to ensure that shade management devices are in place, glazing was installed as specified, air-leakage standards have been metthese are the static elements of the building. Commissioning can also evaluate other claims about the construction materials such as VOC emission content and durability. It is important that the products that were specified for the building meet the manufacturers' claims (and are appropriate for the project.)

Benefits of building commissioning include the following:

- Energy savings and persistence of savings

- Improved thermal comfort with proper environmental control

- Improved indoor air quality

- Improved operation and maintenance with documentation

- Improved system function that eases building turn-over from contractor to owner.

\section{Feedback Loops}

Quality is a process ideally supported by feedback within the corporate structure and across the full range of product. Every department—design, construction, purchasing, warranty, sales, and marketing - should report performance successes and failures to every department for each and every product type, taking full advantage of feedback loops. In reality, many production builders set up little incentive for quality of product, erring in favor of quantity of product. But some builders are beginning to understand that it is not just how much profit a company can make, but how much profit a company retains, once the set-asides for warranty and claims are factored in. More than one builder is asking its managers a question like this:

"If we are currently setting aside about $\$ 5,000$ for each home we build to cover warranty and claims, how much quality management can we afford?”

Production builders in today's housing market are generally not having trouble making profits, just keeping them. If financial incentives can be created for quality of product, the reduction in warranty and claims can be used to finance the quality incentive structure. Feedback loops are a key element of any such quality management approach.

\section{Quality Management Summary}

In order to achieve whole-house energy savings of $30 \%$ or more, we are managing energy flows on, in, and through the structure to such a degree that we must manage the flow of air and moisture with equal attention. The links among energy efficiency, comfort, indoor air quality, durability, and moisture are not optional, they are built into the physics that builders face and the expectations buyers bring. Likewise, quality management is not an option when building highperformance homes. It is a process inherent to systems-thinking and systems-engineering. Without the quality management tools to implement the principles of physics and building science, higher performance in housing is simply a technical exercise, not a business proposition. 


\section{Building Component Design Details}

\section{Building Enclosure Integrity}

A house is an environmental separator whose function is to separate the inside from the outside as required by the local environment and the wishes of its occupants. A house creates an interior environment that is different from the exterior environment. This interior environment should be controllable by the occupants in a manner that meets their needs.

In order to function as an environmental separator, the elements, components, assemblies, and sub-systems that comprise a house must meet specific objectives, including the following:

- Control of heat flow

- Control of airflow

- Control of rainwater

- Control of groundwater

- Control of water vapor flow.

Control of Heat Flow

The key strategy in the control of heat flow is the use of thermal insulation in a manner that continuously encloses the conditioned space. If a conditioned space is considered a cube, then all six surfaces enclosing the cube are encased by thermal insulation. In the typical home this means both the above- and below-grade walls are insulated: the attic ceiling/roof assembly and the foundation slab.

Fully insulating a basement slab is not necessary to meet the $30 \%$ savings goal. However, it is a recommended approach for all new houses from a moisture-control perspective if basements are to be intended for occupancy. Installing carpets and other floor finishes over uninsulated concrete basement floor slabs often leads to problems with dust mites and mold in floor coverings.

With wood-frame construction, effective control of heat flow means exterior walls framed with $2 \times 6$ framing where cavities are insulated with fiberglass batts, spray-applied cellulose, or lowdensity spray-applied foams. In addition, the exterior 2x6 framing is sheathed with rigid-foam insulating sheathing.

In general, insulating sheathing is not necessary to meet the $30 \%$ savings goal. However, insulating sheathing has other significant benefits, particularly in the areas of moisture control. Inwardly driven moisture from reservoir claddings, such as brick and stucco, can be controlled by insulating sheathing. Additionally, the use of insulating sheathing of sufficient thickness allows the removal of interior vapor barriers and vapor retarders, thereby enhancing the inward drying of the assembly. In other words "double vapor barriers" can be avoided.

Insulating sheathing also has cost advantages over oriented strand board (OSB) and plywood sheathings when coupled with innovative framing techniques for wind and seismic loadings.

Reducing heat-flow in wood frame construction can be accomplished by minimizing the amount 
of framing materials through which conductive heat transfer can occur, increasing the cavity thickness to accommodate more thermal insulation, and using sheathing materials that provide thermal resistance.

Materials can be reduced at corners and where interior partition walls intersect exterior walls. Thermal bridging can be reduced at door and window openings through the use of insulated headers and using hangers to eliminate king studs and cripple studs. Stud spacing can also be increased to 24-in. spacing and point-loading trusses.

Increasing cavity thickness to accommodate more thermal insulation can be facilitated in wall framing by using thicker framing materials and, at the intersection of roof trusses and exterior walls, through the use of specialized trusses. In all truss and roof assemblies, baffles should be installed to prevent the wind washing of thermal insulation and to prevent insulation from blocking ventilation in vented roof assemblies.

Fenestration with a maximum U-value of 0.35 and SHGC value of 0.4 or lower is recommended.

\section{Control of Airflow}

One of the key strategies in the control of airflow is the use of air barriers. Air barriers are systems of materials designed and constructed to control airflow between a conditioned space and an unconditioned space. The air barrier system is the primary air enclosure boundary that separates indoor (conditioned) air and outdoor (unconditioned) air. In multi-

unit/townhouse/apartment construction, the air-barrier system also separates the conditioned air from any given unit and adjacent units. Air-barrier systems typically define the location of the pressure boundary of the building enclosure.

The air-barrier system also separates garages from conditioned spaces. In this regard, the airbarrier system is also the "gas barrier" and provides the gas-tight separation between a garage and the remainder of the house or building.

Air-barrier systems keep outside air out of the building enclosure or inside air out of the building enclosure depending on climate or configuration. Sometimes, air-barrier systems do both.

Air-barrier systems can be located anywhere in the building enclosure-at the exterior surface, the interior surface, or at any location in between. In Mixed-Humid climates, interior air-barrier systems control the exfiltration of interior, often moisture-laden, air. Whereas exterior air-barrier systems control the infiltration of exterior air and prevent wind washing through cavity insulation systems.

Numerous approaches can be used to provide air-barrier systems in buildings. Rigid materials, such as gypsum board, exterior sheathing materials like plywood or OSB, and supported flexible barriers are typically effective air-barrier systems if joints and seams are sealed.

Spray-applied foam insulations can be used as interstitial (cavity) air-barrier systems. Damp spray-applied cellulose does not meet the performance requirements of air barrier materials or assemblies-it is an air retarder.

The significant advantage of exterior air-barrier systems is the ease of installation and the lack of detailing issues related to intersecting partition walls and service penetrations. An additional advantage of exterior air-barrier systems is the control of wind washing that an exterior air seal provides with insulated-cavity frame assemblies. 
The significant disadvantage of exterior air-barrier systems is their inability to control the entry of air-transported moisture into insulated cavities from the interior. As a result, most exterior airbarrier systems are insulated on their exterior side with rigid or semi-rigid insulations that are not sensitive to wind washing.

An advantage of interior air-barrier systems over exterior systems is that they control the entry of interior moisture-laden air into insulated assembly cavities during heating periods. The significant disadvantage of interior air-barrier systems is their inability to control wind washing through cavity insulation.

Installing both interior and exterior air-barrier systems can address the weakness of each.

The practice of using framing elements in conjunction with the interior gypsum sheathing can meet the requirements of a building envelope air-barrier system. In this approach, the primary responsibility for reduction of air-leakage openings is shared by both the framer and the gypsumboard installer.

Air leakage at the platform frame floor assembly can be reduced by sealing the rim joist to the frame wall or plate below and the sub-floor sheathing above. This is typically accomplished by using a continuous bead of sub-floor adhesive to seal the sub-floor sheathing to the rim joist and caulking to seal the bottom of the rim joist assembly to the plate below. Gaskets and other seals can also be utilized. Where floor trusses or other manufactured wood-product floor-system components are used (wood I-beams), solid rim joist material installed in a continuous manner should be provided to prevent air leakage at the rim joist assembly.

Air leakage between the bottom plates of exterior walls and the sub-floor sheathing is controlled by sealing the bottom plate to the sub floor. This is typically accomplished by installing a continuous bead of sealant or caulk under wall plates.

Air leakage at floor assemblies where cantilevers occur is also controlled at rim joist locations. Blocking utilizing wood or rigid insulation can be used with both exterior and interior cantilever floor assemblies. Where floor-framing members are installed parallel to exterior walls (or garage walls), solid rim-joist material can be installed directly over wall plates to provide for air barrier continuity.

Air leakage through sub-floor sheathing installed over unconditioned spaces, such as vented crawl spaces, unconditioned garages, or cantilevered floors over exterior walls, can be controlled by sealing all panel joints.

Tubs, shower stalls, and one-piece manufactured tub/shower enclosures installed on exterior walls can provide the single largest source of air-leakage areas when uncontrolled. Rigid sheathing material should be installed on the interior surfaces of exterior walls and sealed to framing and sub-floor sheathing before the installation of tubs and shower enclosures. Thin, noninsulating sheathings can be installed in a manner that allows the installation of interior gypsum board sheathing over sheathing edges without noticeably altering wall thickness. With one-piece manufactured tub/shower enclosures, the entire height of the interior surface of exterior walls should be sheathed. This usually requires the installation of cavity insulation before the installation of the interior sheathing.

Where fireplaces are installed on exterior walls, air leakage can be as significant as air leakage at tubs and shower stalls. Fireplace enclosure framing should be lined on the interior with rigid sheathing material. Such enclosures should be considered as small rooms that are conditioned. 
Accordingly, they require a sealed top, bottom, and three sides. Gypsum board, plywood, wafer board, and foil-covered pressed paper can provide satisfactory performance when sealed. This will also greatly reduce callbacks from cold drafts coming from fireplaces.

Interior soffit assemblies above cabinetry on exterior walls or adjacent insulated ceilings and attics also require air sealing. Where the ends of soffit assemblies or framing boxing in mechanicals intersect exterior walls, the "footprint" of the soffit or framing against the exterior wall should be enclosed with sheathing.

Window and door openings can be sealed by the framer sealing the window or door unit to the rough framing with foam, caulk, or other sealant. Alternatively, the drywaller can return the gypsum-board interior finish to the window or door unit and seal the joint with caulk.

Interior utility chases or dead spaces between two closely spaced walls, dropped ceilings, and split levels require special attention. Sealing responsibilities are shared between framers and drywallers at dropped ceilings and split-levels. Blocking is installed and sealed by the framers; gypsum board is installed and sealed by the drywallers.

Attic access openings located within conditioned spaces should also be sealed as well as flue pipe penetrations.

Whole-house fans require a cover that can be installed during the heating season in an airtight manner. Some whole-house fan units come equipped with airtight covers. Those units that do not have covers can have removable covers site-manufactured in a similar manner to removable attic access covers.

If these air-sealing strategies are followed, it should not be difficult to achieve a target air leakage rate of less than $0.25 \mathrm{CFM} 50\left(\mathrm{ft}^{3} / \mathrm{min}\right.$ at $\left.50 \mathrm{~Pa}\right)$ per square foot of thermal envelope area.

\section{Control of Moisture}

\section{Control of Rainwater}

The fundamental principle of rainwater control is to shed water by layering materials in such a way that water is directed downward and outward from the building or away from the building. It applies to assemblies such as walls, roofs, and foundations, as well as to the components that can be found in walls, roofs, and foundations such as windows, doors, and skylights. It also applies to assemblies that connect to walls, roofs, and foundations such as balconies, decks, railings, and dormers.

Layering materials to shed water applies to the building as a whole. Overhangs can be used to keep water away from walls. Canopies can be used to keep water away from windows, and site grading can be used to keep water away from foundation perimeters.

All exterior claddings pass some rainwater. Siding leaks, brick leaks, stucco leaks, stone leaks, etc. Therefore, some control of this penetrating rainwater is required. In most walls, this penetrating rainwater is controlled by a drainage plane that directs the penetrating rainwater downward and outward.

Drainage planes are water-repellant materials (building paper, house wrap, foam insulation, etc.) that are located behind the cladding and are designed and constructed to drain water that passes through the cladding. They are interconnected with flashings, window and door openings, and 
other penetrations of the building enclosure to provide drainage of water to the exterior of the building. The materials that form the drainage plane overlap each other shingle fashion or are sealed so that water flow is down and out of the wall.

Materials that absorb and store rainwater when it rains located on the outside of buildings can create problems. They can act like reservoirs or sponges absorbing and holding water when exposed to rain. Stored water can migrate elsewhere and cause problems. Common reservoirs are brick veneers, stuccos, wood siding, wood trim, and fiber-cement cladding.

The best approach to dealing with reservoirs is to eliminate them or disconnect them from the building. Back priming (painting all surfaces, back, front, edges and ends of wood siding, cement siding and all wood trim) gets rid of the moisture storage issue with these materials.

Back-venting brick veneers and installing them over foam sheathings disconnects the brick veneer moisture reservoir from the building. Installing stucco over two layers of building paper or over an appropriate capillary break, such as foam sheathing, similarly addresses stucco reservoirs.

\section{Control of Groundwater}

The fundamental principles of groundwater control are to keep rainwater away from the foundation wall perimeter and to drain groundwater with sub-grade perimeter drains before it gets to the foundation wall. This applies to slabs, crawlspaces, and basements.

Concrete and masonry are sponges-they can wick water by capillarity. This is the main reason that damp-proofing (the black tar-like coating) is applied to exterior basement walls. The dampproofing fills in the pores in the concrete and masonry to reduce ground-water absorption. The damp-proofing is a capillary break. Under concrete floor slabs, the stone layer combined with polyethylene serves a similar function (they act as capillary breaks). Unfortunately, the capillary rise through footings is typically ignored. This can be a major problem if foundation perimeter wall are finished or insulated.

In new construction, a capillary break should be installed on the top of the footing between the footing and the perimeter foundation wall. This can be done by damp-proofing the top of the footing or by installing a membrane at this location.

The interior insulation and finishing approach must take into account the moisture migrating up through the footing. This is best accomplished by installing rigid-foam insulation on the interior of the assembly to protect the interior finishes.

The best foams to use have a perm rating of greater than 1 perm for the thickness used. This means limiting extruded polystyrene insulation to less than 1-in. thickness for walls (more than 1 in. thick and they do not breathe sufficiently) and making sure that the rigid insulation is not faced with polypropylene skins or foil facings. Additionally, because foams need to be protected from fire, and this is often done with gypsum board, only latex paint should be used on interior gypsum finishes (because it breathes).

Capillary control also applies to slab-on-grade construction and crawlspaces. Monolithic slabs need plastic ground covers that extend under the perimeter grade beam and upward to grade. Additionally, the exposed portion of slabs must be painted with latex paint to reduce water absorption, and a capillary break must be installed under perimeter wall framing. 


\section{Control of Water Vapor Flow}

The fundamental principle of control of water in the vapor form is to keep it out and to let it out if it gets in.

The following things are discouraged:

- The installation of vapor barriers on both sides of assemblies (i.e., “double vapor barriers”).

- The installation of vapor barriers, such as polyethylene vapor barriers, foil-faced batt insulation, and reflective radiant-barrier foil insulation on the interior of air-conditioned assemblies.

- The installation of vinyl wall coverings on the inside of air-conditioned assemblies.

The following things are encouraged:

- The construction of assemblies that are able to dry by diffusion to at least one side and in many cases to both sides.

- The ability to use insulating sheathings without the creation of “double vapor barriers.”

- The ability to use damp spray insulations with insulating sheathings without the creation of “double vapor barriers.”

\section{Specific Recommendations}

- Soil surfaces shall be graded away from below-grade envelope surfaces.

- Materials next to below-grade envelope surfaces shall be free-draining and shall connect to a sub-grade drainage system through a filter media that will prevent fines build-up in the drainage system.

- A clay cap or other water-flow-resistant surface layer shall be installed to prevent surface water from draining into the free-draining material next to below-grade envelope surfaces.

- Below-grade surfaces shall be provided with a damp-proofing layer or coating that will be effective as a capillary break.

- All surfaces subject to wind-driven rain or snow shall be provided with a drainage plane or layer that will prevent rain-wetting of internal materials.

- Indoor relative humidity should be maintained at the center of the room or as low as necessary to keep the room air next to cool/cold surfaces at less than $70 \%$ relative humidity.

- All building envelope assemblies should include at least one air barrier.

- All crawl space assemblies should have a continuous impermeable ground cover that functions as both an air barrier and vapor retarder.

- Provide air-barrier systems that control air movement from the interior into the exterior enclosure assemblies.

- Vapor diffusion retarders are not required in a Mixed-Humid climate region as a result of the fluctuating seasonal weather conditions, without a dominating drive direction. Flow-through wall assemblies that allow drying in either direction are recommended. 
- Provide secondary air barriers that control wind washing from the exterior.

- Control interior relative humidities during the coldest portion of the heating season (maintain below $40 \%$ in the southern Mixed-Humid climate region, 35\% in the northern region). Controlled mechanical ventilation (dilution with outside air) at the rate recommended by ASHRAE 62.2 has been shown to provide sufficient dilution to reduce interior moisture below these levels in detached single-family houses. Multi-family units may require higher ventilation rates depending on moisture generation. Whole-house humidification is not recommended under any circumstances.

- Allow wet or moist materials used in construction to dry toward the exterior.

\section{Envelope Systems}

\section{Foundation Systems}

The function of a foundation system is to hold up the building. This involves facilitating the transfer of loads from above-grade to the ground. Foundation systems, depending on their configuration and location, may also have to control other factors, such as heat flow, airflow, rainwater, groundwater, and water vapor flow.

\section{Slab on Grade}

Structure. In Mixed-Humid climates, the primary slab-on-grade approach can involve a monolithic slab-grade beam or grade beams poured separately from the slab. Post-tensioning in some cases occurs.

Insulation and Air Infiltration. In Mixed-Humid climates, the perimeter of the concrete must be thermally isolated from the ground. This thermal insulation extends from the bottom of the grade beam to the top of the slab. A sill gasket also provides an air seal between the foundation and the frame structure on top.

Water Management, Drainage, Vapor Diffusion. As in all foundation systems, the perimeter grade must slope away from the foundation to reduce the saturation of ground adjacent the structure. With monolithic slab-grade beam assemblies, the entire concrete assembly must be isolated from the ground with a capillary break. This involves installing a polyethylene sheet membrane under the grade beam extending to grade. The exposed portion of the foundation above grade is damp-proofed using latex paint. The sill gasket functions as the primary capillary break between the stem wall and the frame structure. A polyethylene sheet membrane vapor barrier should be installed in direct contract with the concrete slab - a sand layer should never be installed between the polyethylene sheet membrane and the concrete slab.

Interaction with Mechanical Systems. Passive sub-slab ventilation is recommended to reduce atmospheric air pressure soil gas drivers. Excessively long-duration interior negative pressures should be avoided. A depressurization limit of 5 Pascals is recommended for continuously operating exhaust appliances. A depressurization limit of 20 Pascals is recommended for intermittent operating exhaust appliances. Only sealed-combustion, direct-vent, or power-vented appliances that do not allow combustion by-products into the house should be installed within the pressure boundary of the building enclosure. 


\section{Crawl Space}

Structure. In Mixed-Humid climates the recommended crawl space approach involves conditioned crawl space construction. Vented crawlspaces are energy inefficient compared to conditioned crawl spaces when ducts are present, and interfere with ground coupling where the ground can act as a heat sink during air conditioning.

Insulation and Air Infiltration. The perimeter wall of crawl spaces must be insulated. Interior rigid insulation is the insulation system of choice because it is not water sensitive. The assembly must be fire rated. The interior location is preferred from both a constructability perspective and insect-resistance perspective. This thermal insulation extends from the top of the footing to the underside of the floor framing. A sill gasket provides an air seal between the foundation and the frame structure.

Water Management, Drainage, Vapor Diffusion. As in all foundation systems, the perimeter grade must slope away from the foundation to reduce the saturation of ground adjacent the structure. All below-grade surfaces in ground contact should be damp-proofed. A continuoussealed air barrier and vapor-barrier ground cover should be installed. If the interior crawl space grade is below the exterior grade a perimeter drain system is required. This perimeter drain works best when located on the exterior of the foundation assembly.

Interaction with Mechanical Systems. Excessive long-duration interior negative pressures should be avoided. A depressurization limit of 5 Pascals is recommended for continuously operating exhaust appliances. A depressurization limit of 20 Pascals is recommended for intermittent operating exhaust appliances. Only sealed-combustion, direct-vent, or power-vented appliances that do not allow combustion by-products into the house should be installed within the pressure boundary of the building enclosure. Passive sub-ground cover ventilation is recommended to reduce atmospheric air pressure soil gas drivers.

Conditioning of the crawl space should be accomplished by supplying conditioned air to the crawl space either via a dedicated duct or via transfer air from the house where a continuously operating exhaust fan is used as the pressure driver.

\section{Basement}

Structure. In Mixed-Humid climates the recommended basement approach involves insulating and conditioning the basement. Un-insulated, unconditioned basements are energy inefficient compared to insulated conditioned basements and interfere with ground coupling where the ground can act as a heat sink during air conditioning.

Insulation and Air Infiltration. The perimeter wall of basements must be insulated. Interior rigid insulation is the insulation system of choice because it is not water sensitive. The assembly needs to be fire rated. The interior location is preferred from both a constructability perspective and insect-resistance perspective.

The thermal insulation would ideally extend from the top of the footing to the underside of the floor framing to complete the thermal envelope, but an alternate option is use upper half height insulation with consideration for the overall energy consumption of the home versus budget constraints. Upper half height insulation covers most of the heat loss from basement walls, in that it covers the area that fluctuates most seasonally, while the lower half sees more constant 
temperatures. Full wall insulation kept 6 in. off the basement floor has also been successfully implemented in some projects. In any of these cases, a sill gasket provides an air seal between the foundation and the frame structure.

Water Management, Drainage, Vapor Diffusion. As in all foundation systems, the perimeter grade must slope away from the foundation to reduce the saturation of ground adjacent the structure. All below-grade surfaces in ground contact should be damp-proofed. A continuoussealed air barrier and vapor-barrier ground cover should be installed. If the interior basement floor elevation is below the exterior grade, a perimeter drain system is required. This perimeter drain works best when located on the exterior of the foundation assembly.

Interaction with Mechanical Systems. Excessive long-duration interior negative pressures should be avoided. A depressurization limit of 5 Pascals is recommended for continuously operating exhaust appliances. A depressurization limit of 20 Pascals is recommended for intermittent operating exhaust appliances. Only sealed-combustion, direct-vent, or power-vented appliances that do not allow combustion by-products into the house should be installed within the pressure boundary of the building enclosure. Passive sub-ground cover ventilation is recommended to reduce atmospheric air pressure soil gas drivers. Conditioning of the basement should be accomplished by supplying conditioned air to the basement either via a dedicated duct or via transfer air from the house where a continuously operating exhaust fan is used as the pressure driver.

\section{Building Enclosure Integration Strategies}

\section{Walls}

The function of wall systems is to provide environmental separation between the interior and exterior, transfer wind and seismic loads to the foundation, and transfer loads from the roof to the foundation. As part of the provision for environmental separation, wall systems have to control heat flow, airflow, rainwater, and water-vapor flow.

Structure. In Mixed-Humid climates, the primary structural approach is site-built wood-frameutilizing engineered elements, including prefabricated lintels, headers, and sheet goods, such as OSB, plywood, and gypsum wallboard.

Resistance to shear loads as a result of wind and seismic events must be provided. The choice of construction or framing approach addressing shear loads should reflect the local conditions. For example, houses constructed in low-wind zones can be constructed with wood frame assemblies with non-structural sheathings and metal cross braces or wood "let-in" braces. Whereas a similar home built in a higher wind zone, such as in a coastal wind zone, or built in a more severe seismic zone may have to be constructed with structural sheathing or inset shear panels.

The following are the principle means of controlling lateral loads:

- Metal cross braces

- Wood “let-in” braces

- Structural sheathing such as plywood or OSB

- Proprietary shear panels. 
Insulation and Air Infiltration. The optimum approach to insulation involves 2x6 advanced frame walls with insulating sheathing replacing OSB or plywood sheathing. Other strategies include 2 x 6 framing with OSB or plywood sheathing, or 2x4 framing with insulating sheathing. Cavity insulation is either unfaced fiberglass batt insulation, dry installed or damp sprayed fiberous insulation, or spray applied foams.

Air-infiltration control is provided by an air barrier. An interior air barrier is used, specifically the interior gypsum sheathing combined with using framing elements, such as draft-stopping and fire-stopping components.

Water Management, Drainage, Vapor Diffusion. Rainwater management is provided by using a weather resistive barrier (housewrap, tar paper, etc.) as a drainage plane and integrating windows and doors with the weather resistive barrier to provide drainage plane continuity.

Vapor diffusion is allowable in a Mixed-Humid climate as a result of the fluctuating seasonal conditions. Therefore, no specific vapor diffusion control techniques are required.

Interaction with Mechanical Systems. The tighter the building enclosure, the greater the pressure differential created with exhaust appliances. The use of an air barrier results in a tighter building enclosure.

Excessive long-duration interior negative pressures should be avoided. A depressurization limit of 5 Pascals is recommended for continuously operating exhaust appliances. A depressurization limit of 20 Pascals is recommended for intermittent-operating exhaust appliances. Only sealedcombustion, direct-vent, or power-vented appliances that do not allow combustion by-products into the house should be installed within the pressure boundary of the building enclosure.

\section{Windows}

Proper use and selection of windows can make a tremendous difference in the desirability, usefulness, and energy consumption of interior spaces. Unfortunately, the introduction of holes through the building enclosure in the form of windows brings about challenges both from space conditioning energy and water management perspective. Wall insulation levels are often 5-10 times higher than that of windows, and walls prevent direct radiant heat gain. On the other hand, windows provide lighting, beneficial solar heat gain during heating seasons and the opportunity for natural ventilation, three significant energy advantages.

Window U-values are recommended to be 0.40 or lower in the Mixed-Humid climate region. However, with the current window marketplace, low-e, double-pane windows can readily achieve a U-value of 0.35 with minimal additional cost.

The 2004 Supplement to the 2003 International Residential Code (IECC 2003, 2004) requires a SHGC of 0.40 in the Hot-Dry, Mixed-Dry, Marine, Hot-Humid, and southern parts of the MixedHumid climate regions. Relatively low (0.30) SHGC glazing has been used successfully in 30\% improvement homes in all climate regions. While a low SHGC unit reduces beneficial heating season solar gain, Building America teams have found that where no attention is paid to passive solar design, low-SHGC windows generally provide a cost-effective option for builders, when all the systems interactions benefits are considered. Therefore to minimize overall energy consumption, it is simplest to use windows that prevent radiant, conductive, and convective heat flow. The following are the reasons for this: 
- Traditional production-builder house models are oriented in any direction. Using lower SHGC glazing in all windows assures an overall reduction of the heat gain during the cooling season, regardless of how the house is placed with respect to the sun. This reduction in heat gain reduces the load on the air conditioning system.

- Air-conditioning equipment is sized based on peak load. Using lower-SHGC glazing reduces peak load and, in turn, reduces air-conditioning unit sizes. Smaller air-conditioning systems have lower airflow rates and, therefore, require smaller ducts. Lower airflow rates also require smaller fans, which use less electricity to operate. Reducing the size of the airconditioning (AC) system also means cost savings to the builder, which can be reinvested in other energy upgrades.

- Use of lower SHGC glazing, by cutting the solar gain that varies in direction throughout the day, helps maintain more uniform room temperatures throughout the house. Even with zoned systems, it is not possible to control all room temperatures individually, and solar gain is one of the largest factors causing overheating and room-to-room imbalances.

However, it should be noted that two Building America production home builders have expressed a willingness to experiment with using higher SHGC for south-oriented windows as part of BA research.

Windows and window openings also tend to be the source of most water intrusion problems in buildings. Therefore, the water management details of proper window installation are critical for the long-term durability of the building. Energy efficient buildings that have moisture problems and need to be renovated or fixed in the short term are significant energy and material wasters. Providing pan flashing under windows and properly tying the window into the drainage plane are of the utmost importance to keeping water out of the walls that surround the windows.

\section{Floors}

The function of floor systems is to provide environmental separation between the interior and exterior where they intersect the exterior enclosure, to transfer wind and seismic loads to the foundation by functioning as a diaphragm, and to transfer loads from the floor to the vertical load bearing assemblies, which then transfer the loads to the foundation. As part of the provision for environmental separation, floor systems have to control heat flow, airflow, rainwater, and watervapor flow.

Structure. In Mixed-Humid climates, the primary structural approach is site-built wood framing utilizing engineered elements, such as prefabricated I-joists and sheet goods, such as OSB.

Insulation and Air Infiltration. The optimum approach to insulation involves using spray foam insulation on the interior of the rim joist assembly.

Air-infiltration control is provided by an air barrier. The air barrier is the rim joist assembly itself sealed to the framing elements above and below using sealant or spray-foam insulation.

Water Management, Drainage, Vapor Diffusion. Rainwater management is provided by using a weather resistive barrier as a drainage plane and integrating this with the insulating sheathing of the frame assembly, either above or below the floor system to provide drainage plane continuity. 
Vapor diffusion is addressed and allowed by installing vapor retarders as opposed to installing vapor barriers on the interior or exterior of assemblies constructed in Mixed-Humid climates.

Interaction with Mechanical Systems. The tighter the building enclosure, the greater the pressure differential created with exhaust appliances. The use of an air-barrier rim-joist assembly results in a tighter building enclosure.

Excessive long-duration interior negative pressures should be avoided. A depressurization limit of 5 Pascals is recommended for continuously operating exhaust appliances. A depressurization limit of 20 Pascals is recommended for intermittent-operating exhaust appliances. Only sealedcombustion, direct-vent, or power-vented appliances that do not allow combustion by-products into the house should be installed within the pressure boundary of the building enclosure.

\section{Roof/Ceiling/Attic}

The function of roof/attic systems is to provide environmental separation between the interior and exterior, as well as to transfer wind and seismic loads to the vertical load bearing assemblies. As part of the provision for environmental separation, roof/attic systems have to control heat flow, airflow, rainwater, and water vapor flow.

Structure. In Mixed-Humid climates, the primary structural approach is site-built wood-framing utilizing engineered elements, such as prefabricated roof trusses and sheet goods, such as OSB and plywood.

Insulation and Air Infiltration. As long as there is no ductwork planned for the attic space, the optimum approach to roof insulation involves blowing insulation on the top surface of ceiling gypsum board. This ceiling insulation level is maintained throughout the entire plane of the ceiling extending to the perimeter walls. Roof trusses are constructed in such a manner as to maintain the thickness of ceiling insulation directly above the top plates of the exterior wall framing. Baffles are installed to control wind washing.

Air infiltration control is provided by an air barrier. The ceiling gypsum board is installed to function as an air barrier. Dropped ceiling areas are draftstopped, ceiling light fixtures are selected to be airtight, and all penetrations through plates are air sealed.

If there is ductwork planned for the attic space in a Mixed-Humid climate, two strategies may be used. One is an unvented, conditioned attic construction that would be recommended in place of insulation blown on top of the ceiling gypsum board. The mechanical equipment and ductwork are then located in the conditioned space, reducing the energy losses due to locating the mechanical equipment in a vented attic. Alternatively, the top surface of the ceiling gypsum board may be insulated in a vented attic with well insulated, sealed ducts above the insulation. With this approach, the total HVAC system leakage (air handler and duct distribution system) to outside should be less than 5\% of air handler flow, and the insulation level on the ducts should be a minimum of R-8.

Water Management, Drainage, Vapor Diffusion. Traditional roofing materials, such as shingles, are used to provide rainwater management at the roof deck.

In the case of a vented attic, vapor diffusion is handled by providing passive or active roof/attic ventilation and by not installing an interior vapor barrier. In the case of an unvented attic, vapor diffusion is accommodated by not installing a vapor barrier on the interior, and the duct system 
provides conditioned air.

Figures 16 and 17 are examples of building envelope details for recommended Mixed Humid crawl space and basement assemblies.

Interaction with Mechanical Systems. Excessively long-duration interior negative pressures should be avoided. A depressurization limit of 5 Pascals is recommended for continuously operating exhaust appliances. A depressurization limit of 20 Pascals is recommended for intermittent operating exhaust appliances. Only sealed-combustion, direct-vent, or power-vented appliances that do not allow combustion by-products into the house should be installed within the pressure boundary of the building enclosure. 


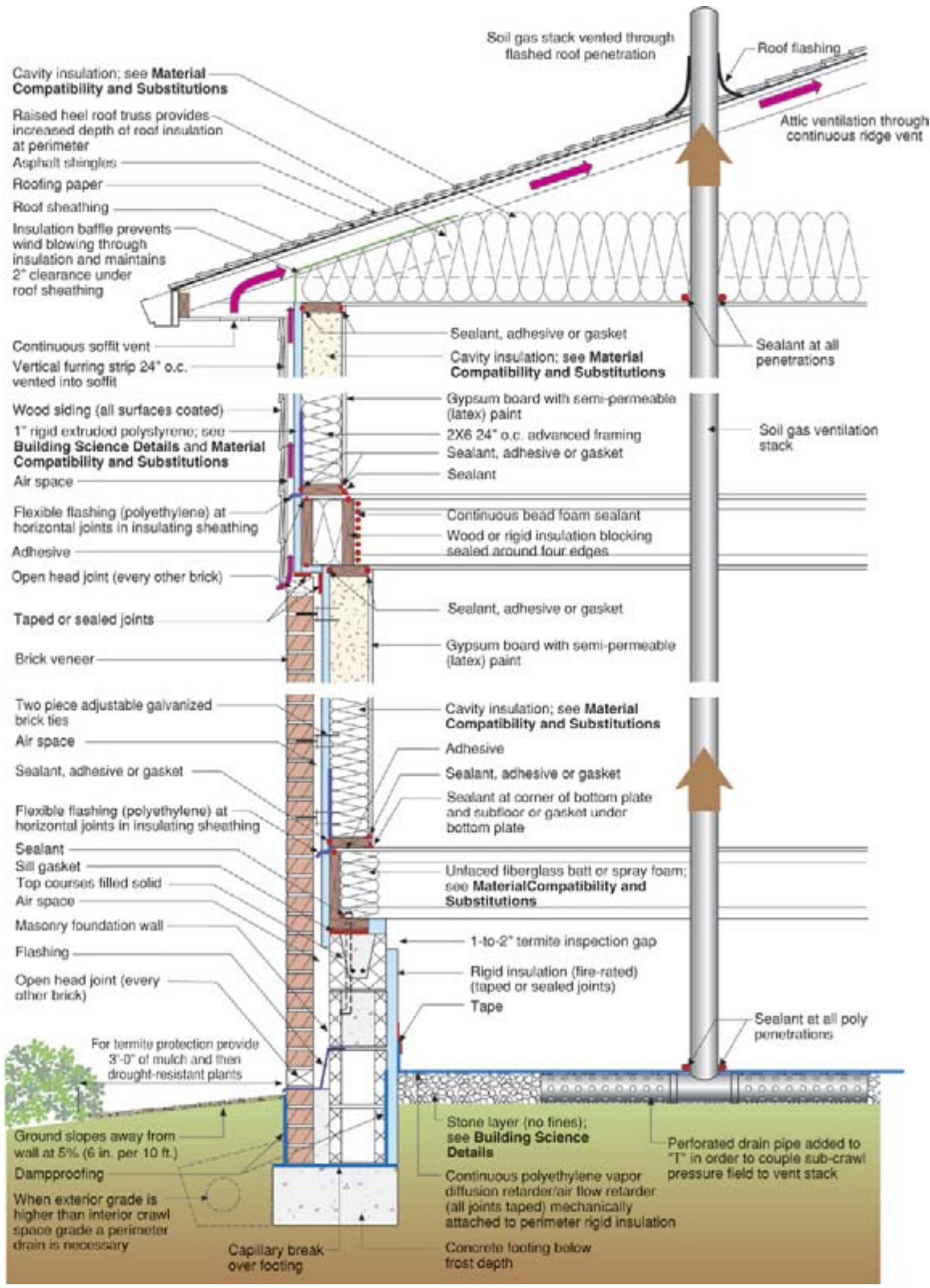

Figure 16. Mixed-Humid: recommended wall section for crawlspace foundation 


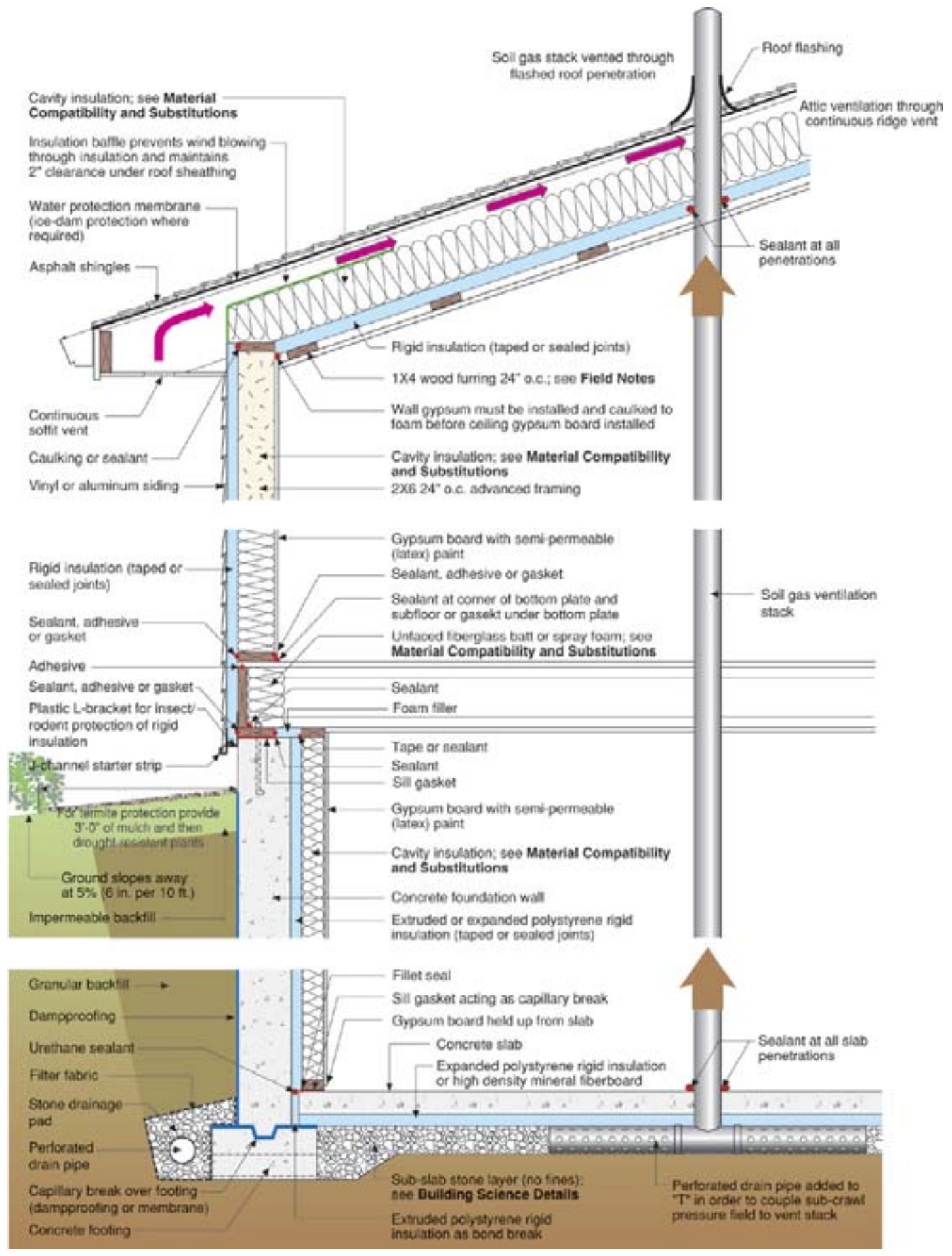

Figure 17. Mixed-Humid: recommended wall section for basement foundation 


\section{Space Conditioning and Ventilation Systems}

\section{Forced Air}

Forced air heating and cooling systems are the most predominant type of system in today's residential new construction market. This is driven primarily by the market for central air conditioning. According to U.S. census data, 91\% of the houses constructed in the northern part and $100 \%$ of the houses constructed in the southern part of the Mixed-Humid climate region in 2005 had central electric air conditioning. Central natural gas-fired furnaces were used in 88\% (northern Mixed-Humid climate region) and 47\% (southern Mixed-Humid climate region) of newly constructed houses in 2005.

To accomplish the target of 30\% whole-house energy savings in the Mixed-Humid climate region, a direct-vent condensing furnace is recommended. Direct-vent furnaces use outdoor air for combustion and can be easily located within the conditioned space. This was the approach taken for several of the case studies provided. In areas where natural gas is not available, a high efficiency electric heat pump is recommended.

Induced draft furnaces draw combustion air from the surrounding space and for "unusually tight construction" (which all 30\% homes should be), outside make-up air must be ducted in. These outside air ducts can cause cold draft complaints and defeat many of the objectives of a tight building envelope. Induced draft furnaces are not recommended for $30 \%$ whole-house energy savings homes.

Locating the forced-air system (air-handler equipment and ducts) within the conditioned space is important to whole-house performance. By locating the furnace within the thermal envelope, not only is the leaky and minimally insulated cabinet within the conditioned space, but all of the ductwork is as well. This minimizes the system inefficiencies associated with air leakage and thermal losses.

Methods for locating the duct system within the conditioned space include the use of open-web floor trusses, dropped ceilings and soffits, modified roof trusses, or an unvented or "cathedralized" attic. ${ }^{28}$ The "best" method depends upon the house plan, the type of foundation, and the builder's preferences.

Homes with basements typically have the equipment located in the basement with ducts that serve the first floor via floor registers. Duct chases should be provided in the first-floor plan to bring supply air to and return air from the second floor. The use of open-web floor trusses provides spaces for ducts to run to serve second-floor registers or up into interior walls for high wall supply registers. Space-conditioning ducts should not be run in outside walls, and return ducts should not be panned. Central hard-ducted returns are recommended with passive return air paths, such as jump ducts or transfer grilles from bedrooms.

Homes with slab foundations commonly have ducts in the attic with ceiling supply registers. For these homes, the opportunity to bring the ducts into the conditioned space with dropped ceilings

\footnotetext{
${ }^{28}$ Hedrick, R., Home Builders Guide to Ducts in the Conditioned Space, www.energy.ca.gov/reports/2003-1117_500-03-082_A-16.PDF
} 
and/or soffits should be considered first. ${ }^{29}$ Alternatively, Building America teams have also employed unvented attics and modified roof trusses.

With the high-performance envelope measures described in previous sections, the annual cooling load for homes in the Mixed-Humid climate region is less severe than it is in warmer climate regions, but it is still substantial. Air-conditioning systems with efficiencies at the new NAECA $^{30}$ minimum efficiency of SEER 13 are usually sufficient. However, the availability of incentives for higher efficiency equipment and/or the specific design and loads of the home could make even higher efficiency equipment an appropriate consideration.

Selecting an efficient air conditioner is only part of the story. Right sizing of air conditioners (using ACCA Manuals J and S [ACCA1995a, 2003]) will minimize operating efficiency losses resulting from cycling. Air conditioners and matching evaporator coils should be selected that have a sensible cooling capacity that meets or slightly exceeds the sensible cooling load from Manual J. Proper installation is required to ensure that air conditioners perform to their rated efficiencies. Improper refrigerant charge can significantly compromise air-conditioner efficiency. Thermostat expansion valves (TXVs), which dynamically adjust refrigerant flow, can compensate for improper charge and should be used instead of orifice-type expansion devices.

Furnaces or air handlers with "variable-speed” BPM DC motors (sometimes called electronically commutated motors, or ECMs) are recommended (Pigg 2003). These motors are more efficient at lower speeds than the more common permanent split-capacitor (PSC) type motors. Efficiency at lower speed operation is increasingly important in systems with multiple gas-firing stages, enhanced dehumidification capability during cooling, air cleaning equipment, or integrated ventilation.

\section{Hydronic}

Where air conditioning is not installed initially, as is often the case for affordable housing, or where radiant heating is desired, a boiler can be considered. For space heating, standard boiler efficiencies are not as high as condensing furnace efficiencies. Condensing boilers are available from a limited number of manufacturers, but they are expensive and their performance has not been thoroughly evaluated by the Building America teams. Nevertheless, when system performance is considered, including the hydronic distribution system and the use of the boiler to supply domestic hot water needs as well, a high efficiency (85\%-87\% AFUE) non-condensing boiler with a power vent or direct vent may be the optimum choice.

The use of domestic water heaters for space heating is discussed further in the section of this report entitled Combination Systems - Space and Water Heating.

\section{Ventilation}

In addition to point-ource exhaust systems that are ducted to the outdoors for bathrooms and kitchen ranges, a whole-house mechanical ventilation system that is capable of meeting the

\footnotetext{
${ }^{29}$ McIlvaine, Beal, and Fairey. Design and Construction of Interior Duct Systems. www.fsec.ucf.edu/bldg/baihp//pubs/interior_ducts.pdf.

${ }^{30}$ NAECA refers to the National Appliance Energy Conservation Act established in 1987.
} 
specifications of ASHRAE Standard $62.2^{31}$ is recommended. For Mixed-Humid climate homes, there are several approaches with varying levels of initial cost and complexity (DOE 2002). The following systems may be appropriate:

- a balanced system using an energy-recovery ventilator

- an exhaust-only system low-sone bath fan rated for continuous duty

- a supply-only system integrated with the central air-handling unit.

Each system has different features and benefits, and there is no clear "best" approach that applies for all builders and homebuyers in the Mixed-Humid climate.

Balanced heat- or enthalpy-recovery systems have the advantages of transferring heat and moisture between the incoming and outgoing airstreams, but have the highest initial cost. The extent that these systems are marketable to potential home buyers is important to the selection of this approach. These systems also provide higher outside flow rates (100 cfm or higher) than called for by ASHRAE 62.2 (60 cfm for a three-bedroom, 3,000- $\mathrm{ft}^{2}$ home). Homeowners need to understand the operation and importance of proper maintenance for these systems to perform properly.

It has been demonstrated in the northern section of the Mixed-Humid climate region that exhaust-only systems are the lowest in initial cost and simplest to implement. ${ }^{32}$ However, the outside air enters the home unfiltered and through unknown locations. The circulation of the ventilation air throughout the home is also dependent upon the house plan, location of the exhaust fan(s), and the frequency of operation for the home's central air handler.

Supply-only systems provide the ability to filter the air. With adequate control of winter indoor humidity levels, a supply-only system with a passive outside air inlet to the central air handler's return with appropriate dampers and controls has been successfully employed in Building America homes.

A central fan integrated ventilation system ("fan-cycling”) provides supply ventilation and whole-house mixing with minimal additional cost to the builder. An outdoor air duct with integral motorized damper is connected to the return side of the air handler and a controller operates the motorized damper and central fan intermittently to provide adequate ventilation by drawing in a percentage of outdoor air as the central fan re-circulates the indoor air. It is important to note that some manufacturers have warranty limitations on low return-air temperatures. The volume of outdoor air brought in and corresponding mixed return-air temperature at winter design conditions should be evaluated to make certain it will be within acceptable limits. As with all mechanical systems, it is also important that the system is properly commissioned. ${ }^{33}$ Two factors that must be considered for this type of ventilation system are the

\footnotetext{
${ }^{31}$ ANSI/ASHRAE 62.2-2004, Ventilation and Acceptable Indoor Air Quality in Low-Rise Residential Buildings.

${ }^{32}$ Furnace Fan Penalty, Energy Design Update, June 2005.

${ }^{33}$ BSC. 2004. Ventilation System Installation and Commissioning Guide. 6 pp; Record No. 35395. Building America Web site document database: www.eere.energy.gov/buildings/building_america/pdfs/db/35395.pdf\#search=\%22Ventilation\%20System\%20Install ation\%20and\%20Commissioning\%20Guide\%22
} 
electricity used to drive the central fan, and the challenge of obtaining the desired ventilation rate through a passive outside air duct.

As with all mechanical systems, it is important that ventilation systems be properly commissioned. Commissioning should include verification of fan operation and control settings and measurement of the outside air volume.

\section{Air Distribution}

For the $30 \%$ energy-savings level, a number of recommendations apply to the design of the duct system:

- Design should be in accordance with ACCA Manual D

- Ductwork should be located within the thermal envelope of the house

- Ducts should not be located in exterior walls

- Ducts must be air-sealed using UL 181-approved mastic or equivalent for the particular duct type

- "Panning” between joists and the use of stud cavities for supply or return air is not recommended

- Ducts may be of galvanized sheet metal, duct board, or flex duct

- There must be continuity of the vapor barrier on insulated ducts not running inside conditioned spaces.

Sometimes duct systems need to run in unconditioned spaces, but this practice should be minimized to the greatest extent possible.

To accommodate heating and cooling units and duct systems within the thermal envelope of the house, a number of techniques may be employed. This typically impacts the architectural design of the house and should be considered at the early schematic phase of design. Keeping ducts inside the conditioned space may also involve framing systems that allow ducts to be run through it, such as an open-web floor-truss system. Alternately, dropped soffits, tray ceilings, and lower ceiling heights in "service" function rooms like baths, hallways, and closets can accommodate ducts inside the envelope. Strategies include the following:

- Locate ducts within an insulated, non-vented, conditioned crawl space or basement

- Locate within an insulated “cathedralized” attic

- Locate in open-web floor trusses

- Develop chase walls to accommodate duct risers

- Design closets inside the conditioned space for locating the air handler in houses using slab on grade construction.

While the distribution system is important from an energy perspective, there are also health, safety, and indoor air quality issues to be considered. The following sections briefly discuss each, with recommended solutions. 


\section{Sealed Forced-Air Distribution Systems}

Leaky duct systems located outside the conditioned space, in addition to the energy losses introduced, may result in indoor-outdoor pressure imbalances that generate significant air leakage through the building envelope. For the 30\% improvement house, extensive duct sealing is typically required. For metal ducts, UL 181-approved mastic is the only acceptable sealing method; for duct board, UL 181 tapes are accepted; and for flex duct, a combination of UL 181approved mastic and strap ties should be used. The target for total duct leakage to the outside is $5 \%$ of the high-speed system-cooling airflow in CFM, as tested at 25-Pa reference pressure. To further reduce duct leakage, do not pan joists or use stud cavities for supply or return air. It is virtually impossible to seal building cavities properly to achieve the target tightness for forcedair systems.

\section{Isolate the HVAC system from areas with potential pollutants}

One of the most potentially hazardous IAQ problems arises when return ducts run through garage spaces where the opportunity exists to draw $\mathrm{CO}$ from automobile exhausts or other pollutants from hazardous chemicals often stored in the garage into the duct system and redistribute it throughout the house. Locating the HVAC unit in the garage is not recommended in the $30 \%$ improved houses, but it is not always possible to relocate the air-handling unit. If the air handler and return-air ducts must be located in the garage, any return-air ductwork and the air handler should be thoroughly sealed with UL 181-approved mastic, with a target leakage between the duct system and the garage of 0 CFM@25 PA. This yields the least possible opportunity for bringing garage air into the return system.

\section{Pressure Balance the System}

Pressure imbalances can cause air movement through the envelope when the HVAC system is operating, wasting energy and potentially causing moisture problems. Imbalanced airflows can also cause room-to-room or floor-to-floor temperature differences, leading to comfort complaints. Finally, imbalanced airflows can draw unwanted pollutants into the house, causing indoor air-quality problems. One key factor in eliminating room-room and indoor-outdoor pressure imbalances is the adequacy of the return air path. In homes with individual-room ducted returns, this is generally not a problem. Individual-room ducted return systems are losing favor because of their costs. From a cost-effectiveness standpoint, a well-designed central return system with individual room pressure relief is considered the standard for the $30 \%$ improvement house. To qualify as well-designed, the return system must incorporate adequate relief from each room where entry doors may be closed. Thus, return air recommendations include the use of ceiling "jump ducts," or transfer grills located in the walls. Door under cuts are generally not considered to be acceptable because they are often inadequate in area and/or blocked by the installation of carpeting. One important consideration in the installation of "jump ducts" or transfer grilles is to maintain a satisfactory acoustic separation between spaces. This is typically accomplished by the use of flex duct, duct lining with sound-absorbent material, a slightly circuitous path, or some combination of these strategies to block sound transmission.

\section{Supply-Air Register Selection and Placement}

The distribution of the heating or cooling air stream from the supply register to the return point is critical to maintaining comfort conditions within the room. In the 30\% improvement house, envelope insulation, including window U-value and SHGC, and air sealing have been improved 
to such an extent that basic comfort needs are more easily met by the HVAC system. In particular, envelope surface temperatures are moderated to a considerable degree, which results in reduced radiant heat loss (or gain) to room occupants, improving comfort conditions. Similarly, solar gains through low-SHGC windows are reduced, considerably improving cooling season comfort conditions. With good air sealing, houses are much less drafty than those built to older construction standards.

All these reduced loads and improved comfort conditions mean room heating/cooling air volumes (at typical supply temperature) may be reduced. If typically sized registers are used, discharge velocities are reduced, and the air has less "throw" within the room. This is a new operating region for forced-air systems and presents a number of challenges to achieving a proper design for good comfort conditions.

In cooling-dominated climates, it has been typical to locate supply registers in the ceiling. This works well for cooling, but may present problems during heating periods. High sidewall and ceiling register placements have been used successfully in Building America projects. To attain optimal performance and comfort, it is critical to properly select registers based on throw characteristics and the volume of air being delivered to the room. This may require designing at the upper limits of recommended face velocities and the purchase of "non-standard" register sizes. It may also require the use of registers with manually operable vanes to fine-tune airflow for optimal comfort.

In general, high-sidewall applications have been used where the register is directed at the wall of dominant heat loss or gain (usually the wall with windows or glass doors) and the register is no more that 12 to13 ft away. Ceiling diffusers with curved blades to help direct the airflow along the ceiling can be used where the wall opposite the dominant load exceeds $13 \mathrm{ft}$.

Research is currently underway in the Building America Program to understand the issues of air distribution in high-performances houses and to develop recommendations for supply and return apertures to achieve the best comfort conditions consistent with a highly energy-efficient system.

There are many issues to consider including the following:

- Register location and discharge pattern

- Discharge velocity

- Discharge temperature

- Effect of return location

- Stratification and mixing patterns

- Part-load operation, heating/cooling variation

- Impact of zoning systems

- Solar load variability

- Buoyancy issues

- $\quad$ Sound issues

- Register/nozzle configurations 
- Register approach conditions - boots

- Dampening and control.

The recommendations that are developed from these ongoing investigations will enhance the current recommendations for houses achieving 30\% whole-house savings and will likely be critical for houses at the $40 \%$ and greater improvement levels.

\section{Duct insulation}

If ducts cannot be brought within conditioned spaced, supply ducts should be insulated to R-8 minimum and return ducts to R-4 minimum. In the Mixed-Humid climate, if ducts must be run in attics, it is not generally recommended to bury ducts under attic insulation without careful consideration for the possibility of condensation. Condensation can form on the outside of the duct vapor barrier and cause moisture problems in the home when buried under additional attic insulation. Similarly, it is critical to make sure all metal fittings are well insulated to avoid condensation.

\section{Dehumidification}

Controlling indoor moisture will consume more energy than not controlling it. However, providing efficient means to limit indoor relative humidity enables other improvement measures that exceed the cost of dehumidification. For example, reducing sensible heat loads by using low solar heat gain windows and getting ducts out of hot attics reduces cooling energy consumption more than the increased energy consumption of supplemental dehumidification. Dehumidifying interior conditioned spaces will consume energy but the benefits of indoor air quality, comfort, and durability are clear. As homes become more energy efficient, they should also be comfortable, safe, and durable, which will ultimately sell more energy efficient homes.

Especially for high-performance, low sensible heat gain homes, the need for supplemental dehumidification begins to become obvious in the mild swing seasons and at night. Low sensible heat gain reduces demand for cooling while a latent load still exists. The addition of supplemental dehumidification to the high-performance house enables the energy savings of efficiency improvements that significantly reduce cooling demand without suffering from high, uncontrolled indoor humidity. The addition of ventilation to standard houses in humid climates produces a slight upward trend in indoor humidity, but differences in occupant behavior can have a larger impact. Internal heat and moisture generation, thermostat set points, thermostat setup and manual thermostat on/off control seem to have the greatest effect. ${ }^{34}$

Use of supplemental dehumidification could be considered a necessity in some climates (hot humid), but in the Mixed-Humid climate region the need for supplemental dehumidification can be more dependent on homeowners' habits with the thermostat and internal moisture generation. Lowering the thermostat cooling set point tends to lower the humidity via the cooling system, whereas elevating the cooling set point tends to increase the humidity. Also, a house with high internal moisture loads will experience heightened humidity, if not for supplemental dehumidification.

\footnotetext{
${ }^{34}$ Rudd, A and H. Henderson. 2005. Monitored Indoor Moisture and Temperature Conditions in Humid Climate U.S. Residences, BSC Deliverable KAAX-3-32443-08.B.2.
} 


\title{
Mechanical, Electrical, and Plumbing Systems
}

\author{
Lighting
}

The development of improved efficiency in residential lighting has been pursued in a number of prototype homes. These have ranged from the simple substitution of screw-in conversion compact fluorescent lamps (CFLs) used in conventional fixtures to a High-Performance Lighting (HPL) approach using a full complement of hard-wired, dedicated compact and linear fluorescent fixtures. In addition to providing excellent light quality, a key objective of several HPL prototype installations has been to provide as much of the basic ambient lighting and key task lighting in the home as possible. The reason for this emphasis is to maximize the efficient light content of the house and minimize the discretionary (usually incandescent) portable lighting provided by the homeowner. This approach yields the greatest reliable lighting energy-use reduction. In addition, fluorescent lamps give off less heat than their incandescent counterparts, thereby lowering internal gains and making homeowners feel more comfortable during cooling conditions.

With the current cost of good quality hard-wired fluorescent fixtures (those with electronic ballasts and good optics), the HPL approach does not appear to be cost effective for a house at the 30\% improvement level. The industry is still lacking a family of more affordable hard-wired fluorescent fixtures that meet production-builder price points. Important steps have been taken in this regard, most notably the development by Lawrence Berkeley National Laboratory, the California Lighting Technology Center, and Lithonia of the recessed downlight twin package. This package offers a pair of good quality recessed downlight at a reduced manufacturing and installation cost. More innovative development of this type is needed across the board for HPL cost reductions. Simple screw-in CFL substitution is a viable strategy at the $30 \%$ level; however, there are questions as to the persistence of energy savings because the homeowner is free to replace the CFL with a traditional incandescent light bulb. A website that discusses lighting options in detail has been developed and is located at www.ibacos.com/hpl1.html.

The following are near-term energy-savings opportunities for new homes. In some cases, these involve newly commercialized products that are just now entering the market, while in other cases these represent systems that show great promise but need further refinement and fieldtesting:

- Lamps with color-rendition index (CRI) of 80 or higher and a color temperature (CT) of 3000 degrees Kelvin

- Screw-in replacement CFL bulbs with instant-on electronic ballasts. Some are available to work with conventional dimmers

- High-quality, high-output residential-grade CFL downlights for kitchens and hallways

- Linear fluorescent bathroom vanity strips (vertical and/or horizontally mounted)

- Bathroom-occupancy sensors with integrated LED nightlight

- LED porch lighting

- LED exterior security luminaire

- High-output LED walkway lighting 
- Evaluation of energy-savings potential from incandescent dimming.

Residential lighting controls represent a significant opportunity for energy savings. Lighting controls generally refers to technologies that turn off (or turn down) lighting systems when they are not needed. Examples include occupancy sensors, photo sensors, dimmers, and timers.

Technologically, residential controls have improved greatly over the past several years, both in terms of the types of controls options available, as well as their quality and functionality.

Because the cost of these systems is decreasing because of increased demand for commercial applications, they have become increasingly attractive for cost-effective residential applications.

Recognizing these technological and market advances, as well as the potential energy savings of these technologies, energy-code officials have begun to look more closely at residential lighting controls. The new 2005 Title 24 building code in California includes strong incentives for homebuilders to utilize occupancy sensors, photo sensors, and dimmers. In fact, many market watchers now anticipate that homebuilders will choose lighting-control alternatives over energyefficient luminaries to comply with this new code because the controls approaches are often more cost-effective.

\section{Major Appliances}

At the present time, the best practice recommendation for the $30 \%$ improvement house is to use ENERGY STAR-rated appliances. Within the ENERGY STAR-rated offerings, there are differences in performance levels, but these are probably not of significance at the $30 \%$ improvement level. It is also recommended that best-in-class appliances for non-ENERGY STAR-rated appliances be installed or recommended for purchase by the homeowner if not provided by the builder.

While not a mechanism for direct source energy reduction, peak-load shifting is a beneficial strategy from a consumer-utility cost perspective where time of use rates are in effect and can have electric utility system benefits by helping to reduce the need for peak power plants. The cost of energy consumption for appliances can be reduced by operating appliances during offpeak hours and refraining or minimizing their use, especially simultaneous use, during peak hours.

An alternative strategy is to minimize the amount of time that appliances are in the high-power mode by ensuring that the appliance is used in the lowest possible power mode when ever practical. ${ }^{35}$

\section{Water Heating and Distribution Systems}

At the 30\% improvement level, energy use for water heating becomes a significant component of total energy use. Consequently, the following guidance has been developed for the design and installation of DHW Systems:

\footnotetext{
${ }^{35}$ International Energy Agency. 2001. Things That Go Blip in the Night: Standby Power and How to Limit it. www.iea.org/textbase/nppdf/free/2000/blipinthenight01.pdf.
} 


\section{DHW Heater Sizing}

The size of tank and first-hour draw pattern can have an impact on the overall energy consumption associated with hot water. Tank size is a function of first-hour rating, draw patterns, and incoming and outgoing water temperatures. The sizing method described below, takes into account the nominal population of a house, the main supply water temperature, and the efficiency of the DHW heating equipment.

\section{Sizing Method for Tank-Type DHW Heater}

Use this procedure for sizing tank-type domestic hot water heaters.

1. Establish the design population of the house by taking the number of bedrooms +1 .

2. Multiply this by the gallons/person for the climate region where the house is located (Figure 18) to get the first-hour rating for the water heater.

3. Using the first-hour rating from Step 2, select a DHW heater that meets or exceeds this rating.

\section{Heater Selection}

The efficiency target for fuel-fired tank-type gas DHW heaters is $0.60 \mathrm{EF}$ or higher. With the tight house construction of the 30\% improvement level, these heaters should be either power vented (which forcibly discharges the products of combustion and draws combustion air from the house), direct vent with dedicated outside air for combustion, or sealed-combustion units that draw combustion air from outdoors and fan discharge combustion gases outdoors. If electricity is

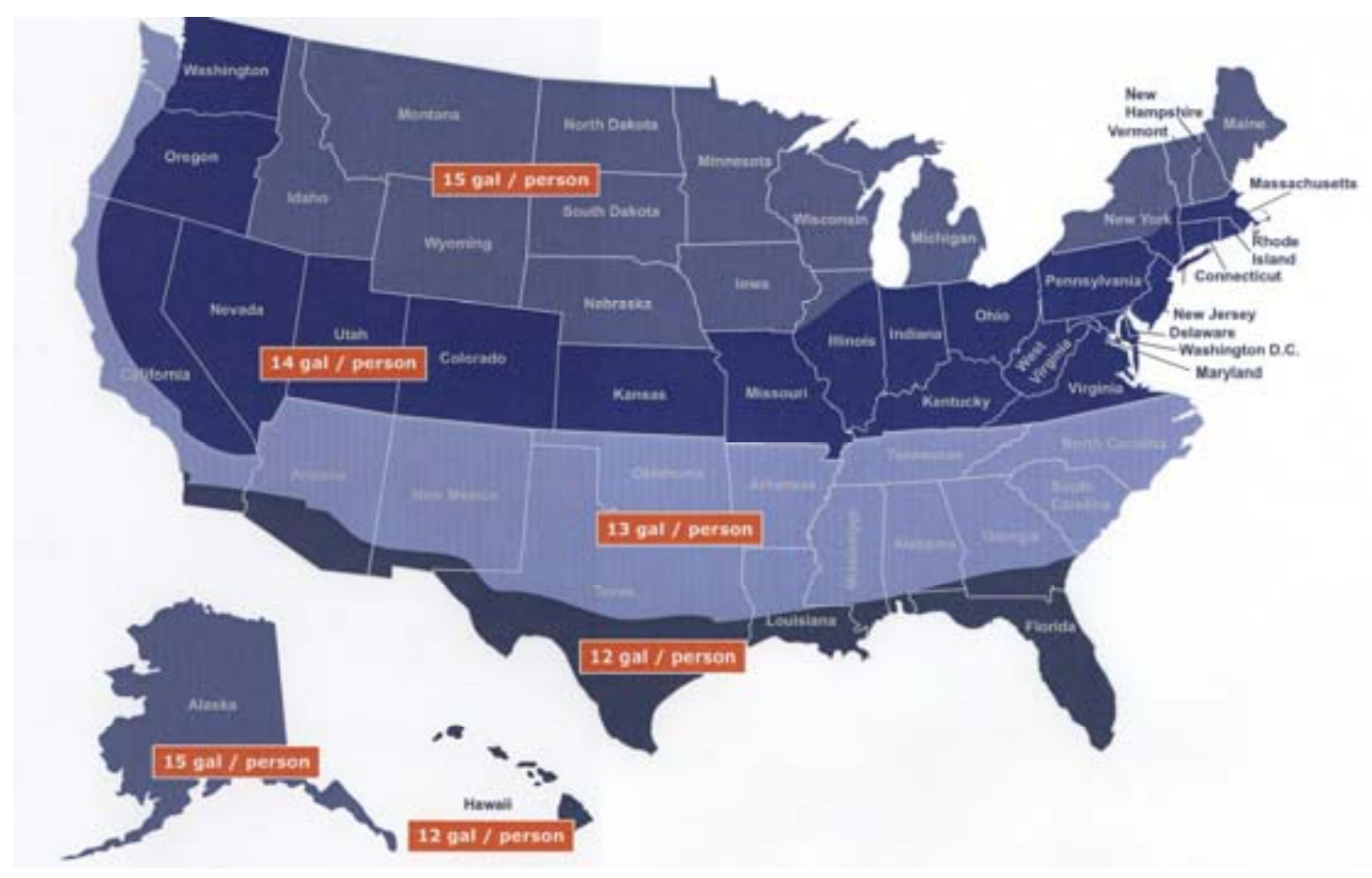

Figure 18. Domestic hot water tank sizing for $135^{\circ} \mathrm{F}$ tank temperature only 
used for heating water, a high-efficiency tank with an EF of greater than 0.90, or a tankless unit could be used. Electric tankless units typically require 240 volts, 60 - 100 amp service, and can induce a significant electric peak load when operating, which may be costly for consumers if they are in a utility service territory that has demand charges or time-of-use rates based on peak power pricing.

Gas-fired tankless water heaters (about $0.84 \mathrm{EF}$ ) can provide significant advantages over the traditional storage tank water heaters for a number of reasons:

- Energy savings: Tankless water heaters have a higher energy factor compared to tank water heaters and are, therefore, a more energy-efficient option.

- Space savings: Tankless water heaters are dimensionally smaller and save space compared to storage tank water heater. This allows for installation in spaces with limited area or in locations closer to the point of use.

- Longer life expectancy and favorable life cycle costs: The tankless water heater has a life expectancy of 15 to 20 years compared to a typical 9 years for storage-tank water heaters. When the replacement of a tank water heater is combined with the lower operating costs, the life-cycle costs of a tankless water heater are generally lower than a tank-type water heater.

Some builders have chosen to install multiple gas-fired tankless units, which may require upsizing of the main gas service when coupled with other gas end-uses in the house (furnace, cooking appliances, dryer, etc.) This could be a significant barrier to widespread adoption, especially in areas with low gas pressures. By installing multiple units, builders are safeguarding against a call from homeowners that there isn't enough hot water, but may be overcompensating because of lack of experience with the tankless gas-fired technology.

If electricity is the energy source for water heating, additional improvements to other areas of the house will likely be needed to achieve the $30 \%$ savings levels, because there is very little room for improvement in electric water-heating efficiency compared to the possible efficiency gains using gas-fired technologies.

Stand-alone electric heat-pump water heaters offer better efficiency than electric resistance heaters, but they are complex, costly, and still evolving as a standard commercial product. They provide the best efficiency when their cold-air discharge can be used to augment home air conditions, which can be a benefit in the Mixed-Humid climate, especially the southern sections of this climate region. Conversely, they can contribute to an additional heating load during the winter. Optimizing these relationships along with this performance variation as a result of supply-water temperature and load pattern is quite challenging. Primarily because of the early state of technology deployment and reliability, stand-alone heat-pump water heaters are not considered a practical choice at the $30 \%$ level. Should these units improve in reliability, and if volume manufacturing brings costs down, then they would be worth considering as part of the overall package.

If a ground-source heat pump is chosen for space heating and cooling, it is possible to use it to generate hot water, either through a desuperheater on the basic water-to-air heat pump or by using a water-to-water system where the heat pump can generate heated or chilled water to be used for space conditioning and domestic hot water. These systems can be effective, but the pricing varies dramatically by region and can be more complex than a traditional gas furnace with DX air-conditioning systems or electric heat pump systems. In an area where no natural gas 
is available, a ground-source heat pump system is an option in all climate regions; however, it requires a skilled and experienced installer base and favorable pricing.

While not required to achieve the $30 \%$ whole-house energy-savings target, there are a number of reliable solar DHW heaters in the market. They represent a range of operating philosophies:

- Storage/non-storage

- Freeze-protected/drain-back

- Passive thermosiphon/pumped cycle, etc.

With good design, these solar systems can all be effective sources of hot water, particularly in sunny climates. What most degrades the performance of solar DHW systems are the details of design, construction, operation, and maintenance. Research has found that a simple set of characteristics, such as a long pipe run from the collector plate combined with a short, infrequent usage pattern, can render the solar contribution nearly negligible. Primarily because of their high cost, solar DHW systems are not considered practical at the 30\% improvement level.

\section{Hot Water Distribution Systems}

The hot water distribution system plays a surprisingly important role in the total energy efficiency of the DHW system. Thermal losses from the hot water distribution piping system while water is flowing, and the losses associated with "stranded" hot water as it cools down once faucets are turned off, can amount to a very substantial portion of total hot water energy use. Thus, guidance on the configuration of the system, its insulation, and patterns of use can help reduce the piping system component of DHW energy use.

Basic guidance on the layout of DHW piping suggests that the DHW source and major use points should be as close to each other as practical. A good example of this would be the location of the DHW heater in a closet adjacent to the kitchen and laundry that are back-to-back. Short lines will minimize "stranded" losses, which can be considered detrimental during the cooling season. Locating tankless water heaters immediately adjacent to high-use clusters, such as a pair of bathrooms in a remote wing or a second floor, is an excellent way to reduce piping heat losses.

All DHW supply piping should be insulated with standard R-4 pipe insulation. It is readily available, inexpensive, and effective. This includes any hot water lines located in concrete slabs or underground. Increasing tank insulation to a minimum of R-12 by adding a tank insulation wrap can also reduce energy consumption.

Research has also shown that "parallel piped” or "homerun” plumbing systems using PEX piping and a central manifold can reduce energy consumption compared to traditional copper "tree and branch” plumbing systems.

To avoid the waste of water as one "waits for the hot water to arrive" and to provide instantaneous hot water, there is growing use of recirculation systems that continuously circulate hot water through the entire system. This continuous circulation of hot water results in high loss of heat from the piping system, even if insulated, and is strongly discouraged in an energyefficient house of any type. 
If a recirculation system must be installed, a push-button type on-demand re-circulator will minimize the energy penalty associated with recirculation systems. The system circulates the water only when the hot water is needed. It is, thus, more energy efficient than the continuous recirculation system. The on-demand circulating pump briefly moves water out of the hot water pipe and back to the DHW heater down the cold water pipe until hot water is sensed at the faucet. This system greatly reduces the waste of water down the drain.

The on-demand circulator is primarily useful for use points that are a long way from the DHW source and represent a substantial water waste while waiting for the hot water to "arrive."

\section{Combination Systems - Space and Water Heating}

For the purposes of this discussion, combination systems refers to any system that uses a single combustion appliance to provide both the space heating and the domestic hot water needs for the home. Combinations systems used by Building America teams have included:

- A high efficiency gas-fired boiler serving hydronic baseboard units for space heating and an indirect storage tank for domestic hot water. Air conditioning, if needed, would be provided by a separate system.

- A gas-fired storage water heater for domestic hot water and serving space heating loads via a hydronic coil in a central fan-coil unit

- A combination boiler which provides hot water for space heating as well as domestic hot water via a separate heat exchanger

- A gas-fired boiler with one or more hydronic coils for space heating and an indirect storage tank for domestic hot water

The primary advantages of these systems are as follows:

- The reduced cost and complexity of only having to vent one combustion appliance. This can be significant when direct-vent equipment is desired.

- The improved energy efficiency for serving the domestic hot water load. Indirect tanks have significantly lower losses than gas-fired storage tanks with flues, and further improvements can be provided by removing the tank losses entirely with a tankless, on-demand system.

An important factor to success for all of these systems, is that the plumbing and HVAC contractors coordinate and cooperate. Builders are often concerned about who is ultimately responsible for the system. Ideally, one contractor would be responsible for the entire system, but when a forced air system is used, this situation is unlikely.

Systems that use a storage water heater to serve both loads should only be considered in homes with modest space heating loads, $25 \mathrm{kBtu} / \mathrm{hr}$ or less at design, thus making these systems suitable for many houses in the Mixed-Humid climate region. Also, careful design and attention to detail is necessary for proper operation of these systems. ${ }^{36}$ Thermo-siphoning during summer airconditioning operation has been observed in several installations.

Common boilers for space heating will typically have lower AFUE ratings than commonly available condensing furnaces. Thus, the magnitude of space heating loads versus domestic water

${ }^{36}$ Combo Space/Water Heating Systems - "Duo Diligence”, Building Science Corporation. 
heating loads is important to the overall whole-house energy savings. Condensing boilers are available from a limited number of manufacturers, but they are expensive and their performance has not been thoroughly evaluated by the Building America teams.

\section{Onsite Power Systems}

A number of on-site power production systems are currently available for Building America projects and others are in the research stage. Most have been used in Building America projects. These systems include the following:

- Photovoltaics

- Engine generator/combo systems

- Fuel cells.

The 30\% improvement level can be achieved most cost effectively through improvements to the envelope; the heating, cooling, and domestic hot water systems; and possibly the lighting and appliance. On-site power systems are very costly and are not recommended as a strategy to achieve the $30 \%$ savings level.

\section{Miscellaneous Electric Loads}

In the Mixed-Humid climate region, miscellaneous electric loads can account for approximately $22 \%$ up to $30 \%$ of the total energy consumption of the house. This load category includes all of the power used for the "stuff" homeowners typically have in their houses - anything that plugs into a wall outlet. There are strategies to reduce these loads, such as using plug strips to turn off devices with power draws like computers and entertainment equipment when not in use, however at this point these strategies are not something the builder is likely to install as part of the construction of the home. At the 30\% energy-savings level, it is not required to address specific strategies for energy efficiency in this load group, however at higher energy-savings levels $(50 \%+)$ lowering the energy consumption of miscellaneous electric loads will be a critical strategy.

\section{Cost Analysis}

\section{Life-Cycle Cost Analysis}

From a purely economic point of view, building energy optimization involves finding the global optimum that balances life-cycle cost versus utility-bill savings. Given a particular energysavings target, economic optimization can be used to determine the optimal design (lowest cost) to achieve the energy-savings goal. The analysis presented below targets $30 \%-39 \%$ whole-house energy savings with respect to the Benchmark by using the BEopt analysis method to investigate cost tradeoffs associated with various residential energy efficiency and renewable-energy technology options in Atlanta, Georgia, which was chosen as a representative city in the MixedHumid climate region.

\section{Building Characteristics Considered in this Study}

For the Prototype building, a two-story 3,000- $\mathrm{ft}^{2}$ and a single-story 1,500- $\mathrm{ft}^{2}$ residential building were used for this study with the front of the buildings facing east. Although complex floor-plan 
geometries can be analyzed, a simple square floor plan was implemented for the purposes of the current analysis. The buildings were modeled with an unvented crawlspace foundation. Both buildings were assumed to have three bedrooms and two bathrooms. The building was assumed to have 1 -ft eaves. Window area was assumed to be $18 \%$ of floor area with $50 \%$ of the window area facing west, $25 \%$ of the window area facing east, $12.5 \%$ of the window area facing north, and $12.5 \%$ of the window area facing south. The non-uniform window distribution was utilized in order to represent a possible "worst case" window distribution from the available window distribution options currently included in the BEopt analysis method.

The energy options considered in the study include space-conditioning systems (up to SEER 18 and $92.5 \%$ AFUE in the current study), envelope systems, hot-water systems, lighting systems, major appliances, and residential PV. The buildings were assumed to use natural gas for the following end uses: cooking, space and water heating, and clothes drying. Air-conditioner capacities less than 1.5 tons were not considered, nor were furnace capacities less than 50 $\mathrm{kBtu} / \mathrm{hr}$. SEER-10 air-conditioners were not included in this analysis because federal minimum equipment efficiencies mandate the manufacture of air conditioners with a minimum SEER-13. No options that would potentially reduce miscellaneous electric loads other than major appliances were included in the study. Also, no options were included that would result in a house that could not comply with the prescriptive compliance path of the 2006 International Energy Conservation Code (IECC).

\section{Occupancy/Operational Assumptions}

Occupancy and operational assumptions are as defined in the Benchmark and include time-ofday profiles for occupancy, appliances, MELs, lighting, domestic hot-water use, ventilation, and thermostat settings.

\section{Base-Case Building}

Results are calculated relative to the Benchmark. The Benchmark defines baseline features, including wall, ceiling, and foundation insulation levels and framing factors; window areas, Uvalues, and solar heat gain factors; interior shading; overhangs; air-infiltration rates; duct characteristics; and heating, cooling, and domestic hot water system efficiencies.

\section{Cost Assumptions}

Each option has an assumed first cost and lifetime (Appendix B). Costs are retail and include national average estimated costs for hardware, installation labor, overhead, and profit. Some are input as unit costs that are then multiplied by a category constant (e.g., ceiling insulation costs are input per square foot and multiplied by ceiling area by BEopt). Some inputs are energyoption specific (e.g., cost of solar water heating systems). Inputs can also be based on total costs (e.g., cost of wall constructions with different insulation values) because BEopt will calculate the differences between option costs.

Construction costs (wall insulation, ceiling insulation, foundation insulation, etc.) are typically based on R.S. Means (1999) cost estimates. Window and HVAC costs are based on quotes from manufacturers' distributors. Appliance costs are based on manufacturers’ suggested retail prices.

Building construction options (wall insulation, ceiling insulation, foundation insulation, windows, etc.) are assumed to have 30-year lifetimes. Equipment and appliance options typically have 10- or 15-year lifetimes. Lifetimes for lighting options (incandescent and compact fluorescent lamps) are modeled based on cumulative hours of use. 
The mortgage interest rate is $5 \%$ above the rate of inflation, which is assumed to be $3 \%$. The onsite power option used for this study is a residential PV system with an installed cost of $\$ 7.50$ per peak Watt DC, including present value of future operation and maintenance costs. This cost is assumed to be independent of PV system size. Additional costs associated with mounting large PV arrays are not considered. For Atlanta, natural gas is assumed to cost $\$ 1.023 /$ Therm, and the cost of electricity is modeled as $\$ 0.0632 / \mathrm{kWh}$. These values are based on the data published by EIA for the month of May 2006.

\section{Simulation Limitations}

Some benefits not considered by the BEopt analysis method will have an influence on the realworld design of a home, such as reduction in warranty and liability exposure, increased customer satisfaction, and higher quality construction practices. The BEopt analysis method does not consider concerns with regard to IAQ, mold, and combustion safety. In a real world design, these factors may lead the designer, engineer, builder, or architect to use equipment or construction practices that increase first cost without reducing utility bills in order to provide better indoor air quality, combustion safety, occupant comfort or other design considerations that have high value to the builder or potential homebuyer. There are also some side effects that the simulations are not equipped to deal with, such as the costs of change in a builder's organization necessary to implement energy-efficient design approaches, the costs of retraining trades to implement Building America strategies, or termination of long-term relationships with a trade because the trade would not adopt energy-efficient practices. There is currently no methodology available to account for these effects in the simulation. Further development of a methodology to account for these effects and collection of appropriate data to inform the simulation would be necessary if there is interest in considering these effects.

The BEopt analysis method is relatively new to the Building America program. The case studies included in the Building America Systems Research Results section were not initially simulated with BEopt nor was BEopt used to guide the design process of the case study homes. The case studies are the result of years of field experience and design work done by Building America teams.

Currently, this analysis method is being used for general programmatic guidance in an effort to understand at what cost and performance specifications efficiency and renewable technologies begin to look attractive when compared to other efficiency and renewable technologies. In its current form, the BEopt analysis method is useful for programmatic studies in terms of weighing the merits of certain efficiency and renewable technologies versus standard construction practices or other technologies using national average cost data, retail cost data, or projected costs for emerging technologies; however, cost of these technologies may be very different on a production or custom-builder scale. The results shown here should not be taken as representative of all builders in this climate region.

As an example of what building efficiency options would lead to a combination of options that would achieve 30\%-39\% whole-house energy efficiency relative to the Benchmark, an optimization was performed with the Atlanta $\mathrm{TMY}^{37}$ weather file. Figure 19 shows the 30\% whole-house energy savings point that falls on the cost-optimal curve for Atlanta.

\footnotetext{
${ }^{37}$ Typical Meteorological Year weather data, http://rredc.nrel.gov/solar/old_data/nsrdb/tmy2/
} 
Based on the costs assumed as shown in Appendix B, and within the limitations of the analysis method and the previously mentioned assumptions, the options selected in Figure 19 would represent a possible least-cost combination for 30\% whole-house energy savings for a singlestory residence in Atlanta. Because costs may vary significantly across the Mixed-Humid climate region, from builder to builder, and over time, this example may not reflect the actual least-cost set of options that would apply to a specific home, builder, and location.

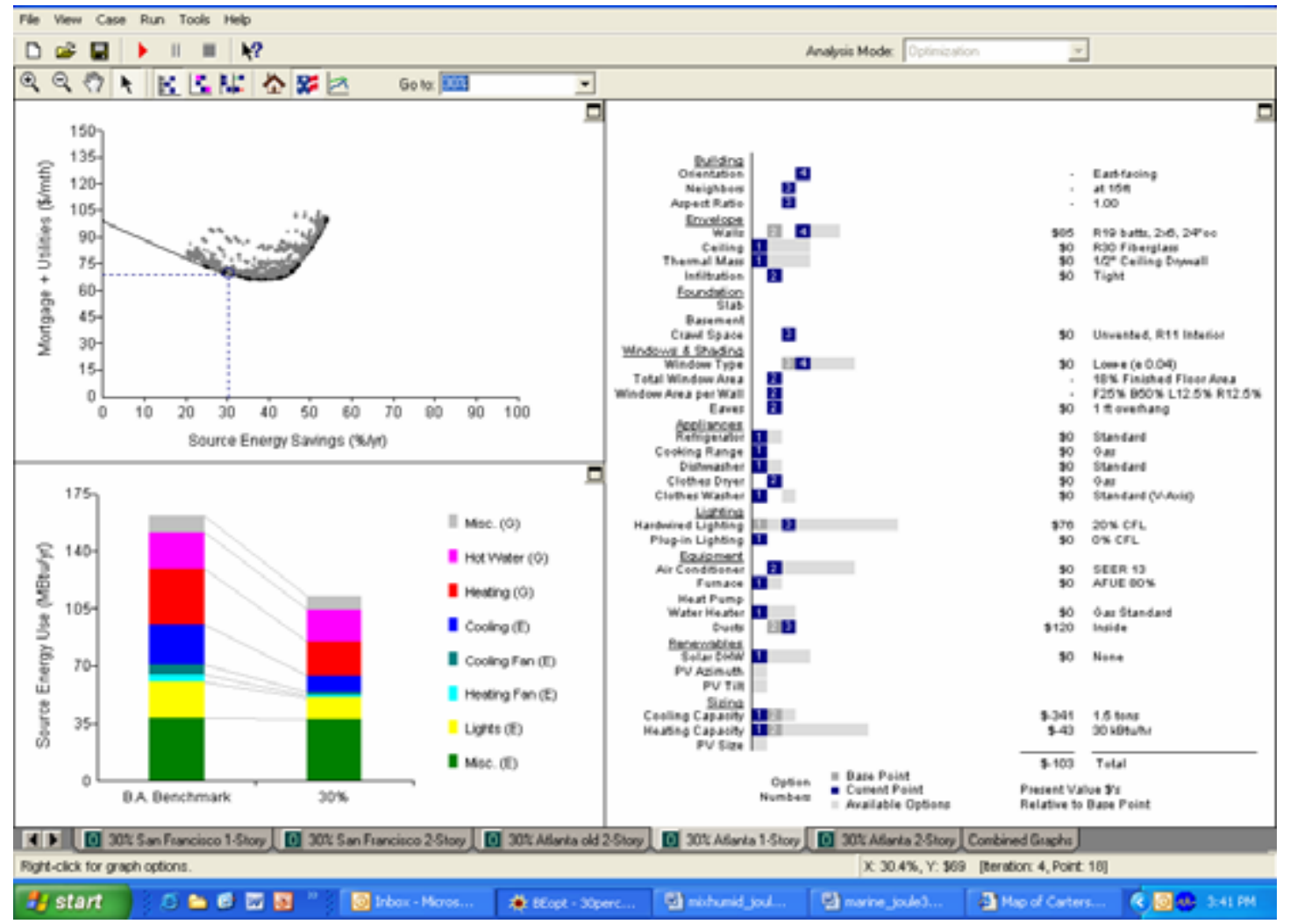

Figure 19. The $30 \%$ point for a single-story Atlanta example case

The results suggest that high-performance windows, ducts in conditioned space, and a small amount of fluorescent lighting is sufficient to achieve the $30 \%$ energy-savings target in Atlanta.

At the other end of the building energy performance range considered here, 39\% whole-house energy savings, the first cost is slightly higher than the 30\% example, but the total energy-related cost is lower. Figure 20 shows an example combination that meets 39\% whole-house energy savings compared to the $30 \%$ combination. 


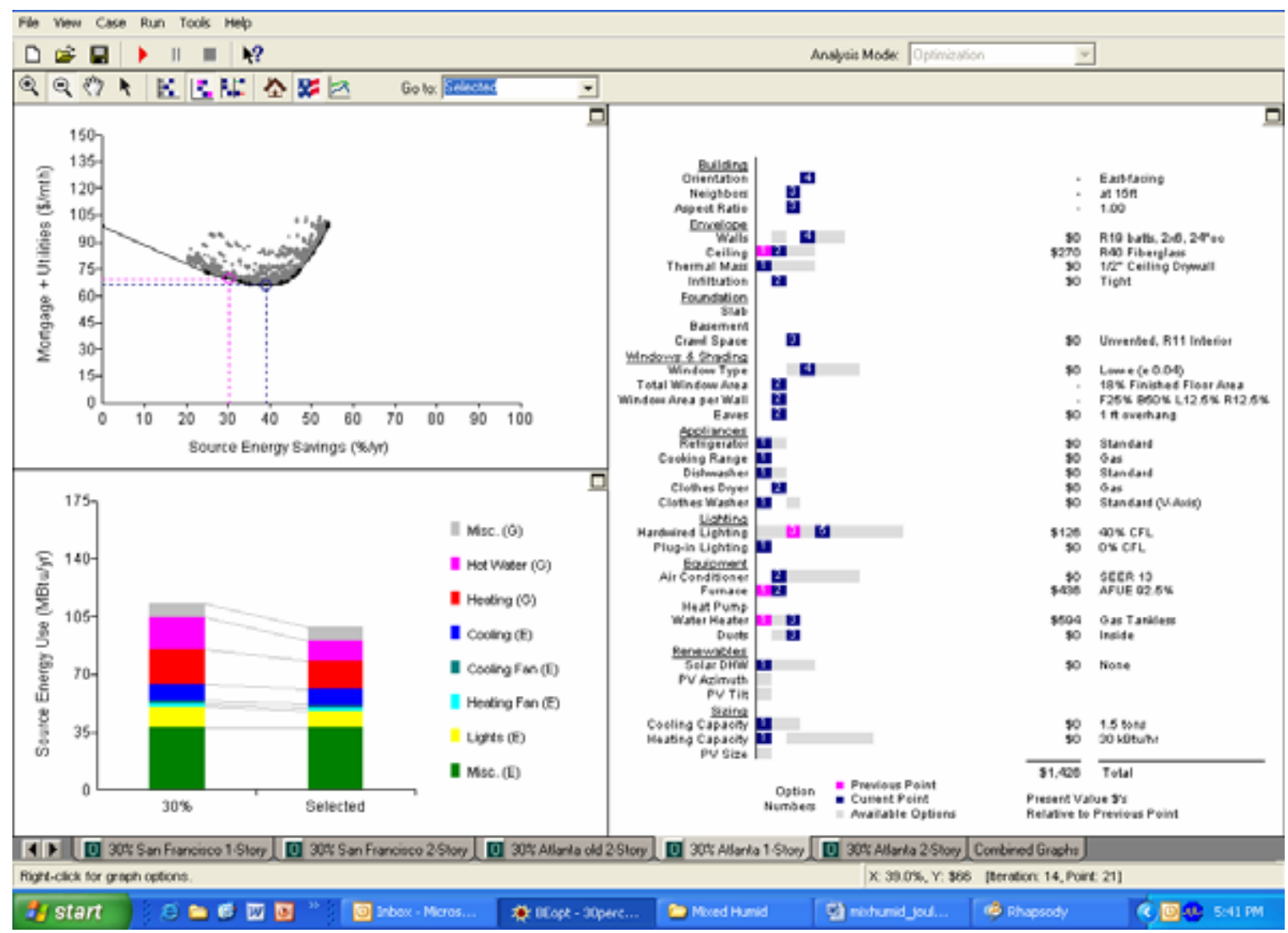

\section{Figure $20 .^{38}$ Comparison of $39 \%$ point to the $30 \%$ point, one-story Atlanta example case}

The comparison of the 30\% combination (represented in magenta) to the $39 \%$ combination (blue only) shown in Figure 20 demonstrates that by utilizing additional ceiling insulation, more fluorescent lighting, a condensing furnace, and a tankless gas water heater, the 39\% energy savings level can be achieved at a lower total cost per month than the $30 \%$ single-story example.

Figure 21 and Figure 22 look at the same energy-performance levels for the two-story case.

The comparison of the $30 \%$ combination (represented in magenta) to the $39 \%$ combination (blue only) shown in Figure 22 demonstrates that by investing in additional basement wall insulation, an ENERGY STAR dishwasher and a SEER-15 air conditioner results in the 39\% point being only slightly more expensive in terms of total cost per month for the two-story example. Table 7 shows detailed features for the $30 \%$ and $39 \%$ example cases.

\footnotetext{
${ }^{38}$ Note that cost show in this figure are incremental relative to the $30 \%$ energy savings point (shown in magenta)
} 


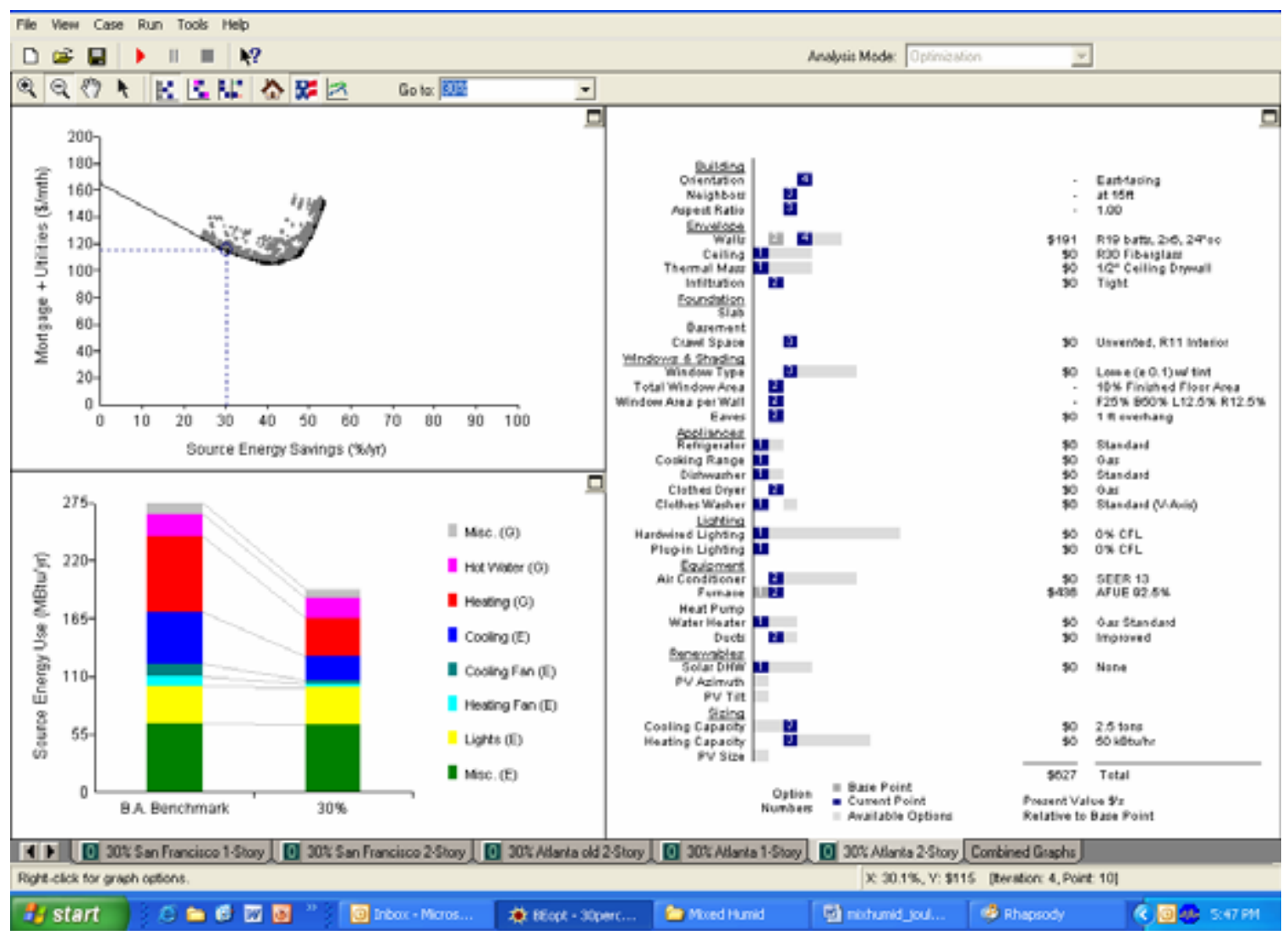

Figure 21 . The $30 \%$ point for the two-story Atlanta example case 


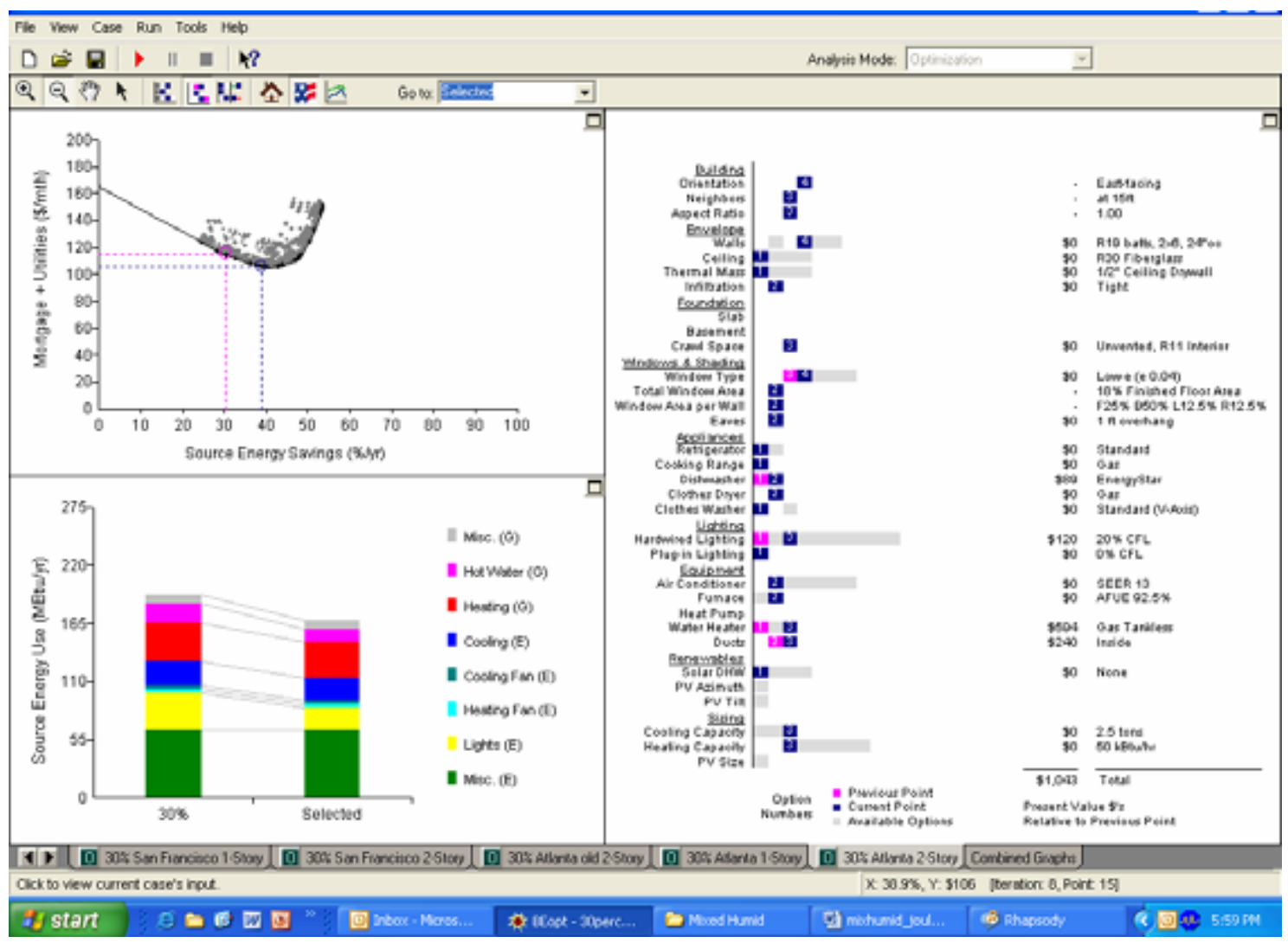

Figure $22 .{ }^{39}$ Comparison of the $39 \%$ point to the $30 \%$ point, two-story Atlanta example case

Table 7 shows very small differences in the options selected between the one- and two-story cases for the energy-savings levels and combinations selected. The differences between one- and two-story examples at the 30\% and 39\% energy-savings level are limited to window type, dishwasher efficiency, and duct location. Within the limitations of the economic model included in the BEopt analysis method, the above example cases would represent a reduction in total monthly cost (mortgage cost - utility cost) when compared to the neutral cost line shown in Figure 6.

${ }^{39}$ Note that costs shown are incremental relative to the $30 \%$ energy-savings point. 
Table 7. Comparison of Single- and Two-Story Cases in Atlanta

\begin{tabular}{|c|c|c|c|c|}
\hline \multirow{2}{*}{$\begin{array}{l}\text { CATEGORY } \\
\text { Number of } \\
\text { Floors }\end{array}$} & \multicolumn{2}{|c|}{$30 \%$ EXAMPLE } & \multicolumn{2}{|c|}{ 39\% EXAMPLE } \\
\hline & One Story & Two Stories & One Story & Two Stories \\
\hline Walls & R-19, 2x6, 24 in. oc & R-19, 2x6, 24 in. oc & R-19, 2x6, 24 in. oc & R-19, 2x6, 24 in. oc \\
\hline Ceiling & $\mathrm{R}-30 \mathrm{FG}$ & $\mathrm{R}-30 \mathrm{FG}$ & $\mathrm{R}-40 \mathrm{FG}$ & $\mathrm{R}-30 \mathrm{FG}$ \\
\hline $\begin{array}{l}\text { Thermal } \\
\text { Mass }\end{array}$ & 1/2-in. Ceiling Drywall & 1/2-in. Ceiling Drywall & 1/2-in. Ceiling Drywall & 1/2-in. Ceiling Drywall \\
\hline Infiltration & $S L A=0.0003$ & SLA $=0.0003$ & $S L A=0.0003$ & $S L A=0.0003$ \\
\hline Crawlspace & $\begin{array}{l}\text { Unvented, R-11 interior } \\
\text { insulation }\end{array}$ & $\begin{array}{l}\text { Unvented, R-11 } \\
\text { interior insulation }\end{array}$ & $\begin{array}{l}\text { Unvented, R-11 interior } \\
\text { insulation }\end{array}$ & $\begin{array}{l}\text { Unvented, R-11 interior } \\
\text { insulation }\end{array}$ \\
\hline Glass Type & $\begin{array}{l}\text { Two-pane, Low-e, } \\
\text { spectrally selective, } \\
U=0.30, \text { SHGC }= \\
0.34, \text { vinyl frame }\end{array}$ & $\begin{array}{l}\text { Two-pane, Low-e with } \\
\text { tint, } U=0.31 \\
\text { SHGC }=0.29 \\
\text { vinyl frame }\end{array}$ & $\begin{array}{l}\text { Two-pane, Low-e, } \\
\text { spectrally selective, } \\
U=0.30, \text { SHGC }=0.34, \\
\text { vinyl frame }\end{array}$ & $\begin{array}{l}\text { Two-pane, Low-e, } \\
\text { spectrally selective, } \\
U=0.30, \text { SHGC }= \\
0.34, \text { vinyl frame }\end{array}$ \\
\hline $\begin{array}{l}\text { Window } \\
\text { Area per } \\
\text { Wall }\end{array}$ & $\begin{array}{l}270 \mathrm{ft}^{2}, 12.5 \% \mathrm{~N} \& \mathrm{~S} \\
50 \% \mathrm{~W}, 25 \% \mathrm{E}\end{array}$ & $\begin{array}{l}540 \mathrm{ft}^{2}, 12.5 \% \mathrm{~N} \& \mathrm{~S} \\
50 \% \mathrm{~W}, 25 \% \mathrm{E}\end{array}$ & $\begin{array}{l}270 \mathrm{ft}^{2}, 12.5 \% \mathrm{~N} \& \mathrm{~S} \\
50 \% \mathrm{~W}, 25 \% \mathrm{E}\end{array}$ & $\begin{array}{l}540 \mathrm{ft}^{2}, 12.5 \% \mathrm{~N} \& \mathrm{~S} \\
50 \% \mathrm{~W}, 25 \% \mathrm{E}\end{array}$ \\
\hline Refrigerator & Standard - 671 kWh/yr & Standard - 671 kWh/yr & Standard - 671 kWh/yr & Standard - 671 kWh/yr \\
\hline $\begin{array}{l}\text { Cooking } \\
\text { Range }\end{array}$ & 45 Therms/yr & 45 Therms/yr & 45 Therms/yr & 45 Therms/yr \\
\hline Dishwasher & $\begin{array}{l}\text { Standard, } 462 \mathrm{kWh} \text {, } \\
\text { eight place setting } \\
\text { capacity, } 131.6 \mathrm{kWh} / \mathrm{yr} \\
\text { machine energy, } \\
5.39 \mathrm{gal} / \text { day DHW }\end{array}$ & $\begin{array}{l}\text { Standard, } 462 \mathrm{kWh} \text {, } \\
\text { eight place setting } \\
\text { capacity, } 131.6 \mathrm{kWh} / \mathrm{yr} \\
\text { machine energy, } \\
5.39 \text { gal/day DHW }\end{array}$ & $\begin{array}{l}\text { Standard, } 462 \mathrm{kWh} \text {, eight } \\
\text { place setting capacity, } \\
131.6 \mathrm{kWh} / \mathrm{yr} \text { machine } \\
\text { energy, } 5.39 \mathrm{gal} / \mathrm{day} \mathrm{DHW}\end{array}$ & $\begin{array}{l}\text { ENERGY STAR, } \\
384 \mathrm{kWh} \text {, eight place } \\
\text { setting capacity, } 82.2 \\
\mathrm{kWh} / \mathrm{yr} \text { machine } \\
\text { energy, } \\
3.76 \mathrm{gal} / \text { day DHW }\end{array}$ \\
\hline $\begin{array}{l}\text { Clothes } \\
\text { Dryer }\end{array}$ & $\begin{array}{l}\text { Gas }-5.7 \mathrm{ft}^{3}, 2.75 \mathrm{EF} \text {, } \\
70.1 \mathrm{kWh} / \mathrm{yr} \\
31.8 \text { therms/yr }\end{array}$ & $\begin{array}{l}\text { Gas }-5.7 \mathrm{ft}^{3}, 2.75 \mathrm{EF} \text {, } \\
70.1 \mathrm{kWh} / \mathrm{yr}, \\
31.8 \text { therms/yr }\end{array}$ & $\begin{array}{l}\text { Gas }-5.7 \mathrm{ft}^{3}, 2.75 \mathrm{EF} \text {, } \\
70.1 \mathrm{kWh} / \mathrm{yr} \\
31.8 \text { therms/yr }\end{array}$ & $\begin{array}{l}\text { Gas }-5.7 \mathrm{ft}^{3}, 2.75 \mathrm{EF} \text {, } \\
70.1 \mathrm{kWh} / \mathrm{yr} \\
31.8 \text { therms/yr }\end{array}$ \\
\hline $\begin{array}{l}\text { Clothes } \\
\text { Washer }\end{array}$ & $\begin{array}{l}\text { Standard, } 3.15 \mathrm{ft}^{3} \text {, } \\
533 \mathrm{kWh} / \mathrm{yr}, 1.16 \mathrm{MEF} \text {, } \\
65.6 \mathrm{kWh} / \mathrm{yr} \text { machine } \\
\text { energy, } 4.63 \mathrm{gal} / \mathrm{day} \\
\text { DHW }\end{array}$ & $\begin{array}{l}\text { Standard, } 3.15 \mathrm{ft}^{3}, \\
533 \mathrm{kWh} / \mathrm{yr}, 1.16 \mathrm{MEF} \text {, } \\
65.6 \mathrm{kWh} / \mathrm{yr} \text { machine } \\
\text { energy, } \\
4.63 \mathrm{gal} / \text { day DHW }\end{array}$ & $\begin{array}{l}\text { Standard, } 3.15 \mathrm{ft}^{3}, \\
533 \mathrm{kWh} / \mathrm{yr}, 1.16 \mathrm{MEF} \text {, } \\
65.6 \mathrm{kWh} / \mathrm{yr} \text { machine } \\
\text { energy, } \\
4.63 \mathrm{gal} / \mathrm{day} \mathrm{DHW}\end{array}$ & $\begin{array}{l}\text { Standard, } 3.15 \mathrm{ft}^{3}, \\
533 \mathrm{kWh} / \mathrm{yr}, 1.16 \mathrm{MEF} \text {, } \\
65.6 \mathrm{kWh} / \mathrm{yr} \text { machine } \\
\text { energy, } \\
4.63 \mathrm{gal} / \mathrm{day} \mathrm{DHW}\end{array}$ \\
\hline Lighting & $\begin{array}{l}20 \% \text { CFL, } 877 \text { kWh/yr } \\
\text { hard-wired, } 331 \text { plug in }\end{array}$ & $\begin{array}{l}\text { 0\% CFL, } 2634 \mathrm{kWh} / \mathrm{yr} \\
\text { hard-wired, } 571 \text { plug in }\end{array}$ & $\begin{array}{l}40 \% \text { CFL, } 643 \mathrm{kWh} / \mathrm{yr} \\
\text { hard-wired, } 331 \text { plug in }\end{array}$ & $\begin{array}{l}20 \% \text { CFL, } 1380 \mathrm{kWh} / \mathrm{yr} \\
\text { hard-wired, } 571 \text { Plug in }\end{array}$ \\
\hline $\begin{array}{l}\text { Air } \\
\text { Conditioner }\end{array}$ & $\begin{array}{l}\text { SEER 13, } 1.5 \text { tons, } \\
0.364 \text { W/CFM AH Fan }\end{array}$ & $\begin{array}{l}\text { SEER 13, } 2.5 \text { tons, } \\
0.364 \text { W/CFM AH Fan }\end{array}$ & $\begin{array}{l}\text { SEER 13, } 1.5 \text { tons, } \\
0.364 \text { W/CFM AH Fan }\end{array}$ & $\begin{array}{l}\text { SEER 13, } 2.5 \text { tons, } \\
0.364 \text { W/CFM AH Fan }\end{array}$ \\
\hline Furnace & 80\% AFUE, $30 \mathrm{kBtu} / \mathrm{hr}$ & $\begin{array}{l}92.5 \% \text { AFUE, } \\
50 \mathrm{kBtu} / \mathrm{hr}\end{array}$ & 92.5\% AFUE, $30 \mathrm{kBtu} / \mathrm{hr}$ & $\begin{array}{l}92.5 \% \text { AFUE, } \\
50 \mathrm{kBtu} / \mathrm{hr}\end{array}$ \\
\hline Ducts & $\begin{array}{l}\text { Inside Conditioned } \\
\text { Space, SA leakage = } \\
1 \%, \text { OA leakage = } \\
0.23 \% \text { of fan flow }\end{array}$ & $\begin{array}{l}\text { Inside Conditioned } \\
\text { Space, SA leakage = } \\
1 \%, \text { OA leakage = } \\
0.23 \% \text { of fan flow }\end{array}$ & $\begin{array}{l}\text { Inside Conditioned Space, } \\
\text { SA leakage }=1 \% \text {, } \\
\text { OA leakage }=0.23 \% \text { of } \\
\text { fan flow }\end{array}$ & $\begin{array}{l}\text { Inside Conditioned } \\
\text { Space, SA leakage = } \\
1 \%, \text { OA leakage = } \\
0.23 \% \text { of fan flow }\end{array}$ \\
\hline $\begin{array}{l}\text { Water } \\
\text { Heater }\end{array}$ & Gas standard, 0.55 EF & Gas standard, 0.55 EF & Gas Tankless, 0.84 EF & Gas Tankless, 0.84 EF \\
\hline
\end{tabular}




\section{First-Cost Impacts}

For all of the 30\%-39\% energy-savings level example cases shown here the first costs are increased. Many builders are reluctant to design first-cost increases into their standard products. To many potential homebuyers, the first cost of a home can make or break a home sale. In order to address first-cost concerns associated with energy-efficient home designs, some builders have implemented guaranteed energy-bill programs that may influence some potential homebuyers such that they would be more willing to absorb the additional first cost into a 30-year mortgage knowing that their monthly cash flow will ultimately be reduced when the utility bill is considered.

Builders who guarantee their homes are willing to tell buyers how much energy the home should use, and they guarantee these levels will not be exceeded. These guarantees are backed up with payments if limits are exceeded. Builders can work with insulation companies or other partners to offer guarantees or caps on their homes' energy costs, or they may develop their own programs. Some cover room comfort by guaranteeing that the temperature will not vary by more than $3^{\circ} \mathrm{F}$ at the center of any room served by the thermostat. A Building America team helped to develop these programs. Information on three of these programs can be found at

- Environments for Living www.eflhome.com/index.jsp

- Engineered for Life www.us-gf.com/engineered.asp

- The Energy Use and Comfort Guarantee www.artistichomessw.com/guarantee.htm (Baechler et al 2004).

In some cases, homebuyers may be eligible for energy-efficient mortgages that allow potential home buyers to qualify for larger loans in order to compensate for additional first costs associated with energy-efficient options that are designed into a home.

The following features for energy-efficient loans are taken from Fannie Mae, the nation's largest source of funding for mortgages. You can learn more about Fannie Mae at www.fanniemae.com.

- Energy-efficient mortgages (EEM) are available for both purchase and refinance in conjunction with most Fannie Mae first-mortgage products, including conventional fixed-rate and adjustable-rate mortgages

- Monthly savings resulting from energy efficiency can be used to qualify borrowers for a larger mortgage. This means consumers can buy more home in the form of energy efficiency or other upgrades.

- The EEM can be used with many Fannie Mae mortgage products. The guidelines of the selected Fannie Mae mortgage apply, with the EEM allowing for the projected energy savings to provide an adjustment to the loan-to-value and qualifying ratios that favor the borrower (Baechler et al 2004).

Table 8 shows the first costs associated with the 30\% and 39\% two-story example cases in Atlanta. These incremental costs are relative to a code minimum house consistent with the worst options included in the simulation, not relative to the Benchmark.

At an 8\% mortgage interest rate, an additional \$1,670 first cost associated with energy efficiency measures only represents an additional $\$ 12$ per month for a 30-year loan term. It is important to note that the cost data used in this analysis may not be representative of actual builder or 
consumer costs in the Atlanta area or other Mixed-Humid climate areas. The actual first cost for energy efficiency options for a particular builder and potential homeowner in the Mixed-Humid climate region may vary substantially from Table 8 . Variations in costs would affect the outcome of the analysis method. Other examples of actual first costs associated with the construction of homes that meet the 30\% - 39\% savings criteria are found in the case studies section of this report and also in the section entitled First Costs and Cost Tradeoffs.

Table 8. Incremental First-Cost for Two-Story Atlanta Case

\begin{tabular}{lcc}
\hline \hline Category & \multicolumn{2}{c}{ Atlanta, Two-story } \\
\cline { 2 - 3 } & $\begin{array}{l}\text { Incremental First-Cost } \\
\text { 30\% Example }\end{array}$ & $\begin{array}{c}\text { Incremental First-Cost } \\
\text { 39\% Example }\end{array}$ \\
\hline \hline Walls & $\$ 191.00$ & $\$ 191.00$ \\
Ceiling & $\$ 0.00$ & $\$ 0.00$ \\
Infiltration & $\$ 0.00$ & $\$ 0.00$ \\
Crawlspace & $\$ 0.00$ & $\$ 0.00$ \\
Window Type & $\$ 0.00$ & $\$ 0.00$ \\
Dishwasher & $\$ 0.00$ & $\$ 89.00$ \\
Lighting & $\$ 0.00$ & $\$ 120.00$ \\
Air Conditioner & $\$ 0.00$ & $\$ 0.00$ \\
Furnace & $\$ 436.00$ & $\$ 436.00$ \\
Ducts & $\$ 0.00$ & $\$ 240.00$ \\
Water Heater & $\$ 0.00$ & $\$ 594.00$ \\
Total & $\$ 627.00$ & $\$ 1,670.00$ \\
\hline
\end{tabular}




\section{Key Cost Tradeoffs}

The analyses for single- and two-story homes in Atlanta show the main trends that result in homes that saves 30\%-39\% whole-house energy relative to the Benchmark. For houses with 30\% energy savings, these trends are improved exterior-wall constructions, crawlspace wall insulation, high-performance glazing, air-sealing measures to reduce infiltration, and ducts in conditioned space. For houses at the upper end of the energy savings range ( 39\%), features such as tankless gas water heaters, condensing furnaces, ENERGY STAR appliances, and elevated levels of compact fluorescent lighting are commonly added. The results indicate that the main driver for energy and cost savings in Atlanta are heating-load reduction strategies (high levels of insulation) coupled with high efficiency furnaces. While most of these measures add to first cost, the total monthly cash flow is actually reduced in terms of a 30-year mortgage when utility bills are considered. Envelope measures, such as improved exterior wall constructions, basement wall insulation, ceiling insulation, high-performance glazing, air-sealing measures to reduce infiltration, and ducts in conditioned space make it possible to reduce heating and cooling loads such that investment in high efficiency reduced-capacity mechanical equipment is possible. The interaction between improving the building envelope and forced-air duct system to reduce the required capacity of mechanical equipment is the primary cost tradeoff for the Mixed-Humid climate, as shown in the case studies and supported by the results from the BEopt analysis method. The case studies for Tindall, Melrose Commons, Longleaf, and Frankford Estates show detailed examples of cost tradeoffs for energy-performance options.

\section{Research Results and Conclusions}

Through the use of systems engineering and operations research, the Building America program has shown that homes that save 30\% whole-house source energy in Mixed-Humid climates can be built on a cost-neutral basis by production builders. Table 9 shows a summary of energyrelated features for the Mixed-Humid case studies included in the following section of this report and examples of results from the use of the BEopt analysis method for a theoretical project in Atlanta. While the specific combinations of technologies used in the case studies or shown in BEopt results may not be cost-optimal solutions for all areas and housing types covered by the Mixed-Humid climate, the key features of the approaches demonstrated in each of these examples can be adapted as needed to provide homes that save 30\% whole-house energy savings.

It should be also noted that the BEopt analysis method is subject to the limitations as described in the Cost Analysis - Life-cycle Cost Analysis section of this report. The case studies are the result of 3 years of field experience and design work done by Building America's research teams. 
Table 9. Summary of Energy Features for Case Studies and BEopt Results for Atlanta

\begin{tabular}{|c|c|c|c|c|c|c|c|c|c|c|c|}
\hline \multicolumn{8}{|c|}{ Case Studies } & \multicolumn{4}{|c|}{ BEopt results } \\
\hline Category & $\begin{array}{l}\text { Longleaf, Pine } \\
\text { Mountain, } \\
\text { Georgia }\end{array}$ & $\begin{array}{c}\text { Habitat, } \\
\text { Montgomery } \\
\text { County, Maryland }\end{array}$ & $\begin{array}{c}\text { Melrose } \\
\text { Commons, } \\
\text { Bronx, New } \\
\text { York }\end{array}$ & $\begin{array}{l}\text { Frankford } \\
\text { Estates, } \\
\text { Baltimore, } \\
\text { Maryland }\end{array}$ & $\begin{array}{c}\text { Grove Park, } \\
\text { Cartersville, } \\
\text { Georgia }\end{array}$ & $\begin{array}{l}\text { Ideal Homes, } \\
\text { Oklahoma } \\
\text { City, } \\
\text { Oklahoma }\end{array}$ & $\begin{array}{l}\text { Legends at } \\
\text { Mansfield, } \\
\text { Columbus, } \\
\text { New Jersey }\end{array}$ & $\begin{array}{l}\text { 30\% Point } \\
\text { (One-Story) }\end{array}$ & $\begin{array}{l}\text { 30\% Point } \\
\text { (Two-Story) }\end{array}$ & $\begin{array}{l}\text { 39\% Point } \\
\text { (Two-Story) }\end{array}$ & $\begin{array}{l}\text { 39\% Point } \\
\text { (Two-Story) }\end{array}$ \\
\hline $\begin{array}{c}\text { Whole-House } \\
\text { Energy } \\
\text { Savings } \\
\end{array}$ & $30 \%$ & $34 \%$ & $30 \%$ & $36 \%$ & $32 \%$ & $36 \%$ & $43 \%$ & $30 \%$ & $30 \%$ & $39 \%$ & $39 \%$ \\
\hline Floor Area $\left(\mathrm{ft}^{2}\right)$ & 1,929 & Not Described & 3,300 & 1,960 & $2,000-3,000$ & $1,400-2,300$ & 5,000 & 1,500 & 3,000 & 1,500 & 3,000 \\
\hline $\begin{array}{l}\text { Number of } \\
\text { Floors }\end{array}$ & 1 & 3 & 3 & 3 & 2 & 1 & 2 & 1 & 2 & 1 & 2 \\
\hline $\begin{array}{l}\text { Number of } \\
\text { Bedrooms }\end{array}$ & 3 & Not Described & 5 & 3 & 3 & 3 & 4 & 3 & 3 & 3 & 3 \\
\hline $\begin{array}{l}\text { Number of } \\
\text { Bathrooms }\end{array}$ & 2 & Not Described & Not Described & 2.5 & Not Described & Not Described & 4 & 2 & 2 & 2 & 2 \\
\hline Walls & $\begin{array}{c}2 \times 4 \\
\text { R-13 spray foam }\end{array}$ & $\begin{array}{l}\text { 2x4, R-9.5 blown- } \\
\text { in cellulose, } \\
\text { R-7 spray foam, } \\
\text { R-5 insulating } \\
\text { sheathing }\end{array}$ & $\begin{array}{c}\mathrm{R}-11 \text { in steel } \\
\text { stud cavities, } \\
\mathrm{R}-3 \text { XPS on } \\
\text { front and end } \\
\text { walls }\end{array}$ & $\begin{array}{c}2 \times 624 \text { in. oc, } \\
\text { R-21 blown } \\
\text { fiberglass }\end{array}$ & $\begin{array}{l}2 \times 624 \text { in. oc, } \\
\text { R-20 blown } \\
\text { cellulose, } \\
\text { R-3 spray foam }\end{array}$ & $\begin{array}{l}2 \times 4, \mathrm{R}-13 \\
\text { blown-in } \\
\text { cellulose, } \\
\text { R-3 insulating } \\
\text { sheathing }\end{array}$ & $2 \times 6, R-18$ & $\begin{array}{l}\text { R-19, } 2 \times 6 \\
24 \text { in. oc }\end{array}$ & $\begin{array}{l}\text { R-19, } 2 \times 6 \\
24 \text { in. oc }\end{array}$ & $\begin{array}{l}\text { R-19, } 2 \times 6 \\
24 \text { in. oc }\end{array}$ & $\begin{array}{l}\text { R-19, } 2 \times 6 \\
24 \text { in. oc }\end{array}$ \\
\hline Ceiling & $\begin{array}{c}\text { R-27 } \\
\text { cathedralized } \\
\text { attic, spray foam } \\
\text { under roof deck }\end{array}$ & $\begin{array}{l}\text { R-38 blown } \\
\text { cellulose }\end{array}$ & $\begin{array}{l}\mathrm{R}-20 \text { poly- } \\
\text { isocyanurate }\end{array}$ & $\begin{array}{l}\mathrm{R}-40 \text { blown } \\
\text { fiberglass }\end{array}$ & $\begin{array}{l}\text { R-38 blown } \\
\text { cellulose }\end{array}$ & $\begin{array}{l}\text { R-30 blown } \\
\text { cellulose }\end{array}$ & $\begin{array}{l}\text { R-30 FG + } \\
\text { R-19 blown } \\
\text { cellulose }\end{array}$ & R-30 FG & R-30 FG & $\mathrm{R}-40 \mathrm{FG}$ & R-30 FG \\
\hline Thermal Mass & Not Described & Not Described & Not Described & Not Described & Not Described & Not Described & Not Described & $\begin{array}{l}\text { 1/2-in. Ceiling } \\
\text { Drywall }\end{array}$ & $\begin{array}{l}\text { 1/2-in. Ceiling } \\
\text { Drywall }\end{array}$ & $\begin{array}{l}\text { 1/2-in. Ceiling } \\
\text { Drywall }\end{array}$ & $\begin{array}{l}\text { 1/2-in. Ceiling } \\
\text { Drywall }\end{array}$ \\
\hline Infiltration & Not Described & $\begin{array}{c}2.5-\mathrm{in}^{2} \text { leakage } \\
\text { area per } 100 \mathrm{ft}^{2} \\
\text { thermal envelope } \\
\text { area }\end{array}$ & $\begin{array}{l}0.07-0.10 \\
\mathrm{ACH}_{\text {ann }}\end{array}$ & Not Described & $\begin{array}{l}0.31-0.47 \\
\mathrm{ACH}_{\mathrm{ann}}\end{array}$ & $\begin{array}{c}2.5-\mathrm{in}^{2} \\
\text { leakage area } \\
\text { per } 100 \mathrm{ft}^{2} \\
\text { thermal } \\
\text { envelope area }\end{array}$ & $0.22 \mathrm{ACH}_{\text {nat }}$ & $S L A=0.0003$ & $S L A=0.0003$ & $S L A=0.0003$ & $S L A=0.0003$ \\
\hline $\begin{array}{l}\text { Basement/Slab/ } \\
\text { Crawl space }\end{array}$ & $\begin{array}{l}\text { Raised slab-on- } \\
\text { grade }\end{array}$ & $\begin{array}{c}\text { Insulated } \\
\text { slab-on-grade, } \\
\text { R-7.5 under slab }\end{array}$ & $\begin{array}{l}\text { Uninsulated } \\
\text { basement }\end{array}$ & $\begin{array}{l}\text { Basement, } \\
\text { R-14 rigid } \\
\text { insulation, } \\
\text { half height }\end{array}$ & $\begin{array}{l}\text { Uninsulated } \\
\text { slab-on-grade, } \\
\text { R-26 framed } \\
\text { floors }\end{array}$ & $\begin{array}{l}\text { Slab-on-grade, } \\
\text { R-4 perimeter } \\
\text { insulation }\end{array}$ & $\begin{array}{l}\text { Basement, } \\
\text { R-12.5 } \\
\text { exterior rigid }\end{array}$ & $\begin{array}{l}\text { Unvented, R-11 } \\
\text { interior } \\
\text { insulation }\end{array}$ & $\begin{array}{l}\text { Unvented, R- } \\
11 \text { interior } \\
\text { insulation }\end{array}$ & $\begin{array}{l}\text { Unvented, R- } \\
11 \text { interior } \\
\text { insulation }\end{array}$ & $\begin{array}{c}\text { Unvented, R-11 } \\
\text { interior } \\
\text { insulation }\end{array}$ \\
\hline Glass Type & $\begin{array}{c}\text { Double-pane, } \\
\text { argon-filled, } \\
\text { low-E, } \\
\text { spectrally } \\
\text { selective, } \\
U=0.38, \\
\text { SHGC }=0.35\end{array}$ & $\begin{array}{c}\text { Double-pane, } \\
\text { low-e, } \\
\text { spectrally } \\
\text { selective, } \\
U=0.33, \\
\text { SHGC }=0.33\end{array}$ & $\begin{array}{l}\text { Low-e, } \\
\text { vinyl frame }\end{array}$ & $\begin{array}{c}\text { Double-pane, } \\
\text { low-e, } \\
\text { spectrally } \\
\text { selective, } \\
U=0.35 \text {, } \\
\text { SHGC }=0.29\end{array}$ & $\begin{array}{c}\text { Double-pane, } \\
\text { low-e, } \\
\text { spectrally } \\
\text { selective, } \\
U=0.36, \\
\text { SHGC }=0.33\end{array}$ & $\begin{array}{c}\text { Double-pane, } \\
\text { low-e, } \\
\text { spectrally } \\
\text { selective, } \\
U=0.39 \\
\text { SHGC }=0.31 \\
\end{array}$ & $\begin{array}{l}\text { Double-pane, } \\
\text { low-e, U=0.36, } \\
\text { SHGC }=0.33\end{array}$ & $\begin{array}{l}\text { Two-pane, Low- } \\
\text { e, spectrally } \\
\text { selective, } \\
U=0.30, \text { SHGC } \\
=0.34, \text { vinyl } \\
\text { frame }\end{array}$ & $\begin{array}{c}\text { Two-pane, } \\
\text { Low-e with } \\
\text { tint, U = 0.31, } \\
\text { SHGC = 0.29, } \\
\text { vinyl frame }\end{array}$ & $\begin{array}{c}\text { Two-pane, } \\
\text { Low-e, } \\
\text { spectrally } \\
\text { selective, } \\
U=0.30, \\
\text { SHGC }=0.34, \\
\text { vinyl frame }\end{array}$ & $\begin{array}{c}\text { Two-pane, } \\
\text { Low-e, } \\
\text { spectrally } \\
\text { selective, } \\
U=0.30, \\
\text { ISHGC }=0.34, \\
\text { vinyl frame }\end{array}$ \\
\hline
\end{tabular}


Table 9 (continued). Summary of Energy Features for Case Studies and BEopt Results for Atlanta

\begin{tabular}{|c|c|c|c|c|c|c|c|c|c|c|c|}
\hline \multicolumn{8}{|c|}{ Case Studies } & \multicolumn{4}{|c|}{ BEopt results } \\
\hline Category & $\begin{array}{l}\text { Longleaf, } \\
\text { Pine } \\
\text { Mountain, } \\
\text { Georgia }\end{array}$ & $\begin{array}{l}\text { Habitat, } \\
\text { Montgomery } \\
\text { County, } \\
\text { Maryland }\end{array}$ & $\begin{array}{c}\text { Melrose } \\
\text { Commons, } \\
\text { Bronx, New } \\
\text { York }\end{array}$ & $\begin{array}{l}\text { Frankford } \\
\text { Estates, } \\
\text { Baltimore, } \\
\text { Maryland }\end{array}$ & $\begin{array}{c}\text { Grove Park, } \\
\text { Cartersville, } \\
\text { Georgia }\end{array}$ & $\begin{array}{c}\text { Ideal Homes, } \\
\text { Oklahoma } \\
\text { City, } \\
\text { Oklahoma }\end{array}$ & $\begin{array}{l}\text { Legends at } \\
\text { Mansfield, } \\
\text { Columbus, } \\
\text { New Jersey }\end{array}$ & $\begin{array}{l}30 \% \text { Point } \\
\text { (One-Story) }\end{array}$ & $\begin{array}{c}30 \% \text { Point } \\
\text { (Two-Story) }\end{array}$ & $\begin{array}{l}39 \% \text { Point } \\
\text { (One-Story) }\end{array}$ & $\begin{array}{l}\text { 39\% Point } \\
\text { (Two-Story) }\end{array}$ \\
\hline $\begin{array}{l}\text { Window Area } \\
\text { per Wall }\end{array}$ & $\begin{array}{c}\text { Not } \\
\text { Described }\end{array}$ & $\begin{array}{c}\text { Not } \\
\text { Described }\end{array}$ & $\begin{array}{c}\text { Not } \\
\text { Described }\end{array}$ & $\begin{array}{c}\text { Not } \\
\text { Described }\end{array}$ & $\begin{array}{c}\text { Not } \\
\text { Described }\end{array}$ & $\begin{array}{c}\text { Not } \\
\text { Described }\end{array}$ & $\begin{array}{c}\text { Not } \\
\text { Described }\end{array}$ & $\begin{array}{l}270 \mathrm{ft}^{2}, 12.5 \% \\
\mathrm{~N} \& \mathrm{~S}, 50 \% \mathrm{~W} \\
25 \% \mathrm{E}\end{array}$ & $\begin{array}{c}540 \mathrm{ft}^{2}, 12.5 \% \\
\mathrm{~N} \& \mathrm{~S}, 50 \% \mathrm{~W} \\
25 \% \mathrm{E}\end{array}$ & $\begin{array}{l}270 \mathrm{ft}^{2}, 12.5 \% \\
\mathrm{~N} \& \mathrm{~S}, 50 \% \mathrm{~W} \\
25 \% \mathrm{E}\end{array}$ & $\begin{array}{c}540 \mathrm{ft}^{2}, 12.5 \% \\
\mathrm{~N} \& \mathrm{~S}, 50 \% \mathrm{~W} \\
25 \% \mathrm{E}\end{array}$ \\
\hline Refrigerator & $\begin{array}{l}\text { ENERGY } \\
\text { STAR }\end{array}$ & $\begin{array}{l}\text { ENERGY } \\
\text { STAR }\end{array}$ & $\begin{array}{l}\text { ENERGY } \\
\text { STAR }\end{array}$ & $\begin{array}{l}\text { ENERGY } \\
\text { STAR }\end{array}$ & $\begin{array}{l}\text { ENERGY } \\
\text { STAR }\end{array}$ & $\begin{array}{l}\text { ENERGY } \\
\text { STAR }\end{array}$ & $\begin{array}{c}\text { Not } \\
\text { Described }\end{array}$ & $\begin{array}{c}\text { Standard - } 671 \\
\text { kWh/yr }\end{array}$ & $\begin{array}{c}\text { Standard - } 671 \\
\text { kWh/yr }\end{array}$ & $\begin{array}{c}\text { Standard - } 671 \\
\text { kWh/yr }\end{array}$ & $\begin{array}{c}\text { Standard - } 671 \\
\text { kWh/yr }\end{array}$ \\
\hline $\begin{array}{l}\text { Cooking } \\
\text { Range }\end{array}$ & $\begin{array}{c}\text { Not } \\
\text { Described }\end{array}$ & $\begin{array}{c}\text { Not } \\
\text { Described }\end{array}$ & $\begin{array}{c}\text { Not } \\
\text { Described }\end{array}$ & $\begin{array}{c}\text { Not } \\
\text { Described }\end{array}$ & $\begin{array}{c}\text { Not } \\
\text { Described }\end{array}$ & $\begin{array}{c}\text { Not } \\
\text { Described }\end{array}$ & $\begin{array}{c}\text { Not } \\
\text { Described }\end{array}$ & 45 Therms/yr & 45 Therms/yr & 45 Therms/yr & 45 Therms/yr \\
\hline Dishwasher & $\begin{array}{l}\text { ENERGY } \\
\text { STAR }\end{array}$ & $\begin{array}{l}\text { ENERGY } \\
\text { STAR }\end{array}$ & $\begin{array}{l}\text { ENERGY } \\
\text { STAR }\end{array}$ & $\begin{array}{l}\text { ENERGY } \\
\text { STAR }\end{array}$ & $\begin{array}{l}\text { ENERGY } \\
\text { STAR }\end{array}$ & $\begin{array}{l}\text { ENERGY } \\
\text { STAR }\end{array}$ & $\begin{array}{c}\text { Not } \\
\text { Described }\end{array}$ & $\begin{array}{c}\text { Standard, } 462 \\
\text { kWh, eight place } \\
\text { setting capacity, } \\
131.6 \mathrm{kWh} / \mathrm{yr} \\
\text { machine energy, } \\
5.39 \mathrm{gal} / \mathrm{day} \\
\mathrm{DHW}\end{array}$ & $\begin{array}{c}\text { Standard, } 462 \\
\text { kWh, eight } \\
\text { place setting } \\
\text { capacity, } 131.6 \\
\text { kWh/yr machine } \\
\text { energy, } 5.39 \\
\text { gal/day DHW }\end{array}$ & $\begin{array}{l}\text { Standard, } 462 \\
\text { kWh, eight } \\
\text { place setting } \\
\text { capacity, } 131.6 \\
\text { kWh/yr machine } \\
\text { energy, } 5.39 \\
\text { gal/day DHW }\end{array}$ & $\begin{array}{c}\text { ENERGY } \\
\text { STAR, } 384 \\
\text { kWh, eight } \\
\text { place setting } \\
\text { capacity, } 82.2 \\
\text { kWh/yr machine } \\
\text { energy, } 3.76 \\
\text { gal/day DHW }\end{array}$ \\
\hline Clothes Dryer & $\begin{array}{c}\text { Not } \\
\text { Described }\end{array}$ & $\begin{array}{c}\text { Not } \\
\text { Described }\end{array}$ & $\begin{array}{c}\text { Not } \\
\text { Described }\end{array}$ & $\begin{array}{c}\text { Not } \\
\text { Described }\end{array}$ & $\begin{array}{c}\text { Not } \\
\text { Described }\end{array}$ & $\begin{array}{c}\text { Not } \\
\text { Described }\end{array}$ & $\begin{array}{c}\text { Not } \\
\text { Described }\end{array}$ & $\begin{array}{c}\text { Gas - } 5.7 \mathrm{ft}^{3} \\
2.75 \mathrm{EF} \\
70.1 \mathrm{kWh} / \mathrm{yr} \\
31.8 \text { therms/yr }\end{array}$ & $\begin{array}{c}\text { Gas - } 5.7 \mathrm{ft}^{3} \\
2.75 \mathrm{EF} \\
70.1 \mathrm{kWh} / \mathrm{yr}, \\
31.8 \text { therms/yr }\end{array}$ & $\begin{array}{c}\text { Gas - } 5.7 \mathrm{ft}^{3}, \\
2.75 \mathrm{EF} \\
70.1 \mathrm{kWh} / \mathrm{yr}, \\
31.8 \text { therms/yr }\end{array}$ & $\begin{array}{c}\text { Gas - } 5.7 \mathrm{ft}^{3}, \\
2.75 \mathrm{EF} \\
70.1 \mathrm{kWh} / \mathrm{yr}, \\
31.8 \text { therms/yr }\end{array}$ \\
\hline $\begin{array}{l}\text { Clothes } \\
\text { Washer }\end{array}$ & $\begin{array}{c}\text { Not } \\
\text { Described }\end{array}$ & $\begin{array}{l}\text { ENERGY } \\
\text { STAR }\end{array}$ & $\begin{array}{c}\text { Not } \\
\text { Described }\end{array}$ & $\begin{array}{c}\text { Not } \\
\text { Described }\end{array}$ & $\begin{array}{c}\text { Not } \\
\text { described }\end{array}$ & $\begin{array}{l}\text { ENERGY } \\
\text { STAR }\end{array}$ & ENERGY STAR & $\begin{array}{c}\text { Standard, } 3.15 \mathrm{ft}^{3} \text {, } \\
533 \mathrm{kWh} / \mathrm{yr}, \\
1.16 \mathrm{MEF}, 65.6 \\
\mathrm{kWh} / \mathrm{yr} \text { machine } \\
\text { energy, } \\
4.63 \mathrm{gal} / \text { day DHW }\end{array}$ & $\begin{array}{c}\text { Standard, } 3.15 \\
\mathrm{ft}^{3}, 533 \mathrm{kWh} / \mathrm{yr}, \\
1.16 \mathrm{MEF}, 65.6 \\
\mathrm{kWh} / \mathrm{yr} \text { machine } \\
\text { energy, } \\
4.63 \mathrm{gal} / \mathrm{day} \\
\mathrm{DHW}\end{array}$ & $\begin{array}{c}\text { Standard, } 3.15 \\
\mathrm{ft}^{3}, 533 \mathrm{kWh} / \mathrm{yr}, \\
1.16 \mathrm{MEF}, 65.6 \\
\mathrm{kWh} / \mathrm{yr} \text { machine } \\
\text { energy, } \\
\text { 4.63 gal/day } \\
\text { DHW }\end{array}$ & $\begin{array}{c}\text { Standard, } 3.15 \\
\mathrm{ft}^{3}, 533 \mathrm{kWh} / \mathrm{yr}, \\
1.16 \mathrm{MEF}, 65.6 \\
\mathrm{kWh} / \mathrm{yr} \text { machine } \\
\text { energy, } \\
4.63 \mathrm{gal} / \mathrm{day} \\
\mathrm{DHW}\end{array}$ \\
\hline Lighting & $\begin{array}{c}10 \% \\
\text { fluorescent }\end{array}$ & $90 \%$ CFL & $\begin{array}{c}100 \% \\
\text { fluorescent }\end{array}$ & $\begin{array}{c}100 \% \\
\text { fluorescent }\end{array}$ & $\begin{array}{c}0 \% \\
\text { fluorescent }\end{array}$ & $\begin{array}{c}10 \% \\
\text { fluorescent }\end{array}$ & $95 \%$ fluorescent & $\begin{array}{c}20 \% \mathrm{CFL} \\
877 \mathrm{kWh} / \mathrm{yr} \text { hard- } \\
\text { wired, } 331 \text { plug in }\end{array}$ & $\begin{array}{c}\text { 0\% CFL, } 2634 \\
\text { kWh/yr hard- } \\
\text { wired, } \\
571 \text { plug in }\end{array}$ & $\begin{array}{c}40 \% \text { CFL, } 643 \\
\text { kWh/yr hard- } \\
\text { wired, } \\
331 \text { plug in }\end{array}$ & $\begin{array}{c}20 \% \text { CFL, } 1380 \\
\text { kWh/yr hard- } \\
\text { wired, } \\
571 \text { Plug in }\end{array}$ \\
\hline Cooling & $\begin{array}{l}14 \text { SEER } \\
\text { air-source } \\
\text { heat pump }\end{array}$ & $\begin{array}{l}13 \text { SEER } \\
\text { air-source } \\
\text { heat pump }\end{array}$ & No cooling & $\begin{array}{l}\text { Two } 13 \\
\text { SEER air } \\
\text { conditioners }\end{array}$ & $\begin{array}{c}\text { Two } 12 \\
\text { SEER air } \\
\text { conditioners }\end{array}$ & $\begin{array}{l}14 \text { SEER } \\
\text { air } \\
\text { conditioner }\end{array}$ & $\begin{array}{l}\text { One } 14 \text { SEER } 3 \\
\text { ton, one } 13 \\
\text { SEER } 2.5 \text { ton }\end{array}$ & $\begin{array}{l}\text { SEER 13, } 1.5 \\
\text { tons, } 0.364 \\
\text { W/CFM AH Fan }\end{array}$ & $\begin{array}{c}\text { SEER } 13,2.5 \\
\text { tons, 0.364 } \\
\text { W/CFM AH Fan }\end{array}$ & $\begin{array}{l}\text { SEER } 13,1.5 \\
\text { tons, } 0.364 \\
\text { W/CFM AH Fan }\end{array}$ & $\begin{array}{c}\text { SEER } 13,2.5 \\
\text { tons, 0.364 } \\
\text { W/CFM AH Fan }\end{array}$ \\
\hline
\end{tabular}


Table 9 (continued). Summary of Energy Features for Case Studies and BEopt Results for Atlanta

\begin{tabular}{|c|c|c|c|c|c|c|c|c|c|c|c|}
\hline \multirow[b]{2}{*}{ Category } & \multirow[b]{2}{*}{$\begin{array}{l}\text { Longleaf, } \\
\text { Pine } \\
\text { Mountain, } \\
\text { Georgia }\end{array}$} & \multirow[b]{2}{*}{$\begin{array}{c}\text { Habitat, } \\
\text { Montgomery } \\
\text { County, } \\
\text { Maryland }\end{array}$} & \multirow[b]{2}{*}{$\begin{array}{c}\text { Melrose } \\
\text { Commons, } \\
\text { Bronx, } \\
\text { New York }\end{array}$} & \multicolumn{3}{|c|}{ Case Studies } & \multirow[b]{2}{*}{$\begin{array}{l}\text { Legends at } \\
\text { Mansfield, } \\
\text { Columbus, } \\
\text { New Jersey }\end{array}$} & \multicolumn{4}{|c|}{ BEopt results } \\
\hline & & & & $\begin{array}{l}\text { Frankford } \\
\text { Estates, } \\
\text { Baltimore, } \\
\text { Maryland }\end{array}$ & $\begin{array}{c}\text { Grove Park, } \\
\text { Cartersville, } \\
\text { Georgia }\end{array}$ & $\begin{array}{l}\text { Ideal Homes, } \\
\text { Oklahoma } \\
\text { City, } \\
\text { Oklahoma }\end{array}$ & & $\begin{array}{l}30 \% \text { Point } \\
\text { (One-Story) }\end{array}$ & $\begin{array}{l}30 \% \text { Point } \\
\text { (Two-Story) }\end{array}$ & $\begin{array}{l}\text { 39\% Point } \\
\text { (One-Story) }\end{array}$ & $\begin{array}{l}\text { 39\% Point } \\
\text { (Two-Story) }\end{array}$ \\
\hline Heating & $\begin{array}{l}8.0 \mathrm{HSPF} \\
\text { air-source } \\
\text { heat pump }\end{array}$ & $\begin{array}{l}8.5 \mathrm{HSPF} \\
\text { air-source } \\
\text { heat pump }\end{array}$ & $\begin{array}{l}86 \% \text { AFUE } \\
\text { direct-vent } \\
\text { boiler, } \\
\text { hydronic } \\
\text { baseboard }\end{array}$ & $\begin{array}{c}\text { Two 93\% } \\
\text { AFUE, } \\
\text { direct-vent } \\
\text { gas furnaces }\end{array}$ & $\begin{array}{l}\text { Two } 92 \% \\
\text { AFUE, } \\
\text { gas furnaces }\end{array}$ & $\begin{array}{l}90 \% \text { AFUE, } \\
\text { gas furnace }\end{array}$ & $\begin{array}{l}\text { Two } 92.1 \% \\
\text { AFUE, gas } \\
\text { furnaces }\end{array}$ & $\begin{array}{c}80 \% \text { AFUE, } 30 \\
\text { kBtu/hr }\end{array}$ & $\begin{array}{c}92.5 \% \text { AFUE, } \\
50 \mathrm{kBtu} / \mathrm{hr}\end{array}$ & $\begin{array}{c}92.5 \% \text { AFUE, } \\
30 \mathrm{kBtu} / \mathrm{hr}\end{array}$ & $\begin{array}{c}92.5 \% \text { AFUE, } \\
50 \mathrm{kBtu} / \mathrm{hr}\end{array}$ \\
\hline Ducts & $\begin{array}{l}100 \% \text { inside } \\
\text { conditioned } \\
\text { space }\end{array}$ & $\begin{array}{c}\text { Inside } \\
\text { conditioned } \\
\text { space, } \\
\text { R-4 insulation }\end{array}$ & No ducts & $\begin{array}{l}\text { Inside } \\
\text { conditioned } \\
\text { space }\end{array}$ & $\begin{array}{c}\text { Buried in attic } \\
\text { insulation, } \\
\text { R-3 spray foam, } \\
90-150 \mathrm{cfm} \\
\text { leakage to } \\
\text { outside @ } 25 \\
\text { Pa }\end{array}$ & $\begin{array}{l}\text { In vented } \\
\text { attic, } \\
\text { R- } 6 \\
\text { insulation, } \\
<5 \% \text { leakage } \\
\text { to outside }\end{array}$ & $\begin{array}{l}\text { Inside } \\
\text { conditioned } \\
\text { space }\end{array}$ & $\begin{array}{c}\text { Inside } \\
\text { Conditioned } \\
\text { Space, SA } \\
\text { leakage = 1\%, } \\
\text { OA leakage = } \\
0.23 \% \text { of fan } \\
\text { flow }\end{array}$ & $\begin{array}{c}\text { Inside } \\
\text { Conditioned } \\
\text { Space, SA } \\
\text { leakage = 1\%, } \\
\text { OA leakage = } \\
0.23 \% \text { of fan } \\
\text { flow }\end{array}$ & $\begin{array}{c}\text { Inside } \\
\text { Conditioned } \\
\text { Space, SA } \\
\text { leakage }=1 \% \text {, } \\
\text { OA leakage = } \\
0.23 \% \text { of fan } \\
\text { flow }\end{array}$ & $\begin{array}{c}\text { Inside } \\
\text { Conditioned } \\
\text { Space, SA } \\
\text { leakage = 1\%, } \\
\text { OA leakage = } \\
0.23 \% \text { of fan } \\
\text { flow }\end{array}$ \\
\hline Ventilation & $\begin{array}{l}\text { Passive inlet } \\
\text { to return side } \\
\text { of } A H\end{array}$ & Not Described & $\begin{array}{l}\text { Continuous } \\
\text { exhaust }\end{array}$ & $\begin{array}{l}\text { Continuous } \\
\text { exhaust }\end{array}$ & $\begin{array}{l}\text { No mechanical } \\
\text { ventilation }\end{array}$ & $\begin{array}{l}\text { Central fan } \\
\text { integrated } \\
\text { supply, } 46 \\
\text { cfm average }\end{array}$ & HRV & $\begin{array}{c}\text { Continuous } \\
\text { exhaust }\end{array}$ & $\begin{array}{l}\text { Continuous } \\
\text { exhaust }\end{array}$ & $\begin{array}{c}\text { Continuous } \\
\text { exhaust }\end{array}$ & $\begin{array}{c}\text { Continuous } \\
\text { exhaust }\end{array}$ \\
\hline $\begin{array}{l}\text { Water } \\
\text { Heater }\end{array}$ & $\begin{array}{l}\text { 40-Gal. } \\
\text { Electric, } \\
0.93 \text { EF }\end{array}$ & $\begin{array}{c}0.9 \mathrm{EF} \\
\text { electric tank }\end{array}$ & $\begin{array}{l}65-\mathrm{gal}, \text { indirect } \\
\text { tank heated by } \\
\text { boiler }\end{array}$ & $\begin{array}{c}\text { Gas tankless, } \\
0.82 \mathrm{EF}\end{array}$ & $\begin{array}{l}40 \text { gallon, } \\
0.59 \text { EF gas } \\
\text { tank }\end{array}$ & $\begin{array}{c}0.59 \mathrm{EF} \text { gas } \\
\text { tank }\end{array}$ & $\begin{array}{c}\text { Gas tankless, } \\
0.85 \mathrm{EF}\end{array}$ & $\begin{array}{c}\text { Gas standard, } \\
0.55 \mathrm{EF}\end{array}$ & $\begin{array}{l}\text { Gas standard, } \\
0.55 \mathrm{EF}\end{array}$ & $\begin{array}{c}\text { Gas Tankless, } \\
0.84 \mathrm{EF}\end{array}$ & $\begin{array}{c}\text { Gas Tankless, } \\
0.84 \mathrm{EF}\end{array}$ \\
\hline $\begin{array}{l}\text { On-site } \\
\text { Power } \\
\text { system }\end{array}$ & None & None & $\begin{array}{l}\text { 2.2-kW PV on } \\
\text { prototype }\end{array}$ & None & None & None & None & None & None & None & None \\
\hline
\end{tabular}


Table 10 summarizes the source of the energy savings by end use for each of the seven case studies. Figure 23 shows the geographic location for each of the case studies. Locations are indicated with stars.

Table 10. Summary of Source Energy Savings by End-Use for the Mixed-Humid Climate Case Studies

\begin{tabular}{cccccccc}
\hline \hline & \multicolumn{6}{c}{ Percent Source Energy Savings } \\
\cline { 2 - 8 } End Use & $\begin{array}{c}\text { Longleaf, } \\
\text { Pine } \\
\text { Mountain, } \\
\text { Georgia }\end{array}$ & $\begin{array}{c}\text { Habitat, } \\
\text { Montgomery } \\
\text { County, } \\
\text { Maryland }\end{array}$ & $\begin{array}{c}\text { Melrose } \\
\text { Commons, } \\
\text { Bronx, } \\
\text { New York }\end{array}$ & $\begin{array}{c}\text { Frankford } \\
\text { Estates, } \\
\text { Baltimore, } \\
\text { Maryland }\end{array}$ & $\begin{array}{c}\text { Outlook } \\
\text { Grove Park, } \\
\text { Cartersville, } \\
\text { Georgia }\end{array}$ & $\begin{array}{c}\text { Ideal Homes, } \\
\text { Oklahoma } \\
\text { City, } \\
\text { Oklahoma }\end{array}$ & $\begin{array}{c}\text { Legends at } \\
\text { Mansfield, } \\
\text { Columbus, } \\
\text { New Jersey }\end{array}$ \\
\hline \hline Space Heating & $39 \%$ & $75 \%$ & $50 \%$ & $51 \%$ & $52 \%$ & $38 \%$ & $53 \%$ \\
Space Cooling & $57 \%$ & $56 \%$ & $2 \%$ & $49 \%$ & $72 \%$ & $59 \%$ & $45 \%$ \\
DHW & $28 \%$ & $1 \%$ & $30 \%$ & $35 \%$ & $13 \%$ & $10 \%$ & $55 \%$ \\
Lighting & $-4 \%$ & $67 \%$ & $66 \%$ & $52 \%$ & $-8 \%$ & $70 \%$ & $68 \%$ \\
$\begin{array}{c}\text { Appliances }+ \\
\text { MEL }\end{array}$ & $5 \%$ & $4 \%$ & $9 \%$ & $2 \%$ & $3 \%$ & $9 \%$ & $5 \%$ \\
$\begin{array}{c}\text { Total Energy } \\
\text { Use }\end{array}$ & $30 \%$ & $34 \%$ & $30 \%$ & $36 \%$ & $32 \%$ & $36 \%$ & $43 \%$ \\
$\begin{array}{c}\text { Number of } \\
\text { Homes }\end{array}$ & 30 & 24 & 210 & 78 & 73 & 208 & 39 \\
\hline
\end{tabular}



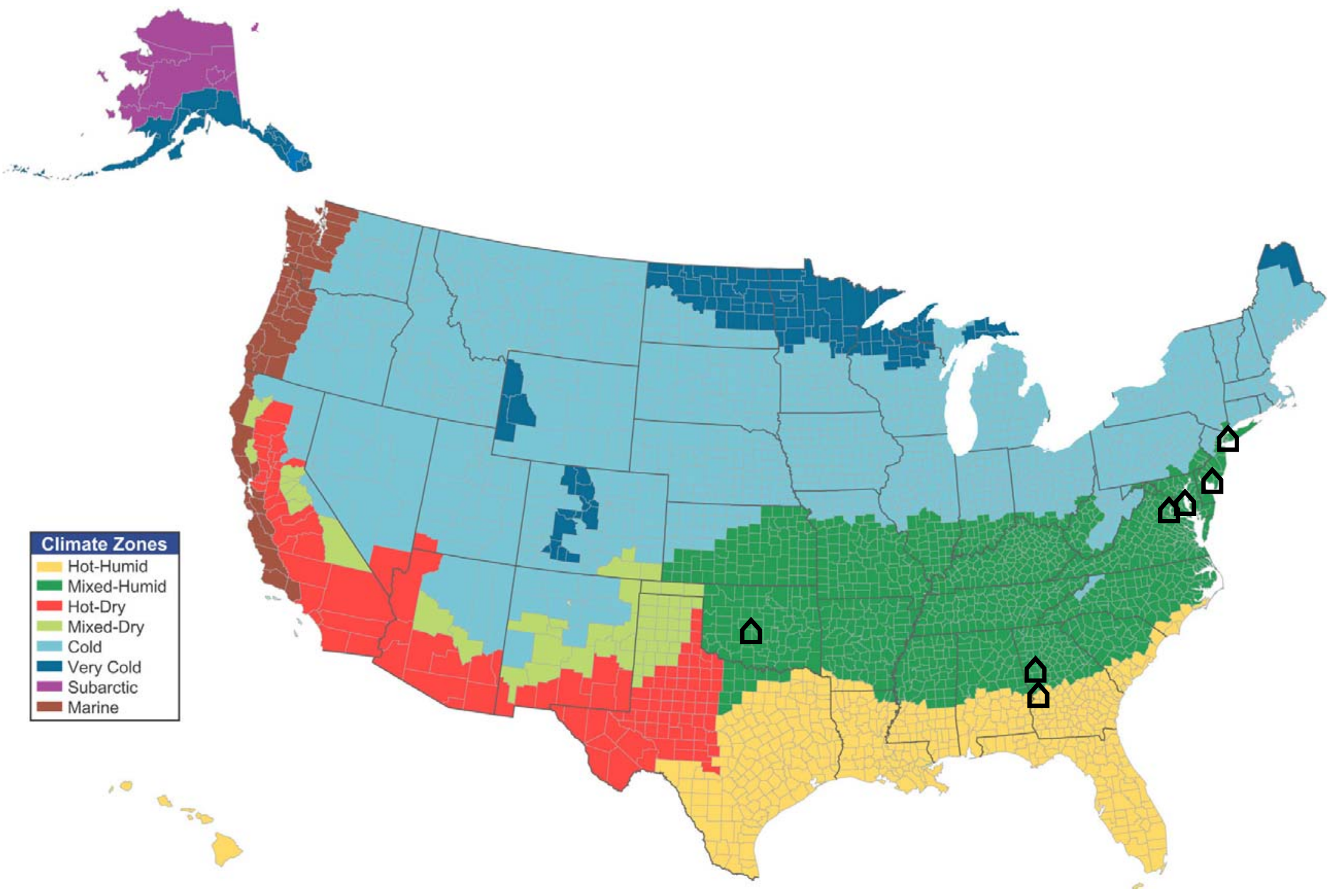

Figure 23. Locations of $\mathbf{3 0} \%$ Mixed-Climate case studies 


\section{Community Case Studies}

\section{Development: Longleaf at Callaway}

\section{Builder:}

Location:

\section{Pine Mountain}

\author{
Pine Mountain, Georgia
}

Longleaf at Callaway (Figure 24) is the first community to meet the standards of quality necessary to be associated with Georgia's famed Callaway Gardens, a wetland-based nature preserve owned by the Ida Cason Callaway Foundation - a non-profit organization dedicated to land stewardship and environmental education.

When the community was first conceived, Cousins Properties, a highly-diversified Atlanta-based real estate developer, began walking the land with Callaway's own horticulturists and leading environmental experts. Their goal was to create a quiet, environmentally friendly community that would value and protect the land. Cousins specifically set its sights on 30\% energy savings levels and needed a builder to help carry that vision forward - enter Fortress Construction.

Fortress Construction, which builds approximately 40 homes each year in the Atlanta area, is focused on building to higher performance standards. A certified professional home builder, Fortress Construction is an ENERGY STAR Homes ${ }^{\circledR}$ partner and one of the first EarthCraft ${ }^{\mathrm{TM}}$ House builders. Before entering this joint venture with Cousins and becoming Pine Mountain, they were already meeting levels near $30 \%$ whole-house energy savings.

David Barnes of Pine Mountain

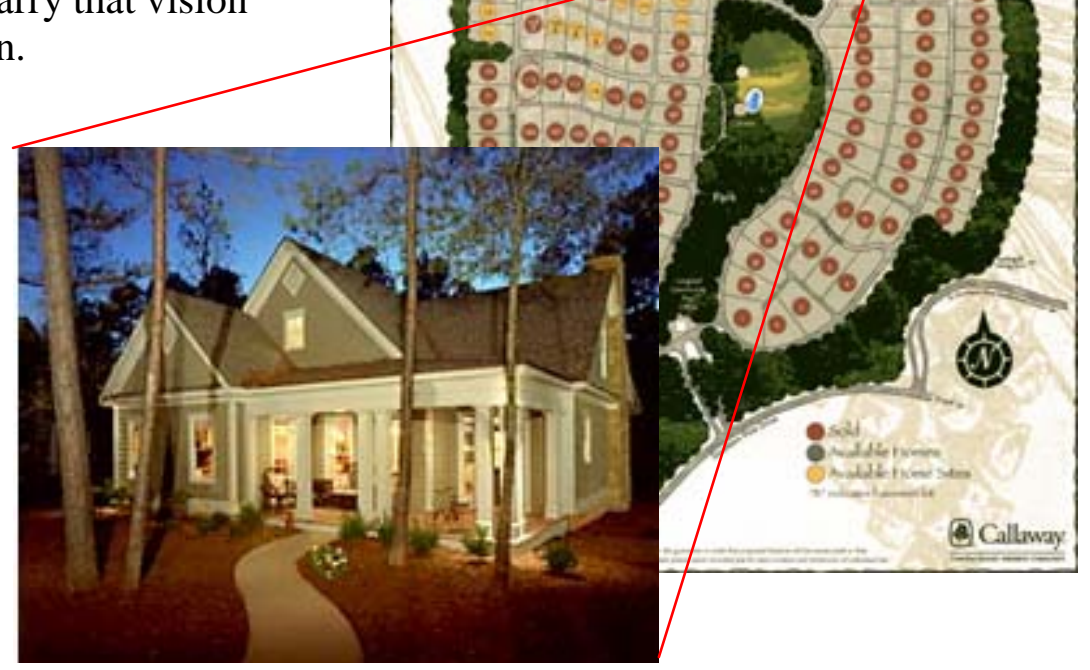

Figure 24. Neighborhood map and home from Longleaf at Callaway said “We (Fortress Construction at the time) didn’t really have to change our building process. We just had to identify where we could get the most 'bang for our buck' in order to meet or exceed 30\% energy savings. Given our climate, we thought that an improved energy envelope and HVAC system would have immediate impact."

Icynene ${ }^{\circledR}$ low-density spray-foam insulation was a key component to sealing the energy envelope. Pine Mountain employed Icynene within all walls and along the roof deck in the attic creating a cathedralized attic space. Insulating the attic in this way created a $100 \%$ conditioned space for the HVAC system and ductwork. 
Better insulation, air sealing, and creating the conditioned space in the attic were vital to reducing the energy load and improving performance of the HVAC systems in Longleaf homes. In addition, Pine Mountain installed programmable thermostats, heat pump units with HPSF 8.0, and 14 SEER air conditioning in each of their homes. Table 11 lists all of the efficient specifications utilized at Longleaf at Callaway.

At the same time, the Pine Mountain partners decided to keep the ideals of the Callaway Foundation in mind, disturbing the land as little as possible. Longleaf at Callaway is built on land that is subject to periodic heavy rains and is adjacent to acres of preserved wetlands. In order to let the water follow its natural course with minimal grading, Pine Mountain elected to build the homes on raised slab-on-grade foundations with 4-ft-high stemwalls. While not specifically required as an energy feature, this practice proved to be not only environmentally friendly, but also prudent for the durability of the homes - by minimizing the chance of water damage.

\section{Source Energy Consumption Summary}

An analysis of energy use for the Longleaf at Callaway specifications, in comparison to the Building America Benchmark, shows that the Pine Mountain homes were estimated to consume 30\% less energy. Table 12 lists source energy use and savings for the Longleaf at Callaway community. Savings are relative to the Benchmark. Note that the "Percent of End-Use" column shows how effective the prototype building is at reducing energy use in space heating and cooling, as well as domestic hot water end-use. The "Percent of Total" column shows how the energy reductions in each end-use category contribute to the overall savings.

Table 11. Longleaf at Callaway House Specifications

\begin{tabular}{|c|c|}
\hline \multicolumn{2}{|c|}{ Building Envelope } \\
\hline Ceiling & R-27 cathedralized attic (Icynene under roof deck) \\
\hline Walls & $\begin{array}{c}2 \times 4 \text { wood framing @ } 16 \text { in. oc ( } 0.23 \text { framing factor) } \\
\text { R-13 Icynene insulation }\end{array}$ \\
\hline Floor & Raised slab-on-grade, uninsulated \\
\hline Windows & Low-e, gas-filled; $U=0.38 ;$ SHGC $=0.35$ \\
\hline Infiltration & $\begin{array}{l}\text { Tight construction, utilizing the airtightness benefits } \\
\text { of Icynene insulation. Tested at } 2.79 \mathrm{ACH} 50\end{array}$ \\
\hline \multicolumn{2}{|l|}{$\begin{array}{l}\text { Mechanical } \\
\text { Systems }\end{array}$} \\
\hline Heating & $\begin{array}{c}\text { HPSF } 8.0 \text { heat pump with programmable } \\
\text { thermostat }\end{array}$ \\
\hline Cooling & 14 SEER heat pump \\
\hline Ducts & All ductwork located in conditioned space \\
\hline & Tested tight ducts - $0 \%$ leakage to the outside \\
\hline Water Heating & $40 \mathrm{Gal}$. Electric, $0.93 \mathrm{EF}$ \\
\hline Lighting & $10 \%$ fluorescent \\
\hline
\end{tabular}


Table 12. Summary of Estimated End-Use Source Energy

\begin{tabular}{ccccc}
\hline \hline & \multicolumn{2}{c}{ Estimated Annual Source Energy } & \multicolumn{2}{c}{ Source Energy Savings } \\
& Benchmark & Prototype & Percent of End-Use & Percent of Total \\
End Use & (MBtu/yr) & (MBtu/yr) & vs. Benchmark & vs. Benchmark \\
\hline \hline Space Heating & 63 & 38 & $39 \%$ & $9 \%$ \\
Space Cooling & 80 & 34 & $57 \%$ & $17 \%$ \\
DHW & 34 & 24 & $28 \%$ & $4 \%$ \\
Lighting & 21 & 22 & $-4 \%$ & $0 \%$ \\
Appliances+ Plug & 65 & 64 & $2 \%$ & $1 \%$ \\
OA Ventilation & 0 & 0 & $0 \%$ & $0 \%$ \\
\hline Total Usage & $\mathbf{2 6 2}$ & $\mathbf{1 8 2}$ & $\mathbf{3 1 \%}$ & $\mathbf{3 1 \%}$ \\
\hline
\end{tabular}




\section{Builder Cost Summary}

Table 13 summarizes the incremental costs to the builder. While Pine Mountain has invested approximately $\$ 6,835$ in first costs over comparable homes in the greater Atlanta market, the builder believes that the added cost is definitely worthwhile, in terms of energy efficiency, environmental impact, and customer satisfaction. Table 14 summarizes the cash-flow analysis for the buyer. Amortized costs are based on a 30-year mortgage at 7\% interest. While the additional cost of the 30\% building practices cost the buyer \$547 annually, they are saving \$663 annually in energy costs. This translates to a net positive cash flow for the homeowner of \$116 per year. Because of Pine Mountain’s commitment to high-performance building practices, Longleaf homes are now viewed by homebuyers and realtors as the best value in the region.

According to Barnes, the conditioned space in the cathedralized attic turned out to be a great selling feature during home tours. "Buyers could not believe how well-insulated and comfortable the attic space is. Our salespeople were able to position the 'top floor' as additional living space, rather than exclusively for storage, which was a big plus for the customer."

Investments in $30 \%$ building practices are also translating into bottom line benefits for residents who have made Longleaf their home. In fact, one resident contacted Pine Mountain to thank them for a $\$ 125$ power bill they received in February.

Pine Mountain has 109 homes under contract or completed with 15 homes currently under construction all at the 30\% energy-savings level. By the end of 2006, all 137 properties in the Callaway community are slated to be sold, and construction will be completed by the fall of 2007. 
Table 13. Longleaf at Callaway Pricing

\begin{tabular}{|c|c|c|c|}
\hline & Standard Construction & Longleaf at Callaway & $\begin{array}{c}\text { Estimated } \\
\text { Cost } \\
\text { Difference }\end{array}$ \\
\hline \multicolumn{4}{|c|}{ Building envelope } \\
\hline Ceiling & $\begin{array}{l}\text { R-30 batt in vented } \\
\text { attic }\end{array}$ & $\begin{array}{l}\text { R-27 cathedralized attic } \\
\text { (Icynene under roof deck) }\end{array}$ & $\$ 5,325$ \\
\hline Walls & $\begin{array}{c}\text { R-15 } 2 \times 4 \text { wood framing } \\
@ 16 \text { in. o/c }\end{array}$ & $\begin{array}{l}\text { 2x4 wood framing @ } 16 \\
\text { in. oc }(0.23 \text { framing factor }) \\
\text { R-13 Icynene insulation }\end{array}$ & $\begin{array}{c}\text { See Icynene } \\
\text { cost above }\end{array}$ \\
\hline Windows & $\begin{array}{c}\text { Clear glass, } \\
U=0.65 ; \text { SHGC }=0.40\end{array}$ & $\begin{array}{c}\text { Low-e, gas-filled, } \\
\mathrm{U}=0.38 ; \mathrm{SHGC}=0.35\end{array}$ & $\$ 660$ \\
\hline \multicolumn{4}{|l|}{$\begin{array}{l}\text { Mechanical } \\
\text { systems }\end{array}$} \\
\hline HVAC & $\begin{array}{l}\text { HPSF } 7.7 \text { / } 13 \text { SEER } \\
\text { heat pump }\end{array}$ & $\begin{array}{c}\text { HPSF 8.0/14 SEER heat } \\
\text { pump }\end{array}$ & $\$ 600$ \\
\hline \multirow[t]{2}{*}{ Ventilation } & None as standard & $\begin{array}{l}\text { Passive inlet to return } \\
\text { side of air handler }\end{array}$ & $\$ 250$ \\
\hline & & Total & $\$ 6,835$ \\
\hline
\end{tabular}

Table 14. Longleaf at Callaway Cash Flows

\begin{tabular}{lc}
\hline \hline Package & 30\% Savings \\
Total Cost & $\$ 6,835$ \\
$\begin{array}{l}\text { Annual Amortized } \\
\text { Cost }\end{array}$ & $\$ 547$ \\
$\begin{array}{l}\text { Annual Energy } \\
\text { Savings }\end{array}$ & $\$ 663$ \\
Net Savings & $\$ 116$ \\
\hline
\end{tabular}


Development: Linganore Woods

Builder: Habitat for Humanity

Location: $\quad$ Montgomery County, Maryland

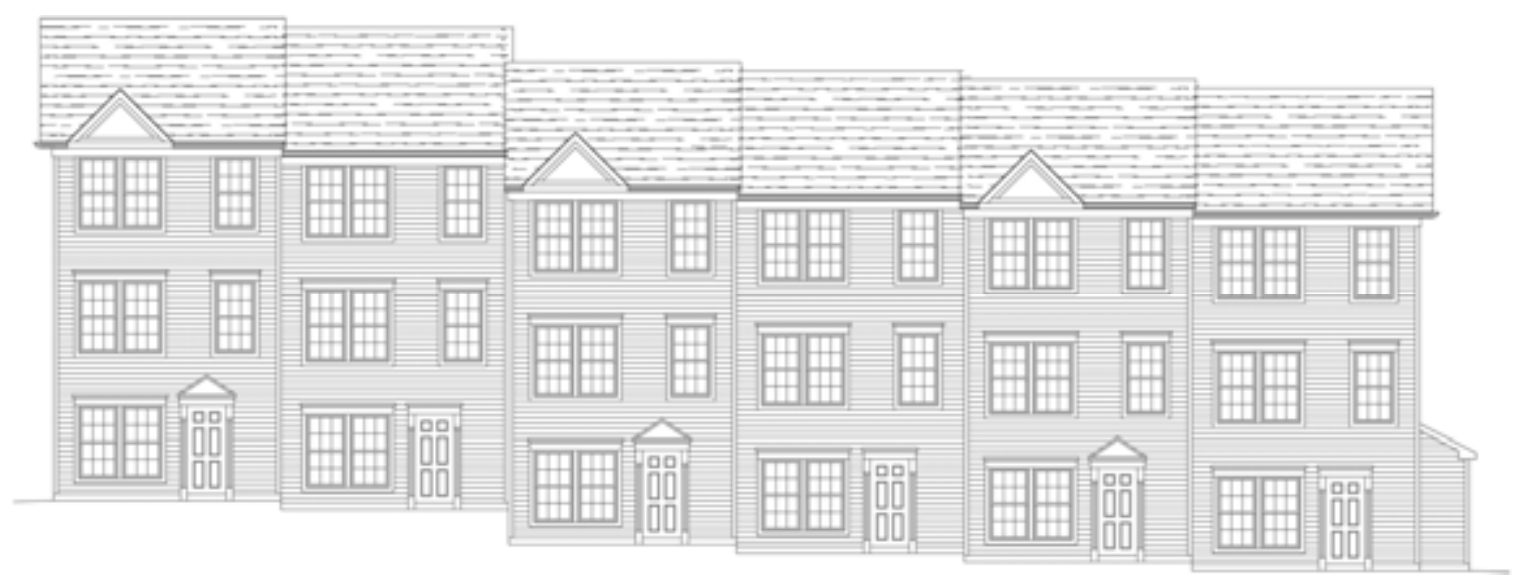

Figure 25. Front elevation of Habitat multi-family project

Habitat for Humanity in Montgomery County, Maryland, is building a multi-family project (Figure 25) using a design that had its origin long before becoming involved with Building Science Corporation (BSC) and Building America. Prior to this project in Montgomery County, building officials had put their foot down on mid-construction changes after noticing projects were growing subsequent to the permitting process - builders were trying to maximize the value of their efforts, without being subjected to issues that might have arisen during permitting. The relevance is that it would have extended the timeframe for getting a permit had significant changes been necessary, and they had already been waiting 9 months with their current submission. Where BSC typically has input during the design process, in this case they needed to adapt techniques for including slab insulation and air-sealing details using methods that could fly under the radar and not impact the structural characteristics of the building. A wall section of the final design is shown in Figure 26, and the key specifications are listed in Table 15.

The use of insulating sheathing, which often throws builders for a loop, was not cited as a problem for Habitat, no doubt because of the experience of the construction manager. The floor presented another challenge and one where BSC was not able to use their preferred approach of foundation insulation, interior to a stem wall and under the floor. Habitat's design used a grade beam / slab-on-grade approach. In light of the permitting difficulties, BSC's recommendation was to insulate on top of the slab, with subfloor covering the foam layer.

Air sealing was another area of design guidance. Reducing air leakage is critical for minimizing the energy use of buildings, and one of the best methods for reducing air leakage is the use of spray-foam insulation. Using spray foam in a few key locations will significantly improve the air leakage, without killing the budget for the project. Key air-leakage areas include rim joists and wall-to-ceiling or -roof connections. 

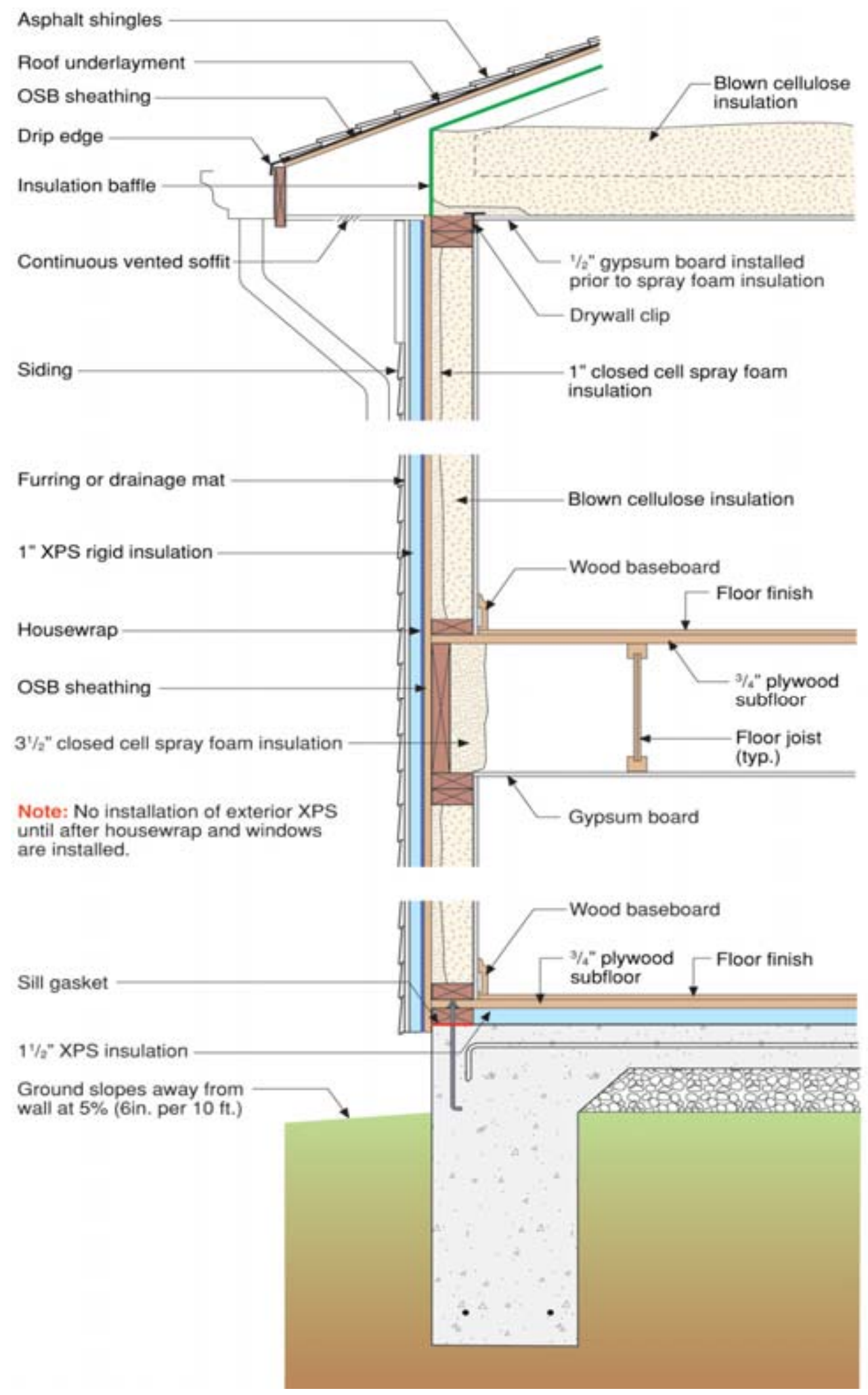

Figure 26. Montgomery County Habitat wall section 


\section{Table 15. House Specifications}

\section{Feature}

\section{Building America Version}

\section{Building envelope}

Ceiling

R-38 flat attic blown insulation

Walls

Foundation

Windows

Infiltration

\section{Mechanical systems}

Heat

Cooling

DHW

Ducts

Leakage

Ventilation
R-5 sheathing, R-7 spray foam, R-9.5 cavity insulation: R-21.5 Slab, R-7.5 1.5 in. XPS on slab, below plywood sub-floor Low-E windows, $\mathrm{U}=0.33, \mathrm{SHGC}=0.33$

$2.5-\mathrm{in}^{2}$ leakage area per $100 \mathrm{ft}^{2}$ envelope

air handler in conditioned space (utility room) 13 SEER split system in conditioned space 0.9 EF Electric hot water tank R-4.2 flex runouts in dropped ceiling or in floor joists none to outside ( $5 \%$ or less) Central fan integrated outdoor-air supply to return of air handler 33\% Duty Cycle: 10 minutes on; 20 minutes off 60-80 CFM continuous average flow Transfer grilles/jump ducts at bedrooms 


\section{Parametric Study}

Figure 27 charts overall source energy-use reduction and shows that the heating, cooling, and lighting loads are greatly diminished with the recommended improvements. Table 16 shows the results in tabular form. Table 17 shows source energy savings by end-use.

\section{Parametric Annual Loads Study}

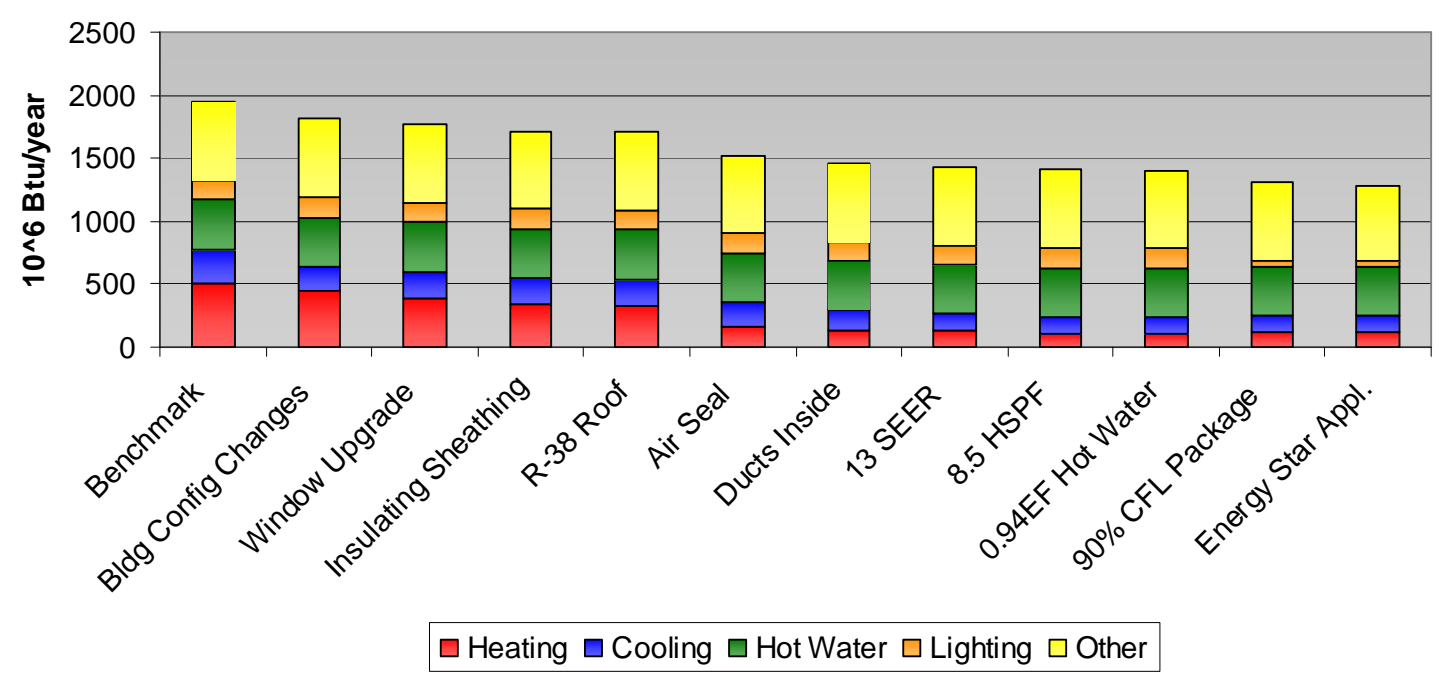

Figure 27. Montgomery County Habitat parametric analysis

Table 16. Summary of Parametric Study

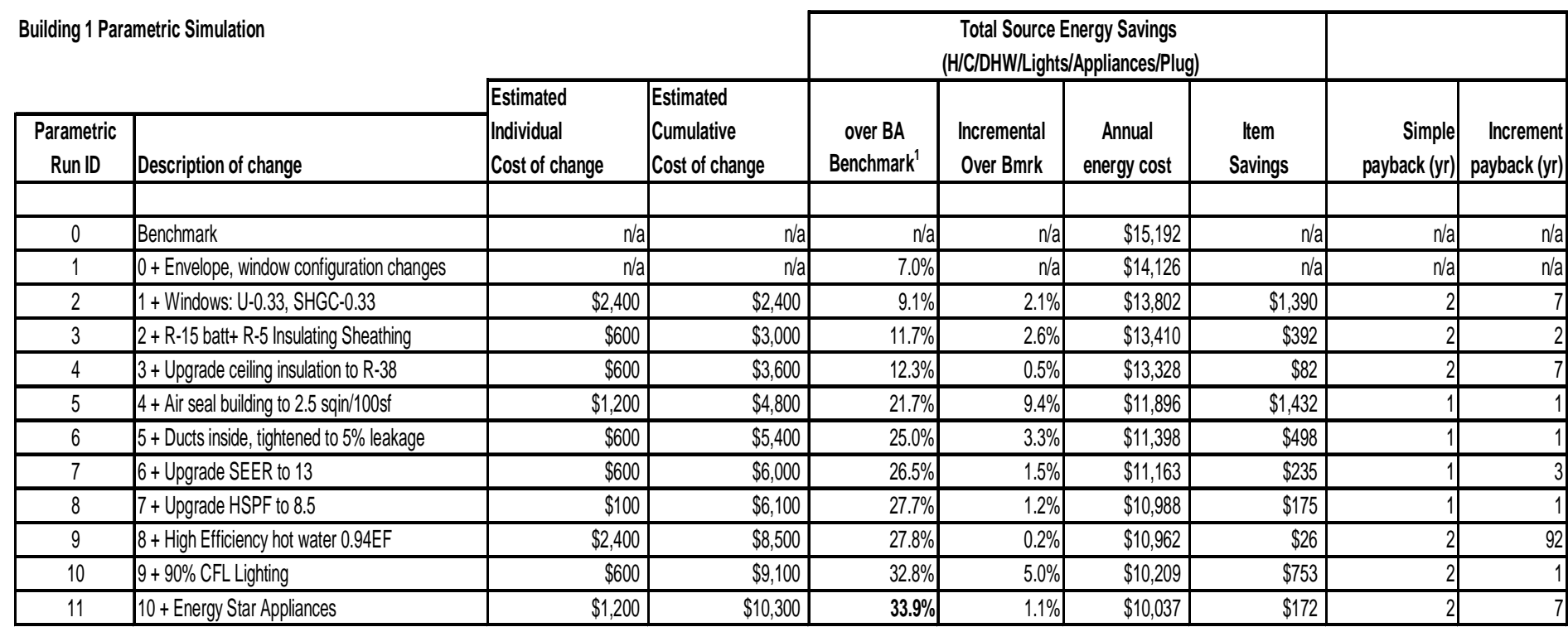




\section{Source Energy Consumption Summary}

Note that the "Percent of End-Use" column shows how effective the prototype building is at reducing energy use in each end-use category. The "Percent of Total" column shows how the energy reductions in each end-use category contribute to the overall savings.

Table 17. Source Energy Savings by End-Use

\begin{tabular}{|c|c|c|c|c|}
\hline & & & \multicolumn{2}{|c|}{ Source Energy Savings } \\
\hline & \multicolumn{2}{|c|}{ Estimated Annual Source Energy } & Percent of End Use & Percent of Total \\
\hline & \multirow{2}{*}{$\begin{array}{c}\text { BA Benchmark } \\
106 \text { BTU/yr }\end{array}$} & \multirow{2}{*}{$\begin{array}{c}\text { Prototype } 1 \\
106 \text { BTU/yr }\end{array}$} & \multirow{2}{*}{ Prototype 1 savings } & \multirow{2}{*}{ Prototype 1 savings } \\
\hline End Use & & & & \\
\hline Space Heating & 502 & 125 & $75 \%$ & $19 \%$ \\
\hline Space Cooling & 276 & 122 & $56 \%$ & $8 \%$ \\
\hline DHW & 391 & 388 & $1 \%$ & $0 \%$ \\
\hline Lighting & 155 & 52 & $67 \%$ & $5 \%$ \\
\hline Appliances + Plug & 622 & 598 & $4 \%$ & $1 \%$ \\
\hline Total Usage & 1946 & 1285 & $34 \%$ & $34 \%$ \\
\hline Site Generation & 0 & 0 & & $0 \%$ \\
\hline Net Energy Use & 1946 & 1285 & $34 \%$ & $34 \%$ \\
\hline
\end{tabular}

\section{Summary}

With improvements that were able to be retrofitted into an existing design for modest change and costs, the energy consumption of the building was greatly reduced. Also, the improvements will create more comfortable interior conditions for the occupants throughout the houses, giving a non-calculable benefit of more useful space per square foot of house area. 
Development: Melrose Commons

Builder: Blue Sea Construction

Location: $\quad$ Bronx, New York

\section{Background}

Melrose Commons (Figure 28), a community of 70 three-family townhomes located in the South Bronx, New York, exemplifies how high performance and affordability can successfully be combined to create a home that is not just affordable to purchase, but affordable to maintain as well. Typically, affordable housing in New York City is built to be affordable on a first-cost basis, making maintenance and energy costs a burden to homebuyers and not-for-profit organizations that own or manage such buildings. Melrose Commons breaks this mold, implementing advanced technologies and Building America design strategies that lower the life-cycle costs.

The first phase of the project, Melrose Commons II, was funded by the New York City Department of Housing Preservation and Development through the New York City Partnership. Developed by MC II Associates and built by Blue Sea Construction in 2002, these 30 initial townhomes were the first

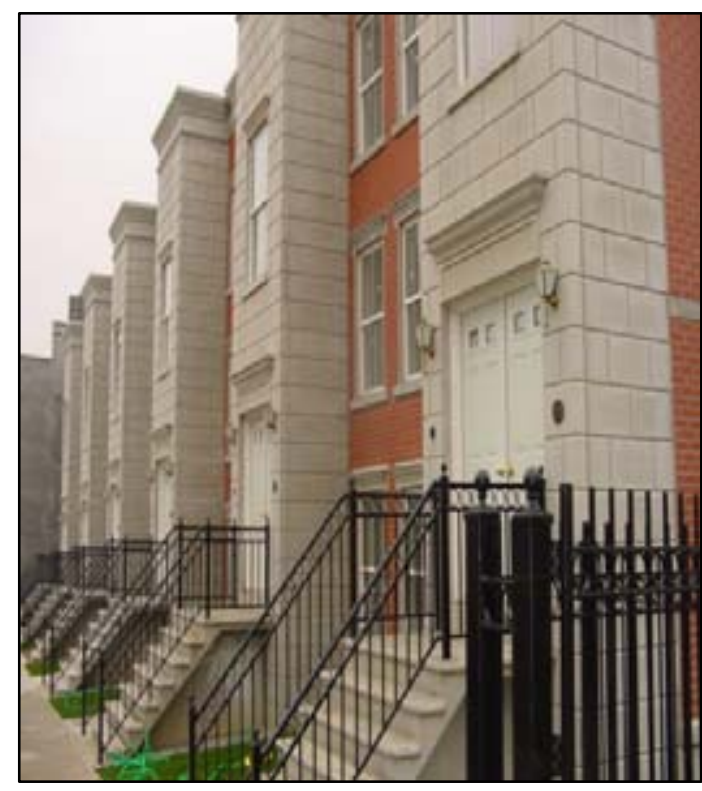

Figure 28. Melrose Commons affordable three-family housing in New York State that met the U.S. Environmental Protection Agency (EPA) and the New York State Energy Research and Development Authority (NYSERDA) ENERGY STAR standards. The homes were designed for first-time homebuyers, promoting small business in the community. The basement, the first full floor, and half of the second floor, comprise the owner's two-bedroom residence. There is a half-floor one-bedroom apartment on the second floor and a full-floor two-bedroom apartment on the top floor. The top two units can be rented out to further subsidize the already affordable mortgage.

Based on the success of Melrose Commons II, the builder, Blue Sea Construction, continued the efficient, affordable construction practices in the neighboring Melrose Commons III. This phase consisted of 40 three-family townhomes, built to the same specifications as Melrose Commons II, and was completed in October 2003. One distinct difference was the addition of a 2.2-kW solar electric system (Figure 29) on the roof of one of the townhomes. Blue Sea took advantage of funding available through the NYSERDA ENERGY STAR/PV Demonstration project to assess the true costs for installing such a system, including costs incurred by the roofers, electricians, and the PV contractor. 


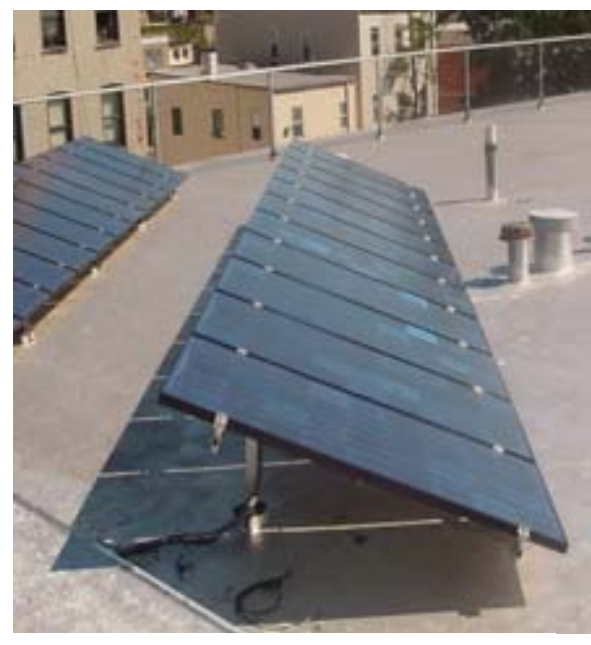

Figure 29. Solar system

The completion of these projects brought much-needed affordable housing to a community in the midst of revitalization. The architecture is such that the homes blend well with the surrounding buildings. The homes feature three-story-high precast concrete panels that form an elegant stone and brick façade. Crown lintels project over windows and doors and a detail cornice caps the perimeter (Figure 30). Totaling 296,100 $\mathrm{ft}^{2}$ of dwelling space, the homes span four city blocks in the Melrose section of the Bronx. The builders and the owners benefited from advanced housing technologies that accent affordability, durability, and marketability.

In January 2004, Melrose Commons II was awarded the U.S. Department of Housing and Urban Development (HUD) Secretary's Platinum Award for Excellence in the 20th Annual Best in American Living Award Competition. In 2005, Melrose Commons earned the NAHB's Energy Value Housing Silver Award. The development also won first-place in the residential category of the Northeast Sustainable Energy Association's (NESEA) 2003 Green Building Awards, competing against high-end, single-family custom homes.

\section{Advanced Technologies}

Design considerations for Melrose Commons primarily focused on energy efficiency, sustainability, and affordability. Below is a summary of several of the advanced technologies incorporated into the 210-home development.

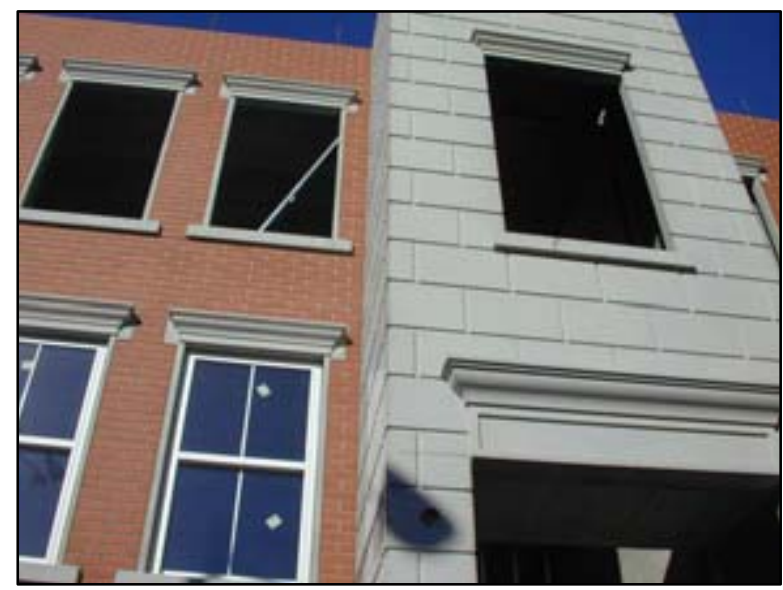

Figure 30. Crown lintels over windows 


\section{Oldcastle Precast Concrete Wall Panels}

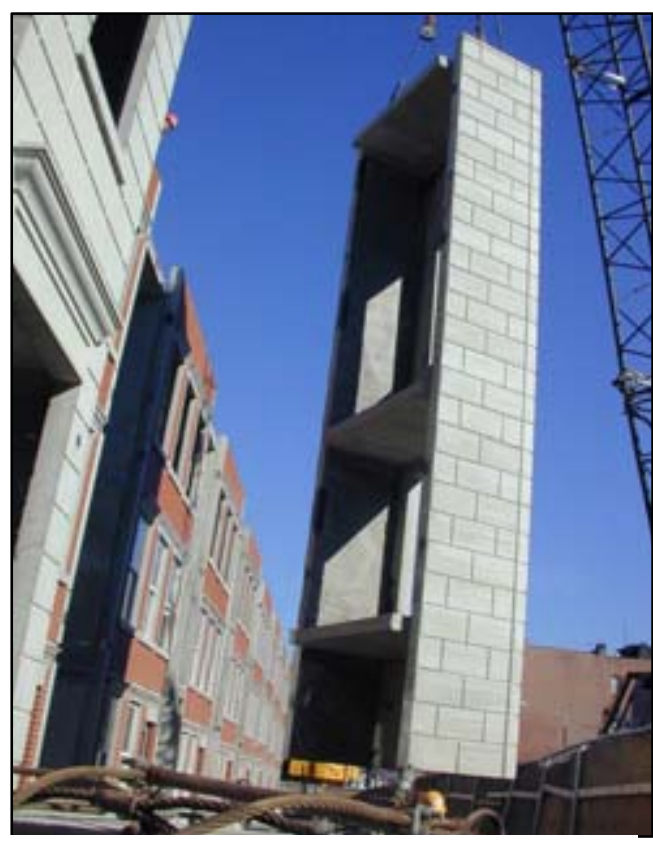

Figure 31. Precast concrete panelized wall system
The Oldcastle precast concrete panelized wall system (Figure 31) offered the builder a means to fast and efficient home construction in lieu of the typical blockand-plank method. The development featured three separate types of unit: end units with three exposed exterior walls; middle units with two exposed exterior walls; and detached units with four exposed exterior walls. Each of the 22-ft-wide and 50-ft-deep homes were constructed from five major precast concrete elements: (1) load-bearing panels to support precast floor planks and roof; (2) non-load bearing panels with decorative precast windows and exterior brick facade; (3) U-shaped panels for entry facade; (4) cornice capping the exterior perimeter; (5) and exterior stairs. The project also used hollow-core panels for the floor and roof. The hollow core panels offered the same durability and strength of traditional precast panels but weighed significantly less. The exterior face of the exterior panels featured a thin brick inlay, a new feature of the Oldcastle panels.

The placement of bricks in the panel is feasible as a result of the self-compacting mixture created by the

addition of superplasticizers. The self-compacting mixture eliminates the need to vibrate the forms to achieve a uniform consistency.

The panels took approximately 3 months to manufacturer. After the site was prepared and the foundation was laid, the panels were shipped to the Melrose Commons site where they were quickly erected with a crane. The first 30 buildings were constructed with a six-man erection crew - one welder, one grouter, and four assemblers - in the span of 4 months. After the panels were placed, the building crew air sealed around floor, electrical boxes, and inside to outside connections.

The use of panels was beneficial in respect to both construction and energy efficiency. Typical practices in this urban neighborhood called for concrete block-and-plank construction. The panels arrived on the site ready to be placed together, allowing for speedy construction throughout the cold and wet winter months. This, in turn, made financing the project easier by reducing carrying charges and the opportunity for theft and vandalism. Because the panels were fabricated off site to exact specifications, the amount of on-site waste was significantly reduced. Concrete as a material offers increased durability and fire resistance. The use of precast concrete panels increased the tightness of the building envelope. Each panel spanned the entire side of a unit, reducing the number of seams and, therefore, opportunities for infiltration.

\section{High-Performance Insulation Strategy}

Rigid Insulation. CARB conducted THERM analysis of the initial insulation specification and found that a significant amount of thermal bridging would occur between the concrete exterior and the metal studs. To reduce this potential failure in R-value, CARB suggested using a 1/2-in. 
extruded polystyrene (XPS) board (Figure 32) between the exterior walls and interior metal studs. The rigid insulation was installed throughout the complex and provided a significant barrier to thermal bridging. R-11 fiberglass batts were then installed in the steel framed cavity.

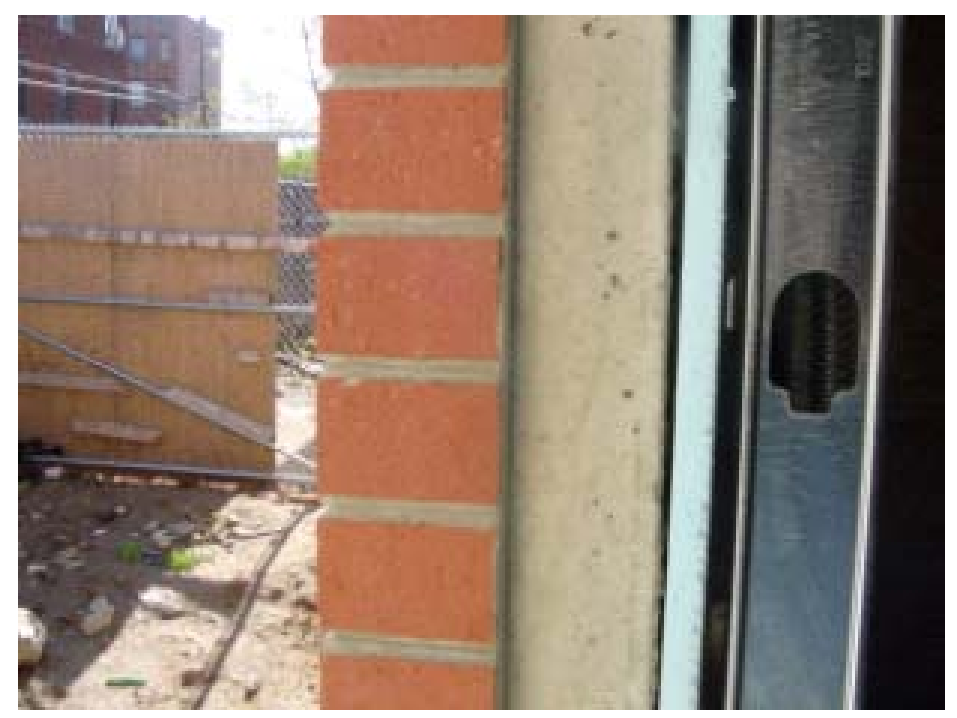

Figure 32. Extruded polystyrene board between the exterior walls and interior metal studs

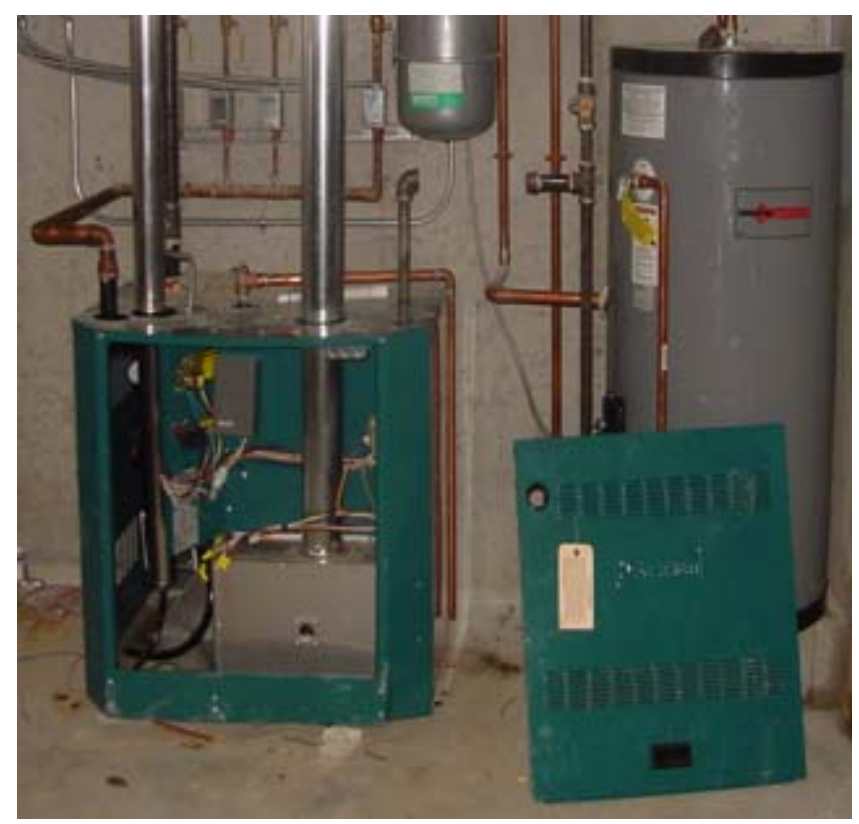

Figure 33. Sealed-combustion, directvent, gas-burning Burnham Revolution boiler with a 65-gal. Bradford-White automatic-storage water heater
Energy Efficient, Integrated Space heating and Domestic Hot Water Sealed Combustion Boiler. Each three-family home comes equipped with a single sealedcombustion, direct-vent, gas-burning Burnham Revolution boiler with a 65-gallon Bradford-White automatic-storage water heater (Figure 33). The single boiler system in each home provides both heating and hot water to all thee units. The boilers are ENERGY STAR-certified and have an AFUE rating of 87. Properly accounting for the building's insulation, reduced air infiltration, and heating load allowed the boiler in the Melrose Commons units to be properly sized with an output rating of 164 $\mathrm{kBtu} / \mathrm{h}$. 
Mechanical Ventilation. Because of the tightness of the precast concrete building envelope, controlled mechanical ventilation was needed to ensure that the homes have adequate fresh air to dilute pollutants and remove humidity from the home.

CARB recommended an "exhaust-only" strategy as the most effective and affordable solution for this situation where heating is the predominant load and there is no central air conditioning or ducted air-distribution system. This approach requires one bath fan in each of the homes be upgraded to a model that has been rated for energy-efficient operation, continuous use, and quiet running. An efficient fan will not be costly for the homeowner to operate. A fan rated for longer run times will not fail after a few months of operation. And lastly, the homeowner is less likely to disable the fan if it runs quietly.

This ventilation system complies with the guidelines set forth by the American Society of Heating, Refrigerating and Air Conditioning Engineers (ASHRAE) in Standard 62.2, Ventilation and Acceptable Indoor Air Quality in Low-rise Residential Buildings.

\section{Renewable Energy}

\section{Photovoltaic System}

As part of a NYSERDA demonstration project, Blue Sea Construction installed a 2.2-kW photovoltaic system on one townhome to assess costs and feasibility. Most of the funding for the solar equipment and installation was provided by NYSERDA. Monitoring shows that generation varies between $3 \mathrm{kWh} /$ day in the winter to $0 \mathrm{kWh}$ /day in the summer. Annual production is approximately 2,400 kWh (\$432) in electricity savings each year.

\section{Additional Features}

To complement the energy-efficient elements utilized in these townhomes, "green” components were also considered to reduce the overall environmental footprint of these units. Additional features that were incorporated into this project are listed below:

- Low-VOC paints, caulks, sealants, and adhesives

- Recycled-content kitchen VCT flooring

- Solid wood and plywood used in lieu of particle board in cabinets and countertop substrates with low-VOC lacquer finishes

- $100 \%$ recycled content PET carpeting and recycled rubber padding

- ENERGY STAR compact fluorescent lighting fixtures throughout the home

- ENERGY STAR refrigerators and dishwashers

- Low-flow fixtures and dual-flush toilets

- Digital programmable thermostats and computer boiler control with outdoor temperature sensors

- Large double-glazed low-e vinyl windows to increase natural lighting

- Concrete with high fly ash content was used in precast panels. 


\section{Overall Building Specification}

These affordable homes feature much higher quality construction than is typical in similar New York City housing. Table 18 displays the improvements made at Melrose Commons over standard block-and-plank construction.

Table 18. Summary of Key Specifications

Melrose Commons Standard Block and Plank

\begin{tabular}{|c|c|c|c|}
\hline \multirow{2}{*}{$\begin{array}{l}\text { Front and } \\
\text { End Wall }\end{array}$} & Construction & $\begin{array}{c}\text { Steel studs inside pre-cast concrete } \\
\text { panels }\end{array}$ & $\begin{array}{l}\text { Steel studs inside laid } \\
\text { concrete blocks }\end{array}$ \\
\hline & Insulation & $\begin{array}{c}\text { R-11 in stud cavities, R-3 XPS } \\
\text { break }\end{array}$ & R-11 in stud cavities \\
\hline \multirow[t]{2}{*}{ Rear Wall } & Construction & $\begin{array}{l}\text { Steel studs, exterior gypsum, } \\
\text { aluminum siding }\end{array}$ & $\begin{array}{l}\text { Steel studs, exterior gypsum, } \\
\text { aluminum siding }\end{array}$ \\
\hline & Insulation & R-11 in stud cavities & R-11 in stud cavities \\
\hline \multicolumn{2}{|l|}{ Windows } & $\begin{array}{c}\text { Insulated, low-e glazing, vinyl } \\
\text { frames }\end{array}$ & $\begin{array}{c}\text { Insulated, clear glazing, metal } \\
\text { frames }\end{array}$ \\
\hline \multicolumn{2}{|c|}{ Roof Insulation } & R-20 Polyisocyanurate & R-20 Polyisocyanurate \\
\hline \multicolumn{2}{|c|}{ Basement Insulation } & Not effective & Not effective \\
\hline \multirow{3}{*}{$\begin{array}{l}\text { Space } \\
\text { Heating }\end{array}$} & Equipment & Direct vent boiler, $86 \%$ AFUE & $\begin{array}{l}\text { Atmospheric boiler, } 80 \% \\
\text { AFUE }\end{array}$ \\
\hline & \begin{tabular}{|l|} 
Distribution \\
\end{tabular} & Hydronic Baseboard & Hydronic Baseboard \\
\hline & Control & 4 zones, reset control & Single zone \\
\hline \multicolumn{2}{|c|}{ Domestic Hot Water } & Indirect tank heated by boiler & Atmospheric tank, $0.54 \mathrm{EF}$ \\
\hline \multicolumn{2}{|l|}{ Lighting } & All permanent fixtures fluorescent & Fluorescent in kitchen only \\
\hline \multicolumn{2}{|l|}{ Appliances } & All supplied appliances Energy Star & Standard appliances \\
\hline \multicolumn{2}{|l|}{ Ventilation } & $\begin{array}{l}\text { Each unit has one low-sone, } \\
\text { efficient bath fan running } \\
\text { continuously (50-60 CFM). }\end{array}$ & $\begin{array}{l}\text { Standard fixtures; no } \\
\text { automatic ventilation. }\end{array}$ \\
\hline
\end{tabular}

\section{Energy and Cost Information}

\section{Home Energy Performance}

The Melrose Commons townhomes received ENERGY STAR certification. Blower-door tests revealed consistently well-sealed envelopes with leakage ranging from 0.07 to 0.10 ACHnat. Classic HERS scores ranged from 88.9 to 89.5. To determine the percentage improvement over the Building America Benchmark, REM/Rate software was used to determine the annual energy consumption from space heating, cooling, and water heating. Tables 19 and 20 show the estimated annual performance of the regional standard, the builder's standard, and the prototype versus the Benchmark. The values in the Benchmark column refer to the reference home for a single Melrose Commons unit. The average Melrose Commons unit is estimated to consume $30 \%$ less source energy than a similar home built to the Benchmark specifications. 


\section{Table 19. Benchmark Analysis, Summary of Site Energy Consumption by End Use}

\begin{tabular}{|c|c|c|c|c|c|c|c|c|}
\hline & \multicolumn{8}{|c|}{ Annual Site Energy } \\
\hline & \multicolumn{2}{|c|}{ BA Benchmark } & \multicolumn{2}{|c|}{ Region Standard } & \multicolumn{2}{|c|}{ Builder Standard } & \multicolumn{2}{|c|}{ BA Prototype } \\
\hline End Use & kWh & Therms & kWh & Therms & kWh & Therms & $\mathrm{kWh}$ & Therms \\
\hline Space Heating & 0 & 939 & 0 & 761 & 0 & 761 & 0 & 472 \\
\hline Space Cooling & 2533 & 0 & 2450 & 0 & 2450 & 0 & 2472 & 0 \\
\hline DHW & 0 & 397 & 0 & 369 & 0 & 369 & 0 & 276 \\
\hline Lighting & 3244 & & 1909 & & 1909 & & 1109 & \\
\hline Appliance/Plug Load & 8300 & 186 & 7382 & 186 & 7382 & 186 & 7382 & 186 \\
\hline OA Ventilation & 332 & & 368 & & 368 & & 368 & \\
\hline Total Usage & 14409 & 1522 & 12109 & 1316 & 12109 & 1316 & 11331 & 934 \\
\hline Site Generation & & & & & & & $\overline{0}$ & \\
\hline Net Energy Use & 14409 & 1522 & 12109 & 1316 & 12109 & 1316 & 11331 & 934 \\
\hline
\end{tabular}

Table 20. Benchmark Analysis, Summary of Source Energy Consumption

\begin{tabular}{|c|c|c|c|c|c|c|c|c|c|c|}
\hline & & & & & \multicolumn{6}{|c|}{ Source Energy Savings } \\
\hline & \multicolumn{4}{|c|}{ Annual Source Energy } & \multicolumn{3}{|c|}{ Percent of End-Use } & \multicolumn{3}{|c|}{ Percent of Total } \\
\hline & Benchmark & Region & Builder & Proto & $\mathrm{BA}$ & Reg & Bldr & BA & Reg & Bldr \\
\hline End Use & MBtu/yr & MBtu/yr & MBtu/yr & MBtu/yr & Base & Base & Base & Base & Base & Base \\
\hline Space Heating & 96 & 78 & 78 & 48 & $50 \%$ & $38 \%$ & $38 \%$ & $15 \%$ & $11 \%$ & $\mathbf{1 1 \%}$ \\
\hline Space Cooling & 27 & 26 & 26 & 27 & $2 \%$ & $-1 \%$ & $-1 \%$ & $0 \%$ & $0 \%$ & $0 \%$ \\
\hline $\mathrm{DHW}$ & 40 & 38 & 38 & 28 & $30 \%$ & $25 \%$ & $25 \%$ & $4 \%$ & $4 \%$ & $4 \%$ \\
\hline Lighting & 35 & 21 & 21 & 12 & $66 \%$ & $42 \%$ & $42 \%$ & $7 \%$ & $3 \%$ & $3 \%$ \\
\hline Appliance/Plug Load & 108 & 99 & 99 & 99 & $9 \%$ & $0 \%$ & $0 \%$ & $3 \%$ & $0 \%$ & $0 \%$ \\
\hline OA Ventilation & 4 & 4 & 4 & 4 & $-11 \%$ & $0 \%$ & $0 \%$ & $0 \%$ & $0 \%$ & $0 \%$ \\
\hline Total & 311 & 265 & 265 & 217 & $30 \%$ & $18 \%$ & $18 \%$ & $30 \%$ & $18 \%$ & $18 \%$ \\
\hline Site Generation & & & & $\overline{0}$ & & & & $0 \%$ & $0 \%$ & $0 \%$ \\
\hline Net Energy Usage & 311 & 265 & 265 & 217 & $30 \%$ & $18 \%$ & $18 \%$ & $30 \%$ & $18 \%$ & $18 \%$ \\
\hline
\end{tabular}

\section{Cost}

Blue Sea Construction provided CARB with costs incurred to improve the homes over Blue Sea's standard construction (Table 21). Costs for the single 2.2-kW photovoltaic system, including extra work required by roofers and electricians, totaled approximately $\$ 24,000$. Most of the funding for the solar equipment and installation was provided by NYSERDA. Other incremental costs are shown below.

For a community that is accustomed to high maintenance costs and substandard housing, these award-winning, affordable homes are proof that there is a better, more efficient, more sustainable alternative by implementing Building America design strategies (Figures 34, 35, and 36). 
Table 21. Constructions Costs Incurred to Improve the Performance of the Melrose Homes

\begin{tabular}{|lc|}
\multicolumn{1}{c}{ Improved System/Specification } & $\begin{array}{c}\text { Incremental Cost per } \\
\text { Three-family Home }\end{array}$ \\
\hline 1/2" rigid insulation outside of metal studs & $\$ 675$ \\
Double glazed, low-e, vinyl-framed windows & $\$ 896$ \\
60 gallon indirect water heater & $\$ 928$ \\
$87 \%$ efficient 164kBtuh sealed combustion & $\$ 1,897$ \\
boiler & $\$ 184$ \\
Digital, programmable thermostats & $\$ 459$ \\
Outdoor reset control & $\$ 45$ \\
Energy Star Refrigerators & 18 \\
Energy Star Dishwasher & $\$ 375$ \\
Compact fluorescent lighting fixtures & $\$ 5,492$ \\
\hline Total Increased Costs & $\$ 1,000)$ \\
\hline NYSERDA Energy Star Homes Incentive & $\$ 4,492$ \\
\hline Net Cost to Builder & \\
\hline
\end{tabular}



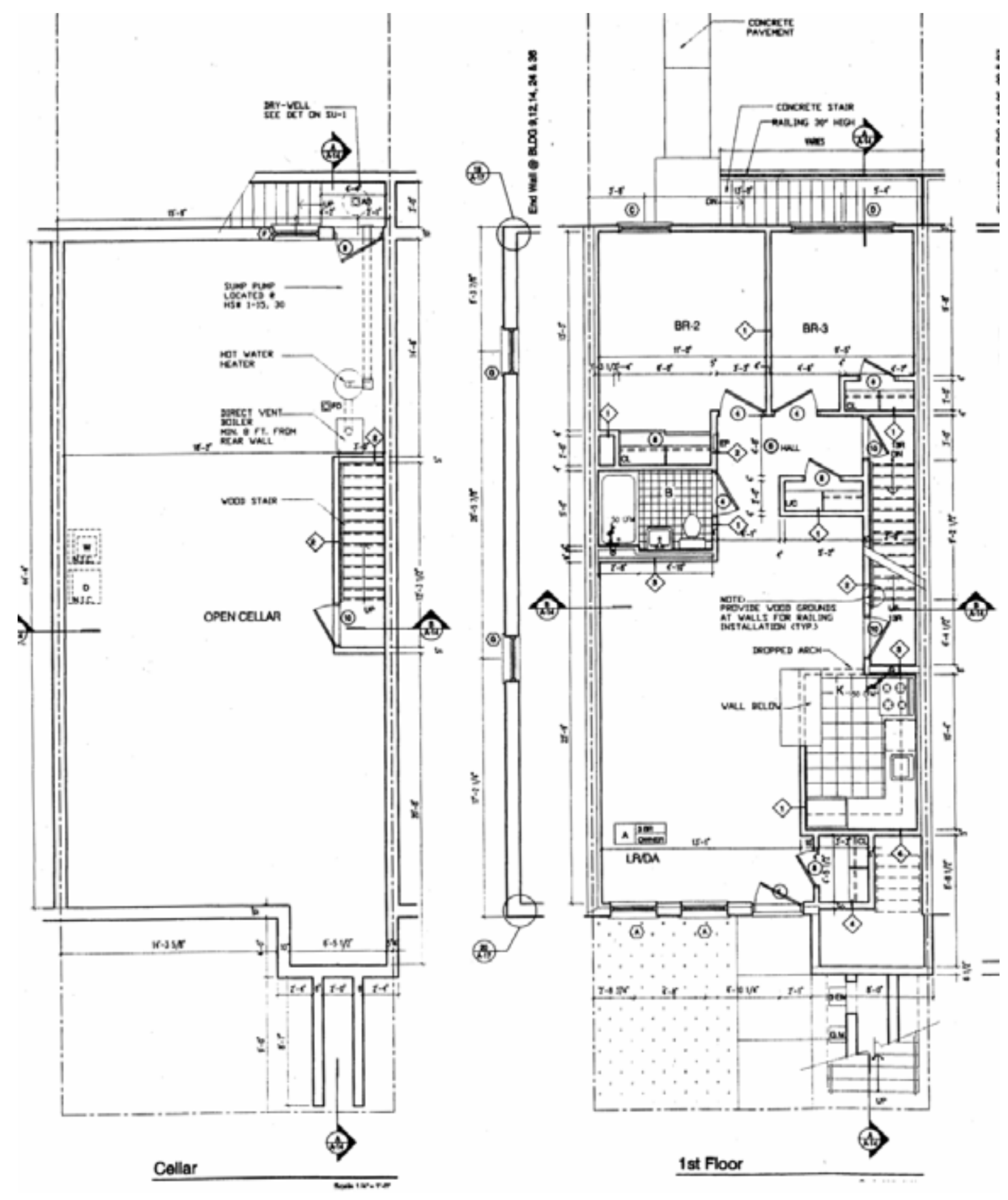

Figure 34. Basement and first-floor plans 


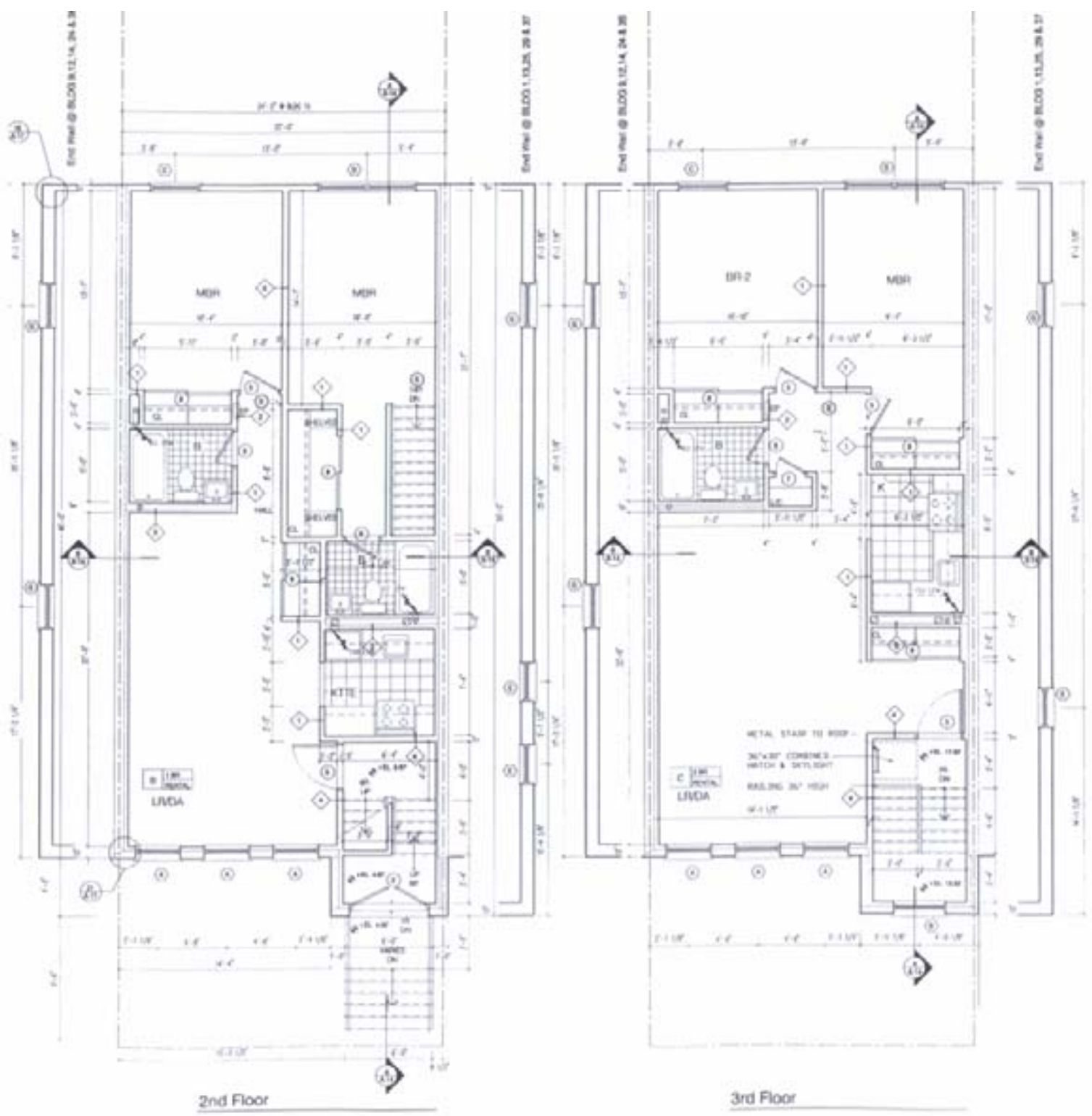

Figure 35. Second- and third-floor plans 
E. 159 STREET

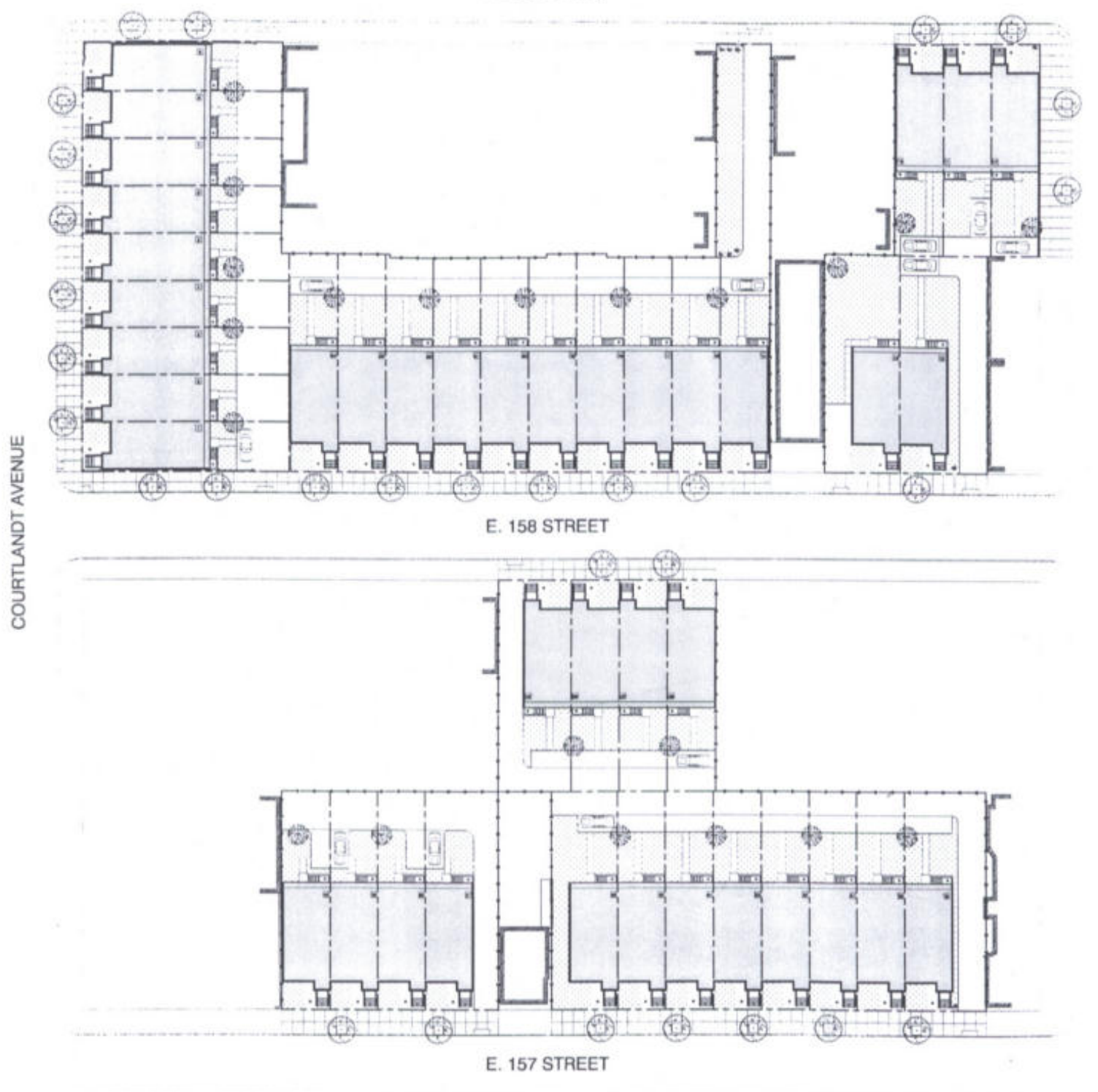

Figure 36. Site plan for Melrose Commons III 


\section{Development: Frankford Estates}

Builder:

Location:

\section{Struever Rouse}

Baltimore, Maryland

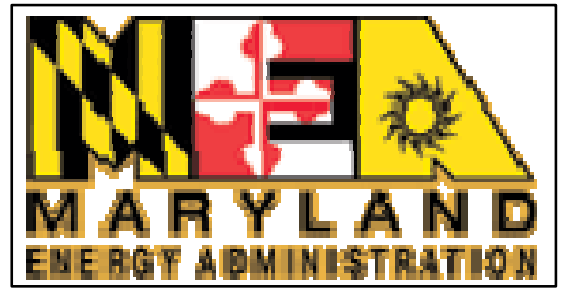

\section{Background}

In response to a 2002 DOE solicitation for State Energy Program Special Projects under the Building America Program, the Maryland Energy Administration (MEA) submitted a proposal to implement an "Energy Efficient and Green Technology Building Templates Program." The MEA promotes energy efficiency and conservation, which in turn facilitates economic development, reduces reliance on foreign fuel supply, and improves the environment. The grant was awarded in July 2002 and the Consortium of Advanced Residential Buildings (CARB) was selected to provide technical assistance. CARB began working with MEA to select suitable builder partners and locate potential sites for this project. Once contracts and funding were in place, a kick-off meeting was held in Baltimore in mid-May 2003. Unfortunately, because of logistical problems with the initial building participants, the project was delayed and did not get off the ground at that time. Interest in this project was renewed, and CARB began to coordinate the next steps with MEA in early May 2005.

The purpose of this grant is to implement the "Energy Efficient and Green Technology Building Templates” in partnership with selected Maryland Homebuilders of new construction and rehabilitation projects. This case study focuses on the construction of three new attached townhouses that exceed the total energy performance of the $1993 \mathrm{MEC}$ by $50 \%$. This equates to an approximate total annual source-energy savings of 30\% when compared to the Building America Benchmark Definition (Hendron 2005). The project also incorporates green building components with regards to the construction materials (caulk, adhesives, insulation, etc.) and the finishing elements (flooring, fixtures, paint, etc.)

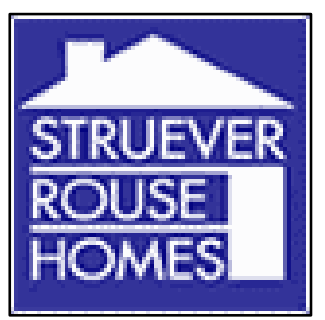

The builder partner selected for the new construction portion of the project is Struever Rouse Homes. A division of Struever Bros., Eccles \& Rouse, Inc., a pioneer of Baltimore's real estate landscape, Struever Rouse Homes is committed to an enduring legacy of building homes and neighborhoods that exemplify the finest urban living options available in today's marketplace.

The three townhomes selected for this project were built in one of Struever Rouse Homes' newest communities, called Frankford Estates (Figures 37 and 38). Frankford Estates is a "Green-Friendly" community that was built with many ecofriendly options. The housing development includes townhomes, duplexes, and single-family homes. This unique community also

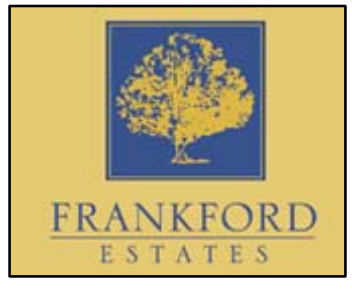
incorporates a pool, clubhouse, playground, and 18 acres of beautifully landscaped grounds into a friendly living environment. The attached prototype townhomes are three stories with a walkout basement. In each townhome, the 1,960 $\mathrm{ft}^{2}$ of living space (excluding unfinished basement) includes three bedrooms and 2.5 baths. The basement was finished in the middle unit. 


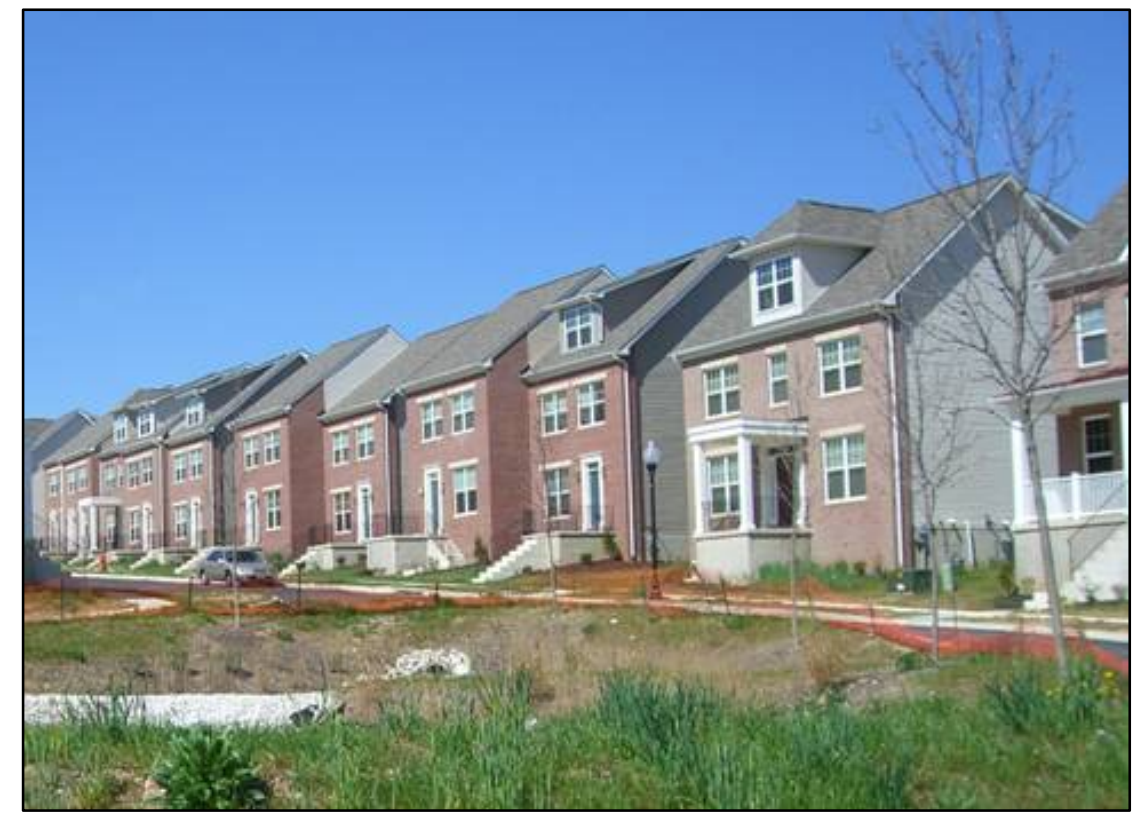

Figure 37. Frankford Estates townhouses

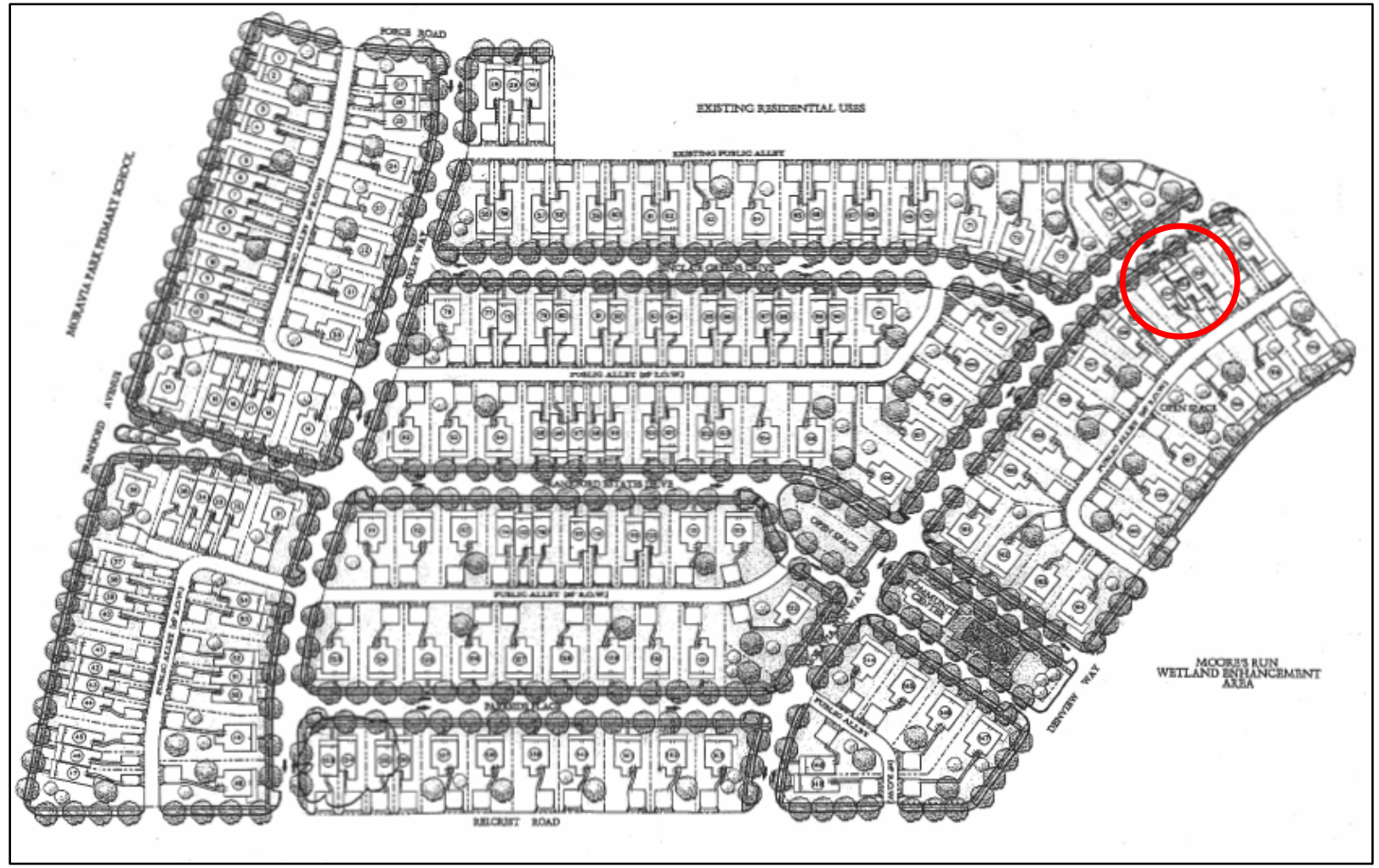

Figure 38. The three townhomes selected for this project 


\section{Advanced Technologies}

Design considerations for Struever Rouse Homes primarily focused on the building envelope and ductwork to provide appropriate insulation and proper air sealing. Table 22 is a chart describing their current building specifications.

Table 22. Struever Rouse Standard Practice Specifications

\begin{tabular}{|l|l|}
\hline \multicolumn{2}{|l|}{} \\
\hline Foundation Walls & R-11 fiberglass batts, half height, interior \\
\hline Rim/Band Joists & R-13 fiberglass batts \\
\hline Exterior Walls & 2x4, 16 in. OC, framed walls \\
\hline Wall Insulation & R-13 fiberglass batts \\
\hline Floor System & Open Web Trusses \\
\hline Windows & Low-e, insulated glass w/ argon (U =0.35, SHGC = 0.29) \\
\hline Ceiling Insulation & Fiberglass Insulation (R-30) \\
\hline Duct System & Designed by HVAC contractor, minimal duct sealing \\
\hline Transfer Grilles & Only door undercuts \\
\hline Space Heating & Two NG furnaces, 80\% AFUE, atmospheric \\
\hline Space Cooling & Two split-system air conditioners, SEER 13, R-22 refrigerant \\
\hline Thermostat & Programmable \\
\hline Water Heating & Gas water heater, EF = 0.61 \\
\hline Lighting & $10 \%$ Fluorescent \\
\hline Appliances & StandardRefrigerator and Dishwasher \\
\hline Ventilation & No mechanical control \\
\hline
\end{tabular}

A detailed summary of several of the advanced technologies incorporated into the three prototype townhomes is discussed below.

\section{Engineered Panel System}

To increase the thermal resistance of the building envelope, CARB recommended switching from 2x4 framing to 2x6 framing. This Optimum Value Engineering (OVE) framing technique reduces the amount of lumber used to build a home while maintaining the structural integrity of the building. Using OVE results in lower material and labor costs and can also improve energy performance. OVE is a new technique for Struever's panelizer. Though they were more than willing to make the framing modifications, they mistakenly spaced the 2x6 wood studs at 16 in. on center, rather than at 24 in. on center. This greatly reduces the cost and green benefits of 2x6 wall construction. It still allows an increase in the thermal resistance of the building envelope, but it is not optimal. This spacing error resulted in a 7\% increase in the overall U-value of the wall assembly. Because of the tight construction schedule, the panels could not be corrected for these prototypes. 


\section{High-Performance Insulation Strategy}

Air sealing the building envelope is a key part of reducing drafts and lowering the home's energy use. Therefore, before installation of insulation into the stud cavities, low-expansion foam was used to air seal all stud cavities and between the bottom cord and subfloor. The use of foam at all seams significantly improves the air tightness of these homes (Figure 39).

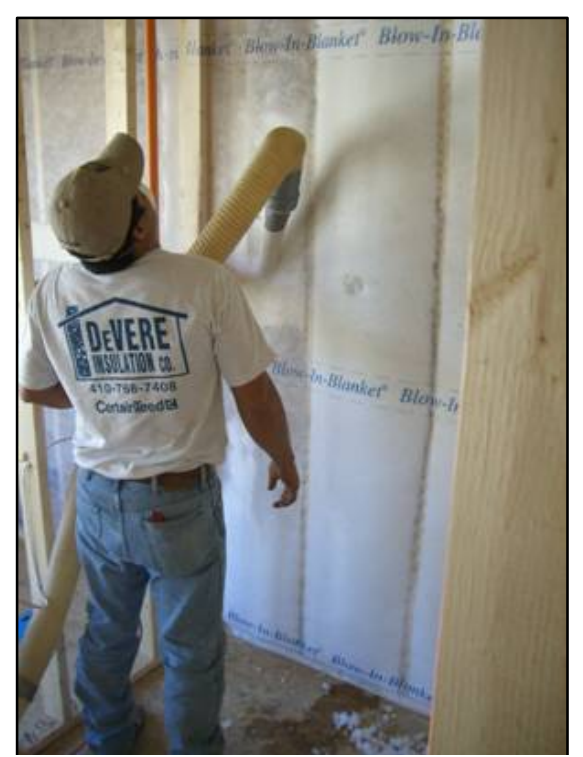

Figure 40. Blanket insulation

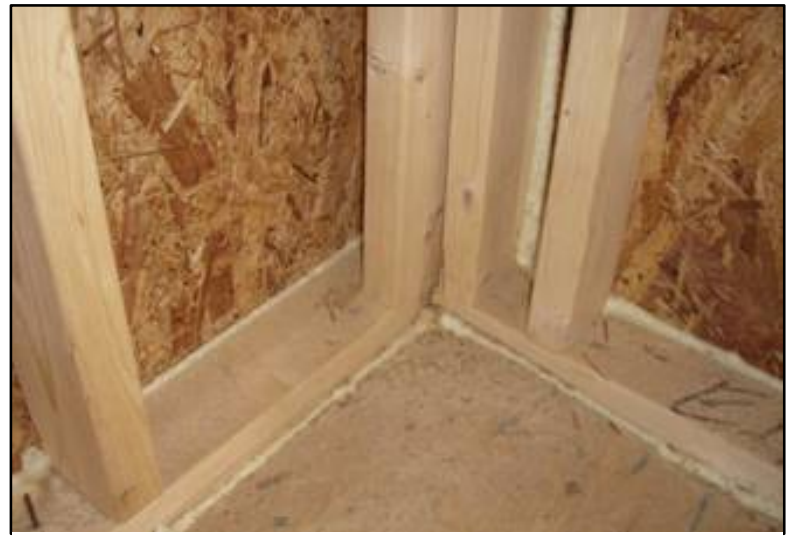

Figure 39. Low-expansion foam used to air seal stud cavities

After the initial air sealing, a Blow-In-Blanket ${ }^{\circledR}$ System (BIBS) was utilized to insulate the walls. Certainteed's Optima ${ }^{\circledR}$ loose-fill fiberglass insulation was pneumatically blown behind non-woven Optima fabric (Figure 40). The compacted fiberglass provides a secondary air retarder. In addition, because the fiberglass insulation is manufactured from recycled glass, sand, and other ingredients, CertainTeed's fiberglass insulation is GreenGuard certified. This certification helps identify products that have been tested for emissions of formaldehyde, volatile organic compounds (VOCs), respirable particles, and other pollutants. The net result of the R-21 blown insulation is a wall assembly that yields an R-value of $19 \mathrm{ft}^{2}-{ }^{\circ} \mathrm{F}-\mathrm{hr} / \mathrm{Btu}-$ far superior to the R-13 fiberglass batts (net wall assembly $\mathrm{R}$-value of $12 \mathrm{ft}^{2}-{ }^{\circ} \mathrm{F}-\mathrm{hr} / \mathrm{Btu}$ ) typically used in this development.

For the basement, the insulation strategy was to use 2 in. of foil-faced polyisocyanurate rigid insulation (Thermax or equivalent product that is rated to be left exposed without a 15-min thermal barrier, such as $1 / 2$-in. gypsum board) adhered to the upper half of the concrete foundation walls using low-emittance construction adhesive (Figure 41). With an insulating R-value of $7 \mathrm{ft}^{2}$ ${ }^{0} \mathrm{~F}$-hr/Btu per in., this closed-cell insulation is better suited to moist basement conditions than standard fiberglass batt insulation. Because most of the heat loss is through the above-grade portion of the foundation, CARB is primarily concerned with insulating the top $4 \mathrm{ft}$ of the foundation. Part of the rear portion of the walk-out basement is framed construction, so the BIBS insulation system was continued for that wall area.

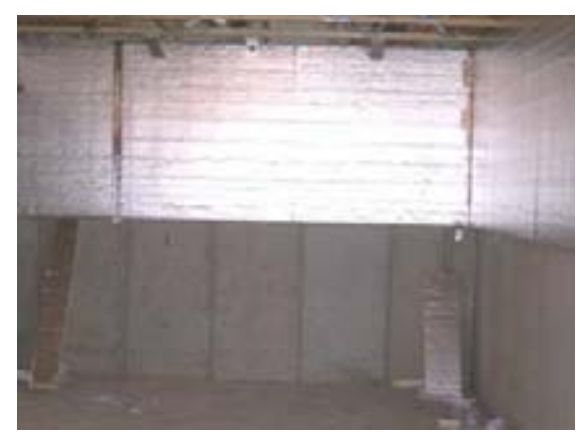

Figure 41. Foil-faced polyisocyanurate rigid insulation 


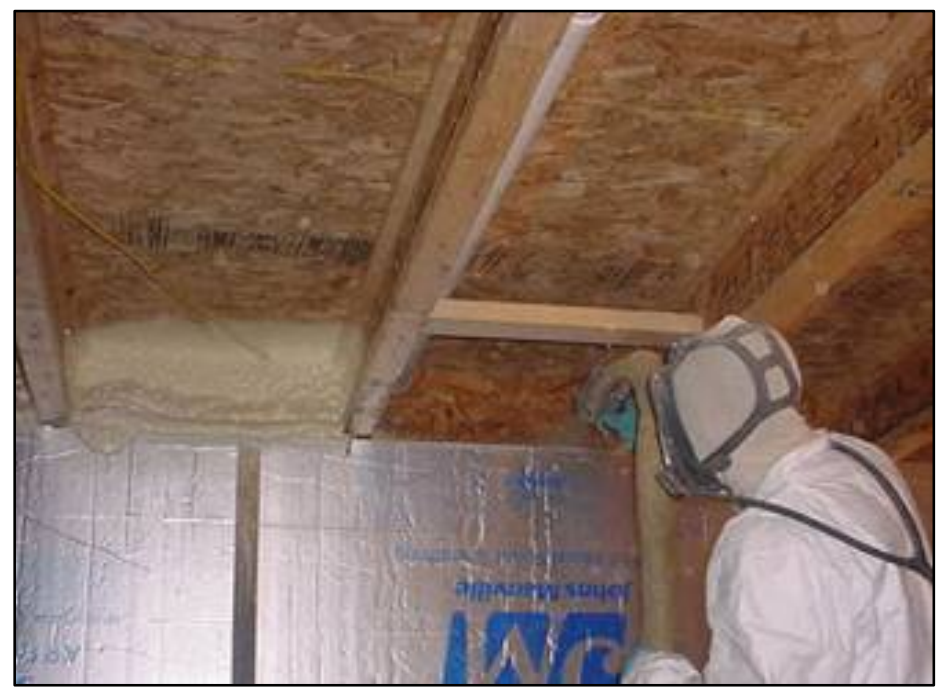

Figure 42. Insulating the box sills of all floors

The final step of this insulation strategy was to insulate the box sills on all floors of the home with a closed-cell, two-component polyurethane spray foam Figure 42). This not only provides additional insulation, it helps to tightly seal all envelope penetrations and mitigates air and moisture problems in the rim and band joists. Bio-based products are available that meet the green goals of this project. The use of the spray foam at the box sills and blown-in wall insulation will further tighten up the envelope significantly.

\section{Energy Efficient HVAC}

To complement the highly insulated building envelope, the builder implemented a number of strategies for optimizing efficiency of the HVAC equipment and distribution system.

\section{HVAC in Conditioned Space}

Why is ductwork allowed to only be insulated up to R-6, when wall and ceiling insulation levels are R-13+ and R-30+, respectively? Ducts outside the building envelope are notorious leakage pathways, drawing in outside air and/or bleeding air that has been conditioned. As much as 20\%$35 \%$ of the energy supplied can be lost through a combination of air leakage and conduction when ducts are located in unconditioned spaces. This can also be a concern for indoor air quality, as these leakage pathways could pull in pollutants, irritants, or moisture from attics.

To keep the ductwork within conditioned space, the HVAC equipment was properly sized according to Manual $\mathrm{J}$ and $\mathrm{D}$ calculations to allow for the most compact system possible. Oversized equipment results in larger ductwork and causes the system to cycle more frequently. Some design changes had to be made for the ductwork supplying the master loft. There is a corner knee wall in the loft where the mechanical equipment for the upper floors is located. This mechanical room was boxed in and air sealed to make it a part of the conditioned space. 
In terms of a compact duct layout, registers were located toward the interior of the rooms. Eliminating long runs of ductwork has two benefits: energy efficiency increases and initial construction cost decreases. The use of open-web floor trusses also allow for easy, direct pathways to supply register locations. In this manner, all the ductwork was able to be integrated into the conditioned space with as minimal a footprint as possible.

By maintaining the HVAC equipment and ductwork within the conditioned space, duct leakage to the outside should be minimal, if not negligible, especially because of the tight building envelope. To further minimize duct leakage, all duct connections were sealed with mastic to help prevent dust, soil, and other pollutants from entering the system.

\section{Mechanical Ventilation}

In conjunction with tightly sealing the envelope, the builder needs to provide controlled mechanical ventilation to ensure that the home has adequate fresh air to dilute pollutants and remove humidity from the home.

CARB has recommended an "exhaust-only" strategy as the most appropriate solution for this project. This approach requires one bath fan in each of the homes be upgraded to a model that has been rated for: energy-efficient operation, continuous use, and quiet running. These three features are keys to the success of this strategy. An efficient fan will not be costly for the homeowner to operate. A fan rated for longer run times will not fail after a few months of operation. And lastly, the homeowner is less likely to disable the fan if it runs quietly.

The fan is partnered with a timer control, which turns the fan on for set periods throughout the day. This ventilation system complies with the guidelines set forth by the American Society of Heating, Refrigerating and Air Conditioning Engineers (ASHRAE) in Standard 62.2, Ventilation and Acceptable Indoor Air Quality in Low-rise Residential Buildings. The upgraded bath fan should be wired to allow occupant control via a manual override switch within the bathroom. The timer switch should also be tied into the fan wiring and remote-wired to a nearby closet to prevent tampering.

All other bathrooms and the kitchen range should still have exhaust fans for local humidity control. CARB requires that all exhaust fans be vented directly to the outside (no recirculating kitchen exhaust fans).

\section{Return Air Pathways}

To allow for a more compact duct design and improved system balance, central return ducts were positioned close to the air handlers. Pressure imbalances, such as those caused by closed bedrooms doors with inadequate door undercuts, cause the HVAC system to work harder than it should. This drops equipment efficiency and can lead to compromised comfort and health. Transfer grilles with a sound/light baffle were installed over the doors of the secondary bedrooms, to reduce pressurization of those spaces and mitigate comfort and moisture concerns. Centralized returns save material cost and energy without compromising performance. 


\section{Additional Features}

To complement the energy-efficient elements utilized in these townhomes, "green” components were also considered to reduce the overall environmental footprint of these units. Additional features that were incorporated into this project are listed below:

- No- or low-VOC paints, caulks, sealants, and adhesives

- Formaldehyde-free fiberglass (GreenGuard certified) and polyisocyanurate insulation

- Bamboo flooring

- Wool carpet with recycled content padding

- Green lighting package (fluorescent lighting fixtures)

- Low-flow fixtures and dual-flush toilets

- Ultra-light trim made from recycled wood

- Kitchen composters

- Kitchen recycling bins

- Media Air Cleaner (HEPA filtration)

- Whole-house carbon filters.

\section{Overall Building Specification}

Table 23 summarizes the building specifications for the three prototype townhomes.

Table 23. Struever Rouse Prototype Specifications

\begin{tabular}{|l|l|}
\hline \multicolumn{2}{|l|}{} \\
\hline Foundation Walls & 2-in. Polyiso, foil-faced rigid insulation board (R-14), half height, interior \\
\hline Rim/Band Joists & Spray-in-place polyurethane foam insulation (R-6.75/in.) \\
\hline Exterior Walls & 2x6, 24 in. OC, framed walls \\
\hline Wall Insulation & Certainteed Optima Blown-In Fiberglass Insulation (R-21) \\
\hline Floor System & Open Web Trusses \\
\hline Windows & Milgard IG low-e, argon-filled (U =0.35, SHGC = 0.29) \\
\hline Ceiling Insulation & Certainteed Optima Blown-In Fiberglass Insulation (R-40) \\
\hline Duct System & Compact System sealed with Mastic (designed by HVAC contractor) \\
\hline Transfer Grilles & R.A.P. Transfer Grilles, 8 in x 8 in. over the doors of each secondary bedroom \\
\hline Space Heating & Two Goodman GMS9045 gas furnaces, 93\% AFUE, direct vent \\
\hline Space Cooling & Two Goodman GSC13 air conditioners, SEER 13 \\
\hline Thermostat & Programmable \\
\hline Water Heating & Noritz tankless gas water heater, EF = 0.82 \\
\hline Lighting & $100 \%$ Fluorescent, specified by Struever Rouse \& reviewed by CARB \\
\hline Appliances & ENERGY STAR ${ }^{\circledR}$ Refrigerator and Dishwasher \\
\hline Ventilation & Upgraded ENERGY STAR ${ }^{\circledR}$ bath fan controlled by Grasslin Pin Timer \\
\hline
\end{tabular}




\section{Energy and Cost Information}

\section{Home Energy Performance}

CARB determined that the energy performance of the current builder home is $17 \%$ better than the Building America Benchmark Home (Hendron 2005). Once this "standard practice" energy performance was established, CARB simulated the impact of alternative specifications on the energy performance of the home. CARB felt the most effective approach for saving energy and lowering operating costs involved an integrated package of upgrades to the mechanical equipment and building envelope. Struever Rouse's standard specifications for the windows and furnace were acceptable for meeting the target energy goals.

CARB recommended increased insulation levels, improved air sealing, location of all the ductwork within the conditioned space, and "on-demand" water heating. To help further reduce electrical loads, $100 \%$ of the lighting was fluorescent fixtures and the builder will provide both an ENERGY STAR ${ }^{\circledR}$ refrigerator and dishwasher. When implemented, this package provided a total annual source energy savings of 36\%, as shown in Table 24 .

\section{Table 24. Energy Savings for Frankford Estates Plan C}

\section{Struever Rouse - Frankford Estates Plan C}

Summary of Energy Consumption by End-Use

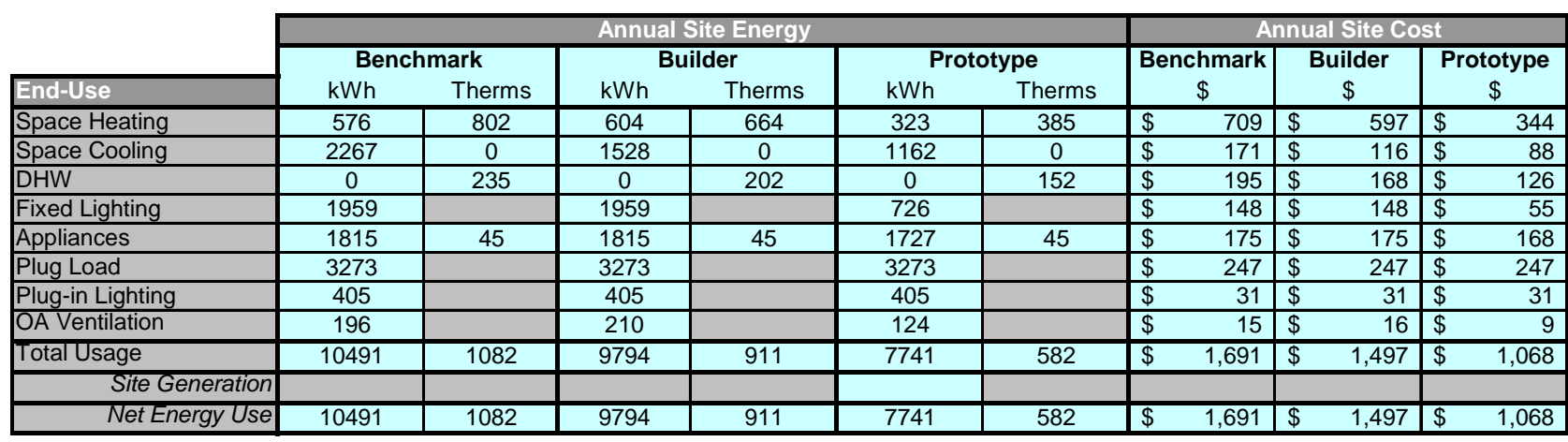

Summary of End-Use Source-Energy and Savings

\begin{tabular}{|c|c|c|c|c|c|c|c|c|c|}
\hline & & & & \multicolumn{4}{|c|}{ Source Energy Savings } & \multirow{2}{*}{\multicolumn{2}{|c|}{ Component \% }} \\
\hline & \multicolumn{3}{|c|}{ Annual Source Energy } & \multicolumn{2}{|c|}{ Percent of End-Use } & \multicolumn{2}{|c|}{ Percent of Total } & & \\
\hline & Benchmark & Builder & Proto & Builder & Prototype & Builder & Prototype & Builder & Prototype \\
\hline End-Use & MBtu/yr & MBtu/yr & MBtu/yr & & & & & & \\
\hline Space Heating & 88.0 & $\overline{74.2}$ & 42.8 & $16 \%$ & $51 \%$ & $6 \%$ & $20 \%$ & $55.1 \%$ & $56.1 \%$ \\
\hline Space Cooling & 24.4 & 16.5 & 12.5 & $33 \%$ & $49 \%$ & $4 \%$ & $5 \%$ & $32.0 \%$ & $14.8 \%$ \\
\hline$\overline{\mathrm{DHW}}$ & 24.0 & 20.6 & 15.5 & $14 \%$ & $35 \%$ & $2 \%$ & $4 \%$ & $13.5 \%$ & $10.5 \%$ \\
\hline Fixed Lighting & 21.1 & 21.1 & 7.8 & $0 \%$ & $63 \%$ & $0 \%$ & $6 \%$ & $0.0 \%$ & $16.5 \%$ \\
\hline Appliances & 24.2 & 24.2 & 23.2 & $0 \%$ & $4 \%$ & $0 \%$ & $0 \%$ & $0.0 \%$ & $1.2 \%$ \\
\hline Plug Load & 35.3 & 35.3 & 35.3 & $0 \%$ & $0 \%$ & $0 \%$ & $0 \%$ & $0.0 \%$ & $0.0 \%$ \\
\hline Plug-in Lighting & 4.4 & 4.4 & 4.4 & $0 \%$ & $0 \%$ & $0 \%$ & $0 \%$ & $0.0 \%$ & $0.0 \%$ \\
\hline OA Ventilation & 2.1 & 2.3 & 1.3 & $-8 \%$ & $36 \%$ & $0 \%$ & $0 \%$ & $-0.6 \%$ & $1.0 \%$ \\
\hline Total & 223.4 & 198.5 & 142.8 & $11 \%$ & $36 \%$ & $11 \%$ & $36 \%$ & $100 \%$ & $100 \%$ \\
\hline Site Generation & & & 0.0 & & $0 \%$ & & $0 \%$ & & \\
\hline Net Energy Usage & 223.4 & 198.5 & 142.8 & $11 \%$ & $36 \%$ & $11 \%$ & $36 \%$ & & \\
\hline
\end{tabular}

The "Percent of End-Use" columns show how effective each building is in reducing energy use over the Benchmark in each end-use category. The "Percent of Total" columns show how the energy reductions in each end-use category contribute to the overall savings. 


\section{Field Inspection}

During the inspection of the mechanical rough-in of the initial townhouse, CARB observed the usage of pressure-sensitive aluminum foil tape to seal the intersection of the flex ducts to the sheet metal ductwork (Figure 43). Using an aluminum-backed butyl tape that is UL-181 A/B rated is acceptable, but CARB has found that the application of mastic to seal ductwork is easier, faster, and more economical. Either way, the current sealing was being done with a non-UL-181 rated product. The HVAC contractor switched to mastic for sealing the ductwork, but it took another CARB site visit before the mastic was being properly applied to achieve the tight ductwork that was required.
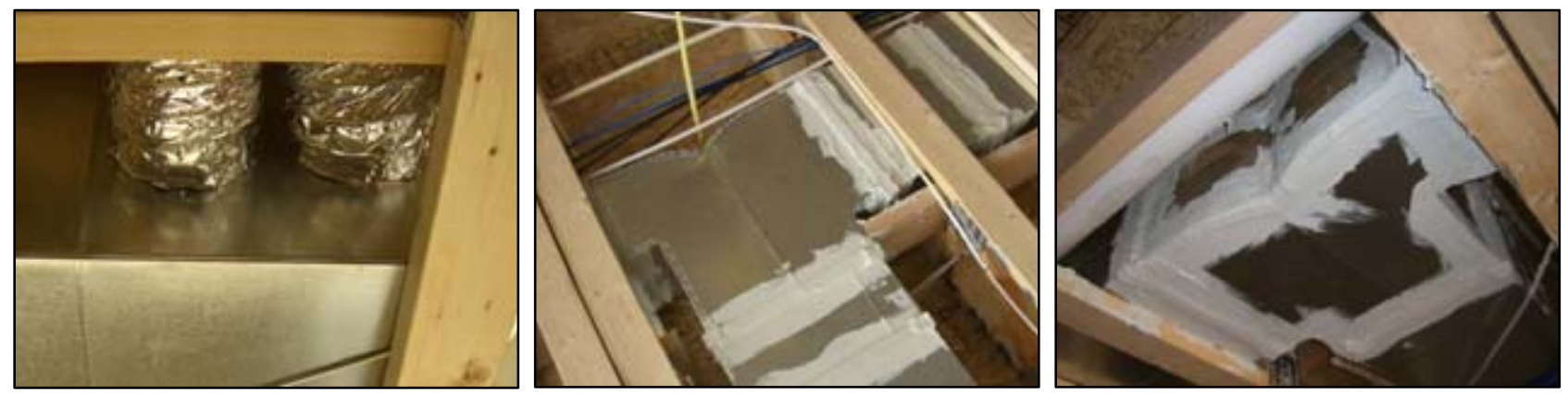

Figure 43. Using pressure-sensitive aluminum foil tape and mastic to seal intersections of ducts

A situation in which various trades are working on the single installation resulted in a mechanical ventilation concern (Figure 44), which is a common occurrence in residential construction. Rather than rotating the pre-installed ventilation fan enclosure $180^{\circ}$, the HVAC contractor simply vented the fan using an $180^{\circ}$ bend in the exhaust vent ductwork. This adds an unnecessary pressure drop to the system and leads to decreased exhaust ventilation capacity.

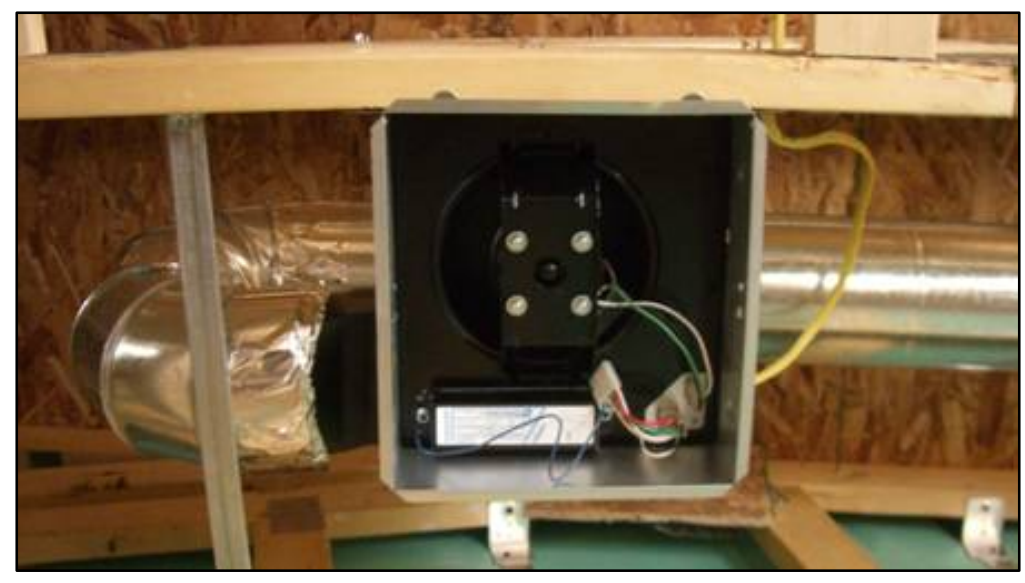

Figure 44. Improperly installed ventilation fan 
A common area that is missed when insulating the building envelope is the fireplace bump out. CARB ensured that the enclosure was fully insulated before installation of the direct vent fireplace. This area is commonly missed because it is not readily accessible (Figure 45).
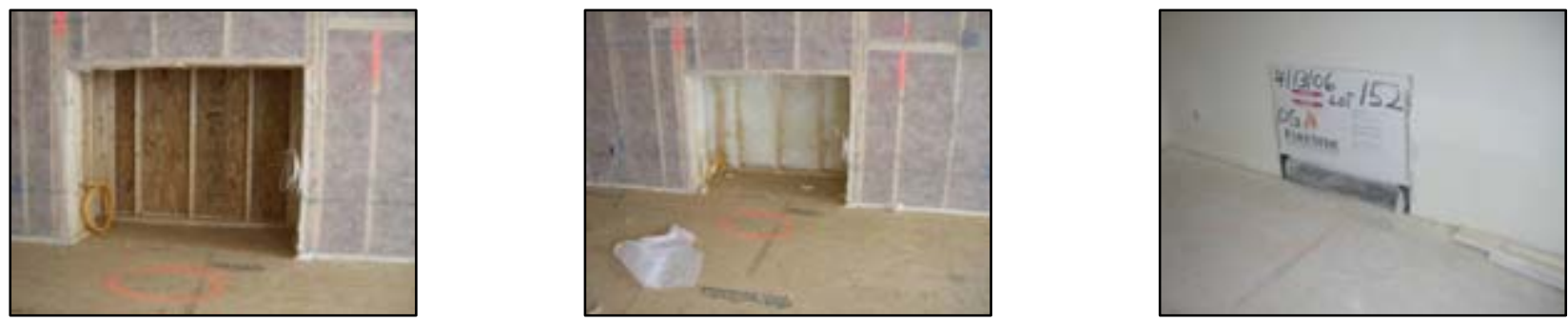

Figure 45. Fireplace bump outs are frequently missed when insulation is installed

\section{Cost}

Based on the cost-benefit analysis and local market drivers, Struever Rouse Homes is likely to incorporate many of the building strategies recommended by CARB into their standard builder package. This package would include $2 x 6$ panelized wall systems (24 in. o.c.) with BIBS, a tankless water heater, high efficiency furnace, and controlled mechanical ventilation. The recommended CARB improvements not only provide annual energy savings, but also work with Struever Rouse Homes focus on healthy and sustainable living.

Table 25 shows the estimated incremental costs for the energy efficiency measures used in this project. In production scale, several of these costs would be lower than were priced out for these prototypes. For one, the 2x6 (24 in. o.c.) wall panels use essentially the same board-feet of lumber as 2x4, 16 in. on-center panels, but because of the error of spacing the 2x6 studs at 16 in. on center, there was around a 70\% price increase for the panels as a result of the increased lumber usage.

\section{Follow-On Activities}

Struever Rouse Homes has given a preliminary commitment to follow up on this project in 2007 with a 75 -unit community in Baltimore at the $30 \%$ performance level.

Table 25. Summary of Incremental Costs for Energy Improvements

\begin{tabular}{|c|c|c|c|c|}
\hline & \multicolumn{3}{|c|}{ Incremental Cost Increase } & \\
\hline Building Component & Lot 152 & Lot 153 & Lot 154 & Improvement \\
\hline Appliances & $\$ 591$ & $\$ 591$ & $\$ 591$ & Energy Star dishwasher and refrigerator \\
\hline Electric & $\$ 1,204$ & $\$ 1,204$ & $\$ 1,204$ & Fluorescent lighting package, ventilation timer \\
\hline Energy Star & $\$ 500$ & $\$ 500$ & $\$ 500$ & air sealing \\
\hline HVAC & $\$ 2,880$ & $\$ 2,930$ & $\$ 2,880$ & 92 AFUE furnace, Energy Star ventilation fan, transfer grilles, Puron A/C \\
\hline Insulation & $\$ 1,795$ & $\$ 535$ & $\$ 1,795$ & BIBS, basement rigid insulation, rim/band foam \\
\hline Plumbing & $\$ 950$ & $\$ 950$ & $\$ 950$ & tankless water heater, dual flush toilet \\
\hline Poured Walls & $\$ 566$ & $\$ 837$ & $\$ 566$ & thicker foundation wall due to $2 \times 6$ framing \\
\hline Wall Panels & $\$ 3,662$ & $\$ 2,945$ & $\$ 3,662$ & $2 \times 6$ framing (but at 16 "o.c.) \\
\hline total & $\$ 12,148$ & $\$ 10,492$ & $\$ 12,148$ & \\
\hline total w/o panels & $\$ 8,486$ & $\$ 7,547$ & $\$ 8,486$ & \\
\hline
\end{tabular}


Figures 46, 47, and 48 show the floor plans for the townhouses.
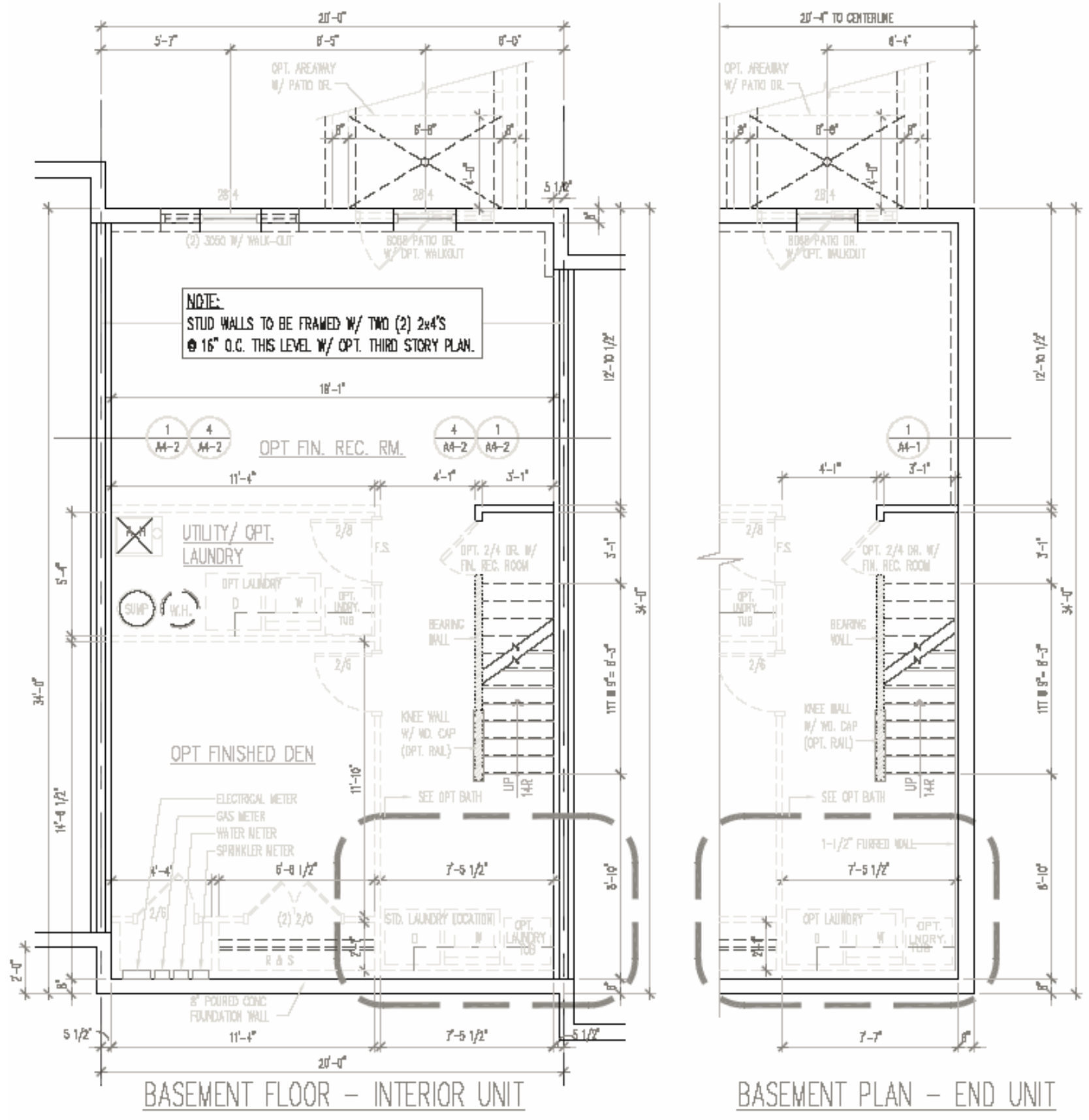

Figure 46. Basement plan 

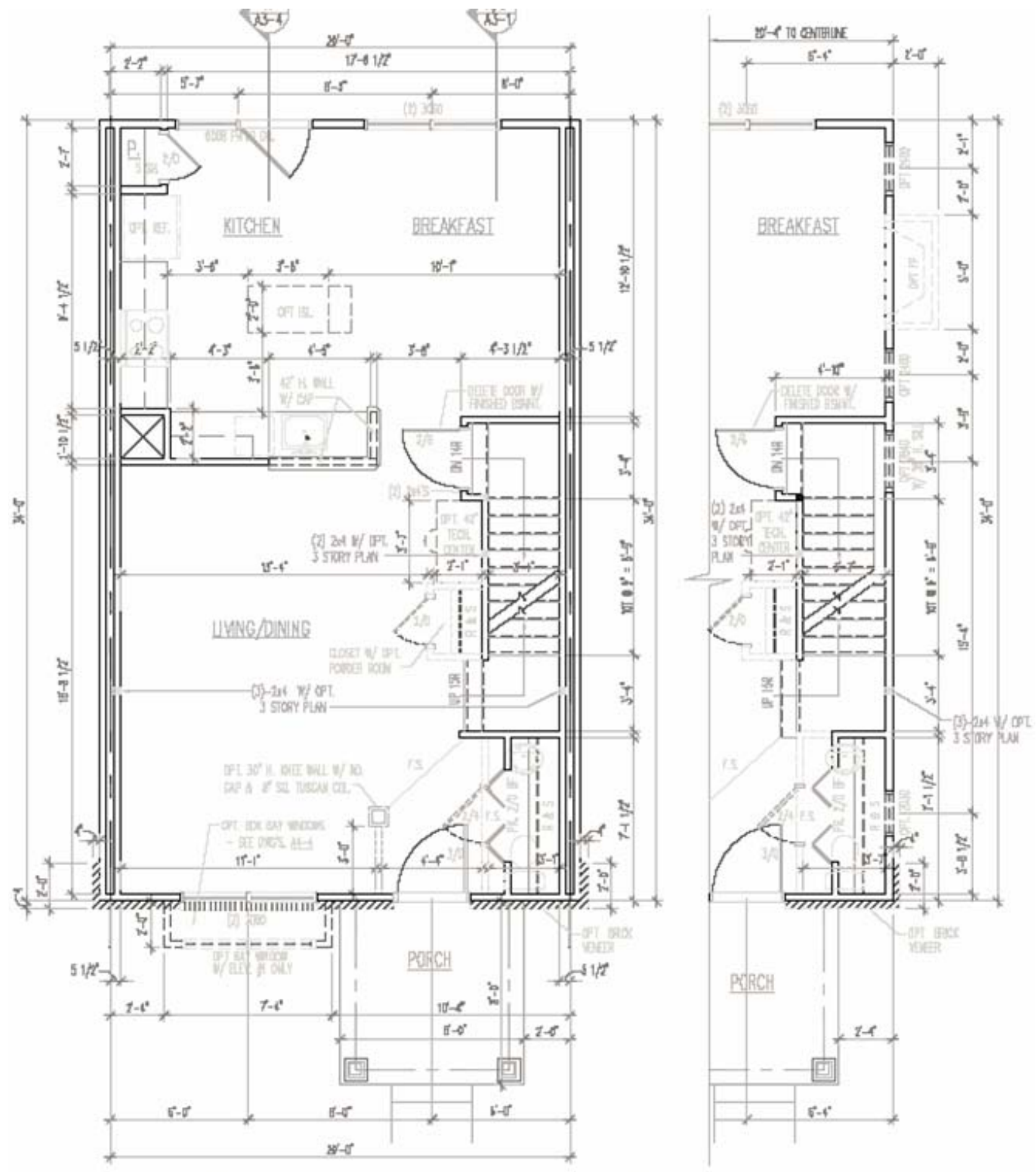

FIRST FLOOR PLAN - KITCHEN REAR

UNIT Q INTERIOR UNIT - ELEV. \#I \& \#2

FIRST FLOOR PLAN - KITCHEN REAR (-) END UNIT - ELEV. \#1 \& \#2

Figure 47. First-floor plan 

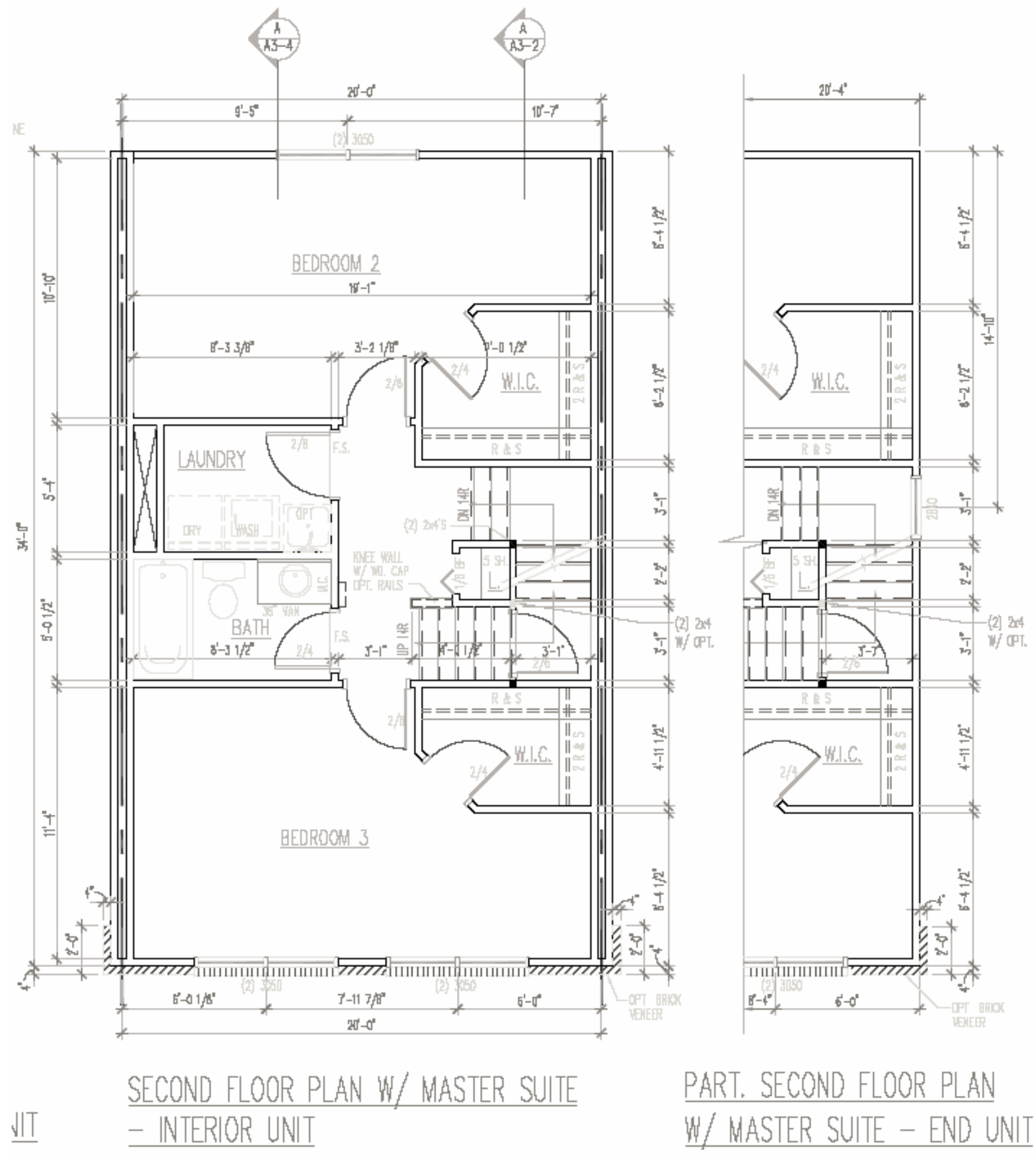

$\frac{\text { PART. SECOND FLOOR PLAN }}{\text { W/ MASTER SUITE - END UNIT }}$

Figure 48. Second-floor plan 


\title{
Development: Grove Park
}

\author{
Builder: Outlook Construction \\ Location: $\quad$ Cartersville, Georgia
}

\section{Background}

Beginning in early 2003, the Consortium for Advanced Residential Buildings (CARB) began working with Outlook Construction near Atlanta, Georgia, to investigate cost-effective performance improvements to its line of affordable homes. Outlook, located in Cartersville, Georgia, is a regional builder that builds about 200 homes a year (Figure 49). They are a relative newcomer to affordable production, having begun business as a custom builder. Before CARB's involvement, Outlook management had embarked on a program of highly effective building envelope initiatives working closely with K.E.S. Insulation, also of Cartersville. The result of that prior work was the development of a very tight and well-insulated standard practice wall system composed of 2x6 framing at 24 in. on-center, R-3 XPS foam sheathing, a $1 / 2$-in. skim of polyurethane foam placed on the interior of the sheathing as an air-barrier, and damp-sprayed cellulose to fill the cavity.

Starting with solid envelope specifications and a good understanding of building science, Outlook approached CARB in order to get to the next level. CARB worked closely with Outlook, KES Spray Insulation, and Meadows Heating and Air to understand the company's needs and to help them achieve the next level of market separation from their competitors. This work has focused on improvements to the HVAC system, refining the insulation and air-sealing, and assisting in further implementing advanced framing techniques and other cost-saving measures.

Based on the success of this initiative, Outlook asked CARB for assistance in designing, engineering, and specifying equipment for a new 120-unit development called Birchwood Farms, by far the largest project Outlook had been involved with to date. In Birchwood Farms, located approximately 45 minutes north of Atlanta, Outlook wanted to improve upon their standard highperformance homes to achieve 1999 HERS scores above 89.

The Birchwood subdivision featured five home models ranging from 1,450 $\mathrm{ft}^{2}$ to 2,100 $\mathrm{ft}^{2}$. The smallest home, the Abigail is a three-bedroom slab-on-grade ranch, the other homes are either raised ranches (split-level entry) or true split-levels. All lower levels in these homes are provided unfinished.

As a follow-up, Outlook requested CARB's assistance once again in 2004 on their new 103-unit Grove Park development. This subdivision would focus on larger two-story homes in the 2,0003,000- $\mathrm{ft}^{2}$ range. Located in Cartersville, Georgia, these homes are two-story, slab-on grade detached houses with attached two-car garages. All homes were to meet the $30 \%$ Building America total source-energy savings goal. Because of utility incentives that distorted the local market, several of the homes did not meet this annual source energy-savings goal, but this is discussed later. 


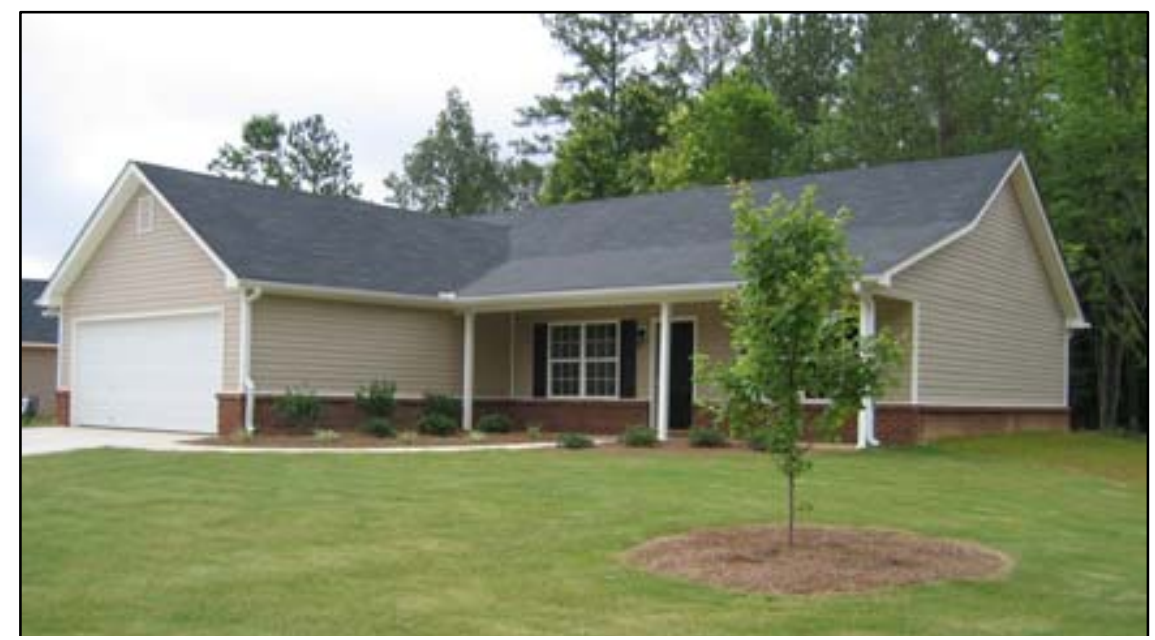

Figure 49. Home in Cartersville, Georgia

Performance verification was done on the Vineyard (Big A-1 floor plan) and Bay Point (Plan C Alley floor plan) model homes as they represent the two most common models in the development (Figures 50 and 51).
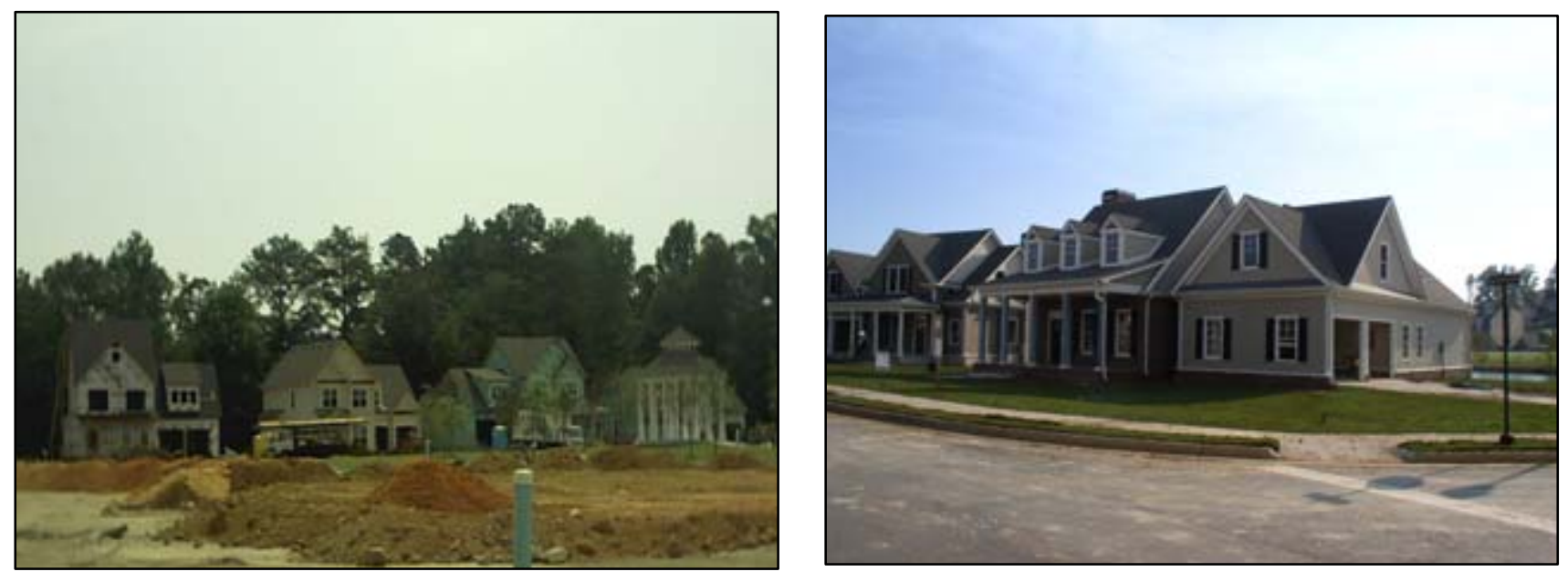

Figure 50. Vineyard and Bay Point model homes 


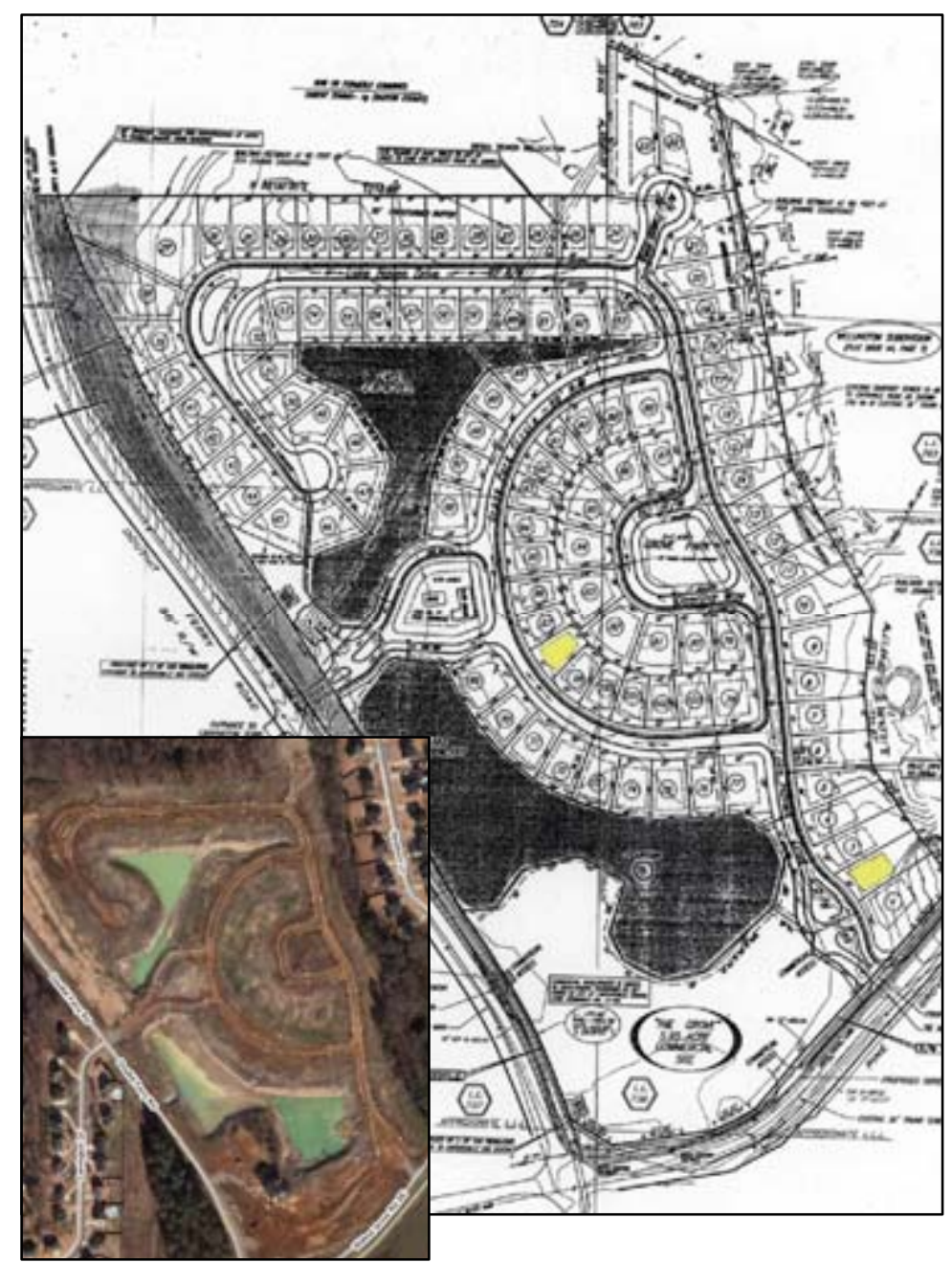

Figure 51. Layout of Grove Park

\section{Advanced Technologies}

Design considerations for Outlook Construction primarily focused on the building envelope and ductwork to provide appropriate insulation and proper air sealing. Below is a summary of several of the advanced technologies incorporated into the Grove Park development.

\section{Engineered Panel System}

The 2x6 panelized open wall system used for the exterior structure helps to contribute to overall quality and tightness of the home. The panels are assembled off-site in a controlled environment with finer tolerances and higher quality than are typically possible with field construction. Fabrication is based on detailed shop drawings generated from the home design.

During design, the location of window and door openings is coordinated with Outlook's standard panel length of $12 \mathrm{ft}$ to minimize the number of studs. While panels are available in longer lengths, the builder finds benefits to working with a standard unit size. Most importantly, the 
12-ft. panels used by Outlook can easily be erected by framing crews and do not require a crane for installation.

The panelized wall system helped Outlook Construction increase jobsite productivity, reduce project cycle time, reduce jobsite waste, and enhance construction quality, including the quality of interior and exterior trim and finishes.

The panels were engineered using Optimum Value Engineering (OVE) framing principles. The OVE framing technique reduces the amount of lumber used to build a home while maintaining the structural integrity of the building. Using OVE results in lower material and labor costs and can also improve energy performance. OVE strategies used for this development include the following: 2x6 wood framing, 24 in. on-center framing, ladders at "T" intersections, open-corner framing, and right-sized headers.

\section{High-Performance Insulation Strategy}

As a builder of ENERGY STAR ${ }^{\circledR}$ Homes, Outlook actively pursues new technologies for creating a highly efficient building envelope. The project team explored various insulation techniques in different housing assemblies to determine optimum methods for insulating the panelized walls. The energy-saving insulating strategies that were used are described here in detail.

Foam Insulation Skim-Coat on Wall Panels. Outlook Construction joined with KES Insulation to develop a unique and highly effective two-step insulation process. In the first step a $1 / 2$-in. layer of polyurethane is sprayed into a wall's stud cavity, creating a sealed space and air barrier. The layer of $2 \mathrm{lb}$. closed-cell foam doubles as a vapor retarder placed to the exterior of the insulation, an ideal location for homes built in hot and humid climates. Spraying polyurethane at the band joists is another insulation method KES uses for additional sealing.

Spray-Applied Cellulose Insulation. In the second step of the wall insulation process, cellulose insulation is damp-sprayed into the remaining 5 -in. stud space. Cellulose is made of recycled products (such as newspaper) and provides an excellent thermal barrier. When the damp mix is sprayed on, interlocking fibers in the cellulose form a continuous coating that seals cracks or openings, eliminating voids, and providing an excellent noise barrier. The combination of foam and cellulose yields R-23 wall insulation values - far superior to the R-13 fiberglass batt insulation typically found in the Atlanta region.

\section{Energy Efficient HVAC}

CARB performed energy modeling to pinpoint opportunities for energy efficiency improvements. To complement the highly insulated building envelope, the builder implemented a number of strategies for optimizing efficiency of the HVAC equipment and distribution system.

Air Handler in Conditioned Space. Working with the designers, a mechanical closet was located within the house, which allows the air handler(s) for the heat pump(s) to be within conditioned space. This represents a significant improvement over the traditional practice of placing equipment in unconditioned garages or attics. Locating the mechanical equipment within conditioned space greatly improves operating efficiency and protects indoor air from contaminants that may be present in unconditioned areas. 
Compact Duct Layout. For the compact duct layout design, registers are located on interior corners of rooms closer to the air handler. Eliminating long runs of ductwork has two benefits: energy efficiency increases and initial construction cost reductions. Utilizing a centralized return also saves on material cost and energy without compromising performance.

Foamed-over Ducts. Leaky and poorly insulated ducts can add $20 \%-40 \%$ to a homeowner's heating and cooling costs. CARB recommended a two-part approach to achieve optimal energy performance from ducts located in the vented attic. First a 1-in. layer of 2-lb. closed-cell polyurethane foam was applied to the ductwork to boost R-values, control condensation, and provide additional air sealing (Figure 52). The application of 1in.of this spray foam increases duct R-value by 7

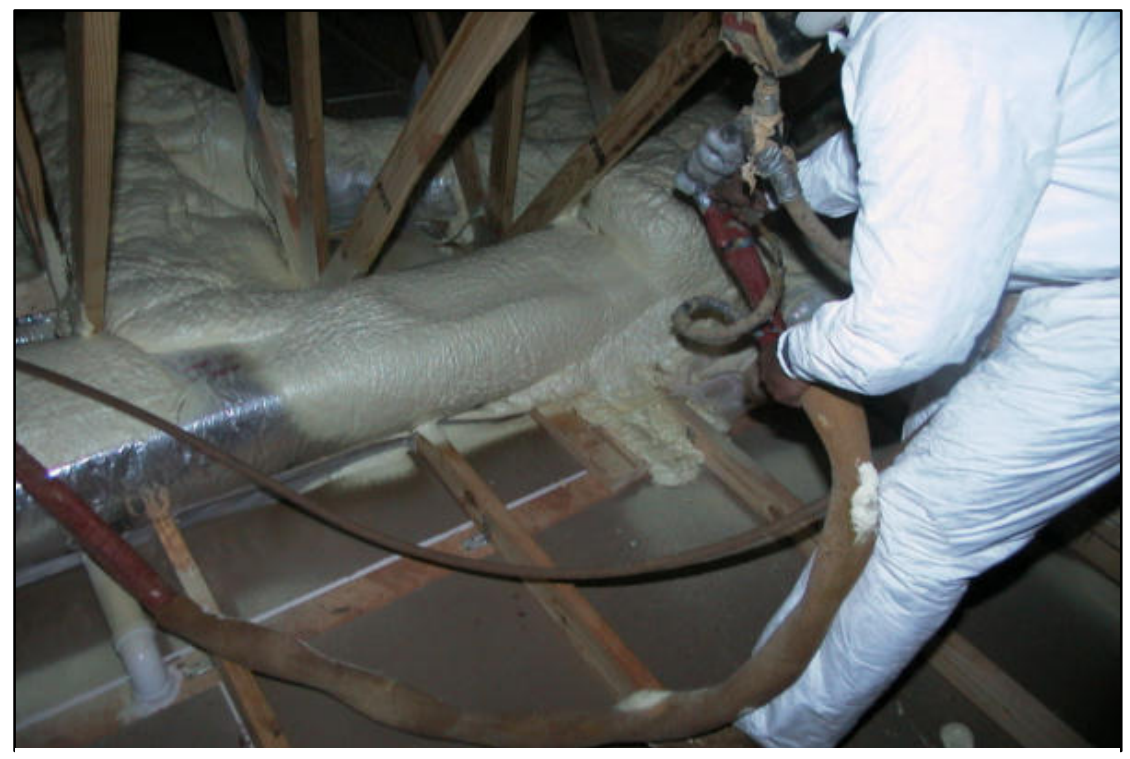

Figure 52. Insulating ducts with closed-cell polyurethane foam

$\mathrm{ft}^{2}{ }^{\circ} \mathrm{F}-\mathrm{hr} / \mathrm{Btu}$, allowing a

duct system R-value of $11 \mathrm{ft}^{2}{ }^{\circ} \mathrm{F}-\mathrm{hr} / \mathrm{Btu}$ to be achieved with conventional R-4.2 $\mathrm{ft}^{2}{ }^{\circ}{ }^{\circ} \mathrm{F}-\mathrm{hr} / \mathrm{Btu}$ duct wrap.

One important advantage of the foam is that it minimizes the likelihood of condensation when ductwork is buried in the attic insulation. The dew point will be located within the foam insulation layer, which is a vapor barrier. In addition, the closed-cell foam helps air seal the ductwork. Foam has the advantage of being easier to apply in hard-to-reach places. The airsealing properties are especially beneficial around registers that penetrate the ceiling (an area that is typically prone to leakage).

Buried Ducts. Foamed-over ducts perform optimally in conjunction with a second energysaving technique: ductwork buried under attic insulation (Figure 53). Burying the ducts under blown-in cellulose insulation minimizes losses from distribution of conditioned air. Ideally ductwork should be placed directly on the gypboard or the bottom chords of the roof trusses; however, sections occasionally need to be lifted above the insulating layer in order to coordinate with the truss webs. The increase in duct system R-value because of burying ducts in loose fill attic insulation depends on the depth of burial.

While buried ducts work well to save heating and cooling energy in any climate, the blown insulation alone does not prevent condensation problems in hot, humid climates. When heat and moisture are prevalent, buried ducts used together with sprayed-on foam yield the best result. 


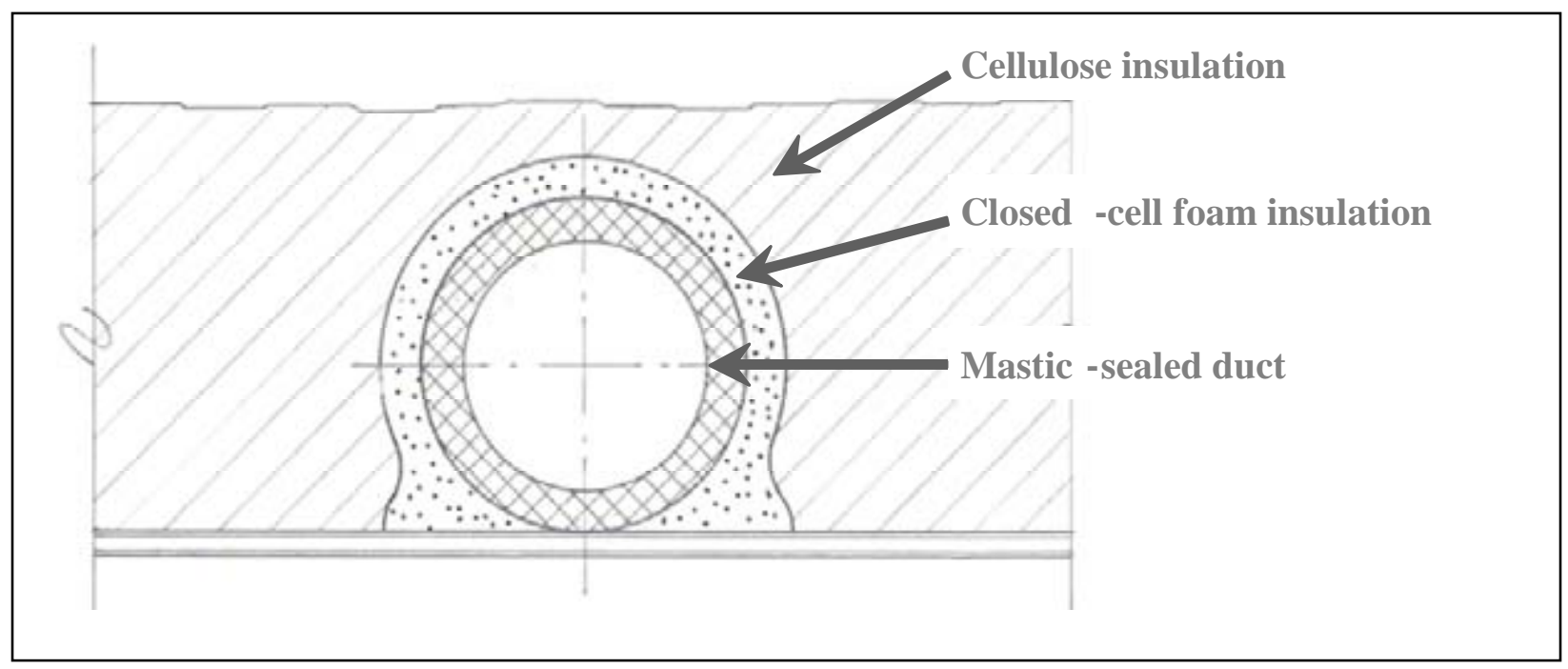

Figure 53. Foamed-over ducts buried in attic insulation

\section{Overall Building Specification}

Table 26 summarizes the building specifications for the two primary Grove Park model types and the Building America Benchmark reference house (Version 3.1). 


\section{Table 26. Features of Grove Park Models Compared to the Benchmark}

\begin{tabular}{|c|c|c|c|}
\hline Characteristic & Benchmark Home & Vineyard Prototype & Bay Point Prototype \\
\hline Slab Construction & poured slab & poured slab & poured slab \\
\hline Slab Insulation & R-4 (2 ft perimeter) & -- & -- \\
\hline Framed Floor Construction & 9 1/2" I-joist @ 16" o.c. & 9 1/2" I-joist @ 16" o.c. & 9 1/2" I-joist @ 16" o.c. \\
\hline Framed Floor Assembly & U- 0.05 & R- 26 batt insulation & R- 26 batt insulation \\
\hline Wall Construction: 1st Floor & $2 \times 6$ wood framing - 16 " o.c. & $2 \times 6$ wood framing - $24 "$ " o.c. & $2 \times 6$ wood framing - 24 " 0.c. \\
\hline Wall Assembly: 1st Floor & U-0.076 & $\begin{array}{l}\text { R-20 blown insulation / R-3 } \\
\text { foam }\end{array}$ & $\begin{array}{l}\text { R-20 blown insulation / R-3 } \\
\text { foam }\end{array}$ \\
\hline Garage Interior Wall Const. & $2 \times 6$ wood framing - 16 " o.c. & $2 \times 6$ wood framing - $24 "$ o.c. & $2 \times 6$ wood framing - $24 "$ o.c. \\
\hline Garage Interior Wall Assembly & U-0.076 & R-20 blown insulation & R-20 blown insulation \\
\hline Ceiling/Roof Construction & wood trusses @ 24" 0.c. & wood trusses @ 24" 0.c. & wood trusses @ 24" 0.c. \\
\hline Ceiling Assembly & $\mathrm{U}-0.036$ & R-38 insulation & R-38 insulation \\
\hline Window Type & benchmark & vinyl double low-e & vinyl double low-e \\
\hline Window U-Value & 0.65 & 0.36 & 0.36 \\
\hline Window SHGC & 0.58 & 0.33 & 0.33 \\
\hline Interior Shading & $\begin{array}{c}\text { interior shading multiplier }=0.7 \text { in } \\
\text { cooling season and } 0.85 \text { in heating } \\
\text { season }\end{array}$ & $\begin{array}{l}\text { interior shading multiplier }=0.7 \text { in } \\
\text { cooling season and } 0.85 \text { in heating } \\
\text { season }\end{array}$ & $\begin{array}{l}\text { interior shading multiplier }=0.7 \text { in } \\
\text { cooling season and } 0.85 \text { in heating } \\
\text { season } \\
\end{array}$ \\
\hline Doors & U- 0.20 & U- 0.40 & U-0.40 \\
\hline Infiltration & 0.47 natural $\mathrm{ACH}$ & $1473 \mathrm{cfm}_{50}\left(0.31 \mathrm{ACH}_{\text {nat }}\right)$ & $3170 \mathrm{cfm}_{50}\left(0.47 \mathrm{ACH}_{\text {nat }}\right)$ \\
\hline Heating System & $\begin{array}{l}\text { Gas Furnaces } \\
78 \text { AFUE }\end{array}$ & $\begin{array}{c}\text { Gas Furnace / (Heat Pump) } \\
80 \text { AFUE / (6.8 HSPF) }\end{array}$ & $\begin{array}{l}\text { (2) Gas Furnace } \\
80 \text { AFUE }\end{array}$ \\
\hline Cooling System & $\begin{array}{l}\text { Air Conditioners } \\
\text { SEER } 10\end{array}$ & $\begin{array}{c}\text { Air Conditioner / (Heat Pump) } \\
\text { SEER } 12 \text { / (SEER 12) }\end{array}$ & $\begin{array}{l}\text { (2) Air Conditioner } \\
\text { SEER } 12\end{array}$ \\
\hline Water Heater & $\begin{array}{c}\text { Gas Water Heater } \\
\text { EF } 0.54\end{array}$ & $\begin{array}{l}\text { Gas Water Heater } \\
\text { EF } 0.59\end{array}$ & $\begin{array}{c}\text { Gas Water Heater } \\
\text { EF } 0.59\end{array}$ \\
\hline HW Tank Size & 40 gals & 40 gals & 40 gals \\
\hline Water Heater Location & garage & garage & garage \\
\hline Duct R-value & R-5.0 & R-3 foamed over ducts & R-3 foamed over ducts \\
\hline Supply Duct Location & $100 \%$ attic & $100 \%$ attic & $50 \%$ attic \\
\hline Return Duct Location & $100 \%$ attic & $100 \%$ garage & $50 \%$ attic \\
\hline AHU Location & interior & garage & mechanical closet \\
\hline Duct Leakage to Outside & $11.5 \%$ & $\begin{array}{l}\text { downstairs: } 44 \mathrm{cfm}_{25} / \text { upstairs: } \\
52 \mathrm{cfm}_{25}\end{array}$ & $\begin{array}{c}\text { downstairs: } 72 \mathrm{cfm}_{25} / \text { upstairs: } \\
78 \mathrm{cfm}_{25} \\
\end{array}$ \\
\hline Leakage Fraction & return: $33 \%$ & return:30\% / AHU: $5 \%$ & return: $10 \% / \mathrm{AHU}: 5 \%$ \\
\hline \multirow{2}{*}{ mechanical ventilation } & -- & -- & $-\cdot$ \\
\hline & -- & -- & -- \\
\hline Programmable Thermostat? & no & yes & yes \\
\hline \multirow{2}{*}{ Temperature } & cooling: $78^{\circ} \mathrm{F}$ & cooling: $78^{\circ} \mathrm{F}\left(81^{\circ} \mathrm{F}\right)$ & cooling: $78^{\circ} \mathrm{F}\left(81^{\circ} \mathrm{F}\right)$ \\
\hline & heating: $68^{\circ} \mathrm{F}$ & heating: $68^{\circ} \mathrm{F}\left(63^{\circ} \mathrm{F}\right)$ & heating: $68^{\circ} \mathrm{F}\left(63^{\circ} \mathrm{F}\right)$ \\
\hline Lighting & $10 \%$ fluorescents & $0 \%$ fluorescents & $0 \%$ fluorescents \\
\hline Energy Star Appliances & -- & refrigerator, dishwasher & refrigerator, dishwasher \\
\hline
\end{tabular}




\section{Energy and Cost Information}

\section{Home Energy Performance}

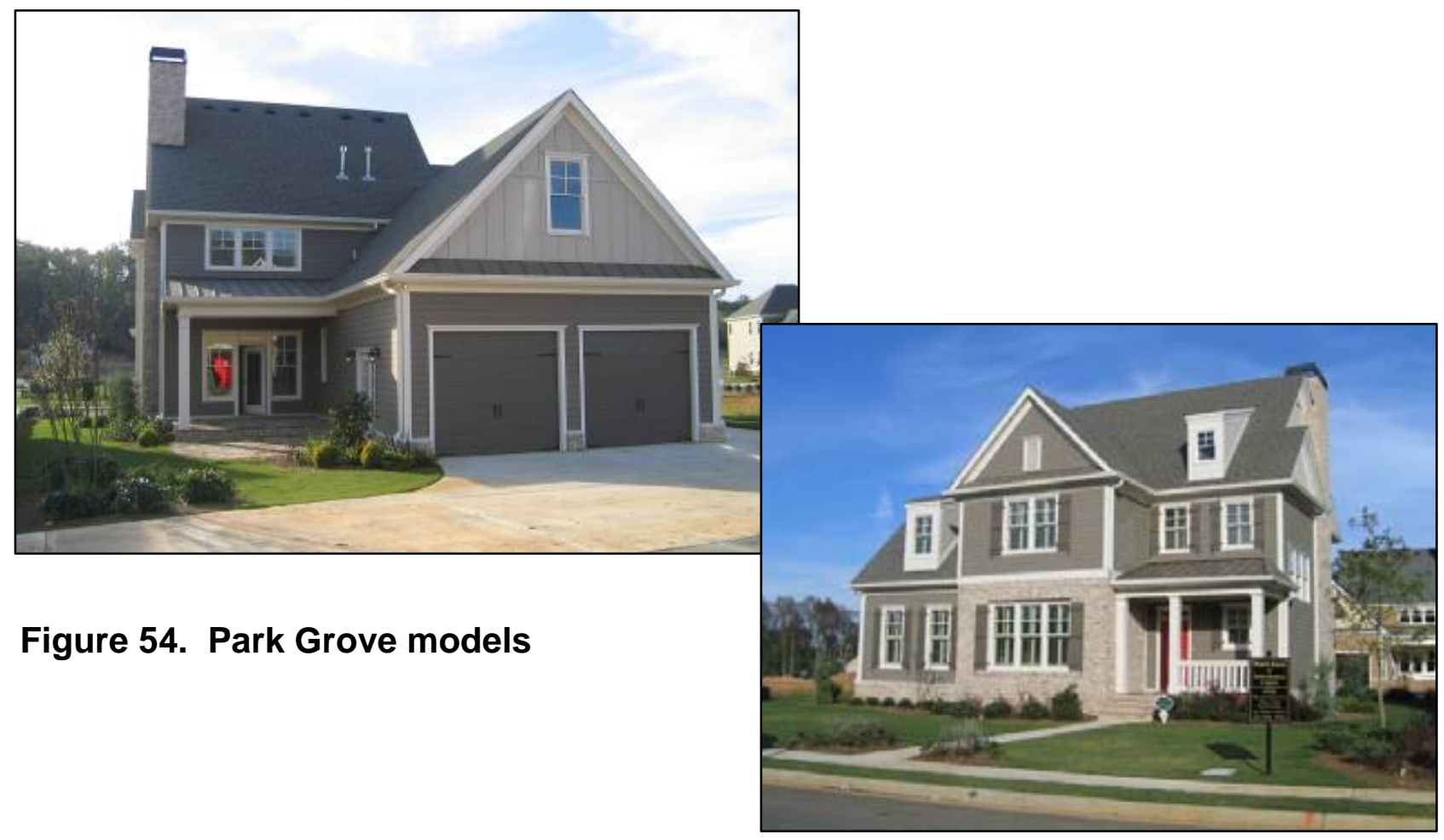

CARB performed a number of tests to evaluate energy performance of the Grove Park prototype homes (Figure 54). Building tightness, duct leakage, and balance of the air-distribution system were quantified. These elements were incorporated into the energy simulation to determine the percentage improvement over the Building America Benchmark. Table 27 shows the estimated annual performance of the Vineyard and Bay Point prototype models versus the Benchmark. The values in the Benchmark column refer to the reference home for the Vineyard and Bay Point models, respectively. The initial Bay Point model did not meet the $30 \%$ total energy savings goal over the Building America Benchmark home. Reasons for this will be discussed later. There is also a final row showing the potential energy savings if all CARB recommendations were incorporated.

Not all projects go as planned. The real story about the heating systems is that CARB initially recommended two heat pumps (upstairs and downstairs) for each home, but local gas utility incentives distort the market by making the builder use gas as the main heat and hot-water fuel in exchange for "free" gas infrastructure in the development. Based on the gas incentives the builder switched to $80 \%$ furnaces for the first (main) floor and heat-pumps or furnaces for the upper floor. CARB intervened with the builder and convinced them to switch to the $92 \%$ condensing furnaces (not the norm for this market) for efficiency and, equally important, indoor combustion, air-quality, and pressure-balance reasons. The HVAC subcontractor agreed to install the 92\% units with no additional cost mark-up for the remaining Grove Park build out. 
Table 27. End-Use Energy Consumption for Grove Park Prototypes

Summary of Energy Consumption by End-Use

\begin{tabular}{|c|c|c|c|c|c|c|c|c|c|}
\hline & \multicolumn{6}{|c|}{ Annual Site Energy } & \multicolumn{3}{|c|}{ Annual Site Cost } \\
\hline & \multicolumn{2}{|c|}{ Benchmark (Vineyard/Bay Point) } & \multicolumn{2}{|c|}{ Vineyard Prototype } & \multicolumn{2}{|c|}{ Bay Point Prototype } & \multirow{2}{*}{$\begin{array}{c}\text { Benchmark } \\
\$\end{array}$} & \multirow{2}{*}{$\begin{array}{c}\text { Vineyard } \\
\$\end{array}$} & \multirow{2}{*}{$\begin{array}{c}\text { Bay Point } \\
\$\end{array}$} \\
\hline End-Use & kWh & Therms & kWh & Therms & kWh & Therms & & & \\
\hline Space Heating & $899 / 288$ & $407 / 411$ & 158 & 223 & 90 & 132 & $346 / 301$ & 164 & 97 \\
\hline Space Cooling & $5016 / 5797$ & 0 & 1401 & 0 & 3640 & 0 & $391 / 452$ & 109 & 284 \\
\hline $\mathrm{DHW}$ & 0 & $221 / 240$ & 0 & 192 & 0 & 209 & $150 / 163$ & 130 & 142 \\
\hline Lighting & $2422 / 3057$ & & 2619 & & 3217 & & $189 / 238$ & 204 & 251 \\
\hline Appliances & $2419 / 2610$ & 0 & 2230 & 0 & 2409 & 0 & $188 / 203$ & 174 & 188 \\
\hline Plug Load & $3375 / 4701$ & & 3375 & & 4701 & & $263 / 366$ & 263 & 366 \\
\hline OA Ventilation & 0 & & 0 & & 0 & & 0.0 & 0 & 0 \\
\hline Total Usage & $14131 / 16453$ & $628 / 651$ & 9783 & 415 & 14057 & 341 & $1527 / 1723$ & 1043 & 1326 \\
\hline Site Generation & & & 0 & & 0 & & & & \\
\hline Net Energy Use & $14131 / 16453$ & $628 / 651$ & 9783 & 415 & 14057 & 341 & $1527 / 1723$ & 1043 & 1326 \\
\hline RecommendedPrototype* & & & 7562 & 296 & 11113 & 228 & & & 1020 \\
\hline
\end{tabular}

Summary of End-Use Source-Energy and Savings

\begin{tabular}{|c|c|c|c|c|c|c|c|c|c|}
\hline & & & & \multicolumn{4}{|c|}{ Source Energy Savings } & & \\
\hline & \multicolumn{3}{|c|}{ Annual Source Energy } & \multicolumn{2}{|c|}{ Percent of End Use } & \multicolumn{2}{|c|}{ Percent of Total } & \multicolumn{2}{|c|}{ Component \% } \\
\hline & Benchmark & Vineyard & Bay Point & Vineyard & Bay Point & Vineyard & Bay Point & Vineyard & Bay Point \\
\hline End-Use & MBtu/yr & MBtu/yr & MBtu/yr & & & & & & \\
\hline Space Heating & $51.2 / 45.0$ & 24.4 & 14.4 & $52 \%$ & $68 \%$ & $12 \%$ & $13 \%$ & $39 \%$ & $53 \%$ \\
\hline Space Cooling & $54.1 / 62.5$ & 15.1 & 39.2 & $72 \%$ & $37 \%$ & $18 \%$ & $10 \%$ & $57 \%$ & $40 \%$ \\
\hline DHW & $22.5 / 24.5$ & 19.6 & 21.3 & $13 \%$ & $13 \%$ & $1 \%$ & $1 \%$ & $4 \%$ & $6 \%$ \\
\hline Lighting & $26.1 / 33.0$ & 28.2 & 34.7 & $-8 \%$ & $-5 \%$ & $-1 \%$ & $-1 \%$ & $-3 \%$ & $-3 \%$ \\
\hline Appliances & $26.1 / 28.1$ & 24.0 & 26.0 & $8 \%$ & $8 \%$ & $1 \%$ & $1 \%$ & $3 \%$ & $4 \%$ \\
\hline Plug Load & $36.4 / 50.7$ & 36.4 & 50.7 & $0 \%$ & $0 \%$ & $0 \%$ & $0 \%$ & $0 \%$ & $0 \%$ \\
\hline OA Ventilation* & 0.0 & 0.0 & 0.0 & $0 \%$ & $0 \%$ & $0 \%$ & $0 \%$ & $0 \%$ & $0 \%$ \\
\hline Total & $216 / 244$ & 148 & 186 & $32 \%$ & $24 \%$ & $32 \%$ & $24 \%$ & $100 \%$ & $100 \%$ \\
\hline Site Generation & & 0 & 0 & & & & & & \\
\hline Net Energy Usage & $216 / 244$ & 148 & 186 & $32 \%$ & $24 \%$ & $32 \%$ & $24 \%$ & & \\
\hline Recommended Prototype* & & 112 & 143 & $48 \%$ & $41 \%$ & $48 \%$ & $41 \%$ & & \\
\hline
\end{tabular}

*Recommended Prototype includes all of CARB's recommendations

Notes: The "Percent of End-Use" columns show how effective each building is in reducing energy use over the Benchmark in each end-use category. The "Percent of Total" columns show how the energy reductions in each end-use category contribute to the overall savings.

$$
\begin{array}{lrl}
\text { energy costs } & \$ 0.0779 / \mathrm{kWh} \text { for electricity } & \begin{array}{l}
\text { Georgia Power Co. } \\
\text { Georgia Average }
\end{array} \\
\$ 0.68 & / \text { therm for natural gas } & \text { Gerg }
\end{array}
$$

\begin{tabular}{|c|c|c|c|}
\hline & \multicolumn{3}{|c|}{ equipment sizing } \\
\hline \multirow[t]{2}{*}{ Benchmark } & $54.5 / 59.5 \mathrm{kBtu} / \mathrm{hr}$ for heating & & \\
\hline & $55.1 / 56.2 \mathrm{kBtu} / \mathrm{hr}$ for sensible cooling & $-->$ & 7.0 nominal tons \\
\hline \multirow{2}{*}{ Vineyard Prototype } & $32.9 \mathrm{kBtu} / \mathrm{hr}$ for heating & & \\
\hline & $20.7 \mathrm{kBtu} / \mathrm{hr}$ for sensible cooling & $-->$ & 2.5 nominal tons \\
\hline \multirow[t]{2}{*}{ Bay Point Prototype } & $42.8 \mathrm{kBtu} / \mathrm{hr}$ for heating & & \\
\hline & $32.8 \mathrm{kBtu} / \mathrm{hr}$ for sensible cooling & $-->$ & 4.0 nominal tons \\
\hline
\end{tabular}

\begin{tabular}{||c||c|}
\hline & 1999 HERS \\
\hline \hline Benchmark & 80.4 / 81.2 \\
Builder & 90.4 \\
Prototype & 90.0 \\
\hline \hline Advanced & $93.3 / 92.5$ \\
\hline
\end{tabular}




\section{Field Inspection}

In the Vineyard model, the mechanical room access is from the garage (Figure 55). The wall between the garage and the mechanical room/interior is insulated. The intent was to place the mechanical equipment in conditioned space. With the use of atmospheric furnaces, the mechanical room requires make-up air that was achieved by having a louvered door. This now makes the mechanical room unconditioned. Therefore, all the interior walls of the mechanical room and the chase above need to be insulated. The foyer, kitchen, laundry room, upstairs hallway, and front bedroom are all adjacent to this mechanical room. If atmospheric furnaces were to be used, then these interior walls would need to be insulated. This also raised the concern of the air handlers drawing garage gases into the living space.

In the Bay Point model, because of the use of atmospheric equipment, an 8 -in. duct to the attic is installed to provide make-up air. First of all, when ducting air into the mechanical room, there should be a high and low register in the mechanical room. The reason for this is that the "two openings will induce a

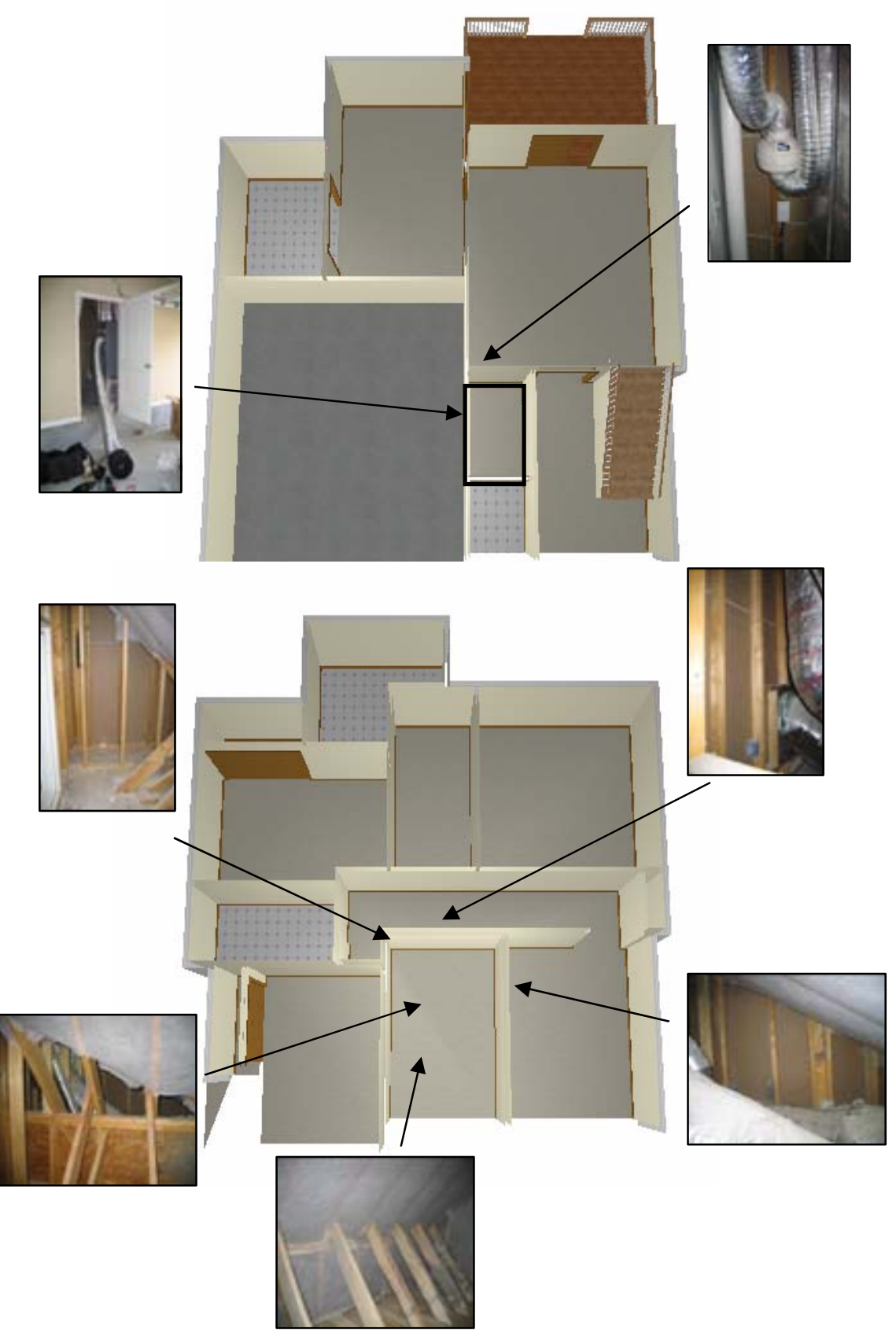

Figure 55. Layout of Vineyard model 
convective air current in the room by admitting cooler, more dense air in the lower opening and allowing the escape of warmer, less dense air through the upper opening (1998 International Mechanical Code).” Regardless, a louvered door should not have been installed between the mechanical room and the living space. The use of the louvered door provides a direct path for unconditioned air to enter the building envelope or for conditioned air to be lost to the exterior.

Another concern that was found during the performance testing was the lack of a proper return air pathway for the master suite. A room-by-room pressure diagnostic was performed to see if the central returns would be adequate. With only a central return in the upstairs hallway, a noticeable pressurization of the bedrooms was observed when doors were closed. The Master Suite (which includes the Master Bedroom, Master Bath, and WIC) saw a pressure increase of up to $18 \mathrm{~Pa}$ when the door to the hallway was closed during the cooling mode. This is a significant pressure difference that will lead to a reduction in HVAC performance and also could be noticeable by the homeowner (comfort issue). The secondary bedrooms were also pressurized when doors were closed, though not as significantly. The use of jumps ducts, rather than just door undercuts, would eliminate this issue.

\section{Recommended Improvements}

CARB continued to work with Outlook Construction to make improvements to their building specifications. The primary change, which Outlook agreed to, was to upgrade the Bryant gas furnaces from the Plus 80 models to the Plus 90 models. Switching to sealed-combustion furnaces reduces heating costs and also allows for the removal of the outdoor make-up air to the mechanical room. By making the mechanical room part of the interior conditioned space, the building envelope will be tighter and duct leakage to the outside is minimized. When only the improved AFUE of the sealed-combustion furnace (minimum AFUE of 92) is considered, there the heating fuel usage reduced by $12 \%-13 \%$, depending on the house model. If improvements in the infiltration and duct leakage to the outside are considered, there will be even more substantial savings. For modeling purposes, an estimated annual natural infiltration rate of $0.15 \mathrm{ACH}$ (value seen in a previously tested Outlook prototype, Cooper 2) was applied, along with switching the mechanical room to interior space and a duct leakage to outside of only $3 \%$. This results in a heating savings between $32 \%$ and $44 \%$ and cooling savings of from $14 \%$ to $16 \%$ annually.

The other atmospheric equipment that is present is the water heater. Though this could be improved simply by upgrading to a direct-vented water heater (EF 0.62), CARB has been recommending switching to a tankless “on-demand” gas water heater (EF 0.82). This would result in a savings of 33\%-37\% on hot water fuel usage.

The last major specification that CARB continues to discuss with Outlook Construction is the design of a compact fluorescent lighting (CFL) package. Switching to a fluorescent lighting package would reduce lighting electrical consumption by two-thirds. This will also provide savings as a result of the lower cooling load.

The net benefit of these added efficiency measures would be a total annual source-energy savings of $41 \%-48 \%$ compared to the Building America Benchmark. 


\section{Cost}

As a small volume regional production builder, Outlook Construction remains flexible and adaptive and is able to quickly integrate new products and techniques into their custom and production homes. Many of the techniques endorsed by CARB have been successfully integrated into production and have become standard practice. These include panelized wall systems, advanced 24-in. on-center framing, open-web floor trusses, polyurethane-foam skim-coated stud cavities, low-e windows, down-sized HVAC, compact HVAC distribution, and others.

The net cost increase for these various improvements is minimized through integrated design, production efficiencies, and cost trade-offs. The $2 \times 6$ wall panels use essentially the same boardfeet of lumber as $2 \times 4,16$-in. on-center panels, while the panelization process raises production by expediting the framing process and reducing waste. Other improvements, such as the low-e windows were adopted by Outlook before the Georgia energy code requirement going into effect. CARB provided the engineering documentation and subsequent testing to assure Outlook that this change allows for a substantially reduced HVAC system essentially negating the increased cost for those windows.

The foamed-over buried ducts similarly have a net-zero cost implication as a result of further HVAC down-sizing. For comparison's sake, the insulator estimated the cost to foam the ducts at approximately $\$ 350$ when done on a production scale. Insulating the exterior wall with a foam skim-coat and 5 in. of damp-spray cellulose constituted the only substantial cost increases.

Of the CARB-inspired specification changes incorporated, only one has not been refined to the point of full implementation: foamed-over buried ducts. The reason for the ducts is two-fold: a production process in which it is currently simpler to foam the ducts before the installation of the ceiling gypsum board and the use of standard (Howe) trusses rather than the use of Warren trusses. The use of the Warren truss would allow for better placement of the ducts directly on the attic floor, hence providing more uniform insulation burial. CARB has since met the builder and the truss fabricator to adopt these changes to more effectively implement the buried duct strategy.

The floor plans are shown in Figures 56, 57, 58, and 59. 


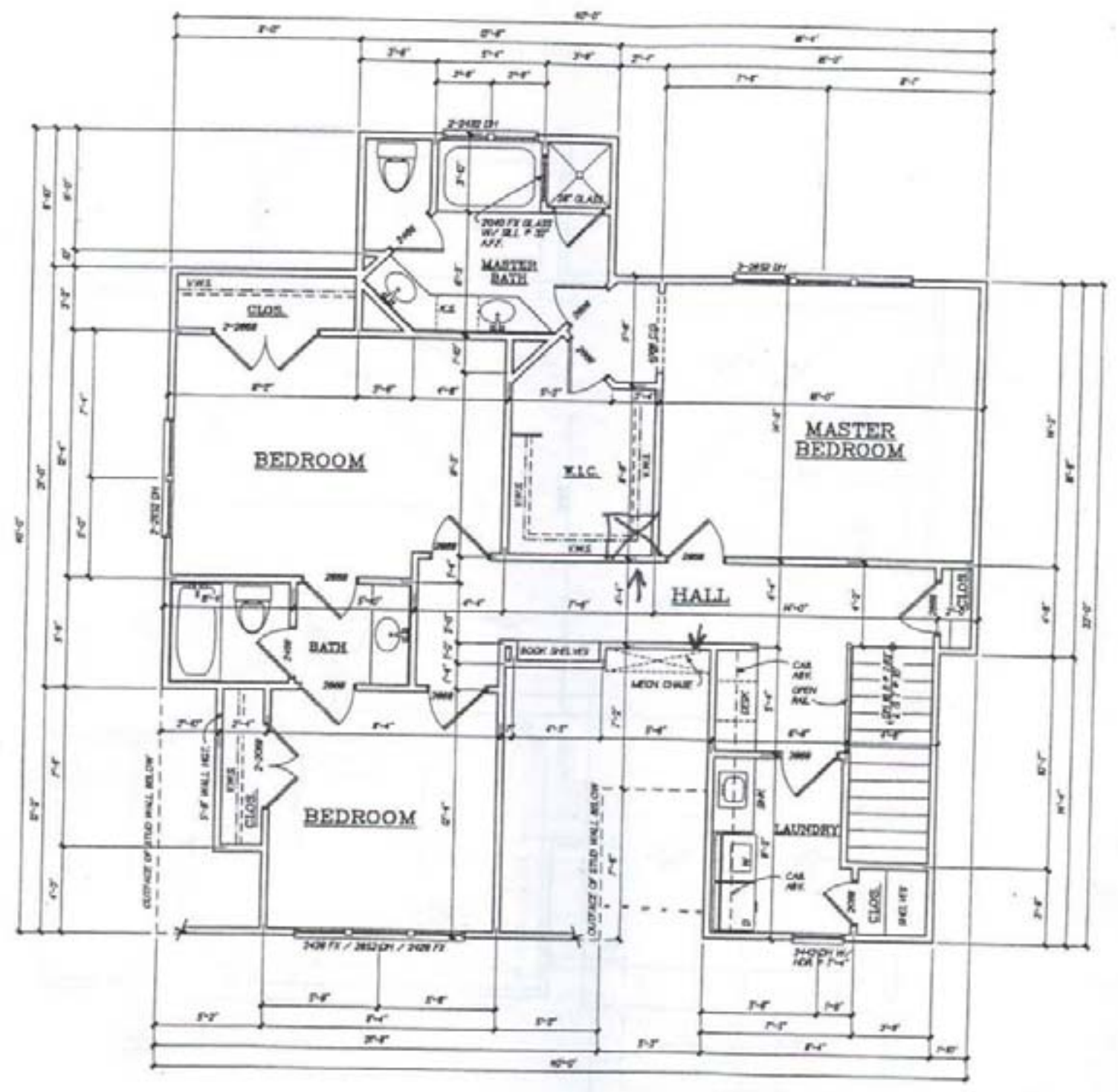

Figure 56. Vineyard floor plan (second floor) 


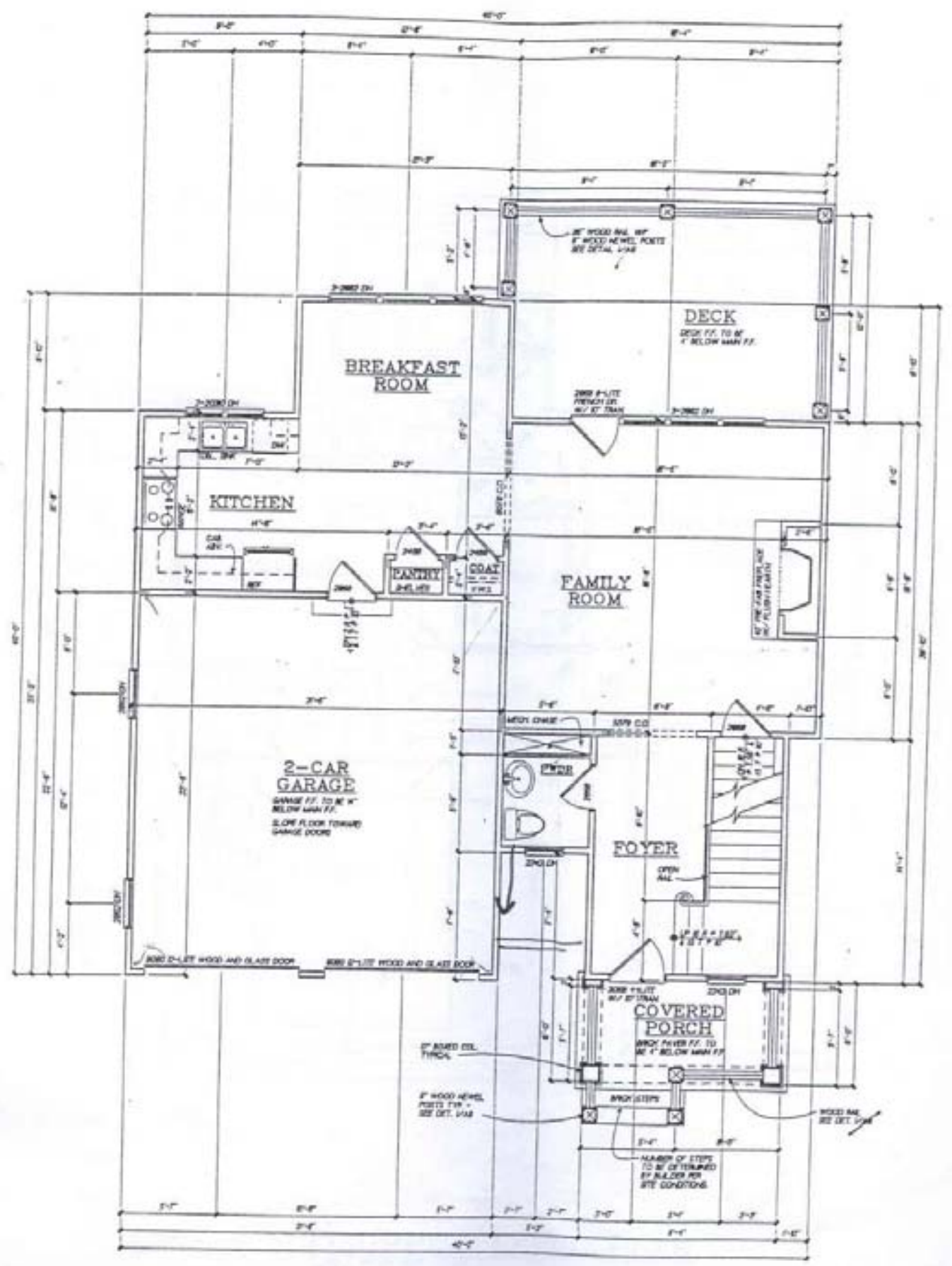

Figure 57. Vineyard floor plan (first floor) 


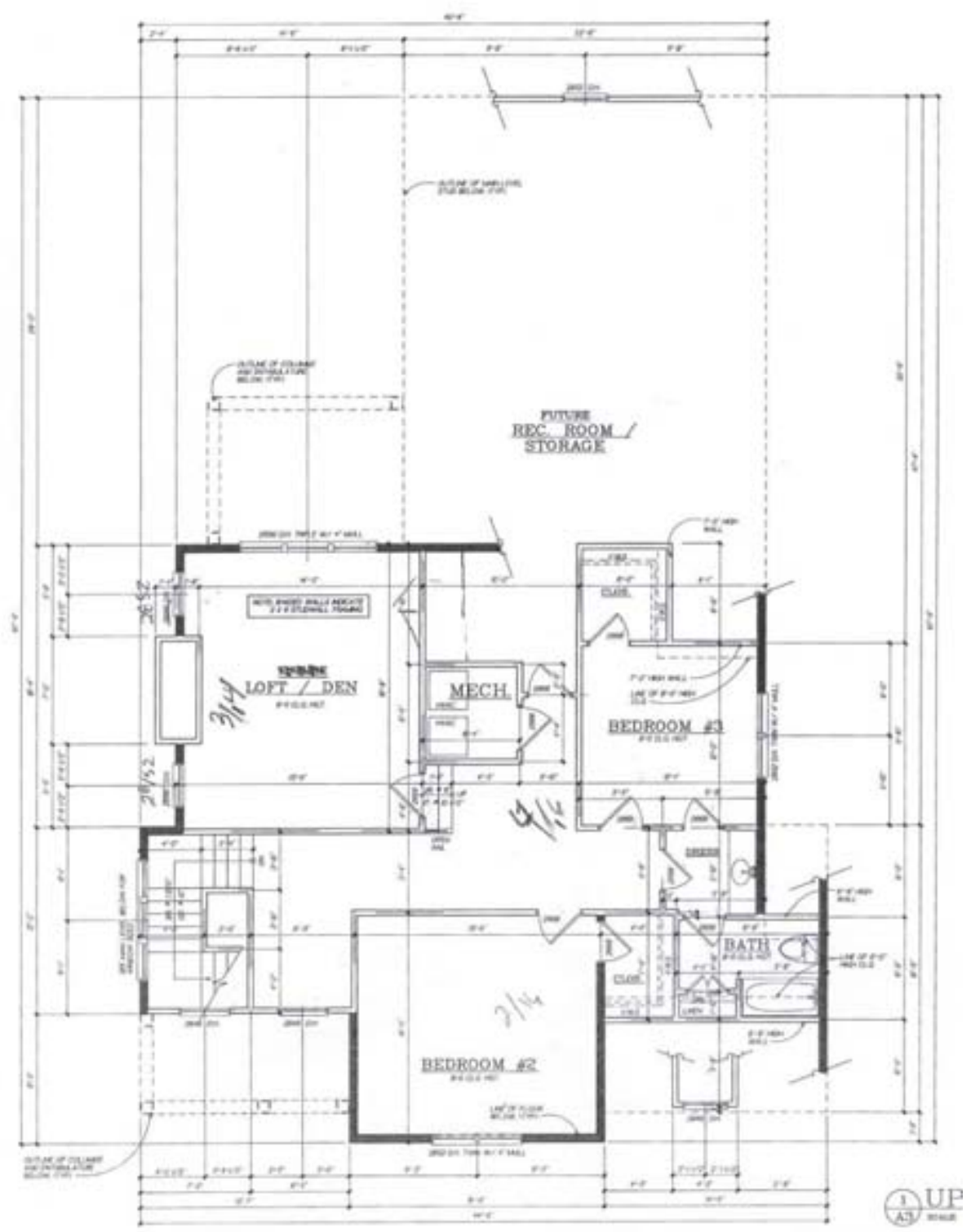

Figure 58. Bay Point floor plan (second floor) 


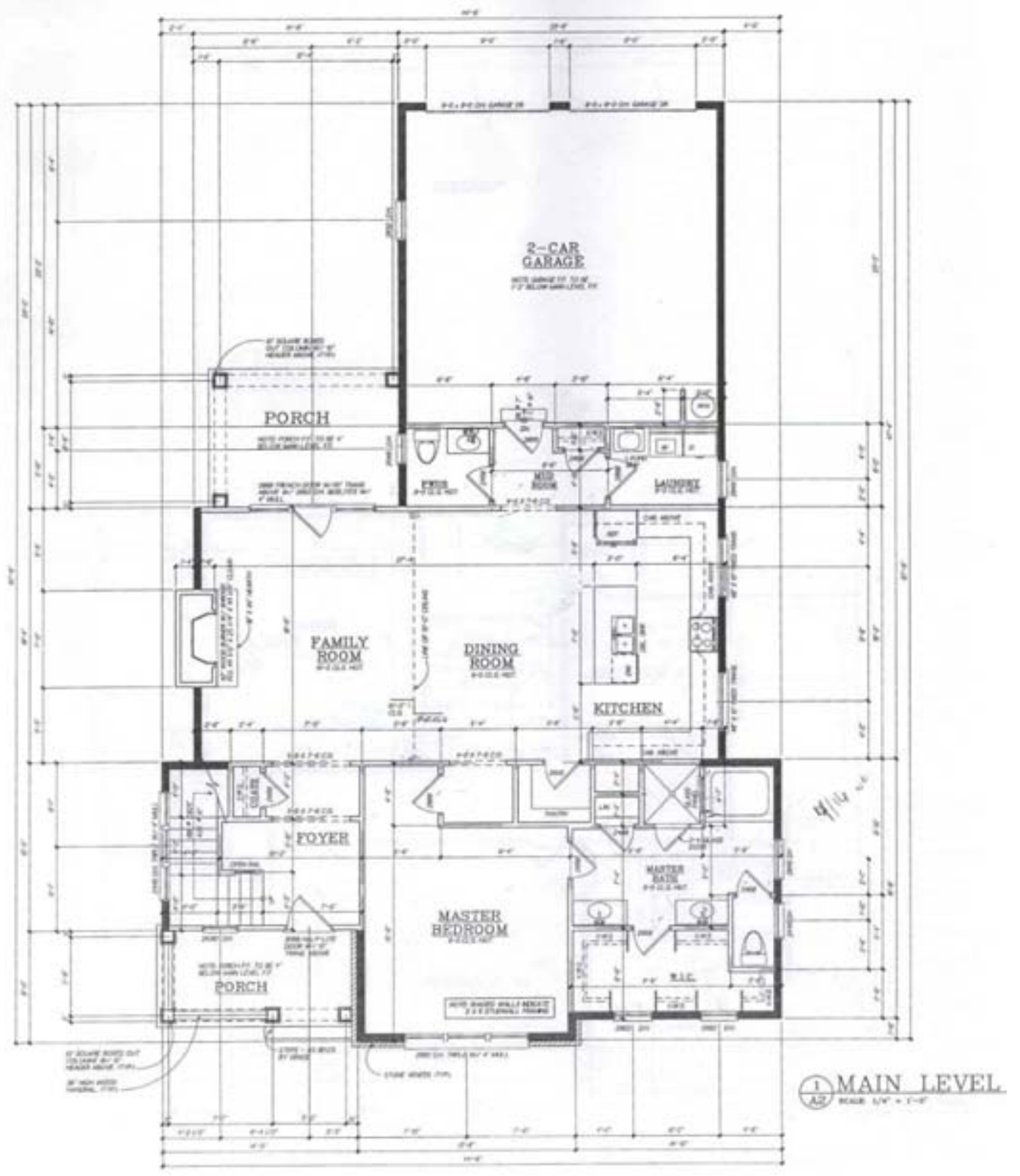

Figure 59. Bay Point floor plan (first floor) 


\section{Development: Valencia}

\section{Builder: Ideal Homes}

Location: Oklahoma City, Oklahoma

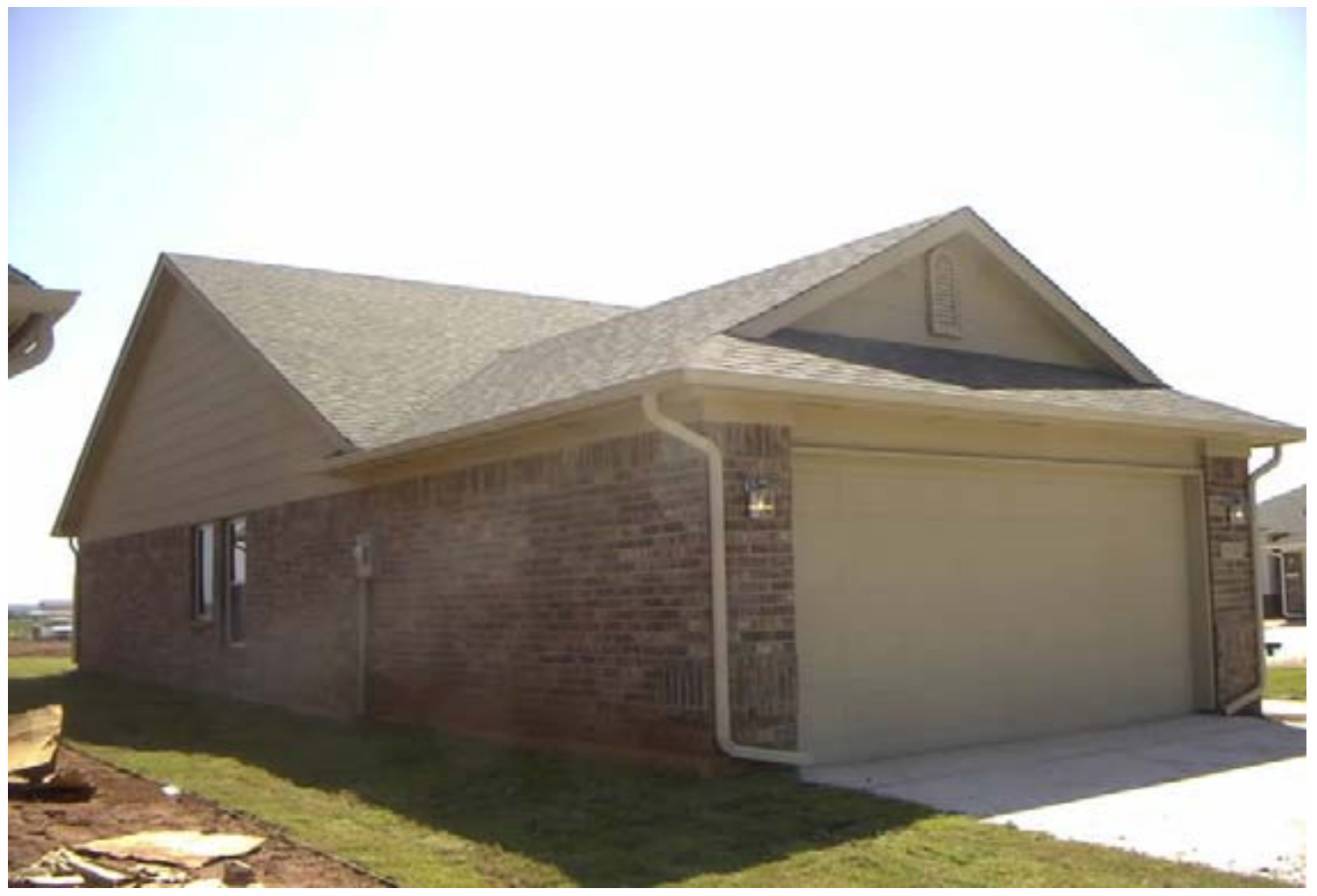

Figure 60. Ideal Homes high-efficiency home near Oklahoma City

Ideal Homes builds developments of high-efficiency homes in the Oklahoma City area, aimed at various price points from modest to custom (Figure 60). They have incorporated several energy upgrades into their standard product and continue to reach for higher efficiency goals with special projects. As they learn from the special projects, they work to include the improved technology into their standard production. At this point, the standard houses use insulating sheathing, slab-edge insulation, air sealing of the framing at connection points, draft stops behind tubs and fireplaces, low-E glazing, 90+\% AFUE furnaces, and 14 SEER cooling systems with low leakage ducts. With these upgrades, they are able to reach into the $30 \%$ overall savings range (Figure 61).

Table 28 summarizes the key specifications for the Ideal Homes project. 


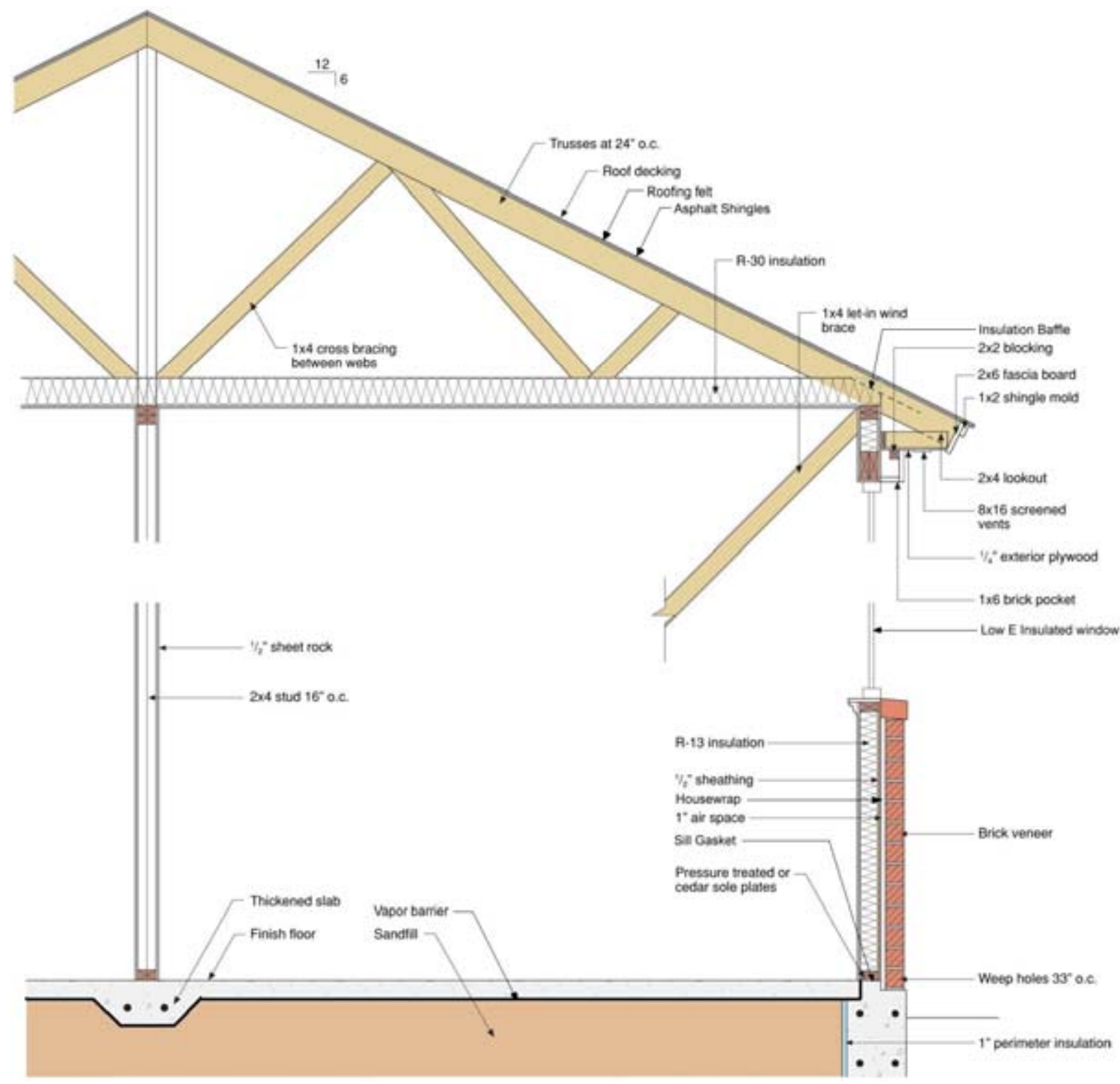

Figure 61. Ideal Homes section detail 


\section{Table 28. House Specifications}

\section{Building envelope}

Ceiling

$\mathrm{R}-30$ blown cellulose at ceiling

Walls

R-15 + R-3 insulating sheathing

Foundation

Slab, R-4 interior insulation

Windows

Double Glazed Vinyl Frame Low-E2

$U=0.39$, SHGC $=0.31$

Infiltration

2.5-in ${ }^{2}$ leakage area per $100 \mathrm{ft}^{2}$ envelope

\section{Mechanical systems}

Heat

90\% AFUE Gas furnace

Cooling

14 SEER A/C unit

DHW

0.59 EF gas tank in garage closet

AHU location

in vented attic

Ducts

In vented attic, R-6 insulation

Leakage

$5 \%$ or less

Supply-only system integrated with $\mathrm{AHU}$

Per ASHRAE 62.2 46 CFM continuous

Ventilation average flow

Lighting

90\% incandescent lighting

Appliances \& Plug

ENERGY STAR Appliances 


\section{Parametric Study}

Figure 62 charts overall source energy use reduction and shows that the cooling and lighting loads are greatly diminished with the recommended improvements. Table 29 summarizes the results in tabular form.

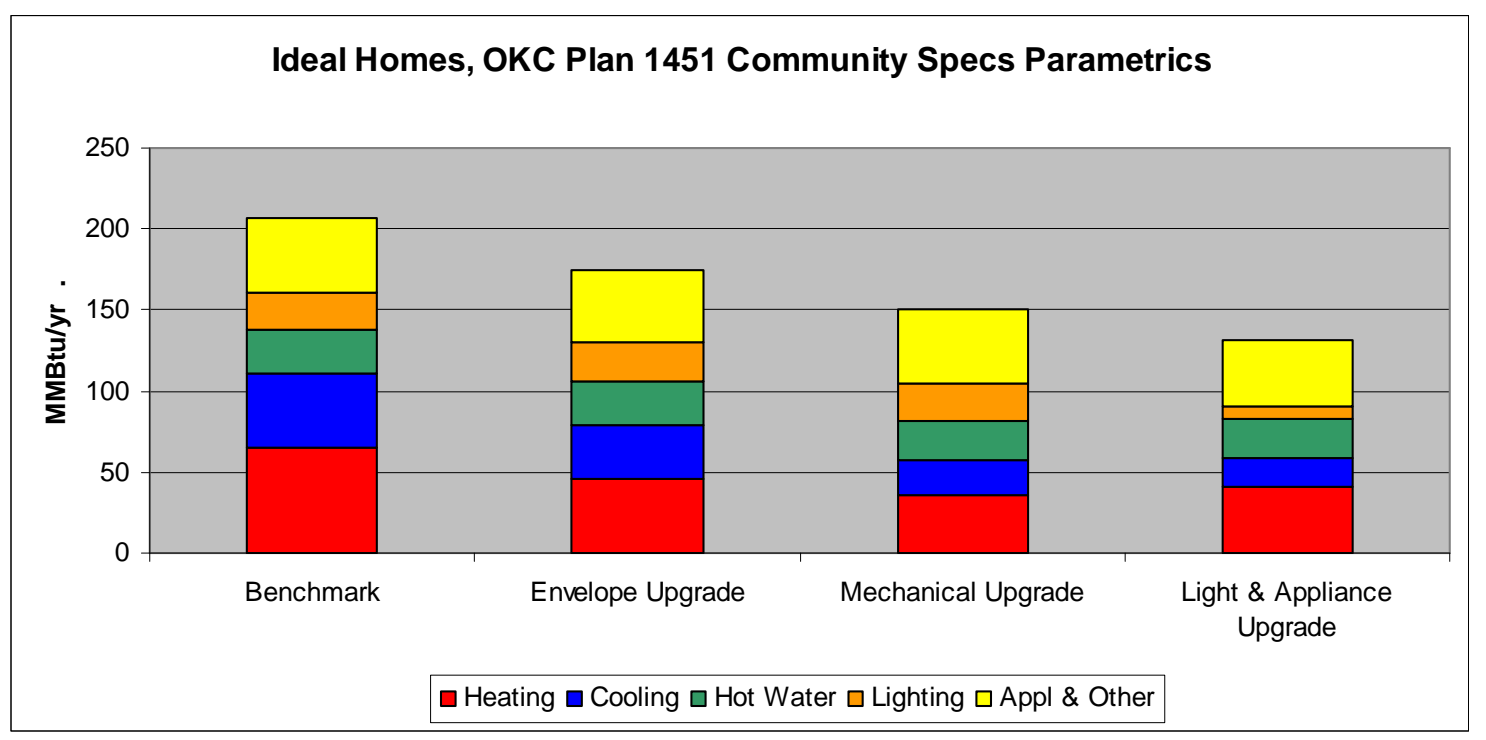

Figure 62. Overall source energy use reduction

Table 29. Tabular Summary of Parametric Study

\begin{tabular}{|c|c|c|c|c|c|c|c|c|c|}
\hline & \multirow{3}{*}{$\begin{array}{l}\text { Estimated } \\
\text { Individual } \\
\text { Cost of change }\end{array}$} & \multirow{3}{*}{\begin{tabular}{|l} 
Estimated \\
Cunnulative \\
Cost of changye
\end{tabular}} & \multirow{2}{*}{\multicolumn{4}{|c|}{$\begin{array}{c}\text { Total Source Energy Savings } \\
\text { (HCDOHWLLLights/Appliances)Plug) }\end{array}$}} & \multirow[b]{3}{*}{$\begin{array}{r}\text { Simple } \\
\text { payback (yr) }\end{array}$} & \multirow[b]{3}{*}{\begin{tabular}{|} 
Incremen \\
payback (yil
\end{tabular}} \\
\hline & & & & & & & & & \\
\hline \begin{tabular}{|l} 
Parametric \\
Run ID
\end{tabular} & Descripition of change & & & $\begin{array}{c}\text { over BA } \\
\text { Benchmark }\end{array}$ & $\begin{array}{l}\text { Incremental } \\
\text { Over Bmrk }\end{array}$ & $\begin{array}{c}\text { Annual } \\
\text { energy cost }\end{array}$ & $\begin{array}{l}\text { litem } \\
\text { Saanngs }\end{array}$ & & \\
\hline \multicolumn{10}{|c|}{$30 \%$ Communitites } \\
\hline 20 & Benchmalk & nla & nla & nla & nla & $\$ 1,395$ & $\mathrm{n} / \mathrm{a}$ & nla & $\mathrm{n} / \mathrm{a}$ \\
\hline 21 & $20+$ Envelope Uppgade & $\$ 1,000$ & $\$ 1,000$ & $15.3 \%$ & $15.3 \%$ & $\$ 1,193$ & $\$ 202$ & 5 & \\
\hline 22 & $21+$ Mechanical Upgrade & $\$ 1,200$ & $\$ 2,200$ & $27.4 \%$ & $12.1 \%$ & $\$ 1,005$ & $\$ 188$ & 6 & \\
\hline 23 & $22+$ Light \& Applanace Upgrade & $\$ 1,000$ & $\$ 3,200$ & $36.2 \%$ & $8.9 \%$ & $\$ 8867$ & $\$ 138$ & 6 & \\
\hline
\end{tabular}




\section{Source Energy Consumption Summary}

Note that the "Percent of End-Use" column shows how effective the prototype building is at reducing energy use in each end-use category; the "Percent of Total" column shows how the energy reductions in each end-use category contribute to the overall savings (Table 30).

Table 30. Source Energy Savings for Ideal Homes

\begin{tabular}{|l|c|c|c|c|}
\cline { 3 - 5 } \multicolumn{1}{c|}{} & \multicolumn{2}{c|}{} & \multicolumn{2}{c|}{ Source Energy Savings } \\
\cline { 2 - 5 } \multicolumn{1}{c|}{} & \multicolumn{2}{c|}{ Est Annual Source Energy } & $\%$ of End Use & $\%$ of Total \\
\cline { 3 - 5 } \multicolumn{1}{c|}{} & BA Benchmark & Prototype 1 & Prototype 1 \\
End Use & Savings & $\begin{array}{c}\text { Prototype 1 } \\
\text { Savings }\end{array}$ \\
\hline Space Heating & 65 & 40 & $\mathbf{3 8 \%}$ & $\mathbf{1 2 \%}$ \\
\hline Space Cooling & 46 & 19 & $\mathbf{5 9 \%}$ & $\mathbf{1 3 \%}$ \\
\hline DHW & 27 & 24 & $\mathbf{1 0 \%}$ & $\mathbf{1 \%}$ \\
\hline Lighting & 23 & 7 & $\mathbf{7 0 \%}$ & $\mathbf{8 \%}$ \\
\hline Appliances + Plug & 46 & 42 & $\mathbf{9 \%}$ & $\mathbf{2 \%}$ \\
\hline Total Usage & 207 & 132 & $\mathbf{3 6 \%}$ & $\mathbf{3 6 \%}$ \\
\hline Site Generation & 0 & 0 & & $\mathbf{0 \%}$ \\
\hline Net Energy Use & 207 & 132 & $\mathbf{3 6 \%}$ & $\mathbf{3 6 \%}$ \\
\hline
\end{tabular}

\section{Summary}

The homes that Ideal builds show that energy efficiency can be integrated into a production setting without undue complexity, nor breaking the budget. It has taken some time for them to implement each next change in their production setting, but their efforts to reach for the next highest level of efficiency have paid off. Ideal continues to search for ways to further improve their energy savings, investigating the use of ground-source heat pumps, desuperheaters, tankless water heaters, solar hot water, and photovoltaic panels, but that is for a future development and case study. 
Development: The Legends at Mansfield

Builder:

Tindall Homes

Location: $\quad$ Columbus, New Jersey

With a background in science and 5 years of building experience under his belt, Mark Bergman founded Tindall Homes in 1986. Over the past 20 years, the company's mission has been to build superior quality homes that offer exceptional long-term value - homes with greater durability and energy efficiency. Tindall builds 20-25 semi-custom homes per year, which meet ENERGY STAR building standards and range in size from 3,800 to 6,000 $\mathrm{ft}^{2}$ (Figures 63 and 64)

When developing the Legends at Mansfield community, Tindall worked with IBACOS to achieve at least $30 \%$ energy-savings levels according to the Building America Benchmark.

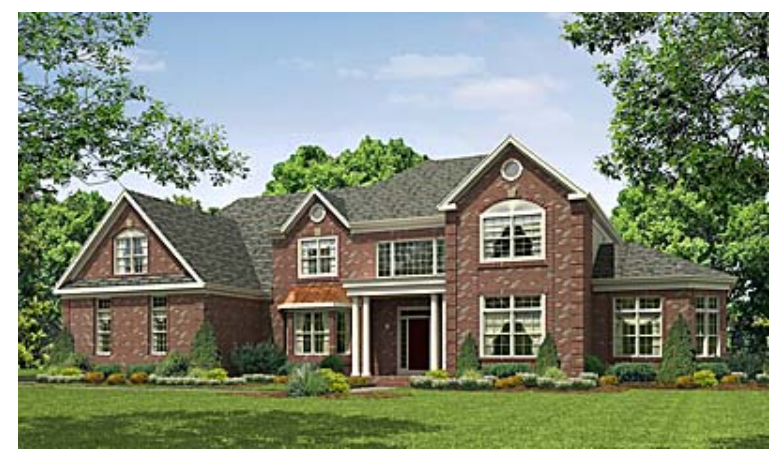

Figure 63. Rendering of Tindall's Morgan home from Legends at Mansfield

MAIN FLOOR

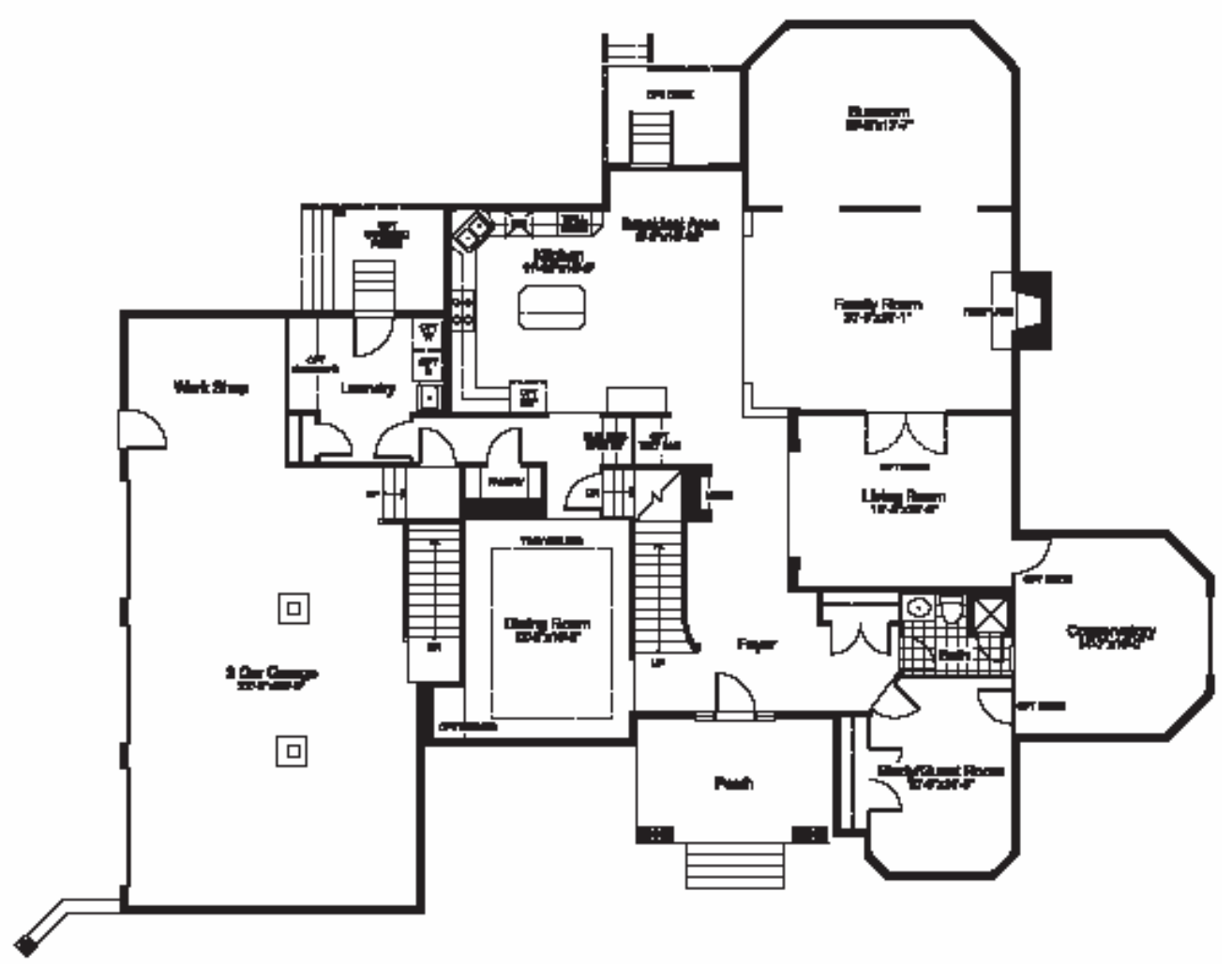

Figure 64. Main floor plan for a Tindall Morgan home from Legends at Mansfield 


\section{Measuring Up}

During the design phase, IBACOS and Tindall explored several options to realize 30\% energy savings, including the use of solar electric systems and improvements to heating, cooling, ventilation, duct work, and the building shell. Rather than selecting a few key areas to focus on, Tindall chose to implement most of the design recommendations.

Consequently, an analysis of energy use in comparison to the Benchmark for New Jersey shows that Tindall's Legends at Mansfield homes were expected to exceed the $30 \%$ Benchmark, consuming $43.2 \%$ less energy than comparable homes. The addition of tankless water heaters, which could be eliminated from the design to remain within the $30 \%$ savings range, enabled Tindall to reach the next energy-efficiency level. After adding solar photovoltaic systems to the plans, the savings estimate increased to $48.4 \%$.

\section{Increased Airtightness}

Before partnering with the Building America program, Tindall installed unfaced fiberglass batt insulation in conventional 2x4 stud walls, with studs located 16 in. on center. By using 2x6 studs placed 24 in. on center for the homes in the Legends at Mansfield community, Tindall was able to reduce the total number of studs used and significantly decrease conductive heat loss through exterior walls. The 3 in. of urethane foam within walls increased the insulation to R-18 and also added to the buildings' airtightness.

\section{Optimized Heating, Ventilation, and Air Conditioning}

Because of their size and the design of their flooring structures, Tindall's homes are typically conditioned by two HVAC systems: one located in the basement to serve the first floor and the other based in the attic to serve the second floor. Locating the second floor HVAC system in the attic results in significant energy loss, as the system is exposed to ambient conditions.

For their Building America project, IBACOS and Tindall elected to use open-web floor trusses for the second-floor structure, allowing plumbing and duct work to run through conditioned space and enabling both HVAC systems to be placed in the basement. With this approach, Tindall reduced end use of heating energy in its Legends at Mansfield properties by $53 \%$ and the use of cooling energy by $45 \%$, both in comparison to the BA Benchmark.

Tindall also replaced its standard ventilation system with a heat-recovery ventilator, which was connected to the return plenum of both furnaces. This upgrade provided a means to bring fresh air in, capturing much of the heat contained in outgoing air before exhausting it. At the same time, better ventilation has resulted in improved air quality and enhanced occupant comfort.

In addition, IBACOS's recommendations allowed Tindall Homes to decrease the size of both heating and cooling equipment. Smaller equipment reduces the cost to the builder by $\$ 800$ per home and contributes significantly to energy savings.

\section{Moisture Resistance}

To keep moisture from penetrating its homes from the ground up, Tindall replaced its standard foundation with pre-insulated, pre-cast concrete walls. The higher cement content and other additives within these walls provide a much greater level of moisture resistance without 
requiring an additional barrier. The design of the wall system provides for a continuous layer of insulation on the foundation wall, and because it is a pre-cast system, the foundation can be installed in 1 to 2 days.

\section{Impact of Solar PV Systems}

When Tindall Homes began its Building America project, photovoltaic systems were a hot option for improving residential energy efficiency in New Jersey. At the time, builders were reimbursed for two-thirds of the investment under the state's rebate program. For Tindall, this program provided more than $\$ 13,000$ in savings on a $\$ 20,000$ system. The builder analyzed the cost of the system versus the benefits it would provide and then decided to offer photovoltaics as a standard feature on all 39 homes in Mansfield Park.

As the project progressed, however, state funding steadily declined, and program implementation became much stricter. The builder ended up installing solar systems on only 14 homes, because they did not receive the rebate level they had expected. While solar had the potential to generate another $5 \frac{1}{2} \%$ in energy savings, it was no longer a cost-effective option.

Table 31 summarizes estimated source energy savings from heating and cooling systems, other improvements Tindall implemented, and photovoltaics. Table 32 provides a snapshot of all of the energy related features of the houses in the community. 
Table 31. Summary of Estimated Source Energy Savings

\begin{tabular}{|c|c|c|c|c|c|c|c|}
\hline \multirow[b]{3}{*}{ End Use } & \multicolumn{3}{|c|}{ Annual Source Energy } & \multicolumn{4}{|c|}{ Estimated Source Energy Savings } \\
\hline & Benchmark & $\begin{array}{c}\text { Tindall } \\
\text { Standard }\end{array}$ & $\begin{array}{l}\text { Project } \\
\text { House }\end{array}$ & Percent of & End-Use & Percent & Total \\
\hline & (MBtu/yr) & (MBtu/yr) & (MBtu/yr) & $\begin{array}{c}\text { vs. } \\
\text { Benchmark }\end{array}$ & $\begin{array}{l}\text { vs. } \\
\text { Standard }\end{array}$ & $\begin{array}{c}\text { vs. } \\
\text { Benchmark }\end{array}$ & $\begin{array}{c}\text { vs. } \\
\text { Standard }\end{array}$ \\
\hline $\begin{array}{l}\text { Space } \\
\text { Heating }\end{array}$ & 401 & 227 & 187 & $53 \%$ & $17 \%$ & $54 \%$ & $8 \%$ \\
\hline $\begin{array}{l}\text { Space } \\
\text { Cooling }\end{array}$ & 74 & 47 & 40 & $45 \%$ & $14 \%$ & $7 \%$ & $1 \%$ \\
\hline DHW & 27 & 20 & 12 & $55 \%$ & $41 \%$ & $-1 \%$ & $2 \%$ \\
\hline Lighting & 44 & 45 & 14 & $68 \%$ & $69 \%$ & $3 \%$ & $7 \%$ \\
\hline Appliances & 28 & 28 & 28 & $0 \%$ & $0 \%$ & $0 \%$ & $0 \%$ \\
\hline Misc. Plug & 104 & 104 & 104 & $0 \%$ & $0 \%$ & $0 \%$ & $0 \%$ \\
\hline Subtotal & 678 & 472 & 387 & $43 \%$ & $18 \%$ & $43 \%$ & $18 \%$ \\
\hline $\begin{array}{l}\text { PV } \\
\text { Generation }\end{array}$ & 0 & 0 & -37 & & & $5 \%$ & $8 \%$ \\
\hline Total & 678 & 472 & 350 & $48 \%$ & $26 \%$ & $48 \%$ & $26 \%$ \\
\hline
\end{tabular}




\section{Table 32. Snapshot of Energy Features}

Foundation Insulation

Wall Construction and Insulation

Ceiling/Roof Construction and Insulation

Windows

Air Sealing

Blower Door Test

Ducts

Duct Losses

Ventilation

Heating Equipment

Cooling Equipment

Hot Water System

Solar PV System

Lighting

Appliances
Exterior R-12.5 polystyrene insulation board

$2 \times 6$ wood frame, 24 in. oc, 3-in. spray urethane (R-18)

Wood trusses 24 in. OC,

Attic (flat) - R-30 fiberglass batts, $\mathrm{R}-19$ blown cellulose (4 1/2 in.)

Attic (cathedral) - R-30 fiberglass batts

Garage ceiling - 2-in. spray urethane (R-12), R-30 fiberglass batts

Low-E, gas-filled; $U=0.36$; $\mathrm{SHGC}=0.33$

Housewrap w/ joints taped, sill sealer, caulk/foam at interior of sill plates, foam around rough openings of windows and doors, draftstopping behind showers/tubs and fireplaces, at kneewalls, and chase "lids," penetrations in top plates and draftstopping airsealed

3.2 $\mathrm{ACH}_{50}$

$100 \%$ conditioned space

$6 \%$ total at 25 Pascals

Heat-recovery ventilator to return plenum of both furnaces

Two natural-gas $92.1 \%$ efficiency furnaces

Two condensing units, first floor 3-Ton / 14SEER, second floor 2.5 Ton / 13-SEER

Two tankless water heaters, energy factor 0.85

2.64-kW grid-connected photovoltaic system

$\approx 95 \%$ linear or compact fluorescent, remainder incandescent

Not provided by the builder 


\section{Builder Innovation, Challenges, and Lessons Learned}

Tindall Homes has invested between $\$ 16,000$ and $\$ 18,000$ more in first costs for its Building America homes in comparison to standard specifications (Table 33 shows a breakdown). Mark Bergman believes the investment was well worth it.

"We all want to make money, but at some point, as a society, we have to evaluate what we are doing," asserted Bergman. "Over their lifetimes, our homes will save more in energy costs than the cost of the energy efficient upgrades, especially when you consider energy prices will likely rise over time, not decrease. If all builders built to save $50 \%$ on energy use, we could make a big difference."

During the modeling process, IBACOS estimated the energy efficiency of the Legends at Mansfield community homes, and the HERS rating came in between 90 and 91 . On average, the homeowners are saving about $\$ 1,500$ a year in utility bills, and, assuming these homes will last for 100 years, they should save approximately 10 times the incremental cost of the upgrades.

"It's also important to recognize that many of the things that are making our homes more energy efficient will also make them last longer," said Bergman. "By implementing Building America recommendations, our homes are more weather resistant, keeping out humidity and dampness problems."

For his next major project, Bergman will leverage his Building America experience to bring energy efficiency to more affordable housing. He will begin development of a 1,500-unit, mixed housing community within the next 2 years. It will be located across the river from Philadelphia and will incorporate solar-electric systems and water-conservation practices in addition to improved building shells and advanced HVAC strategies. 


\section{Table 33. Cost of Tindall Home Compared to Standard Building Practices in New Jersey}

\begin{tabular}{|c|c|c|c|}
\hline Building Envelope & Standard Specifications & $\begin{array}{l}\text { Building America Project House I } \\
\text { Community Specs }\end{array}$ & Cost Difference \\
\hline \multicolumn{4}{|l|}{ Insulation } \\
\hline Ceiling (main) & R-30 Unfaced fiberglass batts & $\begin{array}{l}\text { R-30 kraft-faced (down) fiberglass batts }+R- \\
19 \text { blown cellulose }\end{array}$ & $+\$ 1050$ \\
\hline Garage Ceiling & $\mathrm{R}-19$ unfaced fiberglass batts & $\begin{array}{l}\text { 2-in. urethane foam (R-12) + R-30 kraft-faced } \\
\text { (down) fiberglass batts }\end{array}$ & $+\$ 550$ \\
\hline Above-Grade Walls & $\begin{array}{l}2 \times 4 \text { with } R-3 \text { rigid sheathing on exterior } \\
\text { and } R-13 \text { fiberglass batts }\end{array}$ & $2 \times 6 @ 24$ in. oc w/ 3 in. urethane foam (R-18) & $\begin{array}{l}+\$ 1,000 \text { framing / } \\
+\$ 4,000 \text { insulation }\end{array}$ \\
\hline Basement Walls & $\mathrm{R}-13$ foil faced fiberglass batts & $\begin{array}{l}\text { Precast foundation with integral R-12.5 } \\
\text { insulation board }\end{array}$ & $+\$ 7000$ \\
\hline Windows & $\begin{array}{l}\text { Low-E, vinyl, argon filled, } \mathrm{U}=0.35 \\
\quad \mathrm{SHGC}=0.30\end{array}$ & Low-E, vinyl,, U=0.36, SHGC=0.33. & $+\$ 0$ \\
\hline \multicolumn{4}{|l|}{ Infiltration } \\
\hline Draftstopping & $\begin{array}{l}\text { Lack of draftstopping behind baths/ } \\
\text { showers and fireplaces. }\end{array}$ & $\begin{array}{l}\text { Draftstopping sheathing behind tubs, } \\
\text { showers, and fireplaces, at chase "lids" } \\
\text { and the attic side of attic kneewalls. }\end{array}$ & $+\$ 90$ \\
\hline Airsealing & $\begin{array}{l}\text { Housewrap with joints taped, sill sealer, } \\
\text { caulk/foam at interior of sill plates, } \\
\text { foam around rough openings of } \\
\text { windows and doors, penetrations in } \\
\text { top plates. }\end{array}$ & $\begin{array}{l}\text { Same as standard practice with draftstopping } \\
\text { airsealed }\end{array}$ & $+\$ 0$ \\
\hline
\end{tabular}


Table 33 (continued). Cost of Tindall Home Compared to Standard Practice in New Jersey

\begin{tabular}{|c|c|c|c|}
\hline $\begin{array}{l}\text { MECHANICAL } \\
\text { SYSTEMS }\end{array}$ & STANDARD SPECIFICATIONS & $\begin{array}{l}\text { BUILDING AMERICA PROJECT } \\
\text { HOUSEI COMMUNITY SPECS }\end{array}$ & $\begin{array}{l}\text { COST } \\
\text { DIFFERENCE }\end{array}$ \\
\hline \multicolumn{4}{|l|}{ HVAC } \\
\hline Heating & $\begin{array}{l}2-92.1 \% \text { efficient gas furnaces. Both @ } 75,000 \\
\text { Btu/h input capacity. One furnace was located } \\
\text { in vented attic space. }\end{array}$ & $\begin{array}{l}2-92.1 \% \text { efficient gas furnaces in } \\
\text { conditioned basements. } \\
\text { First floor } 75,000 \text { Btu/h input } \\
\text { Second floor } 50,000 \text { Btu/h input }\end{array}$ & $-\$ 500$ \\
\hline Cooling & $\begin{array}{l}\text { Condensing units ( } 2 \text { ) are } 14 \text { SEER (nominal) } \\
\text { with a } 3 \text {-ton or } 3.5 \text {-ton capacity }\end{array}$ & $\begin{array}{l}\text { 1-13 SEER } 2.5 \text { ton unit } \\
\text { 1-14 SEER } 3 \text { ton unit }\end{array}$ & $-\$ 300$ \\
\hline Ducts & $\begin{array}{l}\text { Sheet metal or flex duct used for all ductwork. } \\
\text { R- } 6 \text { insulated flex duct used in unconditioned } \\
\text { attic. }\end{array}$ & $\begin{array}{l}\text { Sheet metal or flex duct used for all } \\
\text { ductwork. All ductwork in conditioned } \\
\text { space. Closer attention paid to air-sealing } \\
\text { ductwork with mastic. } 6 \% \text { total duct } \\
\text { leakage. }\end{array}$ & $+\$ 0$ \\
\hline Ventilation & $\begin{array}{l}\text { Mechanical ventilator is units located in the } \\
\text { basement and attic. The unit mixes outdoor air } \\
\text { drawn by the furnace fan with indoor air before } \\
\text { the air reaches the return air plenum. }\end{array}$ & Heat-recovery ventilator. & $+\$ 450$ \\
\hline $\begin{array}{l}\text { Structural } \\
\text { Integration }\end{array}$ & TGI floor joists & Open-web floor trusses & $+\$ 0$ \\
\hline Water Heating & $\begin{array}{l}\text { A power-vented } 75 \text {-gallon gas hot water heater } \\
\text { with } 76,000 \text { Btu/h input and energy factor of } \\
0.59\end{array}$ & $\begin{array}{l}\text { Two tankless water heaters with 15,000- } \\
180,000 \mathrm{Btu} / \mathrm{h} \text { input and energy factor of } \\
0.81\end{array}$ & $+1,700$ \\
\hline
\end{tabular}


Table 33 (continued). Cost of Tindall Home Compared to Standard Practice in New Jersey

\begin{tabular}{|c|c|c|c|}
\hline LIGHTING & STANDARD SPECIFICATIONS & $\begin{array}{l}\text { BUILDING AMERICA PROJECT HOUSEI } \\
\text { COMMUNITY SPECS }\end{array}$ & $\begin{array}{l}\text { COST } \\
\text { DIFFERENCE }\end{array}$ \\
\hline \multirow[t]{4}{*}{$\begin{array}{l}\text { \% Fluorescent / } \\
\% \text { Incandescent }\end{array}$} & $100 \%$ Incandescent & $\begin{array}{l}\text { 95\% Fluorescent (strip and compact) / 5\% } \\
\text { incandescent }\end{array}$ & $+\$ 500$ \\
\hline & & TOTAL COST DIFFERENCE without PV & $+\$ 16,290$ \\
\hline & & $\begin{array}{l}\text { Plus cost of } 2.64-\mathrm{kW} \text { grid-connected } \\
\text { photovoltaic system }\end{array}$ & $+\$ 12,000$ \\
\hline & & TOTAL COST DIFFERENCE with PV & $+\$ 28,290$ \\
\hline
\end{tabular}


Table 34 summarizes the incremental costs to the builder compared to their standard practice. While Tindall has invested approximately $\$ 16,290$ in first costs over their standard practice, the builder believes that the added cost is definitely worthwhile, in terms of energy efficiency, environmental impact, and customer satisfaction. Table 34 summarizes the cash-flow analysis for the buyer. Amortized costs are based on a 30-year mortgage at $7 \%$ interest. While the additional cost of the building practices to achieve the $43 \%$ energy savings costs the buyer approximately $\$ 1,296$ annually, they are saving \$1543 annually in energy costs. This translates to a net positive cash flow for the homeowner of $\$ 247$ per year.

Table 34. Tindall Legends at Mansfield Cash Flows

\begin{tabular}{ll}
\hline \hline Total Cost of Energy Efficient Upgrades & $\$ 16,290$ \\
Annual Amortized Costs & $\$ 1,296$ \\
Annual Energy Savings & $\$ 1,543$ \\
$\quad$ Net Savings & $\mathbf{\$} \mathbf{2 4 7}$ \\
\hline
\end{tabular}




\section{Appendix A: Passive Solar Design Considerations}

There are three primary passive design systems: direct gain, indirect gain, and sunrooms.

\section{Direct Gain}

In direct gain (Figure A-1), the sun shines directly into the house through windows, skylights, and clerestories. Depending on the amount and orientation of glazing, thermal mass materials may be needed in walls and floors to absorb the solar radiation and re-release it during the evening. Direct gain can also utilize a strategy called "sun tempering" where glazing is favored on the south side, but limited so that additional thermal mass is not necessary to prevent overheating of south-facing rooms.

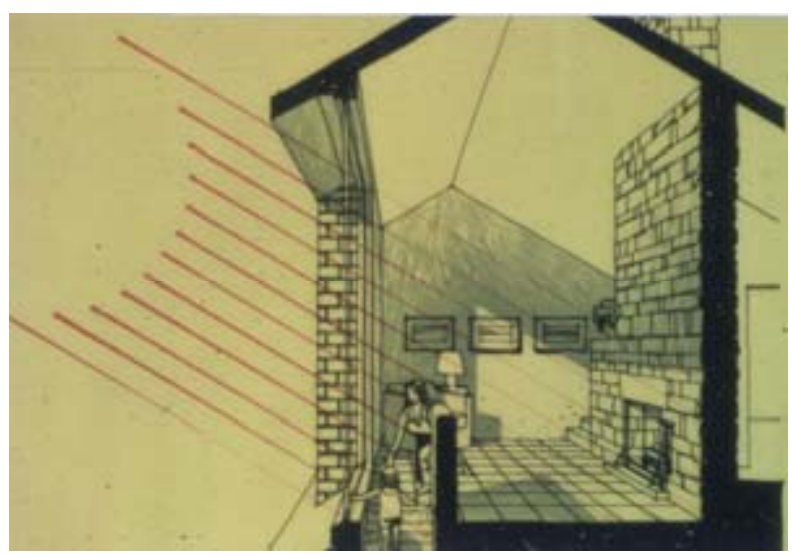

Figure A-1. Direct Solar Gain

\section{Indirect Gain}

Indirect gain (Figure A-2), also called thermal storage wall and Trombe Wall, consists of a thermal mass wall, with direct southern exposure. For example, a thermal storage wall could be a poured-in-place concrete wall or a concrete masonry block wall with the cores filled with concrete. One or more panes of glazing are located immediately on the outside of these mass walls. The outside surface of the mass wall is painted a dark color or coated with a selective surface, such as those used in active solar collectors.

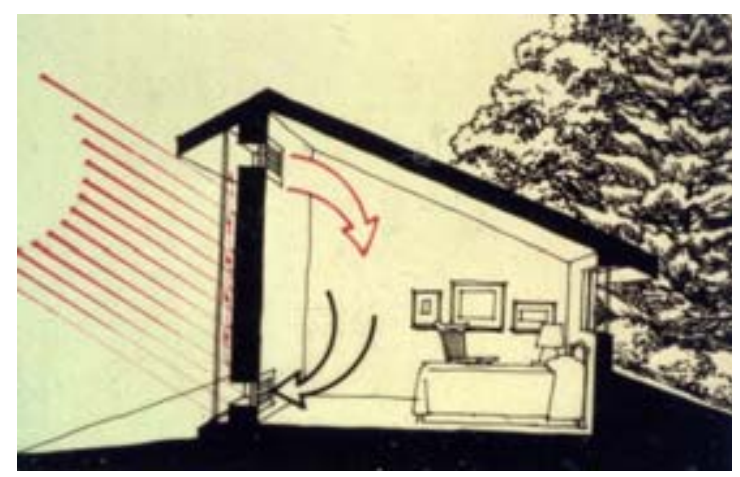

Figure A-2. Indirect Solar Gain 


\section{Sunroom}

Passive solar sunrooms (Figure A-3) can either be isolated or open to the rest of the home. Because of the large areas of glass, it is usually recommended that they include doors and windows that can be closed to isolate them from the rest of the house. In this configuration, the temperature in the sunroom can be permitted to go higher and lower than would be permitted within the home.

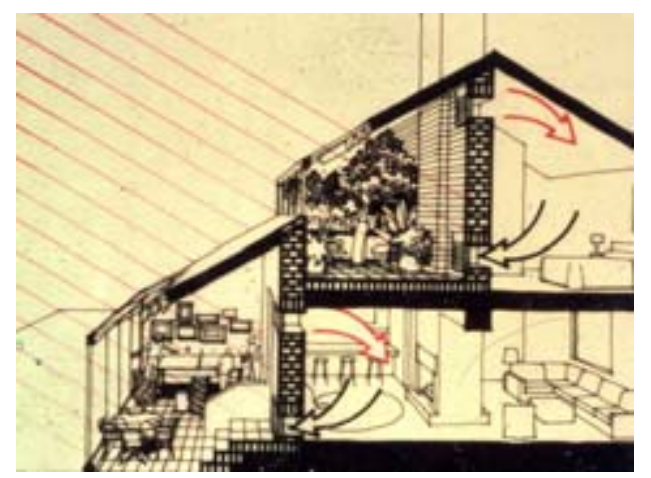

Figure A-3. Passive Solar Gain

To optimize the solar design of the house, which includes size of aperture, glazing performance characteristics (U-value and Solar Heat Gain Coefficient [SHGC]), by orientation, inclusion of mass, and house configuration, it is recommended that detailed energy simulations be undertaken. In general, if passive solar design is to be implemented, the following issues should be addressed, in the following order of importance:

- Site planning to allow for optimizing house orientation

- Orienting the house to optimize solar gains for heating and limiting solar gains during the cooling season. Orienting homes with longer sides and larger glazing areas facing north and south helps to minimize unwanted heat gain in summer and maximize beneficial solar heat gains in winter (Figure A-4).

Builders seeking to optimize individual home and lot orientation can follow these guidelines.

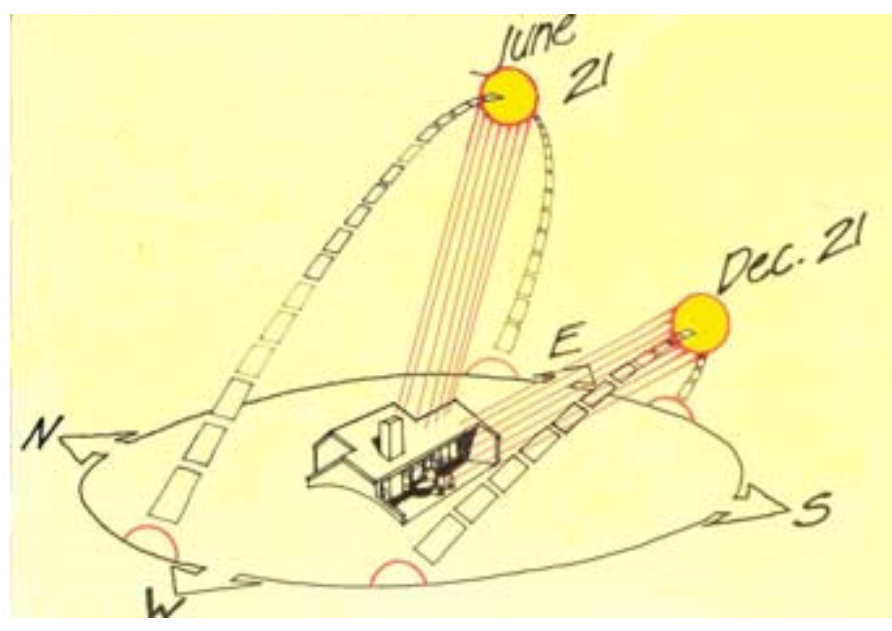

Figure A-4. The paths of the sun in winter and summer over a home with long sides facing north and south 
- Minimize East and West Glazing. Orienting homes so that the sides with the least glazing face east and west can significantly reduce cooling loads and reduce glare. Typically, afternoon sun shining in west windows is most important to minimize or to shade.

- North-south Orientation. Having the longer sides of homes facing north-south is beneficial for reducing both heating and cooling loads. In Mixed-Humid climates, having more glazing face south with adequate shading can minimize cooling and heating loads significantly; however, this must be carefully designed to prevent overheating and comfort complaints. South windows can most easily be shaded with overhangs.

- Architectural Design. Shape the architectural form and solar apertures of the houses to optimize passive solar heating, including appropriate mass to avoid localized overheating and summertime shading to mitigate cooling loads. This is best done in conjunction with hourly energy and room temperature modeling to assure energy savings and occupant comfort. Passive designs typically employ increased use of dense materials like concrete slab floors with tile and increased thickness of drywall or interior brick or concrete walls that have high thermal conductivity and high heat capacities. The increased mass can be as simple as replacing carpeted floors with inexpensive tile floors in slab-on-grade construction. If mass materials are warmed by winter sun and cooled with night ventilation systems in summer, they can add to comfort and reduce use of and consumption by conventional heating and cooling systems.

- Night Cooling: Locate openings to optimize airflow during temperate conditions and to facilitate "night flushing" of heat built up over the day during the relatively cooler evening hours.

Passive design may have a significant impact on the architectural character of the house and may be viewed in a positive or negative manner by builders and homebuyers. Passive strategies may be pursued as a trade-off for other energy improvements; however, careful consideration of occupant comfort must be taken into account. Effective passive solar heat gain can be very beneficial during the heating season, but it is challenging to design well and requires proper linkage of aperture and thermal storage in order to be useful and to avoid discomfort. Overheating can be a significant problem. Passive cooling, both by window shading and glass transmission characteristics, is very beneficial during the cooling season. Window shading can be very effective, but its proper design is critical, and the shading elements may have a strong visual impact on the exterior of the house. Thus, it is not a strategy that is thought to be universally appropriate at the 30\% improvement level. For more information on passive design strategies, see the Passive Solar Industries Council’s passive solar design guidelines. ${ }^{40}$

Architectural Shading Considerations. Shading, like orientation, is not required to achieve $30 \%$ savings, particularly with low-SHGC glazing. However, studies have shown that shading can cut solar heat gain by anywhere from $10 \%$ to $50 \%$. Blocking the sun's rays from striking glazing areas and heating up a home is much more efficient than using air conditioning to cool down an already overheated house.

“Architectural shading” is simple, does not need any maintenance, and may reduce costs

\footnotetext{
${ }^{40}$ Sustainable Building Industries Council. Passive Solar Design Strategies: Guidelines for Home Building. Sustainable Building Industries Council Website. www.psic.org
} 
compared to sophisticated shading devices. Incorporating shading methods into the home during the design phase ensures that a home receives the most effective shading. For example, providing properly designed overhangs shading the south glass adequately can reduce the heat gain during the summer while allowing for heat gain during the winter. Shading the west glass can also minimize the unwanted heat gains. A wide range of shading options is available, including the following:

- Overhangs on South Sides. Extending the roofline a few feet can create shade for a home's south-facing windows. Because sun angles drop in the winter months, south-facing overhangs will let the warming sun into the home when it is needed. Because of low sun angles in summer mornings and afternoons, overhangs on the east or west have little to no effect. Shades for east- or west-facing windows must have some vertical dimension, such as awnings or shade screens.

- Decks and Porches. Adding a covered deck or porch is an excellent way to shade a home and to add living space, too. Porches and covered decks should have enough of an overhang to shield the area from the high sun and still offer a view outside from the interior spaces.

- Awnings. Awnings provide excellent shading for south-, east-, and west-facing windows; awnings will block as much as $65 \%$ of the summer sun's heat $(77 \%$ on an east- or west-facing window), but they have the disadvantage of blocking the top half of the view from the window and reducing ventilation when windows are opened. Retractable canvas awnings can overcome this problem to some extent because they can be extended only when they are needed. This is especially helpful in winter months, when occupants want to let the sun in to warm their home.

- Louvers. Exterior louvers are attractive because their adjustable slats control the level of sunlight entering the building and, depending on the design, can be manually adjusted from inside or outside. The slats can be vertical or horizontal. Louvers remain fixed and are attached to the exteriors of window frames. Careful attention to the louver angle can allow significant winter sun penetration while still excluding all sun in summer.

- Exterior Shade Screens. Retractable shade screens are a good choice for windows that receive direct sunlight. They work much like an inside window shade, except that they are attached to the outside of the window. Most shade-screen manufacturers offer automatic controls for these products. The screens are installed at the top of the window and can be lowered during sunny days and retracted when not needed. Shade screens are generally custom-made. They are a good choice for a homeowner who wants to retrofit for energy efficiency but still wants to see out of a window that gets lots of sun throughout the day. The downside of shade screens is that they can darken the view when pulled down.

\section{Designing Shading Systems}

The following design recommendations generally hold true for properly designed shading devices:

- Use fixed overhangs on south-facing glass to control direct-beam solar radiation. Indirect (diffuse) radiation should be controlled by other measures, such as low-e glazing. 
- To the greatest extent possible, limit the amount of east and west glass because it is harder to shade than south glass. Consider the use of landscaping to shade east and west exposures, awnings, exterior shade screens, or interior highly reflective shades.

- Do not worry about shading north-facing glass because it receives very little direct solar gain.

- Shading affects daylighting; consider both simultaneously. For example, a light shelf bounces natural light deeply into a room through high windows while shading lower windows.

- Do not expect interior shading devices such as Venetian blinds or vertical louvers to reduce cooling loads because the solar gain has already been admitted into the living space. However, these interior devices do offer glare control and can contribute to visual acuity and visual comfort.

- An understanding of sun angles is critical to selecting shading devices.

- Carefully consider the durability of shading devices. Over time, operable shading devices can require a considerable amount of maintenance and repair.

- When relying on landscape elements for shading, be sure to consider the cost of landscape maintenance and upkeep on life-cycle cost.

Shading strategies that work well at one latitude, may be completely inappropriate for other sites at different latitudes. Be careful when applying shading ideas from one project to another. 


\section{Appendix B: Detailed BEopt Analysis Assumptions}

\section{BEopt Cost and Performance Input Assumptions}

As with any analysis study, the results of the analysis are subject to the assumptions used during the study. The cost and performance assumptions used in the present study are documented in this Appendix. These assumptions will be updated on a regular basis as new information becomes available from residential field studies. The use of specific manufacturer names in this Appendix does not represent an endorsement or recommendation for use of a specific product. This Appendix is limited to categories that include multiple options specific to the optimizations performed and may not representative of all the possible options currently available within BEopt.

Table B.1. Utility and Onsite Power Inputs

\begin{tabular}{|c|c|c|c|}
\hline Group & Input Variable & Value & Units \\
\hline \multirow[t]{9}{*}{ Economics } & Electricity Source/Site Ratio & 3.16 & \\
\hline & Electricity Cost & 0.0632 & $\$ / k W h$ \\
\hline & Natural Gas Cost & 1.023 & $\$ /$ therm \\
\hline & Discount Rate & 0.05 & \\
\hline & Mortgage Interest Rate & 0.08 & \\
\hline & Marginal Income Tax Rate & 0.28 & \\
\hline & Analysis Period & 30 & years \\
\hline & $\begin{array}{l}\text { Net Metered Excess Sellback } \\
\text { Rate }\end{array}$ & Local electric rate & $\$ / \mathrm{kWh}$ \\
\hline & Efficiency Cost Multiplier & 1 & \\
\hline \multirow[t]{5}{*}{ Photovoltaics } & Module & Sharp NEH120E1 & \\
\hline & Installed Cost & $\begin{array}{l}7.5 \text { (unless noted } \\
\text { otherwise) }\end{array}$ & $\$ /$ rated W \\
\hline & Derate Factor & Determined by location & $\%$ \\
\hline & Daily Incident Solar & Determined by location & $\mathrm{kWh} / \mathrm{m}^{2}$ \\
\hline & Average System Efficiency & Determined by location & $\%$ \\
\hline
\end{tabular}


Table B.2. BEopt Cost Assumptions

\begin{tabular}{|c|c|}
\hline Category/Option & Unit Cost \\
\hline Basement Insulation & $(\$ / f t)$ \\
\hline Uninsulated & $\$ 0.00$ \\
\hline 4-ft R-5 Exterior & $\$ 0.42$ \\
\hline 4-ft R-10 Exterior & $\$ 0.77$ \\
\hline 8-ft R-10 Exterior & $\$ 0.77$ \\
\hline 8-ft R-15 Exterior & $\$ 1.12$ \\
\hline 8-ft R-20 Exterior & $\$ 1.23$ \\
\hline Wall Construction & $\left(\$ / \mathrm{ft}^{2}\right)$ \\
\hline R-11 batts, $2 \times 4,16$ in. oc & $\$ 3.15$ \\
\hline $\mathrm{R}-13$ batts, $2 \times 4,16$ in. oc & $\$ 3.17$ \\
\hline R-11 batts, $2 \times 4,16$ in. oc +1 -in. foam sheathing & $\$ 3.92$ \\
\hline $\mathrm{R}-19$ batts, $2 \times 6,24$ in. oc & $\$ 3.28$ \\
\hline R-19 batts, $2 \times 6,24$ in. oc +1 -in. foam sheathing & $\$ 4.05$ \\
\hline R-19 batts, $2 \times 6,24$ in. oc +2 -in. foam sheathing & $\$ 4.24$ \\
\hline Ceiling Insulation & $\left(\$ / \mathrm{ft}^{2}\right)$ \\
\hline R-30 Fiberglass & $\$ 0.55$ \\
\hline R-40 Fiberglass & $\$ 0.73$ \\
\hline R-50 Fiberglass & $\$ 0.92$ \\
\hline R-60 Fiberglass & $\$ 1.10$ \\
\hline
\end{tabular}




\section{Table B.2 (continued). BEopt Cost Assumptions}

CategorylOption

Thermal Mass

Standard $1 / 2$-in. Ceiling Drywall

5/8-in. Ceiling Drywall

$2 \times 1 / 2$-in. Ceiling Drywall

$2 \times 5 / 8$-in. Ceiling Drywall

Infiltration

Typical (SLA $=0.0005)$

Tight $(\mathrm{SLA}=0.0003)$

\section{Windows}

Two-pane clear, $\mathrm{U}=0.49, \mathrm{SHGC}=0.76$

Center of Glass, insulated spacer, vinyl frame

Low-e $(e=0.01)$, double-pane, $U=0.32$, SHGC $=$

0.64 Center of Glass, insulated spacer, vinyl frame

Low-e (e = $0.1 \mathrm{w} /$ tint), double-pane, $\mathrm{U}=0.31$, SHGC $=0.37$, Center of Glass, insulated spacer, vinyl frame

Low-e $(e=0.04)$, double-pane, $U=0.3$, SHGC =

0.44 Center of Glass, insulated spacer, vinyl frame

Low-e (e $=0.04 \mathrm{w} /$ tint), double-pane, $\mathrm{U}=0.29$, SHGC $=0.29$ Center of Glass, insulated spacer, vinyl frame

Heat Mirror (HM22), $U=0.21, \mathrm{SHGC}=0.14$, Center of Glass, insulated spacer, Vinyl frame

Heat Mirror (HM TC88), U $=0.18, \mathrm{SHGC}=0.48$,

Center of Glass, insulated spacer, vinyl frame
$\$ 24.77$

Unit Cost

$\left(\$ / \mathrm{ft}^{2}\right)$

$\$ 0.19$

$\$ 0.27$

$\$ 0.38$

$\$ 0.54$

$\left(\$ / \mathrm{ft}^{2}\right)$

$\$ 0.00$

$\$ 0.54$

$\left(\$ / \mathrm{ft}^{2}\right)$

$\$ 21.99$

$\$ 24.77$

$\$ 24.77$

$\$ 24.77$

$\$ 30.32$

$\$ 30.32$ 


\section{Table B.2 (continued). BEopt Cost Assumptions}

\begin{tabular}{|c|c|}
\hline Category/Option & Unit Cost \\
\hline Refrigerator & (\$/unit) \\
\hline Standard - 671 kWh/yr & $\$ 1,099.99$ \\
\hline ENERGY STAR - 572 kWh/yr & $\$ 1,219.99$ \\
\hline Dishwasher & (\$/unit) \\
\hline $\begin{array}{l}\text { Standard, } 462 \mathrm{kWh} \text {, eight place setting capacity, } \\
131.6 \mathrm{kWh} / \mathrm{yr} \text { machine energy, } 5.39 \text { gal/day DHW }\end{array}$ & $\$ 239.00$ \\
\hline $\begin{array}{l}\text { ENERGY STAR, } 384 \mathrm{kWh} / \mathrm{yr} \text {, eight place setting } \\
\text { capacity, } 82.2 \mathrm{kWh} / \mathrm{yr} \text { machine energy, } 3.76 \mathrm{gal} / \mathrm{day} \\
\text { DHW }\end{array}$ & $\$ 299.00$ \\
\hline Clothes Washer & (\$/unit) \\
\hline $\begin{array}{l}\text { Standard, } 3.15 \mathrm{ft}^{3}, 533 \mathrm{kWh} / \mathrm{yr}, 1.16 \mathrm{MEF} \text {, } \\
65.6 \mathrm{kWh} / \mathrm{yr} \text { machine energy, } 4.63 \mathrm{gal} / \mathrm{day} \mathrm{DHW}\end{array}$ & $\$ 419.00$ \\
\hline $\begin{array}{l}\text { ENERGY STAR, top loader, } \mathrm{H} \text {-axis, } 2.9 \mathrm{ft}^{3} \text {, } \\
273 \mathrm{kWh} / \mathrm{yr}, 1.68 \mathrm{MEF}, 72.9 \mathrm{kWh} / \mathrm{yr} \text { machine energy, } \\
3.71 \mathrm{gal} / \mathrm{day} \mathrm{DHW}\end{array}$ & $\$ 799.00$ \\
\hline Lighting & (\$/bulb) \\
\hline Incandescent & $\$ 0.25$ \\
\hline CFL & $\$ 7.99$ \\
\hline
\end{tabular}




\section{Table B.2 (continued). BEopt Cost Assumptions}

\begin{tabular}{|c|c|c|}
\hline Category/Option & \multicolumn{2}{|c|}{ Unit Cost } \\
\hline Air Conditioner SEER value & \multicolumn{2}{|c|}{$\begin{array}{c}\text { Efficiency Cost }(\$)= \\
0.817^{*}\left(\left(186^{*} \text { SEERvalue }\right)-1535\right)\end{array}$} \\
\hline 10 & $\$$ & 265.53 \\
\hline 12 & $\$$ & 569.45 \\
\hline 13 & $\$$ & 721.41 \\
\hline 14 & $\$$ & 873.37 \\
\hline 15 & \multicolumn{2}{|c|}{$\$ 1,025.34$} \\
\hline 16 & \multicolumn{2}{|c|}{$\$ 1,177.30$} \\
\hline 17 & \multicolumn{2}{|c|}{$\$ 1,329.26$} \\
\hline 18 & \multicolumn{2}{|c|}{$\$ 1,481.22$} \\
\hline Air Conditioner Capacity (tons) & \multicolumn{2}{|c|}{$\begin{array}{l}\text { Capacity Cost }(\$)= \\
0.817^{*}\left(563^{*} \text { tons }\right)\end{array}$} \\
\hline 0.5 & \multicolumn{2}{|c|}{$\$ 229.99$} \\
\hline 1.0 & \multicolumn{2}{|c|}{$\$ 459.97$} \\
\hline 1.5 & \multicolumn{2}{|c|}{$\$ \quad 689.96$} \\
\hline 2.0 & \multicolumn{2}{|c|}{$\$ 919.94$} \\
\hline 2.5 & \multicolumn{2}{|c|}{$\$ 1,149.93$} \\
\hline 3.0 & \multicolumn{2}{|c|}{$\$ 1,379.91$} \\
\hline 3.5 & \multicolumn{2}{|c|}{$\$ 1,609.90$} \\
\hline 4.0 & \multicolumn{2}{|c|}{$\$ 1,839.88$} \\
\hline
\end{tabular}




\section{Table B.2 (continued). BEopt Cost Assumptions}

\begin{tabular}{|c|c|}
\hline Category/Option & Unit Cost \\
\hline Furnace Efficiency (\% AFUE) & $\begin{array}{c}\text { Efficiency Cost }(\$)= \\
\left(23.57^{*} \text { AFUE\%*100)-1621 }\right.\end{array}$ \\
\hline $80 \%$ & $\$ 264.60$ \\
\hline $92.5 \%$ & $\$ 559.23$ \\
\hline Furnace Capacity (kBtu/hr) & Capacity Cost $(\$)=2.92^{*} \mathrm{kBtu} / \mathrm{hr}$ \\
\hline $25 \mathrm{kBtu} / \mathrm{hr}$ & $\$ 73.00$ \\
\hline $50 \mathrm{kBtu} / \mathrm{hr}$ & $\$ 146.00$ \\
\hline $75 \mathrm{kBtu} / \mathrm{hr}$ & $\$ 219.00$ \\
\hline $100 \mathrm{kBtu} / \mathrm{hr}$ & $\$ 292.00$ \\
\hline $125 \mathrm{kBtu} / \mathrm{hr}$ & $\$ 365.00$ \\
\hline $150 \mathrm{kBtu} / \mathrm{hr}$ & $\$ 438.00$ \\
\hline $175 \mathrm{kBtu} / \mathrm{hr}$ & $\$ 511.00$ \\
\hline $200 \mathrm{kBtu} / \mathrm{hr}$ & $\$ 584.00$ \\
\hline Water Heater & (\$/unit, install + equip) \\
\hline Gas Standard, 40 gallons, 0.55 EF & $\$ 428.00$ \\
\hline Gas Premium, 40 gallon , $0.62 \mathrm{EF}$ & $\$ 624.08$ \\
\hline Gas Tankless, 0.84 EF & $\$ 1,050.00$ \\
\hline Ducts & $\left(\$ / f^{2} F F A\right)$ \\
\hline $\begin{array}{l}\text { Typical, SA leakage }=10 \% \\
\text { OA leakage }=2.3 \% \text { of fan flow }\end{array}$ & $\$ 0.45$ \\
\hline $\begin{array}{l}\text { Improved, SA leakage }=2.3 \% \text {, } \\
\text { OA leakage }=0.5 \% \text { of fan flow }\end{array}$ & $\$ 0.69$ \\
\hline $\begin{array}{l}\text { Inside Conditioned Space, SA leakage }=1 \% \text {, } \\
\text { OA leakage }=0.23 \% \text { of fan flow }\end{array}$ & $\$ 0.77$ \\
\hline
\end{tabular}




\section{Appendix C. List of Key Trade-based Certifications}

\section{Preferred Contractors Program Draft}

Below is a preliminary list of the different trade classifications and the sub-specializations that could be associated with a new-home certified contractors program. The concept is to have a broad range of specialist classifications and to acknowledge the fragmentation and specialization that is inherent in the construction industry. This encourages even those trades who do a very limited scope of work (i.e., just window installation or just duct rough in) to become certified specialists in their field, which requires them to also have a broader understanding of how that piece fits into the bigger house as a system. This concept will need to be discussed with manufacturers and trade contractors to determine its practicality.

- HVAC

o Load-calculation, Ventilation, and Equipment-selection Specialist

o Duct-Design Specialist

o Air-Distribution System-Installation Specialist

o Equipment-Installation and Start-up Specialist

- Fossil fuel and electric heating

- Refrigeration

- AC / Heat Pump

o Airflow-Balancing Specialist

- Carpentry

o Framing Specialist

- Thermal envelope

o Insulation Specialist

0 Air-sealing Specialist

- Above-grade Moisture Management

o Window- and Door-Installation Specialist

o Wall-Drainage-Plane Specialist

o Roof-Drainage and Flashing Specialist

- Below-grade Moisture Management

o Below-Grade Moisture-Management Specialist

- Designers

o Architect / Residential Designer

o Engineer 
Within each of the specializations is a more detailed description of the probable roles and competencies required.

\section{HVAC}

- Load-calculation, Ventilation, and Equipment-selection Specialist

o Proficiency in ACCA Manual J method for load calculation and how to account for higher performance when calculating heating and cooling loads

o Understands relationship between high-performance house (thermal-envelope strategies to achieve high-performance homes) and heating and cooling loads to be satisfied by the space-conditioning equipment

o Surface-area competencies and understanding of thermal-envelope assemblies (i.e., framing factors, window properties, etc.)

o Understands the types of ventilation systems and their interaction with the heating and cooling equipment

o Understands dedicated humidity-control options and how to integrate with spaceconditioning systems

o Understands the internal gains and latent loads associated with people and ventilation

o Understands the impact of climate, shading, and other environmental impacts on the building

- Duct-Design Specialist

o Understands the impact of duct friction with respect to airflows (equivalent length methods - ACCA Manual D)

0 Familiarity with structural systems and limitations regarding using running-duct systems within structural systems (floor framing systems, walls, etc.)

o Air-distribution options in higher performance homes (high sidewall, central return, etc.)

o Acoustics of air-distribution systems

- Air-Distribution System-Installation Specialist

o Follows layout by Duct-Design Specialist

o Understands duct-dealing techniques

o Understands ventilation-system concepts as they relate to ducts and equipmentinstallation issues

o Certified in duct-system leakage testing

o Sets furnace and inside AC coils as part of air system 
- Equipment-Installation and Start-up Specialists

o Installation of equipment and associated refrigeration

o Start-up and commissioning of heating, cooling, and ventilation systems

- Airflow-Balancing Specialist

o Airflow at the equipment

o Total-system duct-leakage testing

o Room-by-room airflow balancing and measurement

\section{Carpentry}

- Framing Specialist

o Optimum-value engineering of wood-frame structures

- Stack framing

- Wall layout and value-engineering wall-framing techniques

- Floor framing and interaction with HVAC system and plumbing system

- Structural and code limitations

o Air-sealing techniques incorporated during framing (i.e., band-joist gluing and sealing, mud-sill sealing, cantilevers, floors over garages, chases, etc.)

\section{Thermal envelope}

- Insulation Specialist

o Insulation basics

o How insulation works

o Encapsulation requirements

o Types of insulation products, limitations, and applications

o Insulation and flame-spread issues

o Blown-in wall techniques (new and retrofit)

o Damp spray

o Net and fill cavity

o Two-hole method

o Hole and tube (dense pack)

o Blown attic and horizontal cavity (floor, cantilever, etc.)

o Batt installation

o Below-grade insulation systems (interior) 
o Crawl-space vapor-barrier installation

o Sub-Specialist designation

- Air-Sealing Specialist

o Envelope air-tightening techniques

o Window and door rough openings

o Framing intersections

o Bypasses / chases / soffits

o Cantilevers, floors over unconditioned spaces

o Fire codes and safety

o Diagnostics

o Blower door

o Pre- and post-testing

o Blower-door directed air-sealing techniques

o Infrared imaging

o Pressure diagnostics

\section{Above-grade Moisture Management}

- Window- and Door-Installation Specialist

o Flashings

o Integration to drainage plane

- Wall-Drainage-Plane Specialist

o Drainage-plane installation

o Integration with windows and doors

o Integration with roof-flashing systems

o Roof-flashing systems at wall intersections

- Roof-Drainage and Flashing Specialist

o Roof-penetration flashings

o Roof-wall flashing systems

o Integration to wall systems

o Gutter and downspouts 


\section{Below-grade Moisture Management}

- Below-Grade Moisture Management Specialist

o Perimeter drainage systems

o Sub-slab capillary break and vapor-diffusion control

o Capillary break at footing

o Vapor barrier at crawl spaces

o Foundation damp-proofing systems

o Foundation waterproofing systems

\section{Designers}

- Architect / Residential Designer

- Engineer 
Appendix D: National Housing Quality Rating Table

Table D.1. Leadership

Leaders align everyone in the organization with a common purpose, values, and priorities.

\begin{tabular}{|c|c|c|c|c|c|c|c|c|}
\hline & Level 1 & Level 2 & Level 3 & IBACOS Level 3 & Level 4 & IBACOS Level 4 & Level 5 & IBACOS Level 5 \\
\hline $\begin{array}{l}1.1 \\
\text { Company } \\
\text { Mission, } \\
\text { Vision, and } \\
\text { Values }\end{array}$ & $\begin{array}{l}\text { Company's main } \\
\text { quality goal is to } \\
\text { avoid customer } \\
\text { disappointment } \\
\text { and complaints. }\end{array}$ & $\begin{array}{l}\text { Quality and customer } \\
\text { satisfaction is important } \\
\text { to the company but not } \\
\text { included in a written } \\
\text { mission statement. }\end{array}$ & $\begin{array}{l}\text { Written company } \\
\text { mission statement } \\
\text { includes a } \\
\text { commitment to quality } \\
\text { and customer } \\
\text { satisfaction. }\end{array}$ & $\begin{array}{l}\text { Quality is defined in } \\
\text { the five key } \\
\text { performance metrics } \\
\text { (Health, Safety, } \\
\text { Durability, Efficiency \& } \\
\text { Comfort) with } \\
\text { measurable attributes } \\
\text { associated with the } \\
\text { definition. }\end{array}$ & $\begin{array}{l}\text { In addition to level } 3 \text {, } \\
\text { values or principles } \\
\text { important to the } \\
\text { company are included } \\
\text { in a written statement. }\end{array}$ & $\begin{array}{l}\text { Performance metrics } \\
\text { of competition is } \\
\text { Benchmarked and } \\
\text { three of five area } \\
\text { exceed Benchmark } \\
\text { industry standards }\end{array}$ & $\begin{array}{l}\text { In addition to level } 4 \text {, } \\
\text { there is a compelling } \\
\text { future vision of what the } \\
\text { company can become. }\end{array}$ & $\begin{array}{l}\text { Vision is created with } \\
\text { stretch goals for all } \\
\text { five performance } \\
\text { metrics }\end{array}$ \\
\hline $\begin{array}{l}1.2 \\
\text { Senior } \\
\text { Management } \\
\text { Involvement }\end{array}$ & $\begin{array}{l}\text { Senior managers } \\
\text { get involved with } \\
\text { quality to handle } \\
\text { customer } \\
\text { complaints. }\end{array}$ & $\begin{array}{l}\text { Senior managers like } \\
\text { the idea of quality but } \\
\text { are not involved in } \\
\text { improvement activities. }\end{array}$ & $\begin{array}{l}\text { Senior managers } \\
\text { demonstrate personal } \\
\text { commitment to the } \\
\text { company's quality } \\
\text { mission and are often } \\
\text { involved in quality- } \\
\text { related activities }\end{array}$ & $\begin{array}{l}\text { Performance attributes } \\
\text { are given equal weight } \\
\text { to other quality criteria. } \\
\text { Quality Management is } \\
\text { a cross-cutting } \\
\text { management function }\end{array}$ & $\begin{array}{l}\text { Senior managers } \\
\text { constantly } \\
\text { communicate the } \\
\text { company's quality } \\
\text { mission to customers, } \\
\text { employees, and trade } \\
\text { contractors. }\end{array}$ & $\begin{array}{l}\text { One point of contact } \\
\text { for managing the } \\
\text { performance attributes } \\
\text { of the home from pre- } \\
\text { design through } \\
\text { warrantee. Goals of all } \\
\text { Senior managers tied } \\
\text { to achieving } \\
\text { performance metrics }\end{array}$ & $\begin{array}{l}\text { In addition to level } 4 \text {, } \\
\text { managers and } \\
\text { supervisors at all levels } \\
\text { are actively engaged in } \\
\text { reinforcing the company } \\
\text { mission, vision, and } \\
\text { values. }\end{array}$ & $\begin{array}{l}\text { All team members are } \\
\text { reinforcing } \\
\text { performance attributes } \\
\text { at all phases and } \\
\text { stages of product }\end{array}$ \\
\hline $\begin{array}{l}1.3 \\
\text { Leadership } \\
\text { Feedback and } \\
\text { Improvement }\end{array}$ & $\begin{array}{l}\text { Senior } \\
\text { management } \\
\text { uses their } \\
\text { experience to } \\
\text { guide the } \\
\text { company toward } \\
\text { their vision for the } \\
\text { future. }\end{array}$ & $\begin{array}{l}\text { Senior managers } \\
\text { actively seek employee } \\
\text { feedback to gauge the } \\
\text { organization's } \\
\text { alignment toward the } \\
\text { company mission, } \\
\text { vision, and values. }\end{array}$ & $\begin{array}{l}\text { In addition to level } 2 \text {, } \\
\text { surveys measure the } \\
\text { alignment of employee } \\
\text { values and beliefs } \\
\text { toward those of the } \\
\text { organization. }\end{array}$ & $\begin{array}{l}\text { Performance metrics } \\
\text { are included in survey }\end{array}$ & $\begin{array}{l}\text { In addition to level } 3 \text {, } \\
\text { senior managers plan } \\
\text { initiatives to reinforce } \\
\text { the company mission, } \\
\text { vision, and values. }\end{array}$ & $\begin{array}{l}\text { Performance metrics } \\
\text { are included in } \\
\text { initiatives }\end{array}$ & $\begin{array}{l}\text { In addition to level } 4 \text {, the } \\
\text { leadership function is } \\
\text { managed as a process } \\
\text { that is continuously } \\
\text { improved through } \\
\text { evaluation, adjustment, } \\
\text { and verification of } \\
\text { results. }\end{array}$ & $\begin{array}{l}\text { Performance } \\
\text { achievements in } \\
\text { homes is used as one } \\
\text { measure of leadership } \\
\text { success }\end{array}$ \\
\hline
\end{tabular}


Table D.1 (continued). Leadership

\begin{tabular}{|c|c|c|c|c|c|c|c|c|}
\hline & Level 1 & Level 2 & Level 3 & IBACOS Level 3 & Level 4 & IBACOS Level 4 & Level 5 & IBACOS Level 5 \\
\hline $\begin{array}{l}1.4 \\
\text { Living the Mission }\end{array}$ & $\begin{array}{l}\text { Employees may } \\
\text { have different } \\
\text { priorities but there } \\
\text { is a general } \\
\text { understanding of } \\
\text { what the company } \\
\text { is trying to } \\
\text { accomplish. }\end{array}$ & $\begin{array}{l}\text { Most employees know } \\
\text { key elements of the } \\
\text { company mission, } \\
\text { values, and vision for } \\
\text { the future and could } \\
\text { explain how it relates } \\
\text { to their job. }\end{array}$ & $\begin{array}{l}\text { Most employees } \\
\text { recognize and support } \\
\text { organizational } \\
\text { mission, values, and } \\
\text { vision, and use them } \\
\text { to guide their decision } \\
\text { making. }\end{array}$ & $\begin{array}{l}\text { Performance metrics } \\
\text { are instilled as one } \\
\text { component that is } \\
\text { used in decision } \\
\text { making }\end{array}$ & $\begin{array}{l}\text { In addition to level } 3 \text {, } \\
\text { survey data shows } \\
\text { that most employees } \\
\text { embrace the company } \\
\text { mission, vision, and } \\
\text { values. } \\
\text { There is a strong } \\
\text { feeling that everyone } \\
\text { is working toward } \\
\text { common goals. }\end{array}$ & $\begin{array}{l}\text { Survey includes } \\
\text { performance metrics } \\
\text { and evaluates } \\
\text { employee } \\
\text { understanding and } \\
\text { implementation of } \\
\text { performance attributes }\end{array}$ & $\begin{array}{l}\text { In addition to level } 4 \text {, } \\
\text { employees actively } \\
\text { reinforce the company } \\
\text { mission, vision, and } \\
\text { values among } \\
\text { themselves during the } \\
\text { course of everyday } \\
\text { work. }\end{array}$ & $\begin{array}{l}\text { Employees are } \\
\text { empowered and } \\
\text { rewarded for } \\
\text { achieving } \\
\text { performance metrics. }\end{array}$ \\
\hline $\begin{array}{l}1.5 \\
\text { Public } \\
\text { Responsibility }\end{array}$ & $\begin{array}{l}\text { Some people at } \\
\text { the company are } \\
\text { personally involved } \\
\text { in activities that } \\
\text { benefit the } \\
\text { community, the } \\
\text { public, or the } \\
\text { housing industry. }\end{array}$ & $\begin{array}{l}\text { When asked, the } \\
\text { company supports } \\
\text { activities to benefit the } \\
\text { community, the public, } \\
\text { or the housing } \\
\text { industry. }\end{array}$ & $\begin{array}{l}\text { Being a responsible } \\
\text { corporate citizen is } \\
\text { regarded as good for } \\
\text { the company. } \\
\text { The company is } \\
\text { actively involved in } \\
\text { activities to benefit the } \\
\text { community, the public, } \\
\text { or the housing } \\
\text { industry. }\end{array}$ & $\begin{array}{l}\text { Company involvement } \\
\text { is related to } \\
\text { performance metrics }\end{array}$ & $\begin{array}{l}\text { In addition to level } 3 \text {, } \\
\text { the company creates } \\
\text { opportunities to be } \\
\text { actively involved in } \\
\text { activities to benefit the } \\
\text { community, the public, } \\
\text { or the housing } \\
\text { industry. }\end{array}$ & $\begin{array}{l}\text { Company initiatives } \\
\text { action that related to } \\
\text { performance metrics }\end{array}$ & $\begin{array}{l}\text { For its size, the } \\
\text { company is one of the } \\
\text { area's leading } \\
\text { business supporters of } \\
\text { activities to benefit the } \\
\text { community, the public, } \\
\text { or the housing } \\
\text { industry. }\end{array}$ & $\begin{array}{l}\text { Company is a } \\
\text { regional or national } \\
\text { leader in supporting } \\
\text { initiatives related to } \\
\text { performance metrics }\end{array}$ \\
\hline
\end{tabular}

Note: Yellow denotes minimum level for considering adopting a 30\% whole-house energy-savings solution set. 
Table D.2. Strategic Planning

Achieving a future vision of what the company can become requires creating and executing a strategic plan for getting there.

\begin{tabular}{|c|c|c|c|c|c|c|c|c|}
\hline & Level 1 & Level 2 & Level 3 & IBACOS Level 3 & Level 4 & IBACOS Level 4 & Level 5 & IBACOS Level 5 \\
\hline $\begin{array}{l}2.1 \\
\text { Company-wide } \\
\text { Success Drivers } \\
\text { and Performance } \\
\text { Measures. }\end{array}$ & $\begin{array}{l}\text { Measures of } \\
\text { company } \\
\text { performance are } \\
\text { limited to sales } \\
\text { and profit. }\end{array}$ & $\begin{array}{l}\text { In addition to level } 1 \text {, } \\
\text { customer } \\
\text { satisfaction is } \\
\text { important, but } \\
\text { performance data is } \\
\text { not tracked. }\end{array}$ & $\begin{array}{l}\text { The current customer } \\
\text { satisfaction rating is one } \\
\text { of the company's } \\
\text { monthly performance } \\
\text { measures } \\
\text { communicated to all } \\
\text { employees. }\end{array}$ & $\begin{array}{l}\text { Customer satisfaction } \\
\text { measurements include } \\
\text { consumer feedback on } \\
\text { performance metrics, } \\
\text { and limited testing to } \\
\text { verify performance } \\
\text { metrics are being } \\
\text { achieved }\end{array}$ & $\begin{array}{l}\text { In addition to level } 3 \text {, } \\
\text { company-wide } \\
\text { performance } \\
\text { measures link directly } \\
\text { to key success } \\
\text { drivers for achieving } \\
\text { the company mission } \\
\text { and vision. }\end{array}$ & $\begin{array}{l}\text { Level } 3 \text { is } \\
\text { supplemented with } \\
\text { statistically valid } \\
\text { sampling plan is in } \\
\text { place to test } \\
\text { performance } \\
\text { metrics }\end{array}$ & $\begin{array}{l}\text { In addition to level } 4 \text {, } \\
\text { operational } \\
\text { performance measures } \\
\text { through all levels of the } \\
\text { company fully support } \\
\text { company-wide } \\
\text { performance measures. }\end{array}$ & $\begin{array}{l}100 \% \text { testing and } \\
\text { commissioning strategy }\end{array}$ \\
\hline $\begin{array}{l}2.2 \\
\text { Strategic Plans }\end{array}$ & $\begin{array}{l}\text { Company } \\
\text { improvement } \\
\text { strategy is to } \\
\text { increase sales } \\
\text { and reduce } \\
\text { costs, but } \\
\text { specific action } \\
\text { plans are not in } \\
\text { place. }\end{array}$ & $\begin{array}{l}\text { The company's } \\
\text { competitive } \\
\text { business strategy } \\
\text { includes improving } \\
\text { customer } \\
\text { satisfaction and } \\
\text { products that } \\
\text { enhance } \\
\text { homeowner value. }\end{array}$ & $\begin{array}{l}\text { In addition to level 2, } \\
\text { written improvement } \\
\text { plans are in place with } \\
\text { measurable goals. } \\
\text { Plans explain how } \\
\text { performance } \\
\text { improvement goals will } \\
\text { be achieved. }\end{array}$ & $\begin{array}{l}\text { Written improvement } \\
\text { plans include } \\
\text { performance standards } \\
\text { and testing } \\
\text { requirements. } \\
\text { Plan outlines cross } \\
\text { functional leader for } \\
\text { performance-based } \\
\text { quality initiative }\end{array}$ & $\begin{array}{l}\text { In addition to level 3, } \\
\text { strategic plans link } \\
\text { directly to } \\
\text { improvement of } \\
\text { company-wide } \\
\text { performance } \\
\text { measures and fully } \\
\text { support the } \\
\text { company's mission } \\
\text { and values. }\end{array}$ & $\begin{array}{l}\text { Performance } \\
\text { measures are } \\
\text { based in integrated } \\
\text { design and } \\
\text { construction } \\
\text { approach. }\end{array}$ & $\begin{array}{l}\text { In addition to level } 4 \text {, a } \\
\text { systematic approach is } \\
\text { in place for using factual } \\
\text { information and data to } \\
\text { plan improvements to } \\
\text { organizational } \\
\text { performance and } \\
\text { competitive position. }\end{array}$ & $\begin{array}{l}\text { Measured data form } \\
\text { preplanning through } \\
\text { warrantee costs are } \\
\text { tracked to evaluate total } \\
\text { system design } \\
\text { strategies and } \\
\text { implementation results }\end{array}$ \\
\hline $\begin{array}{l}2.3 \\
\text { Plan Deployment }\end{array}$ & $\begin{array}{l}\text { The senior } \\
\text { managers who } \\
\text { make the } \\
\text { strategic plans } \\
\text { also carry out } \\
\text { the improvement } \\
\text { initiatives. } \\
\text { Employees are } \\
\text { involved on an } \\
\text { as-needed basis. }\end{array}$ & $\begin{array}{l}\text { Senior managers } \\
\text { develop the } \\
\text { strategic plan with } \\
\text { some employee } \\
\text { input. } \\
\text { The plan is used to } \\
\text { set departmental } \\
\text { objectives. }\end{array}$ & $\begin{array}{l}\text { In addition to level } 2 \text {, } \\
\text { senior managers } \\
\text { organize employee } \\
\text { teams to carry out } \\
\text { improvement projects } \\
\text { that may involve } \\
\text { multiple departments. }\end{array}$ & & $\begin{array}{l}\text { A systematic process } \\
\text { is in place for } \\
\text { involving most } \\
\text { employees in the } \\
\text { development of } \\
\text { strategic objectives, } \\
\text { carrying out action } \\
\text { plans to achieve } \\
\text { them, and monitoring } \\
\text { progress. }\end{array}$ & $\begin{array}{l}\text { Most employees } \\
\text { are involved in the } \\
\text { performance } \\
\text { standards setting } \\
\text { process, and } \\
\text { understand the role } \\
\text { these standards } \\
\text { play within the } \\
\text { context of a larger } \\
\text { quality initiative }\end{array}$ & $\begin{array}{l}\text { In addition to level } 4 \text {, } \\
\text { trade contractors, } \\
\text { product suppliers, and } \\
\text { business partners are } \\
\text { involved in the } \\
\text { company's strategic } \\
\text { improvement process. }\end{array}$ & $\begin{array}{l}\text { Outside partners are an } \\
\text { integrated part of the } \\
\text { performance standard } \\
\text { setting and execution } \\
\text { process, particularly in } \\
\text { the design process and } \\
\text { construction phase. }\end{array}$ \\
\hline $\begin{array}{l}2.4 \\
\text { Monitoring } \\
\text { Progress to Plan }\end{array}$ & $\begin{array}{l}\text { Progress is } \\
\text { monitored on an } \\
\text { as-needed basis. }\end{array}$ & $\begin{array}{l}\text { Quarterly review } \\
\text { meetings monitor } \\
\text { improvement } \\
\text { progress. }\end{array}$ & $\begin{array}{l}\text { Monthly review } \\
\text { meetings monitor actual } \\
\text { versus planned } \\
\text { improvement activities. } \\
\text { Adjustments to plans } \\
\text { are made to } \\
\text { accommodate current } \\
\text { status. }\end{array}$ & $\begin{array}{l}\text { Measurements of key } \\
\text { performance attributes } \\
\text { are made to judge } \\
\text { achievement of goals }\end{array}$ & $\begin{array}{l}\text { In addition to level } 3 \text {, } \\
\text { measurement data is } \\
\text { used to monitor } \\
\text { performance toward } \\
\text { strategic objectives. }\end{array}$ & $\begin{array}{l}\text { Track data as a } \\
\text { function of design } \\
\text { effectiveness and } \\
\text { construction } \\
\text { improvements }\end{array}$ & $\begin{array}{l}\text { In addition to level } 4 \text {, } \\
\text { root causes of plan } \\
\text { variances are } \\
\text { systematically analyzed, } \\
\text { understood, and used to } \\
\text { prevent future problems } \\
\text { and project future } \\
\text { performance. }\end{array}$ & $\begin{array}{l}\text { Data is used to } \\
\text { feedback into design } \\
\text { process and records are } \\
\text { kept of unsuccessful } \\
\text { designs and reasons for } \\
\text { failure. }\end{array}$ \\
\hline
\end{tabular}

Note: Yellow denotes minimum level for considering adopting a 30\% whole-house energy-savings solution set. 
Table D.3. Customer Satisfaction

Sustaining high levels of customer satisfaction requires performing well from the customer's point of view.

\begin{tabular}{|c|c|c|c|c|c|c|c|c|}
\hline & Level 1 & Level 2 & Level 3 & IBACOS Level 3 & Level 4 & IBACOS Level 4 & Level 5 & IBACOS Level 5 \\
\hline $\begin{array}{l}\text { 3.1a } \\
\text { Market Research }\end{array}$ & $\begin{array}{l}\text { Market requirements } \\
\text { are learned mainly } \\
\text { from customer } \\
\text { requests. }\end{array}$ & $\begin{array}{l}\text { In addition to level 1, } \\
\text { market trends are } \\
\text { learned from tours of } \\
\text { other builders' products } \\
\text { and builder magazines. }\end{array}$ & $\begin{array}{l}\text { In addition to level 2, } \\
\text { detailed price and } \\
\text { feature comparisons } \\
\text { with other builders are } \\
\text { used to analyze } \\
\text { competitive position and } \\
\text { uncover unfilled market } \\
\text { niches. } \\
\text { Feedback from lost } \\
\text { customers is used to } \\
\text { analyze unfilled needs. }\end{array}$ & $\begin{array}{l}\text { Product is } \\
\text { Benchmarked } \\
\text { compared to national } \\
\text { and local standards. } \\
\text { Feedback strategies } \\
\text { also capture data } \\
\text { regarding performance } \\
\text { attributes }\end{array}$ & $\begin{array}{l}\text { In addition to level } 3 \text {, } \\
\text { markets are analyzed } \\
\text { by demographic groups. } \\
\text { Surveys or focus groups } \\
\text { identify customer } \\
\text { preferences for features } \\
\text { and services. }\end{array}$ & $\begin{array}{l}\text { Focus groups also } \\
\text { include exploration of } \\
\text { key performance } \\
\text { features in housing } \\
\text { according to company } \\
\text { 5-year stretch } \\
\text { performance goals }\end{array}$ & $\begin{array}{l}\text { In addition to level } 4 \text {, } \\
\text { the design of products } \\
\text { and services anticipate } \\
\text { market trends. They are } \\
\text { planned through } \\
\text { analysis of changing } \\
\text { demographics, } \\
\text { economic forecasts, } \\
\text { emerging technologies, } \\
\text { style trends, and other } \\
\text { leading indicators. }\end{array}$ & $\begin{array}{l}\text { Predictive analysis of } \\
\text { trends in building } \\
\text { performance, world } \\
\text { energy, and builder } \\
\text { litigation inform market } \\
\text { trends }\end{array}$ \\
\hline $\begin{array}{l}3.1 \mathrm{~b} \\
\text { Product Design } \\
\text { Processes }\end{array}$ & $\begin{array}{l}\text { A company expert } \\
\text { or consultants } \\
\text { create new home } \\
\text { designs. }\end{array}$ & $\begin{array}{l}\text { In addition to level } 1 \text {, } \\
\text { select employees } \\
\text { provide some input into } \\
\text { the design process. }\end{array}$ & $\begin{array}{l}\text { A new home design } \\
\text { team includes } \\
\text { construction and sales } \\
\text { personnel. }\end{array}$ & & $\begin{array}{l}\text { In addition to level 3, } \\
\text { homeowners, } \\
\text { employees, and trade } \\
\text { contractors are } \\
\text { systematically included } \\
\text { in the home design } \\
\text { process. }\end{array}$ & $\begin{array}{l}\text { Pre-design and } \\
\text { schematic design phase } \\
\text { activities are used to } \\
\text { incorporate a integrated } \\
\text { design process that } \\
\text { embraces a systems } \\
\text { approach to } \\
\text { performance }\end{array}$ & $\begin{array}{l}\text { In addition to level } 4, \text { a } \\
\text { process is in place to } \\
\text { regularly review existing } \\
\text { designs and feedback } \\
\text { from customers to make } \\
\text { design improvements. }\end{array}$ & $\begin{array}{l}\text { Existing product is } \\
\text { redesigned over time to } \\
\text { include more cost } \\
\text { effective implementation } \\
\text { of performance metrics }\end{array}$ \\
\hline $\begin{array}{l}3.2 \\
\text { Customer } \\
\text { Satisfaction Drivers }\end{array}$ & $\begin{array}{l}\text { Avoiding } \\
\text { homeowner } \\
\text { disappointment with } \\
\text { the constructed } \\
\text { product is the main } \\
\text { customer } \\
\text { satisfaction priority. }\end{array}$ & $\begin{array}{l}\text { Completing the home } \\
\text { on time with a short } \\
\text { punch list at final } \\
\text { inspection is the } \\
\text { company's main focus } \\
\text { for satisfying customers. }\end{array}$ & $\begin{array}{l}\text { In addition to level 2, } \\
\text { the customer } \\
\text { experience and } \\
\text { relationship with the } \\
\text { builder are important } \\
\text { customer satisfaction } \\
\text { drivers. } \\
\text { Meeting customer } \\
\text { expectations is } \\
\text { recognized as the key } \\
\text { to reliably satisfying } \\
\text { customers. }\end{array}$ & $\begin{array}{l}\text { Builder monitors } \\
\text { expectation set by other } \\
\text { builders, and seeks to } \\
\text { set similar consumer } \\
\text { expectations through } \\
\text { sales process }\end{array}$ & $\begin{array}{l}\text { Exceeding customer } \\
\text { expectations is an } \\
\text { important company } \\
\text { priority. } \\
\text { Employees understand } \\
\text { how their team and } \\
\text { department } \\
\text { performance contributes } \\
\text { to overall customer } \\
\text { satisfaction. }\end{array}$ & $\begin{array}{l}\text { Builder sets higher } \\
\text { customer expectations } \\
\text { than competition in } \\
\text { sales process, by } \\
\text { making performance } \\
\text { attributes explicit. }\end{array}$ & $\begin{array}{l}\text { In addition to level } 4 \text {, } \\
\text { anticipating individual } \\
\text { needs is recognized as } \\
\text { the means to achieve } \\
\text { the highest levels of } \\
\text { customer satisfaction. }\end{array}$ & $\begin{array}{l}\text { Builders guarantee } \\
\text { certain key success } \\
\text { drivers that are related } \\
\text { to the performance } \\
\text { standards and attributes } \\
\text { of the home (i.e., } \\
\text { energy costs and } \\
\text { supply, comfort, } \\
\text { durability, etc.) }\end{array}$ \\
\hline
\end{tabular}


Table D.3 (continued). Customer Satisfaction

\begin{tabular}{|c|c|c|c|c|c|c|c|c|}
\hline & Level 1 & Level 2 & Level 3 & IBACOS Level 3 & Level 4 & IBACOS Level 4 & Level 5 & IBACOS Level 5 \\
\hline $\begin{array}{l}3.3 \\
\text { Customer } \\
\text { Relationship } \\
\text { Management }\end{array}$ & $\begin{array}{l}\text { Maintaining good } \\
\text { customer } \\
\text { relationships } \\
\text { through final } \\
\text { inspection is the } \\
\text { main priority. } \\
\text { Everyone has his or } \\
\text { her own way of } \\
\text { working with } \\
\text { customers, with } \\
\text { varying degrees of } \\
\text { effectiveness. }\end{array}$ & $\begin{array}{l}\text { Maintaining good } \\
\text { customer relationships } \\
\text { through the end of the } \\
\text { warranty period is the } \\
\text { main priority. } \\
\text { Policies for dealing with } \\
\text { customers are in place } \\
\text { for the sales process. }\end{array}$ & $\begin{array}{l}\text { Relationships with } \\
\text { customers are } \\
\text { recognized as a key } \\
\text { customer satisfaction } \\
\text { driver. } \\
\text { A process is in place for } \\
\text { creating positive } \\
\text { customer relationships } \\
\text { in sales, construction, } \\
\text { and service phases. }\end{array}$ & & $\begin{array}{l}\text { In addition to level } 3 \text {, } \\
\text { customer expectations } \\
\text { for key customer } \\
\text { satisfaction drivers are } \\
\text { systematically managed } \\
\text { throughout the } \\
\text { customer relationship. } \\
\text { Customers are viewed } \\
\text { as customers for life. }\end{array}$ & $\begin{array}{l}\text { Key Satisfaction Divers } \\
\text { include Performance } \\
\text { standards }\end{array}$ & $\begin{array}{l}\text { In addition to level } 4 \text {, } \\
\text { the customer } \\
\text { relationship process is } \\
\text { designed to } \\
\text { systematically exceed } \\
\text { customer expectations. } \\
\text { Customer satisfaction } \\
\text { data on each customer } \\
\text { contact point is used to } \\
\text { set standards and } \\
\text { improve the relationship } \\
\text { process. }\end{array}$ & $\begin{array}{l}\text { Performance Standards } \\
\text { are designed to set a } \\
\text { higher level of customer } \\
\text { expectation, and } \\
\text { process is in place to } \\
\text { exceed those } \\
\text { expectations }\end{array}$ \\
\hline $\begin{array}{l}\text { 3.4a } \\
\text { Customer } \\
\text { Satisfaction } \\
\text { Measurement }\end{array}$ & $\begin{array}{l}\text { Customer } \\
\text { satisfaction } \\
\text { feedback data } \\
\text { consists of final } \\
\text { inspection punch } \\
\text { lists and warranty } \\
\text { callbacks. }\end{array}$ & $\begin{array}{l}\text { Customer satisfaction is } \\
\text { measured occasionally } \\
\text { by surveys or by asking } \\
\text { customers. } \\
\text { Some questions ask } \\
\text { customers to rate } \\
\text { employee performance. }\end{array}$ & $\begin{array}{l}\text { All customers are } \\
\text { surveyed on their } \\
\text { satisfaction with the } \\
\text { home and the customer } \\
\text { experience during the } \\
\text { sales, construction, and } \\
\text { warranty service } \\
\text { periods. } \\
\text { Questions focus on } \\
\text { process performance } \\
\text { rather than employee } \\
\text { ratings. }\end{array}$ & $\begin{array}{l}\text { Survey links } \\
\text { expectations of housing } \\
\text { performance compared } \\
\text { to actual experience of } \\
\text { living in home (i.e., } \\
\text { comfort, energy } \\
\text { performance, durability, } \\
\text { noise, etc.) }\end{array}$ & $\begin{array}{l}\text { In addition to level } 3 \text {, } \\
\text { customer satisfaction } \\
\text { survey questions are } \\
\text { directly linked to known } \\
\text { customer satisfaction } \\
\text { drivers. }\end{array}$ & $\begin{array}{l}\text { Measurements for } \\
\text { customer satisfaction } \\
\text { include questions on } \\
\text { key performance } \\
\text { drivers. }\end{array}$ & $\begin{array}{l}\text { In addition to level } 4 \text {, } \\
\text { feedback from } \\
\text { customers and } \\
\text { employees is used to } \\
\text { refine survey questions } \\
\text { and improve the survey } \\
\text { process. }\end{array}$ & $\begin{array}{l}\text { New metrics for } \\
\text { satisfaction are } \\
\text { developed for the } \\
\text { industry }\end{array}$ \\
\hline $\begin{array}{l}3.4 b \\
\text { Sharing of } \\
\text { Customer } \\
\text { Satisfaction } \\
\text { Feedback }\end{array}$ & $\begin{array}{l}\text { Customer } \\
\text { complaints are } \\
\text { shared with the } \\
\text { persons } \\
\text { responsible. }\end{array}$ & $\begin{array}{l}\text { Customer letters and } \\
\text { surveys are routinely } \\
\text { circulated among } \\
\text { employees. }\end{array}$ & $\begin{array}{l}\text { In addition to level 2, } \\
\text { Summary customer } \\
\text { satisfaction data is } \\
\text { available to all } \\
\text { employees. Trends are } \\
\text { tracked and posted for } \\
\text { all to see. } \\
\text { Senior managers } \\
\text { frequently discuss } \\
\text { customer feedback with } \\
\text { employees. }\end{array}$ & & $\begin{array}{l}\text { Customer satisfaction } \\
\text { ratings are routinely } \\
\text { communicated to the } \\
\text { organization as one of } \\
\text { the company-wide } \\
\text { performance measures. } \\
\text { Relevant customer } \\
\text { satisfaction data is } \\
\text { shared with suppliers } \\
\text { and trade contractors. }\end{array}$ & $\begin{array}{l}\text { Performance data is } \\
\text { included in these survey } \\
\text { results }\end{array}$ & $\begin{array}{l}\text { Customer satisfaction is } \\
\text { one of the company's } \\
\text { vital few key success } \\
\text { measures that are } \\
\text { tracked monthly by the } \\
\text { company's performance } \\
\text { management system. }\end{array}$ & $\begin{array}{l}\text { Customer satisfaction is } \\
\text { linked to performance of } \\
\text { housing, not just buying } \\
\text { and construction } \\
\text { process }\end{array}$ \\
\hline
\end{tabular}


Table D.3 (continued). Customer Satisfaction

\begin{tabular}{|c|c|c|c|c|c|c|c|c|}
\hline & Level 1 & Level 2 & Level 3 & IBACOS Level 3 & Level 4 & IBACOS Level 4 & Level 5 & IBACOS Level 5 \\
\hline $\begin{array}{l}3.5 \\
\text { Customer } \\
\text { Satisfaction } \\
\text { Results }\end{array}$ & $\begin{array}{l}\text { Percentage of } \\
\text { customers who } \\
\text { would recommend } \\
\text { the company to a } \\
\text { friend is not } \\
\text { measured. }\end{array}$ & $\begin{array}{l}\text { More than } 75 \% \text { of } \\
\text { customers surveyed } \\
\text { would recommend the } \\
\text { company to a friend. } \\
\text { Customer satisfaction } \\
\text { seems to be } \\
\text { improving. }\end{array}$ & $\begin{array}{l}\text { More than } 85 \% \text { of } \\
\text { customers surveyed } \\
\text { would recommend the } \\
\text { company to a friend. } \\
\text { There are measured } \\
\text { improvements in } \\
\text { customer satisfaction. }\end{array}$ & $\begin{array}{l}\text { More than } 85 \% \text { of } \\
\text { customers surveyed } \\
\text { feel home meets the } \\
\text { company standard of } \\
\text { performance }\end{array}$ & $\begin{array}{l}\text { More than } 90 \% \text { of } \\
\text { customers surveyed } \\
\text { would recommend the } \\
\text { company to a friend. } \\
\text { Customer satisfaction } \\
\text { shows measured } \\
\text { improvements in most } \\
\text { products and services. }\end{array}$ & $\begin{array}{l}\text { More than } 90 \% \text { of } \\
\text { customers surveyed } \\
\text { feel home meets the } \\
\text { company standard of } \\
\text { performance }\end{array}$ & $\begin{array}{l}\text { More than } 95 \% \text { of } \\
\text { customers surveyed } \\
\text { would recommend the } \\
\text { company to a friend. } \\
\text { Customer satisfaction } \\
\text { shows strong } \\
\text { improvements in most } \\
\text { products and services. }\end{array}$ & $\begin{array}{l}\text { More than } 95 \% \text { of } \\
\text { customers surveyed } \\
\text { feel home meets the } \\
\text { company standard of } \\
\text { performance }\end{array}$ \\
\hline
\end{tabular}

Note: Yellow denotes minimum level for considering adopting a 30\% whole-house energy-savings solution set. 


\begin{tabular}{|c|c|c|c|c|c|c|c|c|}
\hline & Level 1 & Level 2 & Level 3 & IBACOS Level 3 & Level 4 & IBACOS Level 4 & Level 5 & IBACOS Level 5 \\
\hline $\begin{array}{l}\text { 4.1a } \\
\text { Creating High- } \\
\text { Performance } \\
\text { Work Processes }\end{array}$ & $\begin{array}{l}\text { Meeting minimum } \\
\text { performance } \\
\text { expectations is an } \\
\text { important priority for } \\
\text { most employees. }\end{array}$ & $\begin{array}{l}\text { Most employees have } \\
\text { well-defined } \\
\text { responsibilities. } \\
\text { Finding ways to reduce } \\
\text { costs is the main focus } \\
\text { of work improvement } \\
\text { activities. }\end{array}$ & $\begin{array}{l}\text { Key work processes are } \\
\text { well defined. } \\
\\
\text { Customer satisfaction } \\
\text { and cost are important } \\
\text { work improvement } \\
\text { priorities. }\end{array}$ & $\begin{array}{l}\text { "Building performance } \\
\text { quality management" } \\
\text { has been identified as a } \\
\text { key work process, and } \\
\text { has been assigned } \\
\text { within the organization }\end{array}$ & $\begin{array}{l}\text { Customer needs drive } \\
\text { work systems design } \\
\text { and improvements. } \\
\text { Some work systems are } \\
\text { modeled on industry } \\
\text { best practices. }\end{array}$ & $\begin{array}{l}\text { The integrated design } \\
\text { process has been } \\
\text { mapped and assigned }\end{array}$ & $\begin{array}{l}\text { Key processes have } \\
\text { high-performance } \\
\text { approaches and goals } \\
\text { based upon world-class } \\
\text { Benchmarks. Key } \\
\text { performance metrics are } \\
\text { tracked and used for the } \\
\text { control and improvement } \\
\text { of processes. }\end{array}$ & $\begin{array}{l}\text { All processes associated } \\
\text { with key building- } \\
\text { performance standards } \\
\text { have been identified and } \\
\text { documented }\end{array}$ \\
\hline $\begin{array}{l}\text { 4.1b } \\
\text { Bench-Marking } \\
\text { Business } \\
\text { Processes }\end{array}$ & $\begin{array}{l}\text { Information on how } \\
\text { other builders do } \\
\text { things is obtained } \\
\text { mostly from } \\
\text { publications and } \\
\text { seminars. }\end{array}$ & $\begin{array}{l}\text { Occasional visits to } \\
\text { other builders are made } \\
\text { to get some good ideas. }\end{array}$ & $\begin{array}{l}\text { Regular visits to other } \\
\text { builders are made to } \\
\text { compare performance } \\
\text { results and set } \\
\text { improvement objectives. }\end{array}$ & $\begin{array}{l}\text { Those builders visited } \\
\text { include others who are } \\
\text { improving building } \\
\text { performance at Level } 3 \\
\text { and at least one at Level } \\
4\end{array}$ & $\begin{array}{l}\text { In addition to level 3, } \\
\text { detailed studies of other } \\
\text { builders' operations are } \\
\text { used to design } \\
\text { operational } \\
\text { improvements. }\end{array}$ & $\begin{array}{l}\text { Those builders visited } \\
\text { include others who are } \\
\text { improving building } \\
\text { performance at Level } 4 \\
\text { and at least one at Level } \\
5\end{array}$ & $\begin{array}{l}\text { In addition to level } 4 \text {, a } \\
\text { systematic approach is } \\
\text { used to study } \\
\text { organizations outside } \\
\text { the construction } \\
\text { industry, make } \\
\text { improvements, and set } \\
\text { long-range goals. }\end{array}$ & $\begin{array}{l}\text { Outside organizations } \\
\text { studied reflect similar } \\
\text { core values of } \\
\text { performance in the } \\
\text { product developed }\end{array}$ \\
\hline $\begin{array}{l}4.2 \\
\text { Performance } \\
\text { Management }\end{array}$ & $\begin{array}{l}\text { Performance is } \\
\text { managed by } \\
\text { monitoring the } \\
\text { productivity of } \\
\text { individual employees. }\end{array}$ & $\begin{array}{l}\text { In addition to level } 1 \text {, } \\
\text { conformance to } \\
\text { department budgets is } \\
\text { used to manage } \\
\text { financial performance. }\end{array}$ & $\begin{array}{l}\text { Performance } \\
\text { management focuses on } \\
\text { the productivity of key } \\
\text { business processes. } \\
\text { Results are tracked and } \\
\text { reviewed monthly. }\end{array}$ & $\begin{array}{l}\text { Building to a predefined } \\
\text { performance standard is } \\
\text { identified as a key } \\
\text { business process }\end{array}$ & $\begin{array}{l}\text { In addition to level 3, key } \\
\text { work processes have } \\
\text { performance measures } \\
\text { that link directly to } \\
\text { company-wide key } \\
\text { success measures. } \\
\text { Results are shared with } \\
\text { all employees. }\end{array}$ & $\begin{array}{l}\text { Performance attributes } \\
\text { are measured and used } \\
\text { in this process }\end{array}$ & $\begin{array}{l}\text { In addition to level 4, } \\
\text { employees, teams, and } \\
\text { trade contractors have } \\
\text { performance measures } \\
\text { for their own processes } \\
\text { that support company- } \\
\text { wide key success } \\
\text { measures. }\end{array}$ & $\begin{array}{l}\text { Trades perform } \\
\text { performance } \\
\text { measurements during } \\
\text { work }\end{array}$ \\
\hline $\begin{array}{l}4.3 \\
\text { Process } \\
\text { Improvement }\end{array}$ & $\begin{array}{l}\text { Problems are handled } \\
\text { as they occur to avoid } \\
\text { customer complaints. }\end{array}$ & $\begin{array}{l}\text { Changes to company } \\
\text { processes are made } \\
\text { occasionally to prevent } \\
\text { recurring problems. } \\
\text { Some employees are } \\
\text { involved in improvement } \\
\text { projects. }\end{array}$ & $\begin{array}{l}\text { Improving company } \\
\text { processes is an } \\
\text { important part of } \\
\text { everyone's job. } \\
\text { There are many } \\
\text { improvements made } \\
\text { throughout the company. } \\
\text { The company uses a } \\
\text { systematic method to } \\
\text { make improvements. }\end{array}$ & $\begin{array}{l}\text { Process of designing } \\
\text { and building for } \\
\text { performance is identified } \\
\text { as a key process } \\
\text { improvement area }\end{array}$ & $\begin{array}{l}\text { An effective strategy } \\
\text { and goals are in place } \\
\text { for involving the entire } \\
\text { workforce in problem } \\
\text { solving and quality } \\
\text { improvement. } \\
\text { Most employees have } \\
\text { been trained in the } \\
\text { company's process } \\
\text { improvement methods. }\end{array}$ & $\begin{array}{l}\text { Quality Process } \\
\text { management involves } \\
\text { workforce to continually } \\
\text { improve performance }\end{array}$ & $\begin{array}{l}\text { In addition to level 4, all } \\
\text { major trade contractors } \\
\text { participate in the } \\
\text { company's problem- } \\
\text { solving and quality } \\
\text { improvement system. }\end{array}$ & $\begin{array}{l}\text { Performance measures } \\
\text { are part of trade } \\
\text { feedback and design } \\
\text { process involving trades }\end{array}$ \\
\hline
\end{tabular}


Table D.4 (continued). Performance Management

\begin{tabular}{|c|c|c|c|c|c|c|c|c|}
\hline & Level 1 & Level 2 & Level 3 & IBACOS Level 3 & Level 4 & IBACOS Level 4 & Level 5 & IBACOS Level 5 \\
\hline $\begin{array}{l}4.4 \\
\text { Improvement } \\
\text { Results }\end{array}$ & $\begin{array}{l}\text { Some company work } \\
\text { processes seem to } \\
\text { be improving, but } \\
\text { there are no } \\
\text { measures of } \\
\text { progress. }\end{array}$ & $\begin{array}{l}\text { Some company work } \\
\text { processes show } \\
\text { measured quality } \\
\text { improvements. }\end{array}$ & $\begin{array}{l}\text { Most company work } \\
\text { processes show } \\
\text { measured quality } \\
\text { improvements. }\end{array}$ & & $\begin{array}{l}\text { Most company work } \\
\text { processes show } \\
\text { measured quality } \\
\text { improvements and } \\
\text { excellent quality } \\
\text { results. }\end{array}$ & $\begin{array}{l}\text { Performance metrics } \\
\text { are included in this } \\
\text { measurement }\end{array}$ & $\begin{array}{l}\text { Most measures of } \\
\text { organizational } \\
\text { effectiveness are } \\
\text { considered } \\
\text { Benchmarks for the } \\
\text { industry. }\end{array}$ & $\begin{array}{l}\text { Performance } \\
\text { standards are } \\
\text { considered } \\
\text { Benchmarks as well }\end{array}$ \\
\hline $\begin{array}{l}4.5 \\
\text { Financial } \\
\text { Improvement } \\
\text { Results }\end{array}$ & $\begin{array}{l}\text { Some improvements } \\
\text { have resulted in cost } \\
\text { reductions. }\end{array}$ & $\begin{array}{l}\text { Substantial cost } \\
\text { reductions have been } \\
\text { made but have not yet } \\
\text { helped improve home } \\
\text { sales. }\end{array}$ & $\begin{array}{l}\text { Home sales and } \\
\text { company profitability } \\
\text { show improvement. }\end{array}$ & $\begin{array}{l}\text { Profitability is in some } \\
\text { way attributable to } \\
\text { performance } \\
\text { standards (reduction in } \\
\text { callbacks, improved } \\
\text { value, etc.) }\end{array}$ & $\begin{array}{l}\text { Company's share of } \\
\text { home sales is } \\
\text { increasing. } \\
\text { Company profitability } \\
\text { shows excellent } \\
\text { results with positive } \\
\text { trends. }\end{array}$ & $\begin{array}{l}\text { Metric is developed to } \\
\text { measure overall cross } \\
\text { cutting impact of } \\
\text { performance on Value, } \\
\text { cycle, and operations } \\
\text { to measure overall } \\
\text { profitability }\end{array}$ & $\begin{array}{l}\text { In addition to level } 4 \text {, } \\
\text { company profitability is } \\
\text { consistently among } \\
\text { the best among } \\
\text { builders in the area. }\end{array}$ & \\
\hline
\end{tabular}

Note: Yellow denotes minimum level for considering adopting a 30\% whole-house energy-savings solution set. 
Table D.5. Human Resources

The human resources system must develop the full potential of employees and drive the right behaviors in support of company performance and learning objectives.

\begin{tabular}{|c|c|c|c|c|c|c|c|c|}
\hline & Level 1 & Level 2 & Level 3 & IBACOS Level 3 & Level 4 & IBACOS Level 4 & Level 5 & IBACOS Level 5 \\
\hline \multirow{3}{*}{$\begin{array}{l}5.1 \mathrm{a} \\
\text { Employee } \\
\text { Satisfaction }\end{array}$} & \multirow{3}{*}{$\begin{array}{l}\text { The company shows a } \\
\text { general concern for } \\
\text { employee well-being } \\
\text { and morale. }\end{array}$} & \multirow{2}{*}{$\begin{array}{l}\text { Company shows that } \\
\text { employee well-being and } \\
\text { morale are priorities in } \\
\text { making business } \\
\text { decisions. }\end{array}$} & \multirow{2}{*}{$\begin{array}{l}\text { In addition to level 2, } \\
\text { employee satisfaction is } \\
\text { recognized as important } \\
\text { for the company's } \\
\text { success. }\end{array}$} & & \multirow{3}{*}{$\begin{array}{l}\text { The company } \\
\text { understands which } \\
\text { factors drive employee } \\
\text { satisfaction. } \\
\text { Employee surveys } \\
\text { measure employee } \\
\text { satisfaction and the } \\
\text { information is used to } \\
\text { improve the work } \\
\text { environment. }\end{array}$} & \multirow{3}{*}{$\begin{array}{l}\text { Relationship to } \\
\text { performance standards } \\
\text { and end product is } \\
\text { measured as a } \\
\text { component of employee } \\
\text { satisfaction }\end{array}$} & \multirow{3}{*}{$\begin{array}{l}\text { In addition to level } 4 \text {, } \\
\text { employee satisfaction is } \\
\text { integrated into the } \\
\text { company's strategic } \\
\text { planning process with } \\
\text { long-range goals and } \\
\text { action plans. }\end{array}$} & \multirow{3}{*}{$\begin{array}{l}\text { Performance is one } \\
\text { metric used in the } \\
\text { strategic planning } \\
\text { process }\end{array}$} \\
\hline & & & \multirow{2}{*}{\multicolumn{2}{|c|}{$\begin{array}{l}\text { Senior managers take } \\
\text { initiatives to do what } \\
\text { they think will improve } \\
\text { the work environment. }\end{array}$}} & & & & \\
\hline & & $\begin{array}{l}\text { There are occasional } \\
\text { morale-building } \\
\text { activities. }\end{array}$ & & & & & & \\
\hline $\begin{array}{l}5.1 \mathrm{~b} \\
\text { Jobsite Safety }\end{array}$ & $\begin{array}{l}\text { There are occasional } \\
\text { safety-related training } \\
\text { activities. }\end{array}$ & $\begin{array}{l}\text { Health and safety } \\
\text { training is provided to all } \\
\text { field employees. }\end{array}$ & $\begin{array}{l}\text { Company shows that } \\
\text { employee health and } \\
\text { safety are priorities in } \\
\text { making business } \\
\text { decisions. }\end{array}$ & & $\begin{array}{l}\text { In addition to level } 3 \text {, } \\
\text { there is an organized } \\
\text { approach to analyzing } \\
\text { causes of injuries and } \\
\text { preventing accidents. }\end{array}$ & & $\begin{array}{l}\text { In addition to level } 4 \text {, } \\
\text { trade contractors are } \\
\text { involved in an organized } \\
\text { approach to prevent } \\
\text { injuries. }\end{array}$ & \\
\hline $\begin{array}{l}5.1 \mathrm{c} \\
\text { Job } \\
\text { Responsibilities }\end{array}$ & $\begin{array}{l}\text { Employees learn job } \\
\text { responsibilities from } \\
\text { on-the-job experience. }\end{array}$ & $\begin{array}{l}\text { Job descriptions define } \\
\text { job responsibilities. }\end{array}$ & $\begin{array}{l}\text { In addition to level } 2, \\
\text { most employees clearly } \\
\text { understand their job } \\
\text { responsibilities and how } \\
\text { their job contributes to } \\
\text { company performance. }\end{array}$ & $\begin{array}{l}\text { Job Responsibilities are } \\
\text { also tied to Building } \\
\text { Performance }\end{array}$ & $\begin{array}{l}\text { In addition to level 3, } \\
\text { employees feel } \\
\text { responsible for } \\
\text { performing their job to } \\
\text { meet the needs of other } \\
\text { employees who depend } \\
\text { on them. }\end{array}$ & $\begin{array}{l}\text { One measure is in } \\
\text { relation to building } \\
\text { performance by internal } \\
\text { survey of employees and } \\
\text { trades }\end{array}$ & $\begin{array}{l}\text { In addition to level } 4 \text {, } \\
\text { employees are expected } \\
\text { to take initiatives that } \\
\text { exceed customer } \\
\text { expectations or solve } \\
\text { their problems. }\end{array}$ & \\
\hline $\begin{array}{l}\text { 5.1d } \\
\text { Teamwork }\end{array}$ & $\begin{array}{l}\text { Individual effort is the } \\
\text { main way things get } \\
\text { done. }\end{array}$ & $\begin{array}{l}\text { Some natural work } \\
\text { groups are formed into } \\
\text { operating teams with } \\
\text { shared responsibilities. }\end{array}$ & $\begin{array}{l}\text { Most employees are part } \\
\text { of an operating team } \\
\text { with a well-understood } \\
\text { purpose. } \\
\text { Teams are the main way } \\
\text { that day-to-day work } \\
\text { gets done. }\end{array}$ & $\begin{array}{l}\text { Performance attributes } \\
\text { and standards are part } \\
\text { of the purpose within a } \\
\text { team }\end{array}$ & $\begin{array}{l}\text { In addition to level 3, } \\
\text { teamwork is the primary } \\
\text { mechanism for solving } \\
\text { problems and making } \\
\text { performance } \\
\text { improvements. }\end{array}$ & $\begin{array}{l}\text { Problem solving and } \\
\text { improvements include } \\
\text { building performance } \\
\text { standards related issues }\end{array}$ & $\begin{array}{l}\text { In addition to level } 4 \text {, } \\
\text { employees are actively } \\
\text { engaged in teams that } \\
\text { perform key } \\
\text { management functions } \\
\text { for the company. }\end{array}$ & $\begin{array}{l}\text { Integrated design } \\
\text { process brings team } \\
\text { members in from all } \\
\text { levels of the organization } \\
\text { and trade partners }\end{array}$ \\
\hline
\end{tabular}


Table D.5 (continued). Human Resources

\begin{tabular}{|c|c|c|c|c|c|c|c|c|}
\hline & Level 1 & Level 2 & Level 3 & IBACOS Level 3 & Level 4 & IBACOS Level 4 & Level 5 & IBACOS Level 5 \\
\hline $\begin{array}{l}5.2 \\
\text { Workforce } \\
\text { Development }\end{array}$ & $\begin{array}{l}\text { Skills are learned on } \\
\text { the job. }\end{array}$ & $\begin{array}{l}\text { Work-related training is } \\
\text { delivered as needed } \\
\text { when time and budget } \\
\text { allows. }\end{array}$ & $\begin{array}{l}\text { There is a company } \\
\text { training budget. Most } \\
\text { employees receive } \\
\text { some training. } \\
\text { Most employees have } \\
\text { personal training and } \\
\text { development plans. }\end{array}$ & $\begin{array}{l}\text { Key general training on } \\
\text { issues related to } \\
\text { building-performance } \\
\text { standards is provided } \\
\text { and specifically related } \\
\text { to company } \\
\text { performance standards }\end{array}$ & $\begin{array}{l}\text { In addition to level 3, the } \\
\text { company's training and } \\
\text { hiring plan is aimed at } \\
\text { developing the skills } \\
\text { necessary for achieving } \\
\text { the long-range company } \\
\text { vision. }\end{array}$ & $\begin{array}{l}\text { Training for building } \\
\text { performance is } \\
\text { specialized by employee } \\
\text { and function, }\end{array}$ & $\begin{array}{l}\text { In addition to level } 4 \text {, the } \\
\text { company has a } \\
\text { systematic skills- } \\
\text { development program } \\
\text { for key job positions. }\end{array}$ & $\begin{array}{l}\text { Key positions are } \\
\text { targeted for more in- } \\
\text { depth building-science } \\
\text { training }\end{array}$ \\
\hline $\begin{array}{l}5.3 \\
\text { Employee } \\
\text { Evaluation and } \\
\text { Compensation } \\
\text { Systems }\end{array}$ & $\begin{array}{l}\text { Most employees } \\
\text { receive an annual } \\
\text { performance review. }\end{array}$ & $\begin{array}{l}\text { Annual employee } \\
\text { performance reviews } \\
\text { have well-defined } \\
\text { evaluation criteria. } \\
\text { Bonuses and recognition } \\
\text { reward individual efforts. }\end{array}$ & $\begin{array}{l}\text { In addition to level 2, } \\
\text { employee performance } \\
\text { evaluation criteria are } \\
\text { linked to job } \\
\text { descriptions. } \\
\text { Bonuses focus on team } \\
\text { efforts. }\end{array}$ & $\begin{array}{l}\text { Evaluation criteria } \\
\text { include measurement of } \\
\text { achievement of building- } \\
\text { performance standards }\end{array}$ & $\begin{array}{l}\text { Employee performance } \\
\text { evaluation criteria are } \\
\text { based on fulfillment of } \\
\text { personal development } \\
\text { plans and key elements } \\
\text { of the company mission, } \\
\text { vision, and values. }\end{array}$ & $\begin{array}{l}\text { Building Performance } \\
\text { standards are one of the } \\
\text { Key elements }\end{array}$ & $\begin{array}{l}\text { In addition to level } 4 \text {, } \\
\text { employee bonuses are } \\
\text { linked directly to } \\
\text { performance of the } \\
\text { company's key success } \\
\text { measures. }\end{array}$ & $\begin{array}{l}\text { Building performance is } \\
\text { one Key success } \\
\text { measure }\end{array}$ \\
\hline
\end{tabular}

Note: Yellow denotes minimum level for considering adopting a 30\% whole-house energy-savings solution set. 
Table D.6. Quality Construction Processes

Systematic quality management approaches are necessary to ensure high performing, trouble-free products and services.

\begin{tabular}{|c|c|c|c|c|c|c|c|c|}
\hline & Level 1 & Level 2 & Level 3 & IBACOS Level 3 & Level 4 & IBACOS Level 4 & Level 5 & IBACOS Level 5 \\
\hline $\begin{array}{l}6.1 \\
\text { Setting Quality } \\
\text { Expectations }\end{array}$ & $\begin{array}{l}\text { Informal standards } \\
\text { exist. "We know if it's } \\
\text { OK when we see it." }\end{array}$ & $\begin{array}{l}\text { Construction details } \\
\text { and workmanship } \\
\text { specifications control } \\
\text { known problem areas. }\end{array}$ & $\begin{array}{l}\text { In addition to level } 2 \text {, } \\
\text { the builder, contractor, } \\
\text { and other trades } \\
\text { collaborate to set } \\
\text { quality requirements. } \\
\text { Contract scopes of } \\
\text { work reference specific } \\
\text { construction standards } \\
\text { and workmanship } \\
\text { tolerances. }\end{array}$ & $\begin{array}{l}\text { Performance } \\
\text { standards are selected } \\
\text { and adopted by } \\
\text { builders to meet or } \\
\text { exceed Benchmark } \\
\text { levels in region }\end{array}$ & $\begin{array}{l}\text { In addition to level 3, } \\
\text { requirements analysis } \\
\text { of building codes, } \\
\text { construction standards, } \\
\text { product installation } \\
\text { instructions, and } \\
\text { industry guidelines are } \\
\text { used to set quality } \\
\text { specifications. }\end{array}$ & $\begin{array}{l}\text { Building standards } \\
\text { exceed Benchmark } \\
\text { levels, and are based } \\
\text { on a whole-house } \\
\text { building-science } \\
\text { approach }\end{array}$ & $\begin{array}{l}\text { In addition to level } 4 \text {, } \\
\text { construction detail } \\
\text { drawings are provided } \\
\text { for nearly every aspect } \\
\text { of the home. }\end{array}$ & $\begin{array}{l}\text { Design documentation } \\
\text { includes performance } \\
\text { aspects and integrates } \\
\text { a significant amount of } \\
\text { means and methods } \\
\text { descriptions to assist } \\
\text { trades in } \\
\text { implementation, } \\
\text { including detailed } \\
\text { scopes of work }\end{array}$ \\
\hline $\begin{array}{l}6.2 \\
\text { Assuring } \\
\text { Quality Results }\end{array}$ & $\begin{array}{l}\text { The company fixes any } \\
\text { defects the } \\
\text { homeowner may find } \\
\text { at final walk-through or } \\
\text { during the warranty } \\
\text { process. }\end{array}$ & $\begin{array}{l}\text { Construction personnel } \\
\text { use their experience to } \\
\text { catch defects. }\end{array}$ & $\begin{array}{l}\text { There are inspection } \\
\text { checklists for most } \\
\text { trades. } \\
\text { Formal inspections are } \\
\text { performed for each } \\
\text { phase of construction } \\
\text { by the builder. }\end{array}$ & $\begin{array}{l}\text { Performance } \\
\text { standards are included } \\
\text { on checklists, some } \\
\text { performance testing is } \\
\text { included }\end{array}$ & $\begin{array}{l}\text { In addition to level } 3 \text {, } \\
\text { trade contractors use } \\
\text { checklists to perform } \\
\text { quality self-inspections. } \\
\text { The main function of } \\
\text { builder inspections is } \\
\text { to monitor quality } \\
\text { performance rather } \\
\text { than screen out } \\
\text { defects from trade } \\
\text { contractors. }\end{array}$ & $\begin{array}{l}\text { Performance } \\
\text { standards are included } \\
\text { on checklists, a higher } \\
\text { level of performance } \\
\text { testing is included }\end{array}$ & $\begin{array}{l}\text { Key trades have ISO } \\
9000-\text { based quality } \\
\text { assurance systems. } \\
\text { Conformance to } \\
\text { specifications is a well- } \\
\text { documented process. } \\
\text { Company generally } \\
\text { needs only to spot } \\
\text { check trade contractor } \\
\text { or product quality. }\end{array}$ & $\begin{array}{l}\text { Performance } \\
\text { standards are included } \\
\text { on checklists, a higher } \\
\text { level (up to } 100 \% \text { ) of } \\
\text { performance testing is } \\
\text { included, but may be } \\
\text { done as part of the } \\
\text { trade contractors work. }\end{array}$ \\
\hline $\begin{array}{l}6.3 \\
\text { Quality } \\
\text { Problem } \\
\text { Prevention }\end{array}$ & $\begin{array}{l}\text { Quality problems are } \\
\text { corrected as needed. }\end{array}$ & $\begin{array}{l}\text { In addition to level } 1 \text {, } \\
\text { actions are taken to } \\
\text { prevent chronic } \\
\text { problems. }\end{array}$ & $\begin{array}{l}\text { Defect data is } \\
\text { recorded, trends } \\
\text { monitored, and } \\
\text { improvement } \\
\text { objectives are set. } \\
\text { Actions to solve defect } \\
\text { problems occur } \\
\text { regularly. }\end{array}$ & $\begin{array}{l}\text { Troubleshooting } \\
\text { activities use building } \\
\text { science basis for } \\
\text { performance based } \\
\text { defect analysis }\end{array}$ & $\begin{array}{l}\text { In addition to level 3, } \\
\text { systematic analysis of } \\
\text { root causes are } \\
\text { routinely used to } \\
\text { prevent defects. } \\
\text { Defect prevention } \\
\text { focuses on improving } \\
\text { processes. }\end{array}$ & $\begin{array}{l}\text { Mechanisms in place } \\
\text { to integrate root cause } \\
\text { prevention into design } \\
\text { process }\end{array}$ & $\begin{array}{l}\text { In addition to level } 4 \text {, } \\
\text { employees and trade } \\
\text { contractors are actively } \\
\text { engaged to continually } \\
\text { refine processes } \\
\text { toward zero defect } \\
\text { goals. }\end{array}$ & $\begin{array}{l}\text { Zero defect goals } \\
\text { include performance } \\
\text { attributes of buildings. } \\
\text { Zero Defect is well } \\
\text { defined relative to } \\
\text { performance standards }\end{array}$ \\
\hline
\end{tabular}


Table D.6 (continued). Quality Construction Processes

\begin{tabular}{|c|c|c|c|c|c|c|c|c|}
\hline & Level 1 & Level 2 & Level 3 & IBACOS Level 3 & Level 4 & IBACOS Level 4 & Level 5 & IBACOS Level 5 \\
\hline $\begin{array}{l}6.4 \\
\text { Warranty } \\
\text { Service }\end{array}$ & $\begin{array}{l}\text { Service callbacks are } \\
\text { handled but not } \\
\text { tracked. }\end{array}$ & $\begin{array}{l}\text { Systems are in place } \\
\text { to track warranty } \\
\text { complaints and their } \\
\text { completion. }\end{array}$ & $\begin{array}{l}\text { In addition to level 2, } \\
\text { warranty service data } \\
\text { is used to set priorities } \\
\text { for solving quality } \\
\text { problems. }\end{array}$ & $\begin{array}{l}\text { Warrantee service data } \\
\text { is broken down to } \\
\text { capture root causes }\end{array}$ & $\begin{array}{l}\text { In addition to level } 3 \text {, } \\
\text { response time and } \\
\text { customer satisfaction } \\
\text { with each service call } \\
\text { are important } \\
\text { performance } \\
\text { measures. }\end{array}$ & $\begin{array}{l}\text { Key performance } \\
\text { drivers are identified, } \\
\text { tracked and fed back } \\
\text { to reduce warrantee } \\
\text { calls and improve } \\
\text { customer satisfaction }\end{array}$ & $\begin{array}{l}\text { Warranty service } \\
\text { excellence is among } \\
\text { the best of builders in } \\
\text { the area and a } \\
\text { competitive advantage } \\
\text { of the company. }\end{array}$ & $\begin{array}{l}\text { Warranty specialist are } \\
\text { trained in building } \\
\text { science approach and } \\
\text { use diagnostic skills to } \\
\text { improve product }\end{array}$ \\
\hline $\begin{array}{l}6.5 \\
\text { Product and } \\
\text { Service } \\
\text { Quality } \\
\text { Results }\end{array}$ & $\begin{array}{l}\text { Product and service } \\
\text { quality seems to be } \\
\text { improving, but there } \\
\text { are no measures of } \\
\text { progress. }\end{array}$ & $\begin{array}{l}\text { Problems found at final } \\
\text { inspection are } \\
\text { decreasing. } \\
\text { There are fewer } \\
\text { callbacks. }\end{array}$ & $\begin{array}{l}\text { Data shows that } \\
\text { constructed quality is } \\
\text { improving. }\end{array}$ & $\begin{array}{l}\text { Quality is defined } \\
\text { according to building } \\
\text { science based } \\
\text { performance metrics }\end{array}$ & $\begin{array}{l}\text { Most product and } \\
\text { service quality } \\
\text { performance indicators } \\
\text { show excellent results } \\
\text { with positive trends. } \\
\text { Zero defect final } \\
\text { inspections are } \\
\text { commonplace. }\end{array}$ & $\begin{array}{l}\text { Defects are also } \\
\text { measured by building } \\
\text { science performance } \\
\text { measurements, and } \\
\text { are measured by } \\
\text { testing }\end{array}$ & $\begin{array}{l}\text { All major product and } \\
\text { service quality } \\
\text { performance indicators } \\
\text { show positive } \\
\text { improvement trends } \\
\text { and excellent results. } \\
\text { Most homes have zero } \\
\text { defect final } \\
\text { inspections. }\end{array}$ & $\begin{array}{l}\text { Defects are also } \\
\text { measured by building- } \\
\text { science performance } \\
\text { measurements and are } \\
\text { measured by higher } \\
\text { levels (up to 100\%) } \\
\text { testing }\end{array}$ \\
\hline
\end{tabular}

Note: Yellow denotes minimum level for considering adopting a 30\% whole-house energy-savings solution set. 
Table D.7. Supplier Partnerships

Partnering approaches are essential for high performance relationships with trade contractors and product manufacturers.

\begin{tabular}{|c|c|c|c|c|c|c|c|c|}
\hline & Level 1 & Level 2 & Level 3 & IBACOS Level 3 & Level 4 & IBACOS Level 4 & Level 5 & IBACOS Level 5 \\
\hline $\begin{array}{l}7.1 \\
\text { Trade } \\
\text { Contractor and } \\
\text { Supplier } \\
\text { Relationships }\end{array}$ & $\begin{array}{l}\text { Difficult quality } \\
\text { problems are usually } \\
\text { solved by changing } \\
\text { contractors or } \\
\text { suppliers. }\end{array}$ & $\begin{array}{l}\text { A systematic process } \\
\text { is in place for the } \\
\text { selection of trade } \\
\text { contractors. } \\
\text { Trades and suppliers } \\
\text { participate in solving } \\
\text { problems. }\end{array}$ & $\begin{array}{l}\text { Key trade contractors } \\
\text { and suppliers are } \\
\text { considered partners. } \\
\text { Company helps them } \\
\text { improve quality and } \\
\text { reduce costs. }\end{array}$ & $\begin{array}{l}\text { Performance } \\
\text { standards are a metric } \\
\text { of quality, testing } \\
\text { measures } \\
\text { improvement }\end{array}$ & $\begin{array}{l}\text { In addition to level } 3 \text {, } \\
\text { most major trade } \\
\text { contractors and } \\
\text { suppliers participate in } \\
\text { a systematic approach } \\
\text { to problem-solving and } \\
\text { quality improvement. }\end{array}$ & $\begin{array}{l}\text { Company has } \\
\text { integrated design } \\
\text { process for contractors } \\
\text { to participate in new } \\
\text { construction and } \\
\text { building-science-based } \\
\text { solution / redesign } \\
\text { process for existing } \\
\text { product }\end{array}$ & $\begin{array}{l}\text { In addition to level } 4 \text {, } \\
\text { trade contractors and } \\
\text { suppliers participate in } \\
\text { planning and } \\
\text { implementing long- } \\
\text { term quality } \\
\text { improvements. }\end{array}$ & $\begin{array}{l}\text { Trades are actively } \\
\text { involved in identifying } \\
\text { proper scopes of work, } \\
\text { sequencing, and even- } \\
\text { flow scheduling with } \\
\text { builder }\end{array}$ \\
\hline $\begin{array}{l}7.2 \\
\text { Trade } \\
\text { Development }\end{array}$ & $\begin{array}{l}\text { There are no formal } \\
\text { initiatives to develop } \\
\text { the capabilities of trade } \\
\text { contractors. }\end{array}$ & $\begin{array}{l}\text { Improving trades is } \\
\text { focused on solving } \\
\text { problems. }\end{array}$ & $\begin{array}{l}\text { A general strategy is in } \\
\text { place to develop the } \\
\text { capabilities and } \\
\text { performance of trade } \\
\text { contractors. }\end{array}$ & $\begin{array}{l}\text { Builder provides } \\
\text { general training on } \\
\text { Performance } \\
\text { standards and trades } \\
\text { relation to standards }\end{array}$ & $\begin{array}{l}\text { The company's trade } \\
\text { development plans are } \\
\text { linked directly to } \\
\text { achieving the } \\
\text { company's long-range } \\
\text { vision. }\end{array}$ & $\begin{array}{l}\text { Trades are trained to } \\
\text { understand building } \\
\text { science approach and } \\
\text { integrated designs, } \\
\text { and interrelationship of } \\
\text { their work to the overall } \\
\text { performance standards } \\
\text { and company goals }\end{array}$ & $\begin{array}{l}\text { In addition to level } 4 \text {, } \\
\text { Key trades have their } \\
\text { own development } \\
\text { plans that support the } \\
\text { company vision. } \\
\text { The builder provides } \\
\text { incentives for trades } \\
\text { participating in training } \\
\text { improvement } \\
\text { programs. }\end{array}$ & $\begin{array}{l}\text { Builder required } \\
\text { certified trades in all } \\
\text { key performance } \\
\text { standards areas }\end{array}$ \\
\hline $\begin{array}{l}7.3 \\
\text { Trade } \\
\text { Contractor } \\
\text { Performance } \\
\text { Management }\end{array}$ & $\begin{array}{l}\text { Trade performance is } \\
\text { evaluated when } \\
\text { problems arise or } \\
\text { when contracts are } \\
\text { renewed. }\end{array}$ & $\begin{array}{l}\text { Trade performance } \\
\text { data consists of } \\
\text { inspection punch lists } \\
\text { and callbacks, but } \\
\text { trend data is not } \\
\text { tracked. }\end{array}$ & $\begin{array}{l}\text { Trade performance } \\
\text { trend data is tracked } \\
\text { and reviewed regularly } \\
\text { with the key trades and } \\
\text { used to improve quality } \\
\text { and prevent defects. }\end{array}$ & $\begin{array}{l}\text { Primary use is } \\
\text { checklists, some } \\
\text { performance test data } \\
\text { used to gauge trade } \\
\text { against performance } \\
\text { standards }\end{array}$ & $\begin{array}{l}\text { Customer satisfaction } \\
\text { survey data on } \\
\text { construction } \\
\text { workmanship is used } \\
\text { as a trade performance } \\
\text { indicator. }\end{array}$ & $\begin{array}{l}\text { Performance testing is } \\
\text { used as another metric } \\
\text { for trade performance }\end{array}$ & $\begin{array}{l}\text { Trades use builder } \\
\text { performance data to } \\
\text { monitor and improve } \\
\text { performance. } \\
\text { Trades are recognized } \\
\text { and rewarded for } \\
\text { outstanding } \\
\text { performance. }\end{array}$ & $\begin{array}{l}\text { Performance testing is } \\
\text { used as another metric } \\
\text { for trade performance }\end{array}$ \\
\hline $\begin{array}{l}7.4 \\
\text { Trade } \\
\text { Contractor and } \\
\text { Supplier } \\
\text { Results }\end{array}$ & $\begin{array}{l}\text { Trade contractor } \\
\text { quality seems to be } \\
\text { improving, but there } \\
\text { are no measures of } \\
\text { progress. }\end{array}$ & $\begin{array}{l}\text { Some trade } \\
\text { contractors show } \\
\text { measured quality } \\
\text { improvements. }\end{array}$ & $\begin{array}{l}\text { All major trade } \\
\text { contractors show } \\
\text { measured quality } \\
\text { improvements. }\end{array}$ & $\begin{array}{l}\text { Measurement system } \\
\text { includes key } \\
\text { performance attributes }\end{array}$ & $\begin{array}{l}\text { All major contractors } \\
\text { show excellent quality } \\
\text { results. } \\
\text { Most trade contractors } \\
\text { routinely meet quality } \\
\text { standards. }\end{array}$ & $\begin{array}{l}\text { Quality standards } \\
\text { include Performance } \\
\text { standards }\end{array}$ & $\begin{array}{l}\text { In addition to level } 4 \text {, } \\
\text { all major trade } \\
\text { contractors show } \\
\text { positive quality } \\
\text { improvement trends. }\end{array}$ & $\begin{array}{l}\text { Performance testing } \\
\text { shows improvement } \\
\text { trends. }\end{array}$ \\
\hline
\end{tabular}




\begin{tabular}{|c|c|c|c|c|c|c|c|}
\hline \multicolumn{8}{|c|}{ NHQ Rating Form } \\
\hline \multirow[b]{2}{*}{1.} & \multirow[b]{2}{*}{ Leadership } & \multicolumn{6}{|c|}{$\begin{array}{c}\text { Rating } \\
\text { (circle your choice) }\end{array}$} \\
\hline & & & & & & & \\
\hline 1.1 & Company Mission, Vision and Values & 1 & 2 & 3 & 4 & 5 & $?$ \\
\hline 1.2 & Senior Management Involvement & 1 & 2 & 3 & 4 & 5 & $?$ \\
\hline 1.3 & Leadership Feedback and Improvement & 1 & 2 & 3 & 4 & 5 & $?$ \\
\hline 1.4 & Living the Mission & 1 & 2 & 3 & 4 & 5 & $?$ \\
\hline 1.5 & Public Responsibility & 1 & 2 & 3 & 4 & 5 & ? \\
\hline 2. & Strategic Planning & & & & & & \\
\hline 2.1 & $\begin{array}{l}\text { Company-wide Success Drivers and Performance } \\
\text { Measures }\end{array}$ & 1 & 2 & 3 & 4 & 5 & ? \\
\hline 2.2 & Strategic Plans & 1 & 2 & 3 & 4 & 5 & ? \\
\hline 2.3 & Plan Deployment & 1 & 2 & 3 & 4 & 5 & ? \\
\hline 2.4 & Monitoring Progress to Plan & 1 & 2 & 3 & 4 & 5 & ? \\
\hline 3. & Customer Satisfaction & & & & & & \\
\hline $3.1 \mathrm{a}$ & Market Research & 1 & 2 & 3 & 4 & 5 & ? \\
\hline $3.1 \mathrm{~b}$ & Product Design Processes & 1 & 2 & 3 & 4 & 5 & $?$ \\
\hline 3.2 & Customer Satisfaction Drivers & 1 & 2 & 3 & 4 & 5 & $?$ \\
\hline 3.3 & Customer Relationship Management & 1 & 2 & 3 & 4 & 5 & ? \\
\hline $3.4 a$ & Customer Satisfaction Measurement & 1 & 2 & 3 & 4 & 5 & ? \\
\hline $3.4 \mathrm{~b}$ & Sharing of Customer Satisfaction Feedback & 1 & 2 & 3 & 4 & 5 & ? \\
\hline 3.5 & Customer Satisfaction Results & 1 & 2 & 3 & 4 & 5 & $?$ \\
\hline 4. & Performance Management & & & & & & \\
\hline $4.1 \mathrm{a}$ & Creating High Performance Work Processes & 1 & 2 & 3 & 4 & 5 & ? \\
\hline $4.1 \mathrm{~b}$ & Benchmarking Business Processes & 1 & 2 & 3 & 4 & 5 & $?$ \\
\hline 4.2 & Performance Management & 1 & 2 & 3 & 4 & 5 & $?$ \\
\hline 4.3 & Process Improvement & 1 & 2 & 3 & 4 & 5 & $?$ \\
\hline 4.4 & Improvement Results & 1 & 2 & 3 & 4 & 5 & ? \\
\hline 4.5 & Financial Improvement Results & 1 & 2 & 3 & 4 & 5 & ? \\
\hline 5. & Human Resources & & & & & & \\
\hline $5.1 \mathrm{a}$ & Employee Satisfaction & 1 & 2 & 3 & 4 & 5 & ? \\
\hline $5.1 \mathrm{~b}$ & Jobsite Safety & 1 & 2 & 3 & 4 & 5 & ? \\
\hline $5.1 \mathrm{c}$ & Job Responsibilities & 1 & 2 & 3 & 4 & 5 & ? \\
\hline $5.1 \mathrm{~d}$ & Teamwork & 1 & 2 & 3 & 4 & 5 & ? \\
\hline 5.2 & Workforce Development & 1 & 2 & 3 & 4 & 5 & ? \\
\hline 5.3 & Employee Evaluation and Compensation Systems & 1 & 2 & 3 & 4 & 5 & ? \\
\hline 6. & Quality Construction Processes & & & & & & \\
\hline 6.1 & Setting Quality Expectations & 1 & 2 & 3 & 4 & 5 & ? \\
\hline 6.2 & Assuring Quality Results & 1 & 2 & 3 & 4 & 5 & ? \\
\hline
\end{tabular}




\begin{tabular}{|l|l|c|c|c|c|c|c|}
\hline \hline \multicolumn{10}{|c|}{ NHQ Rating Form } \\
\hline \hline & & \multicolumn{7}{c|}{$\begin{array}{c}\text { Rating } \\
\text { (circle your choice) }\end{array}$} \\
\hline 6.3 & Quality Problem Prevention & 1 & 2 & 3 & 4 & 5 & $?$ \\
\hline 6.4 & Warranty Service & 1 & 2 & 3 & 4 & 5 & $?$ \\
\hline 6.5 & Product and Service Quality Results & 1 & 2 & 3 & 4 & 5 & $?$ \\
\hline 7. & Supplier Partnerships & & & & & & \\
\hline 7.1 & Trade Contractor and Supplier Relationships & 1 & 2 & 3 & 4 & 5 & $?$ \\
\hline 7.2 & Trade Development & 1 & 2 & 3 & 4 & 5 & $?$ \\
\hline 7.3 & Trade Contractor Performance Management & 1 & 2 & 3 & 4 & 5 & $?$ \\
\hline 7.4 & Trade Contractor and Supplier Results & 1 & 2 & 3 & 4 & 5 & $?$ \\
\hline \hline
\end{tabular}




\begin{tabular}{|c|c|}
\hline NHQ Survey information & $\begin{array}{l}\text { Information } \\
\text { Champion }\end{array}$ \\
\hline \multicolumn{2}{|l|}{ Company Mission, Vision and Values } \\
\hline $\begin{array}{l}\text { What are the company mission statement, core values, and vision } \\
\text { for the future? How is this documented and communicated } \\
\text { amongst the staff? }\end{array}$ & \\
\hline $\begin{array}{l}\text { How do senior managers demonstrate a commitment to the } \\
\text { company mission, values, and vision, and to what extent does } \\
\text { this translate to the actions of others throughout the organization? }\end{array}$ & \\
\hline $\begin{array}{l}\text { What feedback mechanisms exist from field to management } \\
\text { relating to company's ability to deliver to the company mission, } \\
\text { values, and progress towards vision? }\end{array}$ & \\
\hline $\begin{array}{l}\text { How does the company understand if employees are in alignment } \\
\text { with the company mission, values, and vision, and are there } \\
\text { activities that specifically encourage and reinforce that alignment? }\end{array}$ & \\
\hline $\begin{array}{l}\text { Does the company facilitate and coordinate opportunities to } \\
\text { benefit the local community in alignment with the mission, values, } \\
\text { and vision? }\end{array}$ & \\
\hline \multicolumn{2}{|l|}{ Strategic Planning } \\
\hline $\begin{array}{l}\text { What measurement mechanisms exist to evaluate if the company } \\
\text { is achieving the mission, progressing towards the vision, and } \\
\text { achieving customer satisfaction and operational performance } \\
\text { metrics? }\end{array}$ & \\
\hline $\begin{array}{l}\text { Is there a written strategic plan that documents the improvement } \\
\text { process in different operational areas, the tools and systems used } \\
\text { to identify areas of weakness and measure company-wide } \\
\text { operational improvements, a detailed strategic plan for } \\
\text { improvements in key areas, and who is involved in developing } \\
\text { specific strategic improvement plans? }\end{array}$ & \\
\hline $\begin{array}{l}\text { What process is in place to implement the plan, and how far } \\
\text { throughout the organization does implementation reach? }\end{array}$ & \\
\hline $\begin{array}{l}\text { What mechanisms are used and how often is review performed to } \\
\text { monitor how well the organization is improving relative to the } \\
\text { strategic plan? How often is the strategic plan updated? }\end{array}$ & \\
\hline
\end{tabular}




\begin{tabular}{|c|c|}
\hline NHQ Survey information & $\begin{array}{l}\text { Information } \\
\text { Champion }\end{array}$ \\
\hline \multicolumn{2}{|l|}{ Customer Satisfaction } \\
\hline $\begin{array}{l}\text { What market research mechanisms are in place to understand } \\
\text { customers, position relative to local competition, and forward } \\
\text { positioning of products based on leading indicators (e.g., } \\
\text { demographics, economic, style, etc.) }\end{array}$ & \\
\hline $\begin{array}{l}\text { What is the design process? Who is involved? What feedback } \\
\text { mechanisms exist? }\end{array}$ & \\
\hline $\begin{array}{l}\text { - What importance is placed on customer satisfaction, and how is } \\
\text { that expressed in the company mission, values, and vision? }\end{array}$ & \\
\hline $\begin{array}{l}\text { What process is in place to guide the customer through the sales } \\
\text { and construction process? }\end{array}$ & \\
\hline $\begin{array}{l}\text { - How is customer satisfaction measured and used throughout the } \\
\text { company to improve the customer relationship process? }\end{array}$ & \\
\hline \multicolumn{2}{|l|}{ Performance Management } \\
\hline $\begin{array}{l}\text { How does the organization set up work processes, identify work } \\
\text { process improvements, and Benchmark against other industry } \\
\text { and non-industry top performers? }\end{array}$ & \\
\hline $\begin{array}{l}\text { - How are work processes measured, and do they support key } \\
\text { company wide success measures? }\end{array}$ & \\
\hline - How are work-processes evaluated and improved? & \\
\hline - How are work-processes tied to the quality of the house? & \\
\hline $\begin{array}{l}\text { - How are company financial results measured, and tied to work } \\
\text { processes? }\end{array}$ & \\
\hline \multicolumn{2}{|l|}{ Human Resources } \\
\hline $\begin{array}{l}\text { - Are employees are surveyed on job satisfaction and have input } \\
\text { on improving employee satisfaction? }\end{array}$ & \\
\hline $\begin{array}{l}\text { What is the company safety plan, and how far into the } \\
\text { organization does it reach? }\end{array}$ & \\
\hline $\begin{array}{l}\text { - How empowered are employees with respect to their job and } \\
\text { achieving key success metric? }\end{array}$ & \\
\hline $\begin{array}{l}\text { - How are teams utilized to perform management functions within } \\
\text { the organization? }\end{array}$ & \\
\hline $\begin{array}{l}\text { What kind of the training and employee development program } \\
\text { exists in the company? }\end{array}$ & \\
\hline
\end{tabular}




\begin{tabular}{|c|c|}
\hline NHQ Survey information & $\begin{array}{l}\text { Information } \\
\text { Champion }\end{array}$ \\
\hline $\begin{array}{l}\text { - How are employees and teams evaluated, compensated, and } \\
\text { given incentive toward key success measures for the company }\end{array}$ & \\
\hline Quality Construction Process & \\
\hline $\begin{array}{l}\text { What are the company's quality standards, and how are these } \\
\text { communicated throughout the organization and to trades? }\end{array}$ & \\
\hline $\begin{array}{l}\text { - How do management, field, and trades monitor consistency and } \\
\text { delivery of product that meets quality standards? }\end{array}$ & \\
\hline $\begin{array}{l}\text { How do the company and the trades monitor and evaluate quality } \\
\text { problems and develop process improvements to eliminate } \\
\text { problems? }\end{array}$ & \\
\hline $\begin{array}{l}\text { - How is warranty service used to identify and fix root causes of } \\
\text { quality problems? }\end{array}$ & \\
\hline $\begin{array}{l}\text { How have these improvements contributed to zero defect at final } \\
\text { inspection, and show positive trends in quality improvement and } \\
\text { excellent results }\end{array}$ & \\
\hline Supplier Partnerships & \\
\hline $\begin{array}{l}\text { - How are trade contractors and suppliers engaged in the } \\
\text { company's quality initiatives? }\end{array}$ & \\
\hline $\begin{array}{l}\text { What strategies are in place to align trade contractors with the } \\
\text { company mission, values, and vision; develop the trades to } \\
\text { achieve quality standards; and provide financial rewards for } \\
\text { achieving quality goals? }\end{array}$ & \\
\hline $\begin{array}{l}\text { How is trade contractor performance tracked, and how is that } \\
\text { data used to continually improve the trade contractor's } \\
\text { performance? }\end{array}$ & \\
\hline $\begin{array}{l}\text { What are the results associated with the trade contractor } \\
\text { initiatives? }\end{array}$ & \\
\hline
\end{tabular}




\section{Appendix E. High-Performance Scopes of Work}

\section{Trade Contractor Standards and Description of Work Performance}

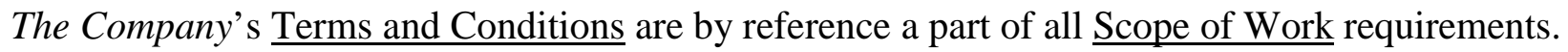
The Company's Construction Documents including Construction Drawings and Specifications, these "Trade Contractor Standards and Description of Work Performance" and the "Trade Contractor Requirements and Checklists" are included by reference as a description of the Work to be performed by The Trade Contractor and are by reference a part of the agreement between The Company and The Trade Contractor.

\section{Construction Requirements}

Generally speaking, the work of Trade Contractor and their employees is expected to be performed in a good and workmanlike manner. Workmanlike quality is defined as workmanship which meets or exceeds those criteria indicated in applicable building codes, The Company's specific performance requirements, NAHB's Residential Construction Performance Guidelines, and manufacturer specifications, using materials and installation methods identified in the construction documents (plans and specifications) and the Trade Contractor Requirements and Checklists. The quality of The Trade Contractor's installation is expected to support the quality of the builder's design and specified materials.

\section{Code Requirements}

All jobs shall conform to those standards stipulated in the building code, mechanical code, plumbing code, and electrical code applicable in the local jurisdiction. "Code" means the minimum standard that will achieve an occupancy permit. It does not necessarily mean "quality" or "high performance."

If any high performance requirements pertaining to the Trade Contractor's Work are in conflict with either the local building code or local code official interpretation of the local building code, it is the responsibility of the Trade Contractor to notify The Company of any conflict as soon as the Trade Contractor becomes aware of any such conflict.

\section{High-Performance Requirements}

High Performance Requirements address the major damage functions that affect materials and buildings: heat, water, radiation (ultraviolet) and biological organisms (which frequently require liquid water). Reducing the risk of damage by these forces is accomplished principally by controlling the following flows across the building enclosure: energy (thermal and ultraviolet radiation), air (heat and moisture), water (liquid, capillary and vapor) and insects and other pests. 
The High Performance Requirements for each Trade Contractor's Work make explicit the general premise that quality and high performance are linked —one cannot be achieved without the other. While a worker could successfully satisfy the requirements in the scopes without understanding the objective or the rational, an informed worker is more likely to satisfy the intent of the requirements and is definitely more likely to devise alternative solutions that may be as or more effective, as easy or easier to accomplish, and as or less expensive.

Trade Contractor-specific High Performance Requirements are contained in the Introduction of the Trade Contractor Requirements and Checklists for each Trade Contractor.

\section{General Requirements}

The general requirements refer to the specific manufacturer's instructions or requirements or a specific trade organization's requirements for performance or installation practices. The Trade Contractor shall notify The Company (Superintendent) if a discrepancy is identified between the manufacturer's requirements and The Company's specific requirements.

All installations are the responsibility of The Trade Contractor. It is also the responsibility of The Trade Contractor to:

1. Ensure that each of their installation employees has read and understands the Trade Contractor Requirements and Checklists.

2. Designate a Trade Contractor supervisory representative to complete and sign the Pre-Work Inspection and the Post-Work Inspection Checklists contained in Trade Contractor Requirements and Checklists.

Completed Pre-Work Inspection and Post-Work Inspection Checklists must be and kept on file at The Trade Contractor's office.

\section{Interaction with Other Trades}

Construction is a process that involves sequential work performed by a variety of subcontractors. The Trade Contractor must understand that his Work does not occur in isolation; rather it must integrate with Work that precedes and follows his Work. Each contractor must therefore preserve the integrity of the prior Work performed by other contractors. The Trade Contractor understands the importance of the continuity of drainage planes, air barriers, and thermal barriers and will train their employees to protect these systems or repair them if they are compromised during their course of their Work. The Trade Contractor Requirements and Checklists expresses trade interaction concerns and items in the Introduction as well as throughout the Requirements, associated Details, and Checklists, but particularly in the Pre-Work Inspection Checklist. The Pre-Work Inspection Checklist in Trade Contractor Requirements and Checklists establishes the status of these systems before The Trade Contractor begins work while the Post-Work Inspection Check List in Trade Contractor Requirements and Checklists verifies their status at the conclusion of The Trade Contractor's work. 


\section{General Comments}

1. The Company considers our Trade Contractors to be experts at producing a high-quality job. But everyone on our construction team-staff, Trade Contractors, and suppliers-recognizes the importance of providing quality in both the product and service areas while on our jobsites and in the homes of our purchasers.

2. Since we work as a team, poor quality or service from any of us reflects unfavorably on all of us. An exceptional level of product quality and highly effective service can help us all to increase our business and grow.

3. The Company's definition of quality construction also requires that every job be completed correctly the first time. When this does not occur, it costs both of us additional money, imposes on the purchaser, and hurts our reputations as quality builders. That is why, in situations where construction was not completed in a quality manner, prompt corrective action is required to remedy specific deficiencies.

4. In the following information the term 'Site Superintendent' refers to any Company representative with authority to perform the specified task. The term Trade Contractor means The Trade Contractor's organization or any representative who is assigned the authority to perform the specified task.

\section{Detailed Job Requirements}

1. A new set of plans is required for each house. Plans are subject to changes and modifications. It is the responsibility of The Trade Contractor to have the new plans before beginning work. Plans should be picked up at the job trailer from the Site Superintendent, or provided to the Trade Contractor's installation crews by the Trade Contractor. Any errors that occur from using an incorrect set of plans will be corrected by The Trade Contractor at no cost to The Company.

2. Purchase orders shall be transmitted to The Trade Contractor from The Company's office and shall be provided in ample time for The Trade Contractor to have the correct materials on hand prior to starting the Work.

3. Specific installation instructions, including associated Details, are supplied in Trade Contractor Requirements and Checklists.

4. Performance testing, when applicable (as detailed below), will be one method of testing the success of the installation.

5. Any items found during the final inspection that need correction shall be corrected before payment will be made. 


\section{Performance Testing}

1. When an appropriate test method exists to evaluate the performance of the installation, it will be detailed in this section. Testing protocols that may apply include $100 \%$ testing (every installation), random percentage (e.g. 1 in 7) or the reserved right to test any installation as determined by The Company or the Site Superintendent. Test protocols, and the definition of successful performance or the threshold for successful performance are detailed in the Trade Contractor Requirements and Checklists .

2. The definition of successful performance or the threshold for successful performance will also be detailed.

3. The Trade Contractor will be responsible for correcting the installation so that performance meets the stated threshold. The cost of corrective action is the responsibility of The Trade Contractor. 


\section{Inspection Checklist}

1. The post-installation inspection checklist documents The Trade Contractor's compliance with the performance requirements that are explicitly detailed in Trade Contractor Requirements and Checklists. The Post-Inspection Checklist is contained in Trade Contractor Requirements and Checklists.

2. Inspection checklists are provided to document successful completion of the installation as included in Trade Contractor Requirements and Checklists. If the installation fails to meet the requirements specified in this Scope of Work or conform to the Finished Detail then The Trade Contractor must correct any deficiency found during any inspection at no cost to The Company. If the deficiency is discovered prior to payment, the deficiency must be successfully corrected before payment will be made.

3. Performance test results will be reported on the Post-Work Inspection Checklist. Note that there are times when the specific performance test cannot be performed until well AFTER the completion of the work, after completion of the checklist and even after the deficiency can be readily remedied by the responsible Trade Contractor. When this occurs, the Trade Contractor will take reasonable and practical measures to fix the performance failure, and develop a corrective action plan with the builder to identify the cause of the performance failure and how the Trade Contractor will meet the performance requirement in the future. It is conceivable that the deficiency for which the Trade Contractor is responsible will be worked out within the broader financial agreements and exchange between The Company and the Trade Contractor, rather than on the level of one particular home.

4. The Trade Contractor and the Site Superintendent must sign-off on all deficiencies attesting that the job is 100-percent complete and is correct per the job requirements found in this Scope of Work.

I agent for

have read and fully understand the above Scope of Work and I hereby agree to perform all work in accordance with the above.

Date:

Signed: Trade Contractor (or agent)

Date:

For The Company 


\section{Mixed-Humid Climate Foundation Requirements and Checklists}

\section{Foundation Requirements}

\section{Introduction - High Performance Foundation}

[NOTE: for the purposes of this scope of work, it is assumed that the foundation contractor is responsible for the foundation, system which includes structural footings, piers, slabs, and walls, the water management system including perimeter drainage and damproofing / waterproofing. To the extent that these activities are separately contracted by The Company, this Scope of Work should be split to focus on those work areas each Trade Contractor will be responsible for.]

High Performance is defined as superior energy efficiency, safety, comfort, and durability. Managing the flows of moisture and air with the same thoroughness as energy protects against the major damage functions a home faces- heat, water, radiation (ultraviolet) and biological organisms (frequently requiring liquid water).

The work of the Foundation Trade Contractor contributes to high performance in the following ways:

- Water management -

o Installation of a capillary break between footings and foundation walls

o Installation of a capillary break on the below-grade portions of exterior foundation walls

o Installation of a capillary break between the soil and the concrete slab

o Installation of a perimeter drain system along footings for basements and crawl spaces where the floor is below the exterior grade

o Installation of a capillary break on both the above grade and below grade perimeter of slab on grade foundations

- Integrity and Continuity of the Thermal Barrier -

o Installation of foundation insulation in a continuous manner

o Installation of sub-slab insulation in a continuous manner

- Integrity and Continuity of the Air Barrier -

o Installation of the concrete and foundation walls so that they can function as an air barrier. This is accomplished by providing control joints and expansion joints in the proper locations. These known areas of actual or potential cracks in the air barrier can then be properly sealed. 
o Installation of continuously sealed vapor barrier ground cover on the floor of a crawl space also provides an air barrier between the soil and air within the crawl space.

- Vapor management -

o Installation of the polyethylene vapor barrier under concrete slab

o Installation of the polyethylene vapor barrier/ground cover on the floor of a crawl space

o Installation of dampproofing on the below ground sections of foundation walls

Construction is a process that involves sequential work performed by a variety of subcontractors.

The Foundation Trade Contractor's work is generally followed by The Framing Contractor, The Roofing Contractor, The Drainage Plane Contractor, The Window Trade Contractor, The Insulating Contractor and later by The HVAC Contractor with these high performance implications:

- Air sealing must be accomplished between the top of foundation walls and the sill plate. Levelness and uniformity of the top of the foundation walls facilitate air sealing.

- Air sealing must be accomplished between rough openings for windows and doors. Dimensional accuracy and uniformity of these openings facilitate air sealing between the foundation wall and windows and doors.

Performance testing is often a key step along the path to high performance.

- Water testing of the perimeter drainage system can determine the ability of the perimeter drainage system to transport water.

- Successful performance is the free flow of water from any section of the perimeter drainage system to the opening to daylight or the sump pit.

The Foundation Trade Contractor will be responsible for correcting deficiencies in installation so that performance meets the requirements of The Company and high performance in these Scopes. The cost of corrective action is the responsibility of The Foundation Trade Contractor. For more comprehensive information on the relationship between foundation installation and high performance homes, see the following resources:

- Builder’s Guide to Mixed-Humid Climates (August 2005) specifically Chapters 2 and 7.

- Building America Best Practices Series Volume 4 (www.nrel.gov/docs/fy05osti/38448.pdf)

- Designs That Work - Mixed-Humid Climates (www.buildingscience.com/designsthatwork/default.htm) 
Pre-Work Inspection: completed and signed by Site Superintendent and The Foundation Trade Contractor

\section{Foundations - Types - Check all that apply to this building}

Slab at Grade - Slab

Basement - BSMT

$\square$ Crawl Space - interior grade below exterior grade - CS-BG

$\square$ Crawl Space - interior grade above exterior grade - CS-AG

Detailed Installation Checklist

1. Install capillary break on top surface of footing using specified material.

2. Install a minimum of 4 inches of crushed stone -0.75 inch diameter, no fines. - under slabs and under ground covers in crawl spaces.

$\square$ 3. Install sub slab soil gas ventilation pipe - 4 inch perforated pipe, minimum total length of 6 feet, with central T-fitting that connects to the vertical solid pipe that will continue through the roof. Cap the short section of vertical pipe (minimum 6 inches above top of finished slab) to prevent concrete entering the pipe.

4. Install sub slab rigid insulation - extruded polystyrene, expanded polystyrene or high density mineral wool - on the crushed stone as specified in plans.

5. Install 0.75 inch rigid insulation as bond break between the foundation walls and the slab edge.

6. If a vapor retarder (polyethylene) is called for, it is installed on top of the rigid insulation in direct contact with the underside of the concrete slab.

7. For slabs with turned down edge, place the rigid insulation against the concrete form and place the polyethylene in footer trench and continue up to the top of the form. The polyethylene is placed interior to the rigid insulation so that the polyethylene will be in direct contact with the concrete. See Figure 1.

8. For slabs at grade with stem wall install rigid insulation along stem wall an under slab as called for in plans.

9. Control joints have been placed at the appropriate locations in all slabs.

10. Perimeter foundation drainage system installed along side the footings as shown in Figure 2.

11 Perimeter drainage system is connected to: (per plans or instructions from The Company)

$\square$ Daylight

$\square$ Interior drainage field and sump pit

12. Dampproofing installed on basement and crawl space walls to height of final grade.

13. Drainage board or free draining "backfill” installed per plans and specs. 


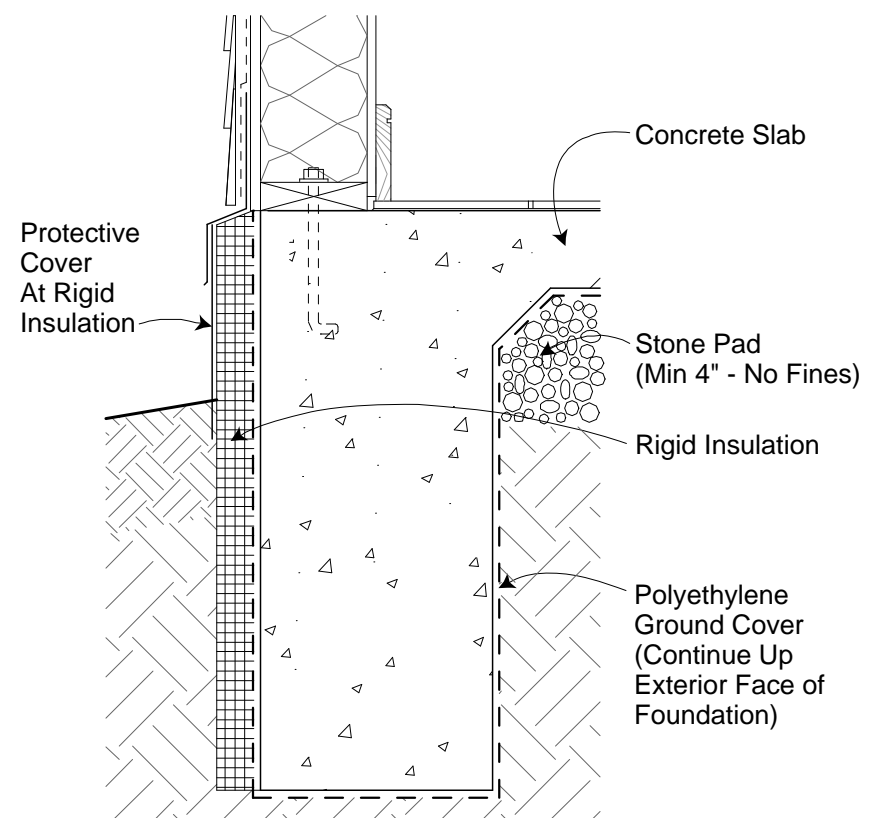

Figure E-1. Slab at grade - polyethylene under turned down edge and rigid insulation along perimeter of slab foundation

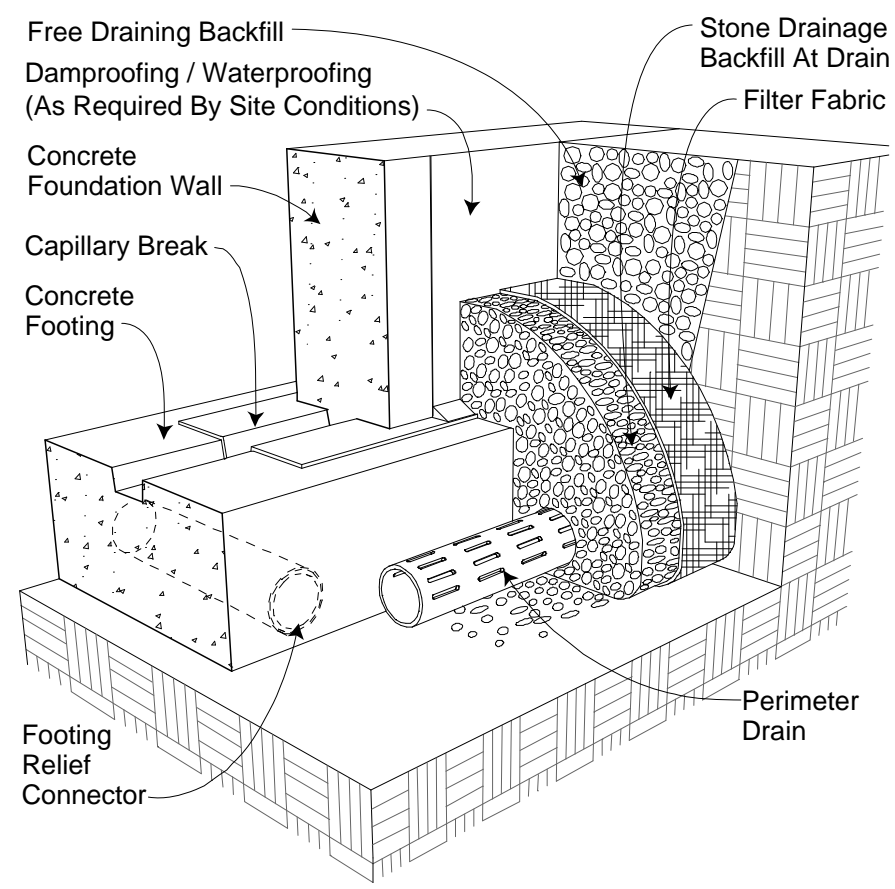

Figure E-2. Perimeter Drainage System along Footer

Refer to additional foundation details contained in the Builder's Guide to Mixed-Humid Climates (August 2005), specifically Chapter 7 and Chapter 10. 


\section{Pre-Work Inspection Checklist}

To be completed before the Trade Contractor starts work on the jobsite:

$\square$ 1. Construction is at the appropriate stage and conditions are acceptable for The Foundation Contractor to begin work.

$\square$ 2. Appropriate materials and equipment are onsite for work to be performed by The Foundation Trade Contractor.

$\square$ 4. The Foundation Trade Contractor has current plans. Record date of plans:

$\square$ 5. The Foundation Trade Contractor has current Company specifications for foundation installations.

$\square$ 6. The Foundation Trade Contractor has reviewed and accepts all high performance items that appear in the Detailed Installation Checklist

Company Rep's Initials

Trade Contractor's Initials 
To be completed before Trade Contractor leaves jobsite:

1 . The perimeter drainage system is installed.

2. The perimeter drainage system terminates to daylight or to the sump pit.

$\square$ 3. Dampproofing is present to final grade on crawl space and basement walls.

4. All site details match the Foundation Details.

$\square$ 5. No unapproved material substitutions have been made from The Company specs.

$\square$ 6. Crushed stone is to the proper depth is present on crawl space floors.

$\square$ 7. The soil gas ventilation pipe is present at the proper location, and marked so as not to be mistaken for a sewer connection.

$\square$ 8. Control joints are present at the correct locations in concrete slabs.

$\square$ 9. Water testing of the perimeter drainage system successfully demonstrated the ability of the drainage pipe to transport water daylight or to the sump pit.

$\square$ 10. The Trade Contractor installer checklist is completed and signed.

Company Rep’s Initials

Trade Contractor's Initials 


\section{Mixed-Humid Climate Framing Requirements and Checklists}

\section{Framing Requirements}

\section{Introduction: High-Performance Framing}

High Performance is defined as superior energy efficiency, safety, comfort, and durability. Managing the flows of moisture and air with the same thoroughness as energy protects against the major damage functions a home faces- heat, water, radiation (ultraviolet) and biological organisms (frequently requiring liquid water).

The work of the Framing Trade Contractor contributes to high performance in the following ways:

- Water management -

o Capillary break installed between ALL bottom plates and concrete or masonry

o Prompt installation of or enablement of prompt installation by a subsequent Trade Contractor of the roofing underlayment over sheathed roofs and weather-resistive barrier on walls

o Installation of framing and sheathing materials not in excess of $19 \%$ moisture content and free of mold growth.

o Installation of structural sheathing and insulating sheathing to prevent, to the greatest extent possible, water penetration into interior during construction, and if applicable as part of the final drainage plane strategy as determined by The Company.

- Integrity and Continuity of the Thermal Barrier -

o Five-sided enclosure (top, bottom, sides, and rear) for insulation in all framing cavities separating conditioned space from unconditioned space for those areas to receive drywall by others. In concealed areas not to receive drywall as a finish material, The Framing Contractor shall coordinate with The Supervisor and The Insulation Contractor to assure that insulation is encapsulated on all six sides (see the Installation Checklist for details, and the EPA Thermal Bypass Checklist, www.energystar.gov/ia/partners/bldrs_lenders_raters/downloads/Thermal_Bypass _Checklist.pdf.).

o Efficient framing, such that two-by stock is used only where structurally necessary.

- Integrity and Continuity of the Air Barrier -

o Air seal at all bottom plates on exterior walls 
o Install plywood or OSB structural sheathing with gaps as required by the manufacturer. Where insulated Sheathing is installed, butt panel joints tightly and tape joints (if applicable).

o In concealed areas not to receive drywall as a finish material, the framing contractor shall coordinate with the site supervisor and insulation contractor to assure that insulation is installed and encapsulated on all six sides of frame wall cavities (see the Installation Checklist for details).

o Installation of draft stops in areas that will not be accessible after completion of framing (see the Installation Checklist for details).

- Vapor management

o No substitutions of sheathing materials with performance properties (including water absorption and vapor permeability) different than the sheathing materials specified.

Construction is a process that involves sequential work performed by a variety of subcontractors. The Framing Trade Contractor's work is generally preceded by The Foundation Trade Contractor, with these high performance implications:

- Foundation insulation - protect this material and replace as necessary when damaged as the result of framing work.

- Foundation drainage system - protect this system and replace as necessary when damaged as the result of framing work.

The Framing Trade Contractor's work is generally followed by The Roofing Contractor, The Drainage Plane Contractor, The Window Trade Contractor, The Insulating Contractor and later by The HVAC Contractor with these high performance implications:

- Flashing and/or weather-resistive barriers installed in rough openings must accommodate integration with window and door unit flashings, particularly at the sill and head.

- Framing layout in high performance homes is done in coordination with HVAC layout of equipment and ducts - do NOT vary from the framing layout or add framing/blocking that could interfere with a high performance HVAC installation.

- Framing, sheathing and airflow retarder components (this last IF installed by the Framing Trade Contractor) must be properly installed to permit full insulation of building cavities in an airtight manner.

Performance testing is often a key step along the path to high performance. Infra-red thermal imaging and air leakage testing (blower door) can act as performance tests for efficient framing and draft stop details. These tests may be used by The Company to verify the contribution of the frame to the thermal and air barriers. Unfortunately these tests can generally be done only at a much later stage of construction when corrective action is quite costly. It is, therefore essential that these details be successfully executed. Successful performance is defined as the addition of no unnecessary framing materials in substitution of thermal insulation and the presence of draft stop materials in all problematic air sealing areas as shown on the framing plans and Details in SOW \#2. 
A critical component of high performance framing can be detailed framing layouts (See Figure 1 in the Installation Checklist). Detailed framing layouts can "codify" thermal and air barrier continuity and integration of framing with HVAC design and installation.

The Framing Trade Contractor will be responsible for correcting deficiencies in installation so that performance meets the requirements of The Company and high performance in these Scopes. The cost of corrective action is the responsibility of The Framing Trade Contractor.

NOTE: The EPA ENERGY STAR program has identified 13 of the most common air leakage and thermal bypasses. For more information, see:

www.energystar.gov/ia/partners/bldrs_lenders_raters/downloads/Thermal_Bypass_Checklist.pdf.

For more comprehensive information on the relationship between framing and high performance homes, see the following resources:

- Builder’s Guide to Mixed-Humid Climates (August 2005)

- $\quad$ Building America Best Practices Series Volume 4 (www.nrel.gov/docs/fy05osti/38448.pdf)

- Designs That Work - Mixed-Humid Climates (www.buildingscience.com/designsthatwork/default.htm)

\section{Detailed Installation Requirements}

$\square$ Pre-Work and Post -Work Inspection checklists will be completed and signed by Site Superintendent and The Trade Contractor

$\square$ 1. Install Capillary break (closed-cell foam sill sealer or rubber membrane) underneath carrying beams at foundation beam pockets.

2. Install a double layer closed-cell foam sill sealer as a capillary break and air seal underneath all bottom plates that rest on concrete or masonry and separate conditioned from unconditioned spaces, including vertical transitions at foundation steps.

$\square$ 3. Install capillary break (closed-cell foam sill sealer or rubber membrane) under interior wall partitions on concrete slabs

4. If a framing layout plan is provided by The Company, install all framing per the framing layout plan (See example in Figure 1 below).

5. Use of structural lumber shall be limited to structural applications. This includes the following on walls that separate conditioned space from unconditioned space (See Figure 2 below):

$\square$ drywall stops at inside corners interior partition/exterior wall drywall stops

$\square$ minimized number of cripples

$\square$ minimized number of studs at rough openings

$\square$ 2- or 3-stud corners top plates (single)

6. All headers are load-tuned - they are sized to the specific load they will carry. Install headers only of the size and material as called out on the framing plans/specifications. 
7. Install a capillary break at locations where wood based sheathing (i.e. plywood, OSB) runs past the framed wall and contacts concrete or masonry. The capillary break is installed between the sheathing and concrete or masonry.

8. All framing cavities that separate conditioned space from unconditioned space are to be framed to form a five-sided (top, bottom, two sides, and rear) cavity to contain the insulation and prevent air from moving through air permeable insulation products (see Figure 3 below). The sixth side of most of these cavities will be completed with the installation of with the interior gypsum board, or other air impermeable finish interior. Those cavities that will NOT be finished with and air impermeable interior sheathing shall be sheathed with thin-profile sheathing, plywood, OSB, gypsum board, or other air impermeable sheathing products by The Framing Contractor. These areas include, but are not necessarily limited to:

a. tub surrounds on exterior walls

b. soffits terminating on exterior walls

c. framed fireplace/entertainment center/seat enclosures on exterior walls

d. plumbing/electrical/HVAC chases at attic or exterior walls

e. other architectural details that require framing on walls that will be insulated

9. All framing cavities that separate conditioned space from unconditioned space shall be sheathed on both sides of the stud cavity. If they are not sheathed as part of the building exterior, they are sheathed with a continuous, air sealed, air impermeable material to accomplish the five-sided enclosure for cavity insulation containment (See Figure 4 below). This includes but is not limited to the following areas:

$\square$ a. attic knee walls

b. ceiling height transition walls that abut attic space

c. walls that abut unconditioned front entryways

d. walls that abut future conditioned space

10. If required by The Company, rigid insulation of the thickness specified in the Specifications shall be installed as exterior sheathing and shall be installed on all walls that separate conditioned from unconditioned space.

$\square$ IF the rigid insulation is part of a continuous air barrier, then all seams in the rigid insulation are taped with material as specified by The Company.

$\square$ IF the rigid insulation is part of the drainage plane, than all vertical seams are taped and all horizontal seams are " $z$ "-flashed with 18-inch wide polyethylene sheathing. That is, after each course of rigid insulation is installed, polyethylene strips are fastened 8 to 9 inches up the framing from the top edge of the rigid insulation, draping down so that as the next course of rigid insulation is installed, the poly flashing forms a weatherlapped joint.

11. Air seal band or rim joists by installing a continuous bead of construction adhesive between the mudsill or top plat and the perimeter band or rim joists, between the subfloor and the perimeter band or rim joists, and at all vertical butt joints in the perimeter band or rim joists. 
$\square$ 12. Exterior sheathing material matches The Company's specifications. Alternate materials must be approved in writing by The Company.

13. Install all framing and framing accessory materials per manufacturer installation requirements. Any deviation from the manufacturer installation requirements must be approved by The Company.

NOTE: If The Company includes roofing underlayment installation in the responsibilities of The Framing Contractor, see the Scopes of Work documents for The Roofing Trade Contractor.

NOTE: If The Company includes drainage plane installation in the responsibilities of The Framing Contractor, see the Scopes of Work documents for The Drainage Plane Contractor.

NOTE: If The Company includes window installation in the responsibilities of The Framing Contractor, see the Scopes of Work documents for The Window Installation Contractor. 


\section{Details and Sequenced Drawings}

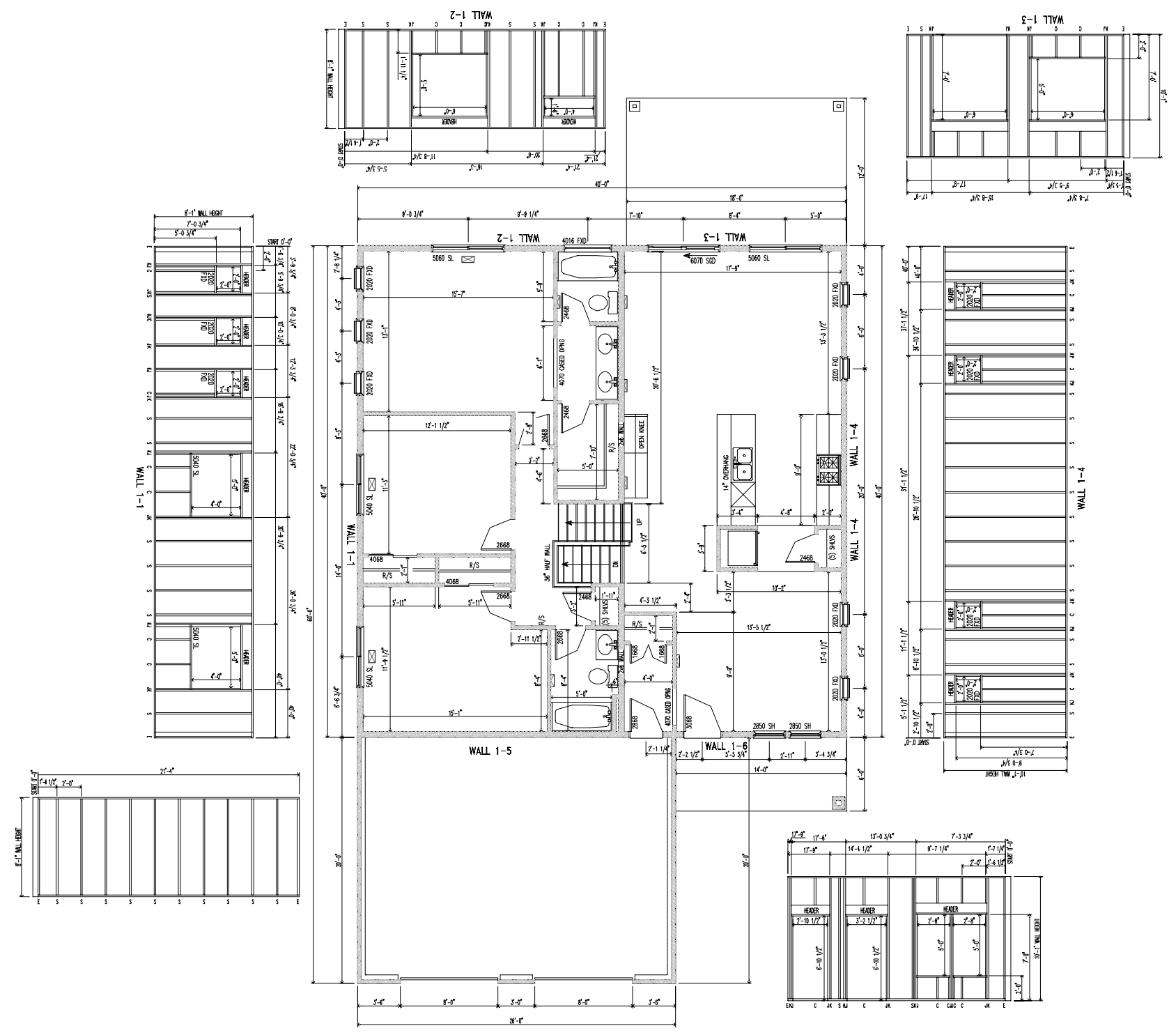

Figure E-3. Framing layout (image courtesy of Building Science Corporation) 


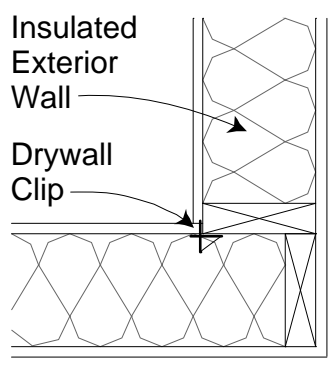

Drywall clip at interior corner

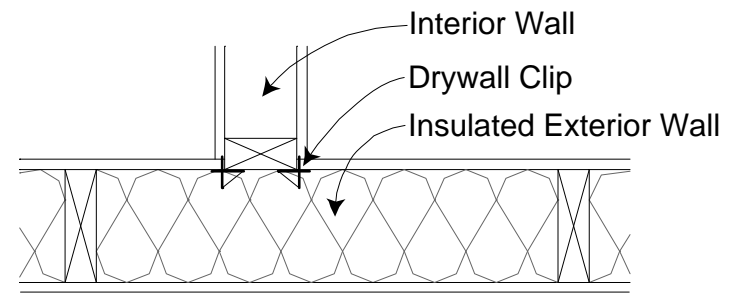

Drywall clips at interior partition
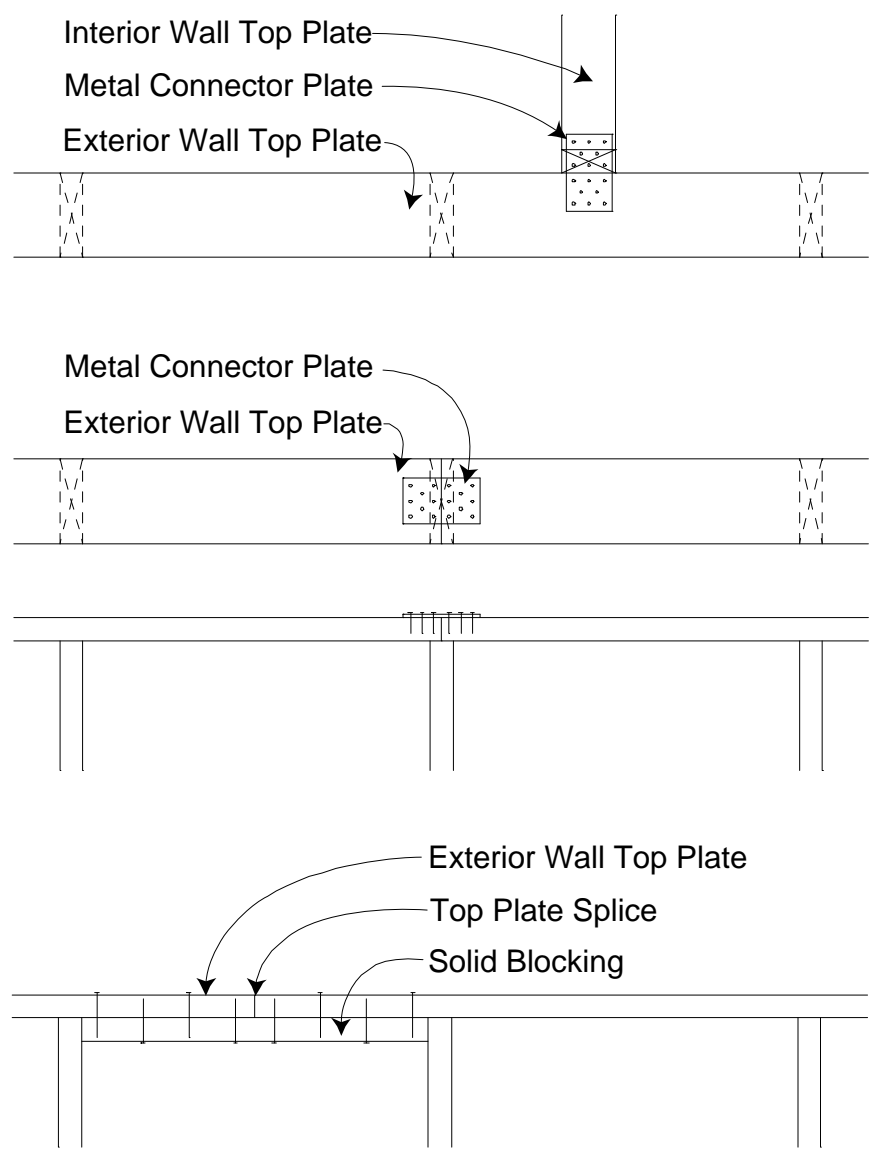

Methods for joining single top plates

Figure E.4. Efficient framing details 


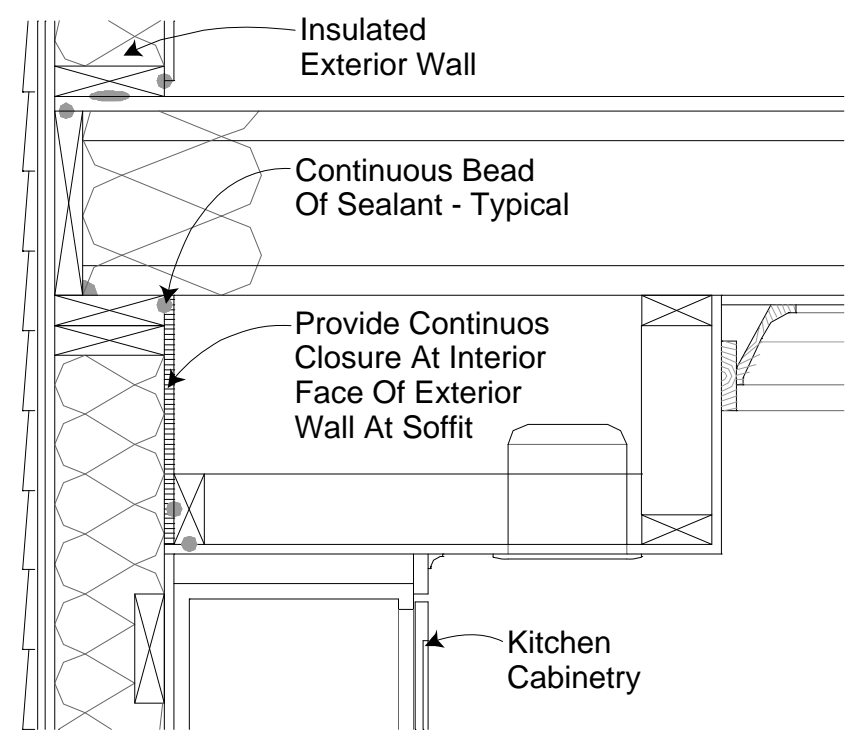

Draft stop behind soffit

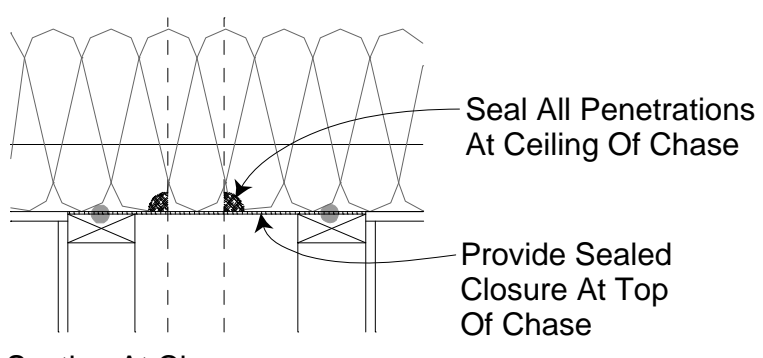

Section At Chase

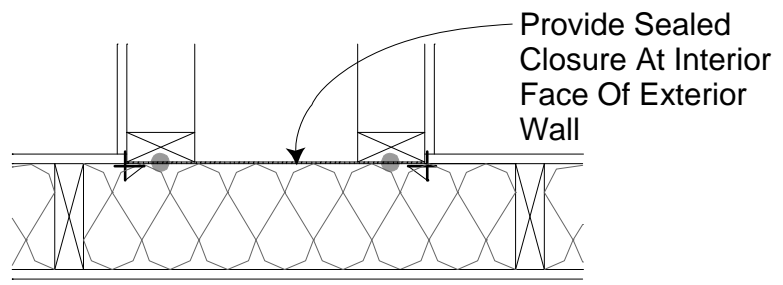

Plan At Chase

Draft stops: Upper drawing shows draft stop where chase meets attic and pipe continues into attic; lower drawing shows draft stopping where chase meets exterior wall.

Figure E-5. Draft Stopping Details - Group 1 


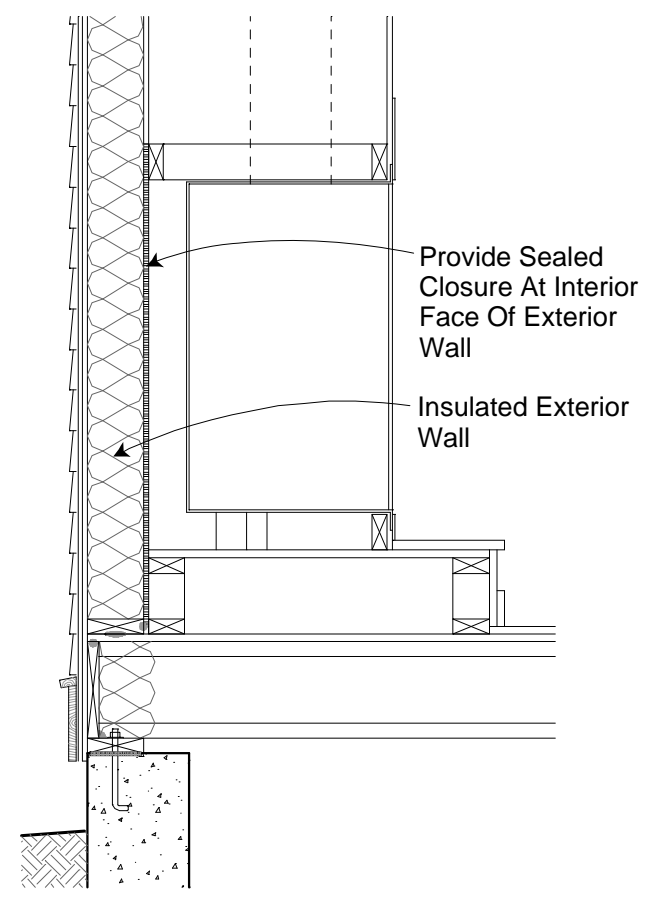

Figure E-6. Draft stop behind fire place insert

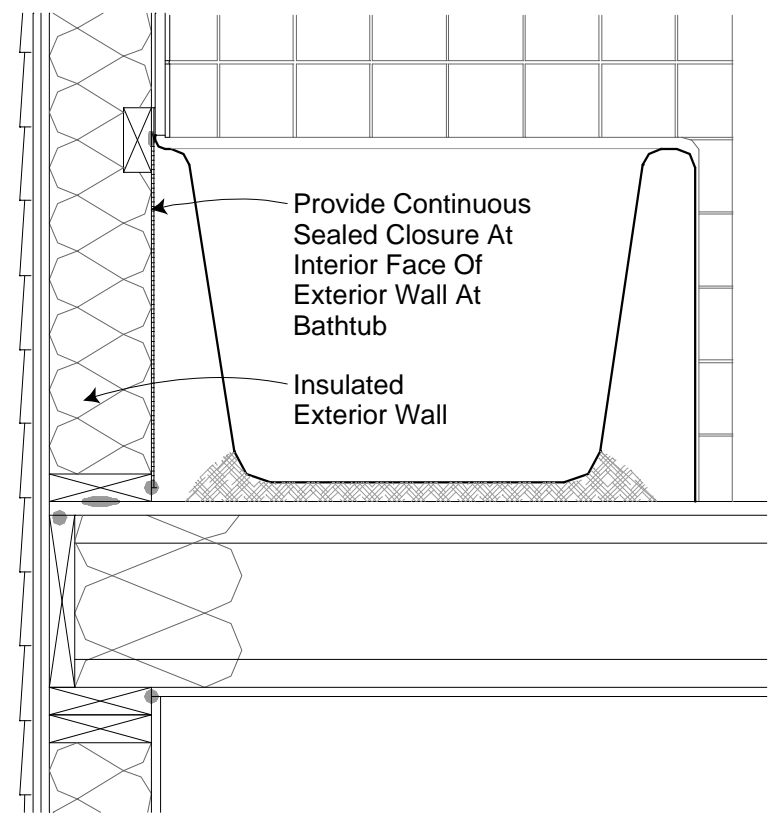

Figure E-7. Draft stop behind bathtub 
For additional framing details, refer the Builder's Guide to Mixed-Humid Climates (August 2005), specifically Chapter 11 . Additional framing details can be found at (www.buildingscience.com/designsthatwork/default.htm)

\section{Pre-Work Inspection Checklist}

To be completed before the Trade Contractor starts work on the jobsite:

1. Construction is at the appropriate stage and conditions are acceptable for The Trade Contractor to begin work.

$\square$ 2. Measured moisture content of framing lumber does not exceed $19 \%$.

3. If available from The Company, HVAC equipment and duct layout and sizing have been reviewed for integration/compatibility with the framing plans.

$\square$ 4. Appropriate materials and equipment are onsite for work to be performed by The Framing Trade Contractor.

5. The Framing Trade Contractor has current plans. Sign off on date of plans:

6. The Framing Trade Contractor has current Company specifications for all framing and framing accessories materials.

$\square$ 7. The Framing Trade Contractor has reviewed and accepts all High Performance Framing Requirements listed in the Introduction to Framing Requirements and Checklists.

$\square$ 8. The Framing Trade Contractor has reviewed and understands/accepts the Framing Requirements and Checklists including the associated details; in particular, five-sided or six-sided containment for all framing cavities that will be insulated.

$\square$ 9. The Framing Trade Contractor has reviewed and understands the HVAC duct layout and other mechanical system layouts, and has coordinated the framing layout with the Supervisor to ensure no conflicts with the work of The Company's HVAC Trade Contractor.

Company Rep’s Initials

Trade Contractor's Initials 


\section{Post-Work Inspection Checklist:}

To be completed before Trade Contractor leaves jobsite:

$\square$ 1. If applicable, all site details match the Company's Framing Layout Plans.

$\square$ 2. All capillary breaks to be installed by the Framing Trade Contractor as set forth in the Framing Requirements and associated Details are in place.

$\square$ 3. Any structural or insulating sheathing is free from damage (holes). Sheathing has been installed according to manufacturer's requirements, and is in accordance with Framing Standards and Description of Work Performance, Framing Requirements, and Company specifications.

$\square$ 4. All site details match the associated Details in the Framing Requirements.

$\square$ 5. All framing cavities that will receive drywall and separate conditioned space from unconditioned space have five-sided containment. All framing cavities that will not receive drywall and separate conditioned space from unconditioned space have been insulated and have six-sided containment.

$\square$ 6. All air sealing measures to be performed by the Framing Trade Contractor as set forth in the Framing Requirements and associated Details have been installed.

7. No unapproved framing material substitutions have been made from The Company specifications.

Company Rep’s Initials

Trade Contractor's Initials 


\section{Mixed-Humid Climate Drainage Plane Requirements and Checklists}

\section{Drainage Plane Requirements}

\section{Introduction: High-Performance Drainage Plane}

High Performance is defined as superior energy efficiency, safety, comfort, and durability. Managing the flows of moisture and air with the same thoroughness as energy protects against the major damage functions a home faces- heat, water, radiation (ultraviolet) and biological organisms (frequently requiring liquid water).

The work of the Drainage Plane Trade Contractor contributes to high performance in the following ways:

- Water management -

o Provides a barrier to prevent rain water that penetrates the finished exterior cladding system, from entering the wall assembly or being introduced into window or door openings

o Provides a pathway for liquid water that has penetrated the cladding system or accumulates due to daily or seasonal changes in thermal and humidity levels behind the cladding system to safely exit the exterior wall assembly

- Integrity and Continuity of the Thermal Barrier -

o The drainage plane, when properly sealed, can also reduce airflow through the wall assembly, which improves the thermal performance of the cavity insulation

- Integrity and Continuity of the Air Barrier -

o The drainage plane, when properly sealed, can function as an airflow retarder

- Vapor management -

o The rate at which water vapor flows into and out of the wall assembly is based in part on the material properties of the drainage plane.

Construction is a process that involves sequential work performed by a variety of subcontractors. The Drainage Plane Trade Contractor's work is generally preceded by The Foundation Trade Contractor and The Framing Contractor with these high performance implications:

- Foundation insulation - protect this material and replace as necessary when damaged as the result of framing work.

- Foundation drainage system - protect this system and replace as necessary when damaged as the result of framing work.

- Sheathing materials installed by The Framing Contractor are key elements of the airflow retarder and the thermal insulation - protect these components and replace or repair as necessary if damage during installation of the drainage plane. 
The Drainage Plane Trade Contractor's work is generally followed by The Window Trade Contractor, The Insulating Contractor and later by The HVAC Contractor with these high performance implications:

- Flashing and/or weather-resistive barriers installed in rough window and door openings must integrate with window and door unit flashings, particularly at the sill and head.

- Flashings at roofs wall intersections and at penetrations through the wall (i.e. plumbing, electrical, vents, HVAC refrigerant lines, etc.) that are provided by other trades must be integrated with the drainage plane to keep water from entering the wall assembly.

- Framing, sheathing and airflow retarder components, IF installed by the Drainage Plane Trade Contractor, must be properly installed to permit full insulation of building cavities in an airtight manner.

Performance testing is often a key step along the path to high performance. Drainage plane installation may be tested for water management performance by spray rack or hose testing. This test would take place after the drainage plane has been integrated with the window/door installations but before the installation of cavity insulation. Successful test results are leak-free drainage plane installations.

The Drainage Plane Trade Contractor will be responsible for correcting deficiencies in installation so that performance meets the requirements of The Company and high performance in these Scopes. The cost of corrective action is the responsibility of The Drainage Plane Trade Contractor.

For more comprehensive information on the relationship between the drainage plane and high performance homes, see the following resources:

- Builder's Guide to Mixed-Humid Climates (August 2005) specifically Chapter 2

- Water Management Guide (WMG, May 2006)

- Building America Best Practices Series Volume 4 (www.nrel.gov/docs/fy05osti/38448.pdf)

- Designs That Work - Mixed-Humid Climates (www.buildingscience.com/designsthatwork/default.htm) 


\section{Detailed Installation Requirements}

\section{a. Drainage Plane After Window Installation}

Pre-Work and Post -Work Inspection checklists will be completed and signed by Site Superintendent and The Drainage Plane Trade Contractor

$\square$ 1. Use the specified drainage plane material, fasteners and sealant or tape.

2. Install according to manufacturer's instructions.

$\square$ 3. Install drainage plane continuously from the bottom to the top of the assembly. (WMG, May 2006): page 39).

4. Weather lap the drainage plane so that the bottom of upper sheets or sections extends over the top of the bottom sheet by a minimum of three inches for horizontal joints. Weather lap vertical joints by a minimum of six inches. Alternate lapping dimensions may be required based on specific manufacturer's installation instructions.

5. Below windows or other penetrations, the drainage plane is installed underneath (interior to) the bottom edge of the sill flashing (WMG, May 2006): Step 9, page 42.); the minimum over lap of the drainage plane material over the flashing at the head of the window is three inches (WMG, May 2006): Step 12, page 43).

6. Above windows or other penetrations, the drainage plane material is installed over (exterior to) the top edge of the head flashing.

7. Flash all wall penetrations, including but not limited to those penetrations for wires, pipes and vents, with the flashing materials or blocks specified by The Company. (WMG, May 2006): pages94-96).

8. Terminate the drainage plane at the correct location as shown on the details and sequenced drawings, providing a pathway for water to leave the assembly.

9. Lap the drainage plan over all flashings provided by the Roofing Trade Contractor, providing a pathway for water to leave the assembly (WMG, (May 2006): pages 87 \& 88)

\section{Details and Sequenced Drawings}

Refer to flashing and drainage plane installation details contained in Builder's Guide to Mixed-Humid Climates (August 2005) and the Water Management Guide (May 2006). 


\section{Pre-Work Inspection Checklist - Drainage Plane After Window Installation}

To be completed before the Trade Contractor starts work on the jobsite:

$\square$ 1. Construction is at the appropriate stage and conditions are acceptable for The Trade Contractor to begin work.

2. Sheathing is installed and attached per Framing SOW.

$\square$ 3. Windows are installed and properly flashed.

$\square$ 3. Appropriate materials and equipment are onsite for work to be performed by The Drainage Plane Trade Contractor.

$\square$ 4. The Drainage Plane Trade Contractor has current plans. Date of plans:

$\square$ 5. The Drainage Plane Trade Contractor has current Company specifications for all drainage plane and drainage plane accessories materials.

$\square$ 6. The Drainage Plane Contractor has reviewed and accepts all High Performance Drainage Plane Requirements listed in the Introduction to the Drainage Plane Requirements and Checklists.

7. The Drainage Plane Trade Contractor has reviewed and understands/accepts the Detailed Installation Requirements 2.a "Drainage Plane-After Windows Installation."

Company Rep's Initials

Trade Contractor's Initials 


\section{Post-Work Inspection Checklist: Drainage Plane After Window Installation}

To be completed before Trade Contractor leaves jobsite:

$\square$ 1. The drainage plane is installed in a weather lapped manner.

$\square$ 2. The drainage plane sections overlap a minimum of three inches for horizontal joints and six in. for vertical joints.

3. The manufacturers recommended or Company specified fasteners were used to attach the drainage plane.

4. Joints between sections of the drainage plane are properly taped (if called for in the Detailed Installation Requirements 2.a. "Drainage Plane After Windows Installation”).

5. The drainage plane properly integrates with the flashing at windows, doors, roof wall intersections, and other penetrations:

$\square$ The drainage plane below windows, doors, and other penetrations is installed under (interior) to the bottom of the flashing.

$\square$ The drainage plane above windows, doors, roof wall intersections, and other penetrations is installed over (exterior) to the top of the flashing.

6. All site details match the Drainage Plane Details in the Drainage Plane Installation Checklist and Details - SOW \#2.

$\square$ 7. No unapproved drainage plane material substitutions have been made from The Company specs.

8. The Drainage Plane Trade Contractor understands that final performance evaluation of the drainage plane may be dependent on performance tests (water testing) that The Company may conduct at any time in the construction process once the Drainage Plane Trade Contractor's work is complete.

Company Rep's Initials

Trade Contractor's Initials 


\section{Detailed Installation Requirements -}

\section{b. Drainage Plane Before Window Installation}

$\square$ Pre-Work and Post -Work Inspection checklists will be completed and signed by Site Superintendent and The Drainage Plane Trade Contractor

$\square$ 1. Use the specified drainage plane material, fasteners and sealant or tape

$\square$ 2. Install according to manufacturer's instructions.

$\square$ 3. Install drainage plane continuously from the bottom to the top of the assembly.

$\square$ 4. Weather lap the drainage plane so that the bottom of upper sheets or sections extends over the top of the bottom sheet by a minimum of three inches for horizontal joints. Weather lap vertical joints by a minimum of six in.. Alternate lapping dimensions may be required based on specific manufacturers installation instructions.

$\square$ 5. Terminate the drainage plane at the correct location providing a pathway for water to leave the assembly.

6. Flash all wall penetrations, including but not limited to those penetrations for wires, pipes and vents, with the flashing materials or blocks specified by The Company.

7. Cut the drainage plane at openings for windows and doors, according to the Details and Sequenced Drawings, in preparation for the installation of windows and doors.

8. Lap the drainage plan over all flashings provided by the Roofing Trade Contractor, providing a pathway for water to leave the assembly (WMG May 2006): page 87 \& 88)

Company Rep’s Initials

Trade Contractor's Initials

\section{2.b. Details and Sequenced Drawings}

Refer to flashing and drainage plane installation details contained in EEBA Builder's Guide to Mixed-Humid Climates (August 2005) and the Water Management Guide (May 2006). 


\section{Pre-Work Inspection Checklist - Drainage Plane Before Window Installation}

1. Construction is at the appropriate stage and conditions are acceptable for The Trade Contractor to begin work.

2. Sheathing is installed and attached per Framing SOW.

3. Appropriate materials and equipment are onsite for work to be performed by The Drainage Plane Trade Contractor.

4. The Drainage Plane Trade Contractor has current plans. Sign off on date of plans: [

5. The Drainage Plane Trade Contractor has current Company specifications for all drainage plane and drainage plane accessory materials.

$\square$ 7. The Drainage Plane Contractor has reviewed and accepts all High Performance Drainage Plane Requirements listed in the Introduction to the Drainage Plane Requirements and Checklists.

8. The Drainage Plane Trade Contractor has reviewed and understands/accepts the Detailed Installation Requirements 2.a "Drainage Plane-Before Windows Installation.”

Company Rep’s Initials

Trade Contractor’s Initials 


\section{Post-Work Inspection Checklist - Drainage Plane Before Window Installation}

1. The drainage plane is installed in a weather lapped manner.

2. The drainage plane sections overlap a minimum of three inches for horizontal joints and six in. for vertical joints.

3. The manufacturers recommended or Company specified fasteners were used to attach the drainage plane.

4. Joints between sections of the drainage plane are properly taped (if called for in Detailed Installation Requirements 2.b.).

5. The drainage plane properly integrates with the flashing at roof wall intersections, and other penetrations:

The drainage plane below penetrations is installed under (interior) to the bottom of the flashing.

The drainage plane above roof wall intersections, and other penetrations is installed over (exterior) to the top of the flashing.

6. All site details match the Drainage Plane Details in the Drainage Plane Installation Checklist and Details 2.b. "Drainage Plane Before Window Installation.”

$\square$ 7. No unapproved drainage plane material substitutions have been made from The Company specs.

8. The Drainage Plane Trade Contractor understands that final performance evaluation of the drainage plane may be dependent on performance tests (water testing) that The Company may conduct later in the construction process after windows and doors have been installed.

Company Rep’s Initials

Trade Contractor's Initials 


\section{Mixed-Humid Climate Windows - Requirements and Checklists}

\section{Window Installation Requirements:}

\section{Introduction - High Performance Window Installation}

High Performance is defined as superior energy efficiency, safety, comfort, and durability. Managing the flows of moisture and air with the same intensity as energy protects against the major damage functions a home faces - heat, water, radiation (ultraviolet) and biological organisms (frequently requiring liquid water).

The work of the Window/Door Trade Contractor contributes to high performance in the following way:

- Water Management - Proper integration of unit flashing, rough opening flashing, and the weather-resistive barrier create a continuous drainage plane keeping liquid water out of the wall assemblies and moving water off of the wall assemblies.

Construction is a process that involves sequential work performed by a variety of subcontractors. The Window/Door Trade Contractor's work is generally integrated with the work of the Drainage Plane Trade Contractor with these high performance considerations:

- The flashing systems and components of both the rough openings and the window/door units must properly integrate with the work of the Drainage Plane Trade Contractor, regardless of whether the window/door unit installation takes place before or after the work of the Drainage Plane Trade Contractor.

The Window/Door Trade Contractor's work is generally followed by the Air Sealing/Insulation Trade Contractor and the Wall Cladding Contractor with these high performance implications:

- The window/door units are adequately shimmed so that minimally-expanding foam insulation can be installed between the rough opening and the unit to contribute to both thermal and air barrier continuity.

- Depending upon the type of wall cladding, the window/door flashing system may need to be integrated with the wall cladding for proper water management.

Performance testing is often a key step along the path to high performance. Window/door installations may be tested for water management performance by spray rack or hose testing. This test would take place after the window/door installations have been integrated with the weather-resistive barrier but before the installation of cavity insulation. Successful test results are leak-free window or door installations.

The Window/Door Trade Contractor will be responsible for correcting deficiencies in installation so that performance meets the requirements of The Company and high performance in these Scopes. The cost of corrective action is the responsibility of The Window/Door Trade Contractor.

For more comprehensive information on the relationship between window/door installation and high performance homes, see the following resources: 
- Water Management Guide (WMG, May 2006))

- Builder's Guide to Mixed-Humid Climates (August 2005)

- Building America Best Practices Series Volume 4 (www.nrel.gov/docs/fy05osti/38448.pdf)

- Designs That Work - Mixed-Humid Climates (www.buildingscience.com/designsthatwork/default.htm)

NOTE: Because window installation can take place before or after the weather-resistive barrier (depending on a number of factors including variations in cladding), and because window installation is different when installed in conjunction with high performance rigid insulation exterior insulation, three different sets of detailed installation requirements follow:

\section{2a. Windows Installed AFTER the Weather-Resistive Barrier}

\section{2b. Windows Installed BEFORE the Weather-Resistive Barrier}

\section{2c. Windows Installed With Rigid Insulation Exterior Sheathing}

\section{2a. Detailed Installation Requirements - Windows Installed AFTER the Weather- Resistive Barrier}

Pre-Work and Post -Work Inspection checklists will be completed and signed by Site Superintendent and The Trade Contractor

1. Use the specified windows, flashing and sealant.

$\square$ 2. Install window according to manufacturer's instructions flashing the opening and window using the detailed written instructions and drawings in this document

\section{Details and Sequence Drawings}

1. Insert backdam using material specified by The Company. (WMG, May 2006): Step 3, page 29)

$\square$ 2. Cut the house wrap drainage plane above the window; temporarily tape the house wrap above the window up and out of the way. (WMG, May 2006): Step 3, page 29)

3. Insert the 2 pieces of adhesive backed sill flashing. The vertical leg of the flashing must be at least 6 inches in length. The interior edge of the flashing must be on top of the back dam. (WMG, May 2006): Step 4, page 29 and Step 5, page 30)

4. Install the corner patches of adhesive flashing. (WMG, May 2006): Step5, page 30)

5. Install window, level and attach according to manufacturer's instructions.

6. Install jamb flashings followed by head flashing. (WMG, May 2006): Step 7 - 8, page31)

7. Remove tape and bring house wrap above window back to its original position and tape the heading flashing. (WMG, May 2006): Step 9, page32

8. Install corner tape patches at head and air seal around entire perimeter on the interior with sealant or non-expanding foam. (WMG, May 2006): Step 10, page32)

Form will be signed by The Trade Contractor thereby indicating that all work has been completed in the manner specified within this Scope of Work. 


\section{2b. Detailed Installation Requirements - Windows Installed BEFORE the Weather- Resistive Barrier}

Pre-Work and Post -Work Inspection checklists will be completed and signed by Site Superintendent and The Trade Contractor

1. Use the specified windows, flashing and sealant.

2. Install window according to manufacturer's instructions flashing the opening and window using the detailed written instructions and drawings in this document

\section{Details and Sequence Drawings}

1. Insert backdam using material specified by The Company. (WMG, (May 2006): Step 2, page 38)

2. Mechanically attach (or adhere by removing upper portion of release paper) the sill apron, using a piece of flashing, building paper or house wrap (as specified) so that the top edge of the strip is flush with the rough opening. The strip should extend 6 in. past each side of the rough opening. At least 3 inches at the bottom of this strip must be unattached so that a section of the drainage plane can be slipped under later. (WMG, (May 2006): Step 3, page 39)

3. Insert the 2 pieces of adhesive backed sill flashing as shown in Sequence Drawing Set 2. The vertical leg of the flashing must be at least 6 inches in length. The interior edge of the flashing must be on top of the back dam. (WMG, (May 2006): Step 4, page 39)

4. Install the corner patches of adhesive flashing (WMG, (May 2006): Step 5, page 40)

5. Install the jamb flashings (WMG, (May 2006): Step 6, page 33)

$\square$ 6. Install the short pieces of flashing under the bottom edge of the jamb flashings and over the sill apron

7. Install a continuous bead of sealant to the backside of the jamb and head flanges. (WMG, (May 2006): Step 7, page 34)

8. Install window, level and attach according to manufacturer's instructions.

9. Install jamb flashings follow by head flashing as shown in Sequence Drawing Set 2. (WMG, (May 2006): Step 8, page 34)

Form will be signed by The Trade Contractor thereby indicating that all work has been completed in the manner specified within this Scope of Work. 


\section{2c. Detailed Installation Requirements - Windows Installed with Rigid Insulation as the Exterior Sheathing and Weather-Resistive Barrier}

$\square$ Pre-Work and Post -Work Inspection checklists will be completed and signed by Site Superintendent and The Trade Contractor

1. Use the specified windows, flashing and sealant.

2. Install window according to manufacturer's instructions flashing the opening and window using the detailed written instructions and drawings in this document

\section{Details and Sequence Drawings}

$\square$ 1. Insert backdam using material specified by The Company. (WMG, (May 2006): Step 2, page 44)

$\square$ 2. Insert the 2 pieces of adhesive backed sill flashing as show. The vertical leg of the flashing must be at least 6 inches in length. The interior edge of the flashing must be on top of the back dam. (WMG, (May 2006): Step 3, page 45)

$\square$ 3. Install the corner patches of adhesive flashing. (WMG, (May 2006): Step 4, page 45)

4. Install the jamb flashings. (WMG, (May 2006): Step 5, page 46)

$\square$ 5. Install a continuous bead of sealant to the backside of the jamb and head flanges.

$\square$ 6. Install window, level and attach according to manufacturer's instructions.

$\square$ 7. Install jamb flashings followed by head flashing. (WMG, (May 2006): Steps $6-7$, pages $46-$ 47.)

$\square$ 8. Install a counter flashing over the head flashing as shown in Sequence Drawing Set 3. Use the specified material (polyethylene, house wrap or building paper) to create a weatherlapped drainage plane from the $\mathrm{z}$-flashing at the horizontal joint in the sheathing above the window to the frame of the window. Use short sections of tape to hold this section of the drainage plane in place until the cladding is installed. (WMG, (May 2006): page 87.)

Form will be signed by The Trade Contractor thereby indicating that all work has been completed in the manner specified within this Scope of Work. 


\section{Pre-Work Inspection Checklist}

To be completed before the Trade Contractor starts work on the jobsite:

1. Construction is at the appropriate stage and conditions are acceptable for the Window/Door Trade Contractor to begin work, particularly in terms of integrating the weather-resistive barrier and both rough opening and window unit flashing.

$\square$ 2. Exterior wall sheathing is cut flush to (is not proud of) the rough opening.

$\square$ 3. Appropriate materials and equipment are onsite for work to be performed by the Window/Door Trade Contractor.

4. The Window/Door Trade Contractor has current plans. Record date of plans: [

5. The Window/Door Trade Contractor has current Company specifications for all window and door materials.

$\square$ 6. The Window/Door Trade Contractor has reviewed and accepts all High Performance Window/Door Requirements listed in the Introduction to Windows - Requirements and Checklists.

$\square$ 7. The Window/Door Trade Contractor has reviewed and understands/accepts the Window/Door Detailed Installation Requirements and Checklists (2.a, 2.b, and 2.c), in particular, the importance of thermal and air barrier continuity.

$\square$ 8. Rough openings for windows and doors are within tolerances provided in the plans and as required for installation according to manufacturer's specifications and the installation requirements.

Company Rep’s Initials

Trade Contractor's Initials 


\section{Post-Work Inspection Checklist}

To be completed after the Trade Contractor has completed all work on the jobsite:

1. Window/Door unit installation accomplishes/will permit proper integration with the weatherresistive barrier.

2. Window/Door installation permits proper integration of wall cladding flashings.

3. Window/door units have not been damaged during installation (mitered corners, flanges, etc.).

4. All site details match the Detailed Installation Requirements.

5. No unapproved material substitutions have been made from The Company specifications.

$\square$ 6. Water testing cannot be conducted until both the window/door and weather-resistive barrier are installed. The Window/Door Contractor will be responsible for corrective action if subsequent water testing identifies water leakage to the interior that is the result of deficient window/door installation.

Company Rep’s Initials

Trade Contractor's Initials 


\section{Mixed-Humid Climate HVAC - Requirements and Checklists}

\section{HVAC Requirements:}

\section{Introduction: High Performance HVAC}

High Performance is defined as superior energy efficiency, safety, comfort, and durability. Managing the flows of moisture and air with the same thoroughness as energy protects against the major damage functions a home faces - heat, water, radiation (ultraviolet) and biological organisms (which frequently require liquid water).

The work of the HVAC Trade Contractor contributes to high performance in the following ways:

- Water management - The HVAC contractor maintains the integrity of the drainage plane by flashing and/or sealing penetrations to the building enclosure made during installation of the HVAC system that are not included in the Drainage Plane Contractor's scope of work.

- Integrity and Continuity of the Air Barrier - The HVAC contractor maintains the integrity of the air barrier by air sealing penetrations to the building enclosure made during installation of the HVAC system that are not included in the Air Sealing/Insulation Trade Contractor's scope of work.

- Energy Efficiency -

o System performance based on the appropriate application of ACCA Manuals J, S and D

o Proper sizing of mechanical equipment, ducts, registers and grilles

o Air sealing of all ducts and plenums and insulating any ducts not inside conditioned space

o Commissioning HVAC component/systems

- Safety -

o Combustion equipment specified and installed to avoid backdrafting and spillage of combustion by-products into the occupied space.

o Outside air ventilation and exhaust systems designed, specified and installed per ASHRAE 62.2 - Ventilation and Acceptable Indoor Air Quality for Low-Rise Residential Buildings.

- Comfort -

o HVAC system maintains operative temperatures and interior relative humidities within ranges as established in ASHRAE 55 - Thermal Comfort Conditions for Human Occupancy

o HVAC system is designed, specified and installed to reduce velocity and pressure induced noise by properly orientating trunk lines, plenums, and returns; properly sizing ducts and register grilles; and installing acoustic lining where necessary.

- Vapor management - Proper sizing and charging of the cooling system help control interior moisture levels, and, where necessary, provide for supplemental dehumidification. 
Construction is a process that involves sequential work performed by a variety of subcontractors. The HVAC Trade Contractor's work is preceded by The Framing Trade Contractor and perhaps some stages of the Air Sealing/Insulation Trade Contractor, with these high performance implications:

- Framing - constructed according to plans so that all ducts can be installed in their designed locations within the conditioned space.

- Air Sealing/Insulation - Air and thermal barrier continuity established by this Trade Contractor is maintained as the HVAC equipment and ducts are installed.

The HVAC Trade Contractor's work is generally followed by Interior Finish Trade Contractors and by finish work of The Plumbing and Electrical Trade Contractors with these high performance implications:

- Duct and duct sealing are not damaged by subsequent Trade Contractors or if damaged, repaired or replaced by the HVAC Trade Contractor via notification of the Site Supervisor.

Performance testing is often a key step along the path to high performance. HVAC performance tests include but are not necessarily limited to:

a. an air tightness test to measure the air tightness of the duct system

b. an air tightness test to measure the air tightness of the entire air distribution system (includes ducts and air handler, and may include associated mechanical ventilation ducts and equipment)

c. system air flow test (total and room testing),

d. room-to-room pressurization test.

e. refrigerant charge test

f. temperature rise across furnace heat exchanger

Successful performance is defined as:

a. Total system leakage no more than ten percent and duct leakage to the outside no more than five percent of the manufacturer's high speed air handler air flow.

b. Air flow at supply plenum is within ten percent of manufacturer rating; air flow to each room is within $10 \%$ of design airflows calculated using ACCA manual J, S \&D.

c. With the air handler on high speed and interior and exterior doors closed, pressures across closed doors are less than or equal to 3 Pascals

d. Superheat method (fixed metering systems) - superheat temperature within $2^{\circ} \mathrm{F}$ of manufacturer recommendation/subcool method (thermal expansion valve systems) subcool temperature within $2^{\circ} \mathrm{F}$ of manufacturer recommendation

e. temperature rise across furnace heat exchanger within manufacturers specifications

The HVAC Trade Contractor will be responsible for correcting deficiencies in installation so that performance meets the requirements of The Company and high performance in these Scopes. The cost of corrective action is the responsibility of The HVAC Trade Contractor. 
For more comprehensive information on the relationship between HVAC and high performance homes, see the following resources:

- Builder's Guide to Mixed-Humid Climates (August 2005), specifically Chapter 1, pages 26 - 30, 44-45, and Chapter 12

- Building America Best Practices Series Volume 4

(www.nrel.gov/docs/fy05osti/38448.pdf)

- Designs That Work - Mixed-Humid Climates (www.buildingscience.com/designsthatwork/default.htm)

- Air Conditioning Contractors of America (ACCA) Manual J, S and D 


\section{Detailed Installation Requirements -}

Pre-Work and Post -Work Inspection checklists will be completed and signed by Site Superintendent and The Trade Contractor

$\square$ 1. HVAC equipment is sized per the ACCA Manual J loads, using methodologies described in Manual S.

$\square$ 2. All HVAC delivery components installed per the sizing of ACCA Manual D and located per the duct layout plan (See Figure 1 for a sample duct layout plan):

$\square$ plenums $\square$ trunks $\square$ ducts $\quad \square$ registers $\square$ grilles

$\square$ 3. All HVAC delivery components, including the air handler cabinet, have been sealed with mastic. Access panels have been sealed with foil faced UL181 tape after final commissioning.

$\square$ 4. All duct boots sealed with mastic to framing and/or subfloor.

$\square$ 5. All HVAC penetrations flashed for water management and sealed for air and thermal barrier continuity.

$\square$ 6. All exhaust fans are ducted to the outside.

7. The mechanical ventilation system installed per The Company specifications (See Figure 2 for a representative Central Fan-Integrated Supply (CFIS) system set-up).

$\square$ 8. Confirm with The Company any material or component substitutions from The Company's HVAC specifications. 


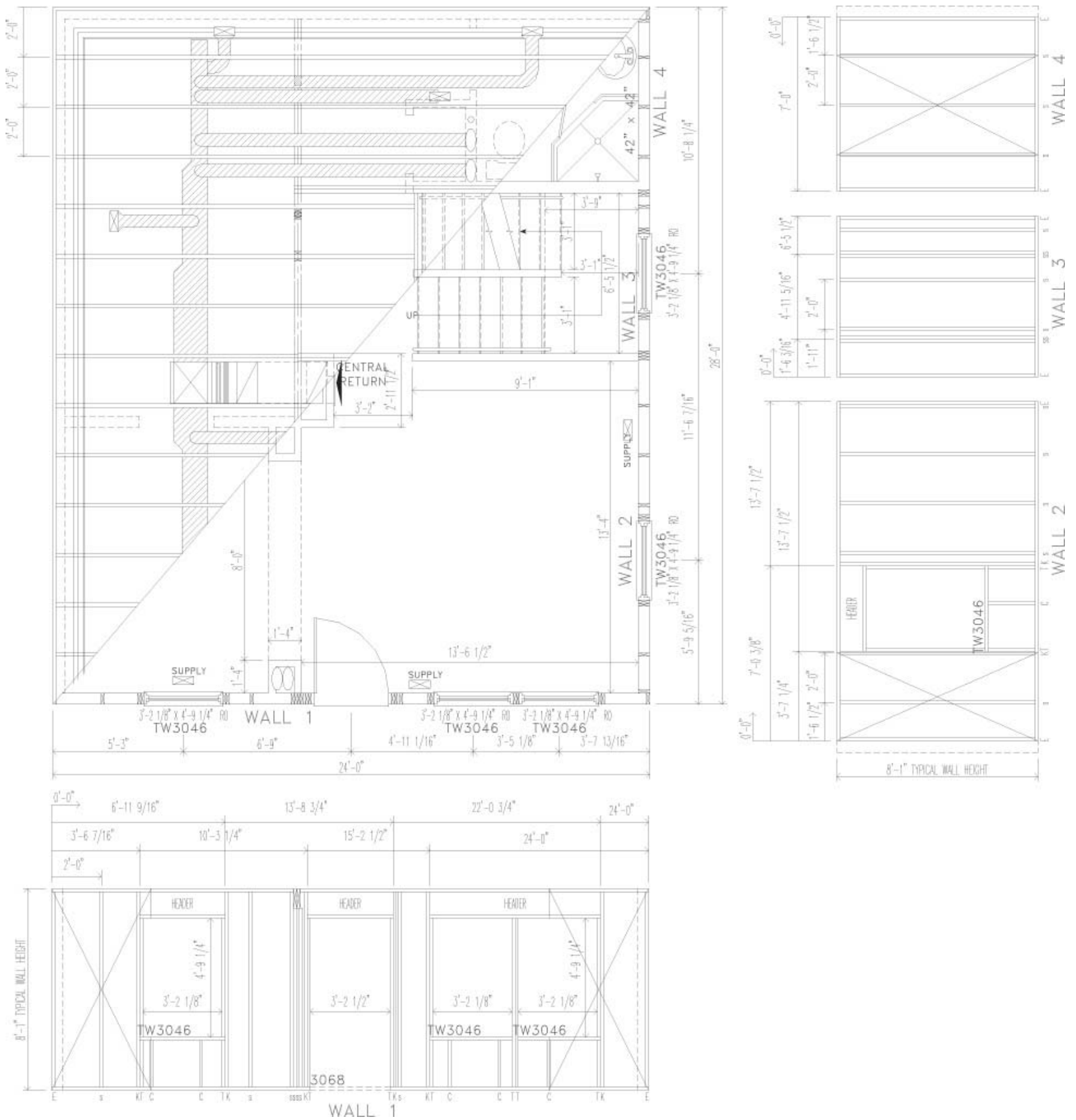

Figure E-8. Sample Duct Layout (Building Science Corporation, "Using Wood Efficiently: From Optimizing Design to Minimizing the Dumpster," August 2002) 


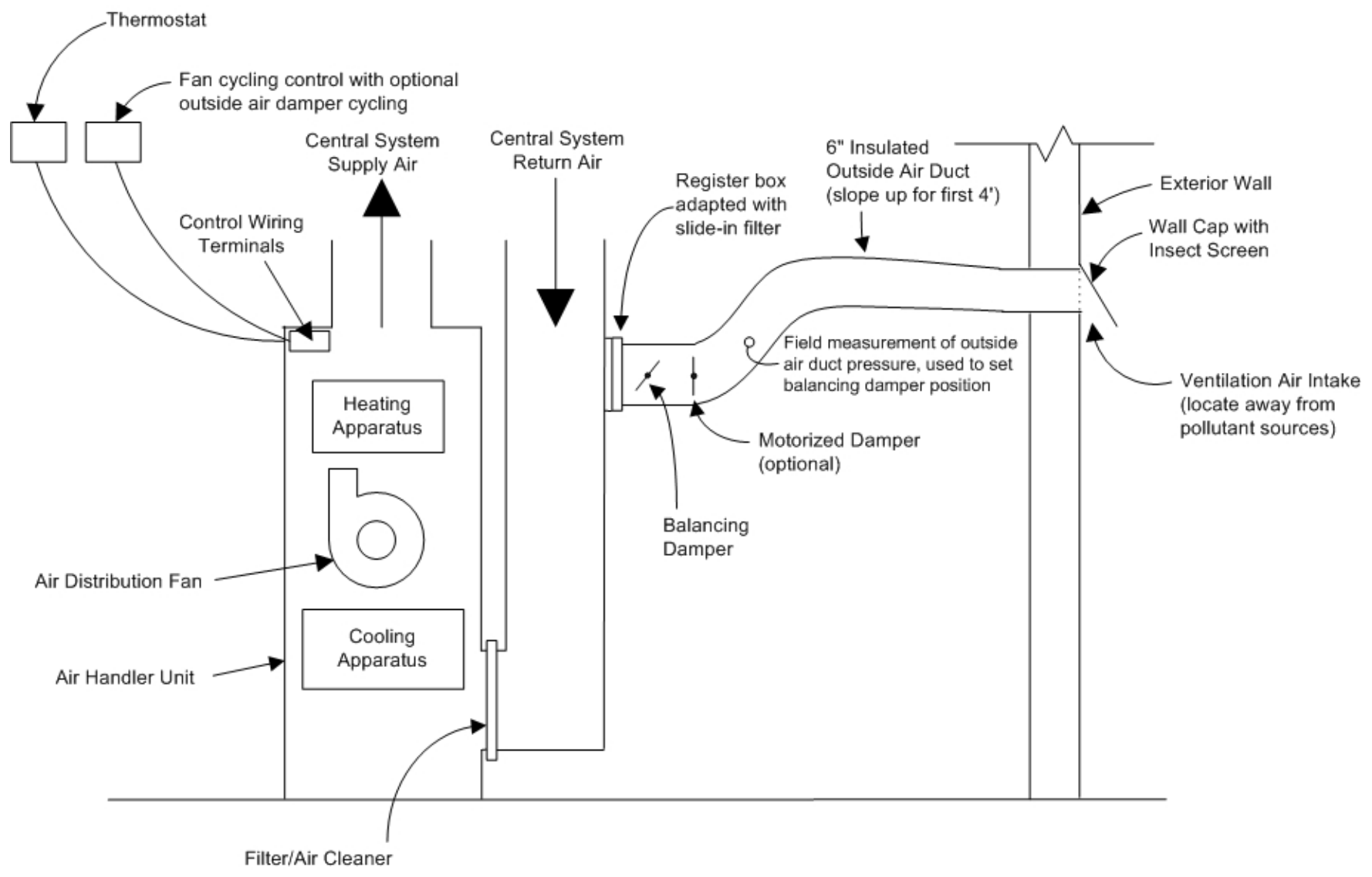

Figure E-9. Central Fan Integrated Supply Ventilation (Building Science

Corporation (www.buildingscience.com/resources/mechanical/fancycling/aircycler details.pdf)

Refer to HVAC duct sealing details contained in the Builder's Guide to Mixed-Humid Climates (August 2005), specifically Chapter 12. Additional high performance HVAC design and installation guidance can be found at www.cee1.org/resid/rs-ac/hvac.php3.

Form will be signed by The Trade Contractor thereby indicating that all work has been completed in the manner specified within this Scope of Work (SOW) document \#2. 


\section{Pre-Work Inspection Checklist}

To be completed before the Trade Contractor starts work on the jobsite:

$\square$ 1. Construction is at the appropriate stage and conditions are acceptable for The HVAC Contractor to begin work.

$\square$ 2. The HVAC Trade Contractor has current plans. Record date of plans:

$\square$ 3. The HVAC Trade Contractor has current Company specifications for all HVAC components and systems.

4. All duct boots sealed with mastic to framing and/or subfloor.

$\square$ 5. All HVAC penetrations flashed for water management and sealed for air and thermal barrier continuity.

$\square$ 6. All exhaust fans are ducted to the outside.

$\square$ 7. The HVAC Trade Contractor has completed or has received from The Company an integrated HVAC system layout and equipment specifications, designed according to ACCA Manual J, S \& D. This layout includes room airflow requirements, duct and terminal locations, grille and register specifications, ventilation system layout and product specifications, and heating/cooling equipment specifications.

8. If available, the HVAC Trade Contractor has received and reviewed a detailed framing layout from The Company and has notified The Company of any conflicts between the detailed framing and ducts layouts.

$\square$ 9. The HVAC Trade Contractor has reviewed and accepts all high performance items that appear in the HVAC Standards and Description of Work Performance (SOW \#1).

10. The HVAC Trade Contractor has reviewed and understands/accepts the HVAC Installation Details and Checklist (SOW \#2).

Company Rep's Initials

Trade Contractor's Initials 


\section{Post-Work Inspection Checklist}

To be completed before Trade Contractor leaves jobsite:

$\square$ 1. All HVAC system components and equipment have been installed per The Company's plans, specifications, and the plan-specific ACCA Manual J/S/D.

$\square$ 2. The following HVAC performance tests have been performed with successful results OR all deficiencies leading to the unsuccessful results have been corrected:

$\square$ Total system leakage:_[result]_[passing threshold]

$\square$ Air flow at supply plenum:_[result]_ [passing threshold]

$\square$ Air flow at supply register(s):_[result]_ [passing threshold]

$\square$ System on/door closed pressure differential:_[result]_[passing threshold]

$\square$ Superheat/subcool refrigerant charge test:_[result]_ [passing threshold]

$\square$ Furnace heat rise test:_[result]_[passing threshold]

$\square$ 3. All site details match the HVAC Details in the HVAC Installation Details and Checklist

Company Rep's Initials

Trade Contractor's Initials 


\section{Mixed-Humid Climate Air Sealing/Insulation - Requirements and Checklists}

\section{Air Sealing/Insulation Requirements:}

\section{Introduction - High Performance Air Sealing/Insulation}

High Performance is defined as superior energy efficiency, safety, comfort, and durability. Managing the flows of moisture and air with the same intensity as energy protects against the major damage functions a home faces - heat, water, radiation (ultraviolet) and biological organisms (frequently requiring liquid water).

The work of the Air Sealing/Insulation Trade Contractor contributes to high performance in the following ways:

- Integrity and Continuity of the Thermal Barrier -

o Complete fill of all framing cavities in the conditioned boundary—no voids, no gaps

o Focus on the largest and most common thermal bypasses

- Integrity and Continuity of the Air Barrier -

o Continuous air sealing at plates and assembly transitions

o Complete air sealing at penetrations

- Vapor management -

o No substitutions of insulation materials with performance properties (including water absorption and vapor permeability) different than the materials specified by The Company.

o Installation of draft stops in areas that will not be accessible after completion of framing (outside wall fireplaces, tub surrounds on outside walls, soffits terminating on outside walls, vertical chases, etc.)

0 The moisture performance of wall and roof assemblies is a function of the combined performance of all assembly components, not the performance of just the "vapor retarder" that is traditionally installed behind the interior sheathing (drywall). It is likely that your local code or your local code official's interpretation of the code may require the installation of a vapor retarder. Consideration should then be given to "smart" vapor retarders to manage vapor movement into and out of assemblies, based on local climate conditions.

o No substitutions of materials with performance properties (including water absorption and vapor permeability) different than the sheathing materials specified.

Construction is a process that involves sequential work performed by a variety of subcontractors. The Air Sealing/Insulation Trade Contractor's work is generally preceded by The Framing 
Trade Contractor, The Plumbing Trade Contractor, The Electrical Trade Contractor, The HVAC Trade Contractor and The Window Installation Trade Contractor with these high performance implications:

- Framed five-sided cavities to receive insulation - framing and exterior sheathing have created five-sided containment for all cavities requiring cavity insulation that will receive drywall to create a continuous thermal barrier.

- Cavities that are to receive thermal insulation in concealed locations that will not receive drywall (i.e. behind tubs and showers on exterior walls, chases, fireplaces, etc.) have been insulated and an air impermeable barrier has been installed to contain the insulation on all six sides.

- Plumbing/Electrical/HVAC - all plumbing/electrical/HVAC penetrations to the conditioned boundary have been made and are ready to be air sealed/insulated.

- Windows and Doors - All windows and doors have been installed and adequately shimmed to permit minimally-expanding spray foam air sealing of rough openings.

The Air Sealing/Insulation Trade Contractor's work is generally followed by The Drywall Trade Contractor with these high performance implications:

- All cavity insulation and air sealing details that will be rendered inaccessible by drywalling have been completed by The Air Sealing/Insulation Trade Contractor.

- An element of the continuous air barrier may be sealant applied to the backside of all drywall at the perimeter of all planes and penetrations (exterior wall outlets, for example). This arrangement must be confirmed with The Company and the Drywall Trade Contractor

Performance testing is often a key step along the path to high performance. Homes will be tested for building enclosure air leakage with a blower door test. Testing protocols that may apply include $100 \%$ testing (every installation), random percentage (e.g. 1 in 7) or the reserved right to test any installation as determined by The Company or the Site Superintendent. The Company reserves the right to further performance test the air sealing and insulation performance by infra-red thermal imaging of the building enclosure. Successful performance by The Air Sealing/Insulation Trade Contractor is determined by:

a. Building enclosure air leakage that does not exceed $0.25 \mathrm{CFM} / \mathrm{square}$ foot of building enclosure surface area at a $50 \mathrm{~Pa}$ air pressure differential.

b. Identification of no significant voids or air leakage upon qualitative infra-red thermal imaging of the building enclosure.

NOTE: "Smoke-testing" during the blower door test and infra-red thermal imaging can help to determine if failure to meet the performance test minimum is the result of Air Sealing/Insulation Trade Contractor deficiencies or damage to The Air Sealing/Insulation Trade Contractor's work by subsequent trades. Each Trade Contractor agrees to stand by the determination of The Company and its performance tests in terms of responsibility for thermal performance.

NOTE: The EPA ENERGY STAR program has identified 13 of the most common air leakage and thermal bypasses. For more information, see: www.energystar.gov/ia/partners/bldrs lenders raters/downloads/Thermal_Bypass_Checklist.pdf. 
For more comprehensive information on the relationship between air sealing/insulation and high performance homes, see the following resources:

- Builder's Guide to Mixed-Humid Climates (August 2005) specifically Chapter 3

- Building America Best Practices for Mixed-Humid Climates

(www.nrel.gov/docs/fy05osti/38448.pdf)

- Designs That Work - Mixed-Humid Climates

(www.buildingscience.com/designsthatwork/default.htm)

- RESNET Adopted Enhancements to the Mortgage Industry National Home Energy

Rating Standards Chapter 3.B. 9. Insulation Installation 


\section{Detailed Installation Requirements -}

Pre-Work Inspection: completed and signed by Site Superintendent and The Trade Contractor (see Air Sealing/Insulation SOW \#3, Trade Contractor \& Site Supervisor Pre/Post Checklist)

\section{Detailed Installation Checklist -}

$\square$ 1. Install attic venting insulation baffles to ensure a continuous pathway for soffit-to-ridge attic ventilation and to prevent any wind that enters the soffit vents from blowing through the insulation material.

$\square$ 2. Air seal/insulate with the materials as specified by The Company.

3. Air seal at all the critical junctions in building enclosure assemblies (See Figure 1 below):

$\square$ mudsills $\square$ bottom plates $\square$ top plates

$\square$ 4. Air seal/insulate at all rim joists.

$\square$ 5. Air seal/insulate at all applicable thermal bypasses:

$\square$ shower/tub at exterior wall

$\square$ attic knee walls

cantilevered floor

$\square$ flue shaft

$\square$ dropped ceiling/soffit

staircase at exterior wall/attic

whole-house fan attic penetration unconditioned space $\square$ conditioned space over garage

$\square$ attic hatch

$\square$ duct shafts

$\square$ piping shaft/penetrations

$\square$ fireplace on exterior wall

$\square$ recessed lighting

walls abutting enclosed but

$\square$ 6. All insulation is installed according to the requirements for Grade I insulation, as defined by the "RESNET Adopted Enhancements to the Mortgage Industry National Home Energy Rating Standards Chapter 3.B. 9. Insulation Installation:”

7. Confirm with The Company any air sealing details that are the express responsibility of trade contractors whose work follows that of the Air Sealing/Insulation Trade Contractor (Drywall Trade Contractor, etc.).

8. Confirm with The Company any material substitutions from The Company's air sealing/insulation specifications before making any substitutions. 


\section{Details and Sequenced Drawings}

Refer to air sealing and insulation details contained in the Builder's Guide to Mixed-Humid Climates (August 2005), specifically Chapter 11. Additional air sealing details can be found at www.buildingscience.com/housesthatwork/airsealing/default.htm and in the Building America Best Practices Guide Volume 4 at www.nrel.gov/docs/fy05osti/38448.pdf

Form will be signed by The Trade Contractor thereby indicating that all work has been completed in the manner specified within this Scope of Work (SOW) document \#2. 


\section{Pre-Work Inspection Checklist}

To be completed before the Trade Contractor starts work on the jobsite:

$\square$ 1. Construction is at the appropriate stage and conditions are acceptable for The Air Sealing/Insulation Contractor to begin work.

$\square$ 2. All framing cavities that will receive cavity insulation have six-sided containment.

$\square$ 3. Roof framing/trusses accommodate [full height/no. of inches] installation of roof/ceiling insulation to the outside plane of the top-story exterior walls.

$\square$ 4. All plumbing/electrical/mechanical penetrations to the building enclosure have been made and are ready for air sealing/insulation.

$\square$ 5. Appropriate materials and equipment are onsite for work to be performed by The Air Sealing/Insulation Trade Contractor.

$\square$ 6. The Air Sealing/Insulation Trade Contractor has current plans. Record date of plans: [ _ I_ _ _ ]

7. The Air Sealing/Insulation Trade Contractor has current Company specifications for all air sealing and insulation materials.

$\square$ 8. The Air Sealing/Insulation Trade Contractor has reviewed and understands/accepts the Air Sealing/Insulation Installation Details and Checklist (SOW \#2); in particular, the importance of thermal and air barrier continuity.

9. The Air Sealing/Insulation Trade Contractor has reviewed and accepts all high performance items that appear in the Air Sealing/Insulation Standards and Description of Work Performance (SOW \#1).

Company Rep’s Initials

Trade Contractor's Initials 


\section{Post-Work Inspection Checklist:}

To be completed before Trade Contractor leaves jobsite:

$\square$ 1. Attic insulation baffles and insulation have been installed such that the pathway is the specified size allowing unobstructed air flow from soffit to ridge.

2. All insulation is installed according to the requirements for Grade I insulation, as defined by the "RESNET Adopted Enhancements to the Mortgage Industry National Home Energy Rating Standards Chapter 3.B. 9. Insulation Installation:"

$\square$ 3. All assembly transitions and thermal bypasses are air sealed and insulated for thermal and air barrier continuity.

4. Any insulating sheathing is free from damage (holes).

$\square$ 5. All site details match the Air Sealing/Insulation Details in the Air Sealing/Insulation Installation Details and Checklist (SOW \#2).

$\square$ 6. No unapproved material substitutions have been made from The Company specs.

$\square$ 7. Trade Contractor understands that final performance evaluation of the air sealing/insulation is dependent on performance tests (blower door and thermal imaging) that The Company may conduct later in the construction process.

Company Rep's Initials

Trade Contractor's Initials 


\section{Appendix F. SNAPSHOT Form}

\begin{tabular}{|l|l|l|l|}
\hline \multicolumn{3}{|c|}{ SNAPSHOT } & \\
\hline Lot \#: & Subdivision: & Address: Form" & Date and time: \\
\hline Model: & & & \\
\hline
\end{tabular}

\section{INITIALIZATION}

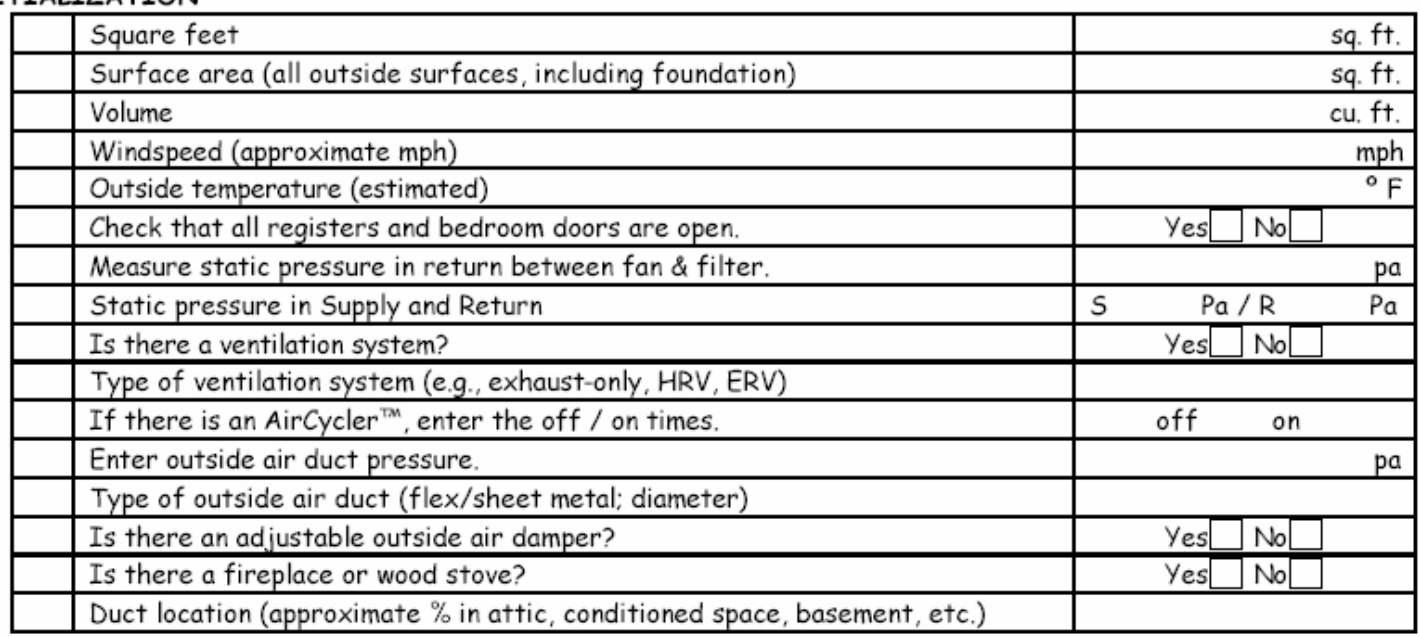

\section{PRESSURE TESTING}

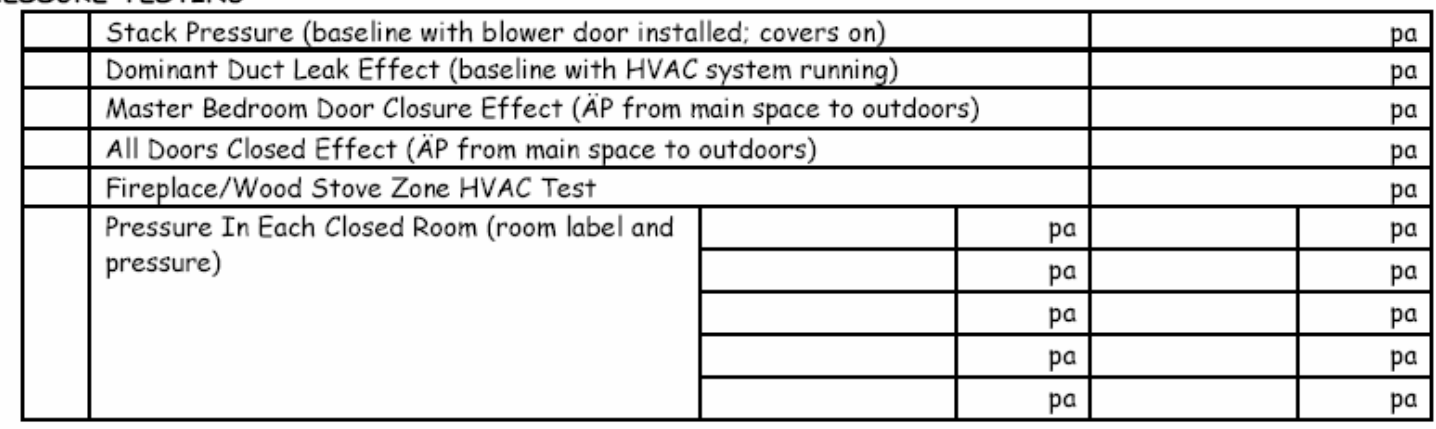

BLOWER DOOR TESTING (BDT)

\begin{tabular}{|l|l|lc|}
\hline & Blower Door Location & & \\
\hline & Total $C F M 50$ (add $C \&$ \& values if available on multipoint test) & CFM50 $=\quad C=\quad n=$ \\
\hline
\end{tabular}

DUCT AIRTIGHTNESS TESTING (DAT)

\begin{tabular}{|l|l|l|}
\hline & DAT CFM25 TOTAL & \\
\hline & DAT CFM25 OUTSIDE & \\
\hline
\end{tabular}

MECHANICALS

\begin{tabular}{|l|l|l|l|}
\hline & Furnace or air handler & Make: & Model: \\
\hline & Air Conditioning & Make: & Model: \\
\hline & Domestic hot water & Make: & Model: \\
\hline
\end{tabular}




\section{References}

ACCA. 2003. Manual J: Residential Load Calculation 8th Edition. Arlington, VA: Air Conditioning Contractors of America.

ACCA. 1995a. Manual S: Residential Heating and Cooling Equipment Selection. Arlington, VA: Air Conditioning Contractors of America, Washington, D.C.

ACCA. 1995b. Manual D: Residential Duct Systems. Arlington, VA: Air Conditioning Contractors of America, Washington, D.C.

ACCA. 1993. Manual T: Air Distribution Basics. Arlington, VA: Air Conditioning Contractors of America, Washington, D.C.

Anderson, R.; Christensen, C.; Barker, G.; Horowitz, S.; Courtney, A.; Givler, T.; Tupper, K. 2004. Analysis of System Strategies Targeting Near-Term Building America Energy-Performance Goals for New Single-Family Homes: FY 2004 Fourth-Quarter Building America Milestone Report. NREL Report No. NREL/TP-550-36920. Golden, CO: National Renewable Energy Laboratory.

Anderson, R.; Christensen, C.; Horowitz, S. 2006. Program Design Analysis using BEopt Building Energy Optimization Software: Defining a Technology Pathway Leading to New Homes with Zero Peak Cooling Demand; Preprint. NREL Report No. NREL/CP-550-39821. Golden, CO: National Renewable Energy Laboratory.

ASHRAE. 2004. ASHRAE 62.2-2003. Ventilation and Acceptable Indoor Air Quality in Low-Rise Residential Buildings. Atlanta, GA: American Society of Heating, Refrigeration, and Air Conditioning Engineers.

Baczek, S.; Yost, P.; and Finegan, S. 2002. Using Wood Efficiently: From Optimizing Design to Minimizing the Dumpster. Westford, MA: Building Science Corporation. www.buildingscience.com/resources/misc/wood efficiency.pdf

Baechler, M. C.; Love, P. M. 2004. Building America Best Practices Series: Volume 1; Builders and Buyers Handbook for Improving New Home Efficiency, Comfort, and Durability in the Hot and Humid Climate. NREL Report No. NREL/TP-550-36960. Golden, CO: National Renewable Energy Laboratory.

Baechler, M. C.; Taylor, Z. T.; Bartlett, R.; Gilbride, T.; Hefty, M.; Love, P. M. 2005a. Building America Best Practices Series: Volume 2. Builders and Buyers Handbook for Improving New Home Efficiency, Comfort, and Durability in the Hot-Dry and Mixed-Dry Climates, Revised. NREL Report No. NREL/TP-550-38360. Golden, CO: National Renewable Energy Laboratory.

Baechler, M. C.; Love, P. M. Building America Best Practices Series: Volume 3, Revised; Builders and Buyers Handbook for Improving New Home Efficiency, Comfort, and Durability in Cold and Very Cold Climate Regions. NREL Report No. NREL/TP-550-38436. Golden, CO: National Renewable Energy Laboratory.

Building Industry Research Alliance (BIRA); Building Science Consortium (BSC); Consortium for Advanced Residential Buildings (CARB); Davis Energy Group (DEG); Florida Solar Energy Center (FSEC); IBACOS; National Association of Home Builders Research Center (NAHBRC); National Renewable Energy Laboratory (NREL). 2006. Building America Residential System Research Results: Achieving 30\% Whole House Energy Savings Level in the Hot-Dry and Mixed-Dry Climates. NREL Report No. NREL/SR-550-38201. Golden, CO: National Renewable Energy Laboratory. 
CABO (Council of American Building Officials). 1995. Mechanical Energy Code 1995. Falls Church, VA: Council of American Building Officials.

CABO (Council of American Building Officials). 1998. Mechanical Energy Code 1998. Falls Church, VA: Council of American Building Officials.

Davis Energy Group. 1993. ACT2 Stanford Ranch Site, Final Design Report. Davis, CA: Davis Energy Group.

DOE (U.S. Department of Energy). 2002. Whole-House Ventilation Systems: Improved Control of Air Quality. NREL Report No. NREL/BR-840-26458.

Griffiths, Dianne, et al. August 23, 2004. Insulation Buried Attic Ducts - Analysis and Field Evaluation Findings. 2004 ACEEE Summer Study on Energy Efficiency in Buildings. Pacific Grove, CA: American Council for Energy-Efficient Economy (ACEEE).

Haas Davenport, Linda. 2000. The Scopes of Work Program: Procedures and Standard to Increase Quality. Washington, D.C.: BuilderBooks.com.

Hendron, R. 2005. Building America Research Benchmark Definition, Updated December 29, 2004. NREL Report No. NREL/TP-550-37529. Golden, CO: National Renewable Energy Laboratory.

IBACOS, Inc. November 2004. Community Scale Process Research Results. Pittsburgh, PA: IBACOS.

International Energy Agency. 2001. Things That Go Blip in the Night: Standby Power and How to Limit it. www.iea.org/textbase/nppdf/free/2000/blipinthenight01.pdf.

International Energy Conservation Code. 2006. International Energy Conservation Code ${ }^{\circledR} 2006$. Country Club Hills, IL: International Code Council, Inc.

Judkoff, R., Neymark, J. 1995. International Energy Agency Building Energy Simulation Test (BESTEST) and Diagnostic Method. NREL Report No. NREL/TP-472-6231. Golden, CO: National Renewable Energy Laboratory (www.eere.energy.gov/buildings/tools_directory/software.cfm/ID=85/pagename=alpha_list).

Lstiburek, Joseph. 2004. Energy and Environmental Building Association. Builder's Guide to Hot Dry Mixed Dry Climates: A Systems Approach to Designing and Building Homes that are Healthy, Comfortable, Durable, Energy Efficient and Environmentally Responsible. Westford, MA: Building Science Press.

NAHB Research Center, Inc. November 2002. Performance Comparison of Residential Hot Water Systems. Upper Marlboro, MD: NAHB Research Center, Inc.

Norton, P.; Hancock, E.; Barker, G.; Reeves, P. 2003. The Hathaway “Solar Patriot” House: A Case Study in Efficiency and Renewable Energy. NREL/TP-550-37731. Golden, CO: National Renewable Energy Laboratory.

Pigg, S. 2003. The Electric Side of Gas Furnaces. Home Energy Magazine. November/December 2003. pp $24-28$.

RAND. 2003. Building Better Homes: Government Strategies for Promoting Innovation in Housing.

RESNET (Residential Energy Services Network). 2002. "Mortgage Industry National Home Energy Rating Systems Accreditation Standards.” Chapter 3, pp. 29-54. San Diego, CA: Residential Energy Services Network.

Rudd, A. and H. Henderson: 2005. Monitored Indoor Moisture and Temperature Conditions in Humid Climate U.S. Residences. BSC Deliverable KAAX-3-32443-08.B.2 
R.S. Means. 1999. Residential Cost Data - 18th Annual Edition. 1999. Kingston, MA: R.S. Means, Company, Inc.

Shelley, Dean, and Fuller. 1981. Energy Principles in Architectural Design Architects California Energy Commission.

Sustainable Building Industries Council. Sustainable Building Industries Council. Passive Solar Design Strategies: Guidelines for Home Building. Sustainable Building Industries Council Website. www.psic.org

U.S. Census Bureau. July 1, 2002, to July 1, 2003. U.S. Census Bureau Housing Unit Estimates (HUEST2003-04), “Annual Estimates of Housing Units for Counties: April 1, 2000, to July 1, 2003.” Last revised September 2, 2004. U.S. Census Bureau: Washington, D.C.

U.S. Department of Energy. January 5, 2005. “House Counts by Climate Zone (detailed)” U.S. Department of Energy, Building America House Performance Database.

Wetter, M. “GenOpt ${ }^{\circledR}$, "Generic Optimization Program,” Seventh International IBPSA Conference, Rio de Janeiro, Brazil. (www.ibpsa.org/proceedings/BS2001/BS01_0601_608.pdf). 
PLEASE DO NOT RETURN YOUR FORM TO THE ABOVE ORGANIZATION.

\begin{tabular}{|l|l|l|l}
\hline 1. & REPORT DATE $(D D-M M-Y Y Y Y)$ \\
November 2006 & 2. & $\begin{array}{l}\text { REPORT TYPE } \\
\text { Subcontractor Report }\end{array}$ & $\begin{array}{l}\text { 3. DATES COVERED (From - To) } \\
\text { January 2005 - November 2005 }\end{array}$ \\
\hline
\end{tabular}

\section{TITLE AND SUBTITLE}

Building America Residential System Research Results: Achieving 30\% Whole House Energy Savings Level in Mixed-Humid Climates

\section{6. $\quad$ AUTHOR(S)}

Building America Industrialized Housing Partnership (BAIHP), Building Industry Research Alliance (BIRA), Building Science Consortium (BSC), Consortium for Advanced Residential Buildings (CARB), Davis Energy Group (DEG), IBACOS, National Association of Home Builders Research Center (NAHBRC), National Renewable Energy Laboratory (NREL)

7. PERFORMING ORGANIZATION NAME(S) AND ADDRESS(ES)

Building America Industrialized Housing Partnership (BAIHP), Cocoa, Florida; Building Industry Research Alliance (BIRA), Stockton, California; Building Science Consortium (BSC), Westford, Massachusetts; Consortium for Advanced Residential Buildings (CARB), Norwalk, Connecticut; Davis Energy Group (DEG), Davis, California; IBACOS, Pittsburgh, Pennsylvania; National Association of Home Builders Research Center (NAHBRC), Upper Marlboro, Maryland

9. SPONSORING/MONITORING AGENCY NAME(S) AND ADDRESS(ES)

National Renewable Energy Laboratory

1617 Cole Blvd.

Golden, CO 80401-3393 5a. CONTRACT NUMBER

DE-AC36-99-GO10337

5b. GRANT NUMBER

5c. PROGRAM ELEMENT NUMBER

5d. PROJECT NUMBER

NREL/SR-550-39744

5e. TASK NUMBER

BET7.8004

5f. WORK UNIT NUMBER

\section{DISTRIBUTION AVAILABILITY STATEMENT}

National Technical Information Service

U.S. Department of Commerce

5285 Port Royal Road

Springfield, VA 22161

13. SUPPLEMENTARY NOTES

NREL Technical Monitors: R. Anderson, R. Hendron, M. Eastment, and A. Jalalzadeh-Azar

14. ABSTRACT (Maximum 200 Words)

The Building America program conducts the system research required to reduce risks associated with the design and construction of homes that use an average of $30 \%$ to $90 \%$ less total energy for all residential energy uses than the Building America Research Benchmark, including research on homes that will use zero net energy on annual basis. To measure the program's progress, annual research milestones have been established for five major climate regions in the United States. The system research activities required to reach each milestone take from 3 to 5 years to complete and include research in individual test houses, studies in pre-production prototypes, and research studies with lead builders that provide early examples that the specified energy savings level can be successfully achieved on a production basis. This report summarizes research results for the 30\% energy savings level and demonstrates that lead builders can successfully provide 30\% homes in the Mixed-Humid Climate Region on a costneutral basis.

15. SUBJECT TERMS

Building America; Whole House Energy Savings; Residential Buildings; Energy Efficiency; Mixed-Humid Climate; Systems Engineering Research

16. SECURITY CLASSIFICATION OF:
\begin{tabular}{l|l|l|}
$\begin{array}{c}\text { a. REPORT } \\
\text { Unclassified }\end{array}$ & $\begin{array}{c}\text { b. ABSTRACT } \\
\text { Unclassified }\end{array}$ & $\begin{array}{c}\text { c. THIS PAGE } \\
\text { Unclassified }\end{array}$ \\
\hline
\end{tabular}

\begin{tabular}{|c|c|}
\hline $\begin{array}{l}\text { 17. LIMITATION } \\
\text { OF ABSTRACT }\end{array}$ & $\begin{array}{ll}\text { 18. } & \text { NUMBER } \\
\text { OF PAGES }\end{array}$ \\
\hline UL & \\
\hline
\end{tabular}

19a. NAME OF RESPONSIBLE PERSON

19b. TELEPHONE NUMBER (Include area code) 


\section{A Strong Energy Portfolio for a Strong America}

Energy efficiency and clean, renewable energy will mean a stronger economy, a cleaner environment, and greater energy independence for America. Working with a wide array of state, community, industry, and university partners, the U.S. Department of Energy's Office of Energy Efficiency and Renewable Energy invests in a diverse portfolio of energy technologies.

\section{Research and Development of Buildings}

Our nation's buildings consume more energy than any other sector of the U.S. economy, including transportation and industry. Fortunately, the opportunities to reduce building energy useand the associated environmental impacts—are significant.

DOE's Building Technologies Program works to improve the energy efficiency of our nation's buildings through innovative new technologies and better building practices. The program focuses on two key areas:

\section{- Emerging Technologies} Research and development of the next generation of energy-efficient components, materials, and equipment

- Technology Integration Integration of new technologies with innovative building methods to optimize building performance and savings

For more information contact: EERE Information Center 1-877-EERE-INF (1-877-337-3463) www.eere.energy.gov

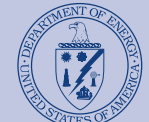

U.S. Department of Energy Energy Efficiency and Renewable Energy

An electronic copy of this publication is available on the Building America Web site at www.buildingamerica.gov

\section{Visit our Web sites at:}

\section{www.buildingamerica.gov}

www.pathnet.org

www.energystar.gov

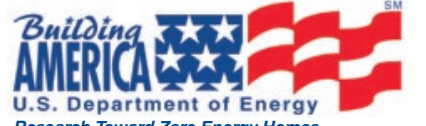
Research Toward Zero Energy Homes

Building America Program

George S. James • New Construction • 202-586-9472• fax: 202-586-8134• e-mail: George.James@ee.doe.gov

Terry Logee • Existing Homes • 202-586-1689 • fax: 202-586-4617• e-mail: terry.logee@ee.doe.gov Lew Pratsch • Integrated Onsite Power • 202-586-1512 • fax: 202-586-8185• e-mail: Lew.Pratsch@hq.doe.gov Building America Program • Office of Building Technologies, EE-2J • U.S. Department of Energy $\bullet 1000$ Independence Avenue, S.W. $\bullet$ Washington, D.C. 20585-0121・ www.buildingamerica.gov

Building Industry Research Alliance (BIRA)

Robert Hammon • ConSol • 7407 Tam 0'Shanter Drive \#200 • Stockton, CA 95210-3370 • 209-473-5000 • fax: 209-474-0817• e-mail: Rob@consol.ws• www.bira.ws

Building Science Consortium (BSC)

Betsy Pettit • Building Science Consortium (BSC) • 70 Main Street • Westford, MA $01886 \bullet 978-589-5100 \bullet$ fax: 978-589-5103• e-mail: Betsy@buildingscience.com • www.buildingscience.com

Consortium for Advanced Residential Buildings (CARB)

Steven Winter • Steven Winter Associates, Inc. • 50 Washington Street • Norwalk, CT $06854 \bullet 203-857-0200 \bullet$ fax: 203-852-0741 • e-mail: swinter@swinter.com•www.carb-swa.com

\section{Davis Energy Group}

David Springer • Davis Energy Group $\bullet 123$ C Street • Davis, CA 95616 • 530-753-1100 • fax: 530-753-4125 • e-mail: springer@davisenergy.com • deg@davisenergy.com • www.davisenergy.com/index.html

\section{IBACOS Consortium}

Brad Oberg •IBACOS Consortium • 2214 Liberty Avenue • Pittsburgh, PA $15222 \bullet 412-765-3664 \bullet$ fax: 412-765-3738 • e-mail: boberg@ibacos.com • www.ibacos.com

Industrialized Housing Partnership (IHP)

Subrato Chandra • Florida Solar Energy Center • 1679 Clearlake Road • Cocoa, FL 32922 • 321-638-1412 • fax: 321-638-1439• e-mail: subrato@fsec.ucf.edu • www.baihp.org

National Association of Home Builders (NAHB) Research Center

Tom Kenney • National Association of Home Builders (NAHB) Research Center $\bullet 400$ Prince George's Boulevard • Upper Marlboro, MD 20774 • 301-430-6246 • fax: 301-430-6180 • toll-free: 800-638-8556 • www.nahbrc.org/

\section{National Renewable Energy Laboratory}

Ren Anderson • 1617 Cole Boulevard, MS-2722 • Golden, C0 80401 • 303-384-7433• fax: 303-384-7540 •

e-mail: ren_anderson@nrel.gov • www.nrel.gov

Tim Merrigan • 1617 Cole Boulevard, MS-2722 • Golden, C0 80401 • 303-384-7349 • fax: 303-384-7540 • e-mail: tim_merrigan@nrel.gov • www.nrel.gov

\section{Oak Ridge National Laboratory}

Pat M. Love • P.0. Box $2008 \bullet$ One Bethel Valley Road • 0ak Ridge, TN 37831 • 865-574-4346 • fax: 865-574-9331 • e-mail: lovepm@ornl.gov • www.ornl.gov

Produced for the U.S. Department of Energy (DOE) by the National Renewable Energy Laboratory, a DOE national laboratory. December $2006 \bullet$ NREL/SR-550-39744

Printed with a renewable-source ink on paper containing at least $50 \%$ wastepaper, including $10 \%$ postconsumer waste. 